\title{
Pavimentações do plano com espelhos e caleidoscópios no desenvolvimento do pensamento geométrico: uma experiência com professores
}

Vitor Hugo Matias dos Santos

DISSERTAÇÃO APRESENTADA

$\mathrm{AO}$

INSTITUTO DE MATEMÁTICA E ESTATÍSTICA

DA

UNIVERSIDADE DE SÃO PAULO

PARA

OBTENÇÃO DO TÍTULO

$\mathrm{DE}$

MESTRE EM CIÊNCIAS

Programa: Mestrado Profissional em Ensino de Matemática

Orientadora: Profa. Dra. Ana Paula Jahn

São Paulo, março de 2020 
Pavimentações do plano para o desenvolvimento do pensamento geométrico: uma experiência com professores

Essa é a versão corrigida da dissertação elaborada pelo candidato Vitor Hugo Matias dos Santos, tal como submetida à Comissão Julgadora. 


\section{Pavimentações do plano com espelhos e caleidoscópios no desenvolvimento do pensamento geométrico: uma experiência com professores}

Vitor Hugo Matias dos Santos

Esta dissertação foi julgada e aprovada para obtenção do Mestrado em Ciências, no Curso de Mestrado Profissional em Ensino de Matemática, do Instituto de Matemática e Estatística da Universidade de São Paulo.

São Paulo, de de 2020.

BANCA EXAMINADORA

Profa. Nielce Meneguelo Lobo da Costa Profa. Orientadora Ana Paula Jahn

Profa. Samira Zaidan 


\section{Agradecimentos}

À minha mãe, Mary Braga e a meu Pai, Rinaldo Martins, pelo amor e suporte em inúmeros momentos da minha vida.

Agradeço também o apoio dos meus irmãos, o Alan Luiz e, em especial, o Matheus Henrique, que me auxiliou na produção de algumas das imagens dessa dissertação.

A minha avó, Célia Matias, por ser uma grande amiga e pelo apoio durante o mestrado e em toda a minha vida.

Aos colegas de curso, em especial, Marcos Alves, Ronan Petean e Fernando Lima, Felipe Garcia, Adriana Martinez e Daniela de Paula, que encararam junto a mim os desafios e etapas do mestrado e tornaram o ambiente universitário mais amistoso, além de me auxiliarem em inúmeras reflexões inseridas nessa pesquisa.

Aos amigos Gabriel Lopes, Geovanna Lopes, Ronan Petean, Erick Gonçalves, Marcela Aparecida, Vagner José e Michel Gaspar que estiveram presentes em inúmeros momentos na minha vida universitária, colaborando na minha formação acadêmica e enquanto ser humano. Pra mim é uma honra ter traçado esse caminho com eles e não estaria onde estou sem todo seu apoio. E a meu amigo Vanderson Sousa, por diversas sugestões e pelo suporte em relação ao formato do texto.

Ao IME-USP (Instituto de Matemática e Estatística da Universidade de São Paulo) pela manutenção do programa MPEM (Mestrado Profissional em Ensino de Matemática), pelo corpo docente, coordenação e administração que evidenciam a importância da valorização do professor de Matemática e sua formação e que possibilitaram a produção desta pesquisa, considerando minha atuação como professor e pesquisador.

À minha orientadora, professora Doutora Ana Paula, por momentos de orientação muito preciosos e decisivos para nortear essa pesquisa. Agradeço também pela parceria em inúmeros projetos, eventos e oficinas, por sempre se preocupar com meu bem-estar e com minhas condições enquanto professor de Matemática e pesquisador.

Às Professoras Doutoras Samira Zaidan e Nielce Lobo da Costa, por inúmeras colaborações com esta pesquisa, desde o momento de minha qualificação até a minha defesa. Agradeço 
profundamente pelas sugestões e reflexões acerca das possíveis difusões do meu trabalho, bem como das possibilidades de continuação em um doutorado.

Aos professores participantes dessa pesquisa, que sempre estiveram muito dispostos a se desdobrarem e articularem suas práticas docentes às atividades propostas no curso, presencialmente e à distância.

Aos orientadores do GTP (Grupo de Teatro da Poli-USP), Neia Barbosa e Luiz Luccas, por me apoiarem e me proporcionarem várias reflexões cognitivas essenciais para a minha profissão e para meu desenvolvimento pessoal. Bem como agradeço aos colegas do GTP, Mardem Junior e Eric Filipi, que me trouxeram muitos momentos de descontração e alegria.

Aos inúmeros colegas de profissão que há vários anos estão me acompanhando e me incentivando a me manter e me desenvolver como professor. Em especial, agradeço à Vanessa Borges e ao Thiago Nogueira, por me apoiarem especificamente nesse período e serem grandes amigos, parceiros de profissão e por toda a colaboração que tive deles, inclusive em reflexões presentes nesse trabalho.

À minha professora de francês, Ida, do CAVC, por me entusiasmar ao estudo dessa língua, o que me possibilitou inúmeras leituras pertinentes dessa pesquisa.

À Patrícia Pereira, pela revisão desse texto e por me auxiliar com muita prontidão.

A meus alunos, com os quais experimentei algumas das atividades que inspiraram as atividades e vivências relatadas nesse trabalho. Também sou grato por ter tido a oportunidade de desenvolvê-las com meus alunos do PIC-OBMEP (Programa de Iniciação Científica da Olimpíada Brasileira de Matemática das Escolas Públicas). E, em especial, sou grato aos alunos que estiveram presentes na minha defesa e me permitiram fazer novas reflexões sobre essa pesquisa.

A meus estagiários, Hugo Zaragossa, João Takano e vários outros, que me apoiaram muito no meu trabalho docente, auxiliando para que eu pudesse sempre manter meu vigor enquanto professor.

A todos amigos, familiares e colegas que direta ou indiretamente fizeram parte da minha formação, o meu muito obrigado. 


\section{Resumo}

\section{SANTOS, V. H. M. dos. Pavimentações do plano com espelhos e caleidoscópios no}

desenvolvimento do pensamento geométrico: uma experiência com professores. 2020. 235

f. Dissertação (Mestrado Profissional em ensino de Matemática) - Instituto de Matemática e Estatística. Universidade de São Paulo, São Paulo. 2020.

O estudo das transformações geométricas planas na Educação Básica pode oferecer ao professor de Matemática diversas oportunidades de tornar mais interessante o ensino de Geometria, por meio de sequências didáticas que envolvam o uso de materiais concretos em atividades experimentais e com discussões coletivas. Dessa forma, o uso de espelhos planos e caleidoscópios em sala de aula pode ser uma abordagem significativa para o aprendizado de Geometria Plana. É isso que se buscou explorar e discutir a partir das experimentações desta pesquisa. Apresenta-se aqui, uma experiência com professores que ensinam Matemática nos diferentes níveis de ensino que se concretizou em um curso de formação continuada ministrado pelo autor dessa dissertação e sua orientadora. Com essa pesquisa buscou-se descobrir em que medida esse curso pôde colaborar com a apropriação, por parte dos professores participantes, de uma abordagem de ensino focada em tarefas exploratórias, no uso de materiais concretos e em uma forma de se elaborar discussões a partir de sequências didáticas de Geometria. $\mathrm{O}$ principal objetivo foi o de colaborar com o desenvolvimento desse grupo no que diz respeito ao conhecimento pedagógico do conteúdo e ao conhecimento do conteúdo a partir de experimentações, discussões e vivências. $\mathrm{O}$ curso ocorreu em oito encontros presenciais e foi composto por diversas atividades acerca de temas envolvendo pavimentações do plano usando espelhos e caleidoscópios, transformações geométricas e polígonos. As atividades foram realizadas, na maioria das vezes, em duplas ou grupos, utilizando materiais concretos e manipuláveis e por meio de discussões coletivas visando desenvolver o pensamento geométrico, a partir da articulação entre a criação de conjecturas por meio de evidências materiais e argumentações lógica-dedutivas, em direção a uma Geometria axiomática. Após a realização do curso, os professores elaboraram uma sequência didática cujas atividades são semelhantes às vivenciadas nos encontros presenciais e fizeram um trabalho final composto por um plano de aula conforme sugestões dos ministrantes, um relatório de como foi o desenvolvimento das atividades com seus alunos e uma discussão dos resultados. As análises interpretativas das discussões finais mostram que, em diferentes medidas, os professores se apropriaram de forma significativa dos conceitos explorados e da forma de se produzir uma sequência didática que vise o desenvolvimento do pensamento geométrico.

Palavras-chave: Pavimentação do plano; caleidoscópio; Educação Matemática; pensamento geométrico; práticas docentes. 


\begin{abstract}
The study of flat geometric transformations in Basic Education can offer the mathematics teacher several opportunities to make the teaching of geometry more interesting, through didactic sequences that involve the use of concrete materials in experimental activities and with collective discussions. Thus, the use of flat mirrors and kaleidoscopes in the classroom may represent a significant approach to learning Flat Geometry. This is what we tried to explore and discuss with this research. This article presents an experience with teachers who teach mathematics at different levels of education that was materialized in a continuing formation given by this dissertation's author and his advisor. We tried to find with this research in which measure this course can collaborate with the appropriation, by the participating teachers, of a teaching approach focused on exploratory tasks, in the use of concrete materials and in a way of elaborating discussions based on didactic sequences of Geometry. The main objectives were to collaborate with the development of this group with regard to the pedagogical knowledge of the content and the knowledge of the content from experiences, discussions and experiments. The course took place in eight face-to-face meetings and was composed of several activities on the themes of plan paving using mirrors and kaleidoscopes, geometric transformations and polygons. The activities were mostly performed in pairs or groups, using concrete and manipulable materials and through numerous collective discussions aimed at developing geometric thinking, from the articulation between the creation of conjectures through material evidence and logical-deductive arguments, towards na axiomatic geometry. After the course, the teachers prepared a didactic sequence whose activities are similar to those experienced in the face-to-face meetings and they made a final activity consisting of a class plan as suggested by the lecturers, a report on how the activities were developed with their students and a discussion of the results. The interpretative analyzes of the final discussions shows that, in different ways, the teachers have significantly appropriated on the explored concepts and in the way of producing a didactic sequence that aims the development of geometric thinking.
\end{abstract}

Keywords: Tessellations; kaleidoscope; Mathematics education; geometric thinking; teaching practices. 


\section{SUMÁRIO}

1. INTRODUÇÃO 10

1.1. A trajetória histórica e curricular da Geometria das Transformações ................. 12

1.2. Escolha do tema de pesquisa.......................................................................... 25

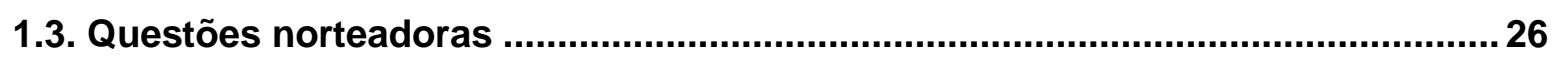

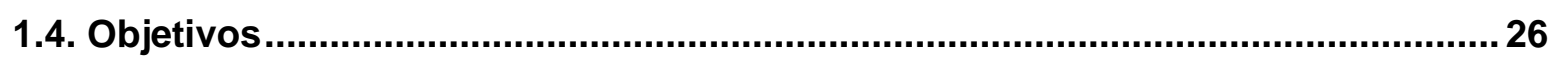

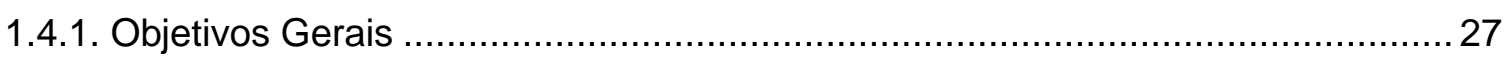

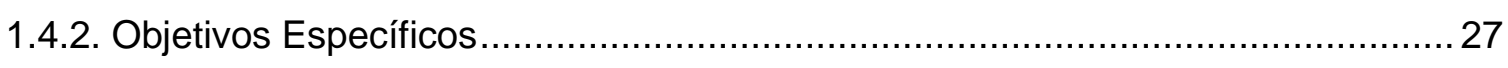

2. O DESENVOLVIMENTO DO PENSAMENTO GEOMÉTRICO......................................... 29

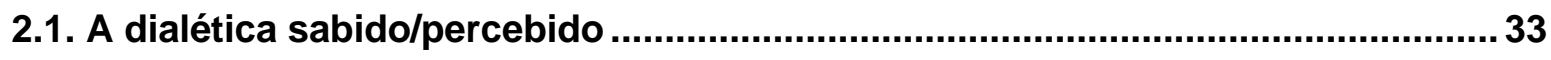

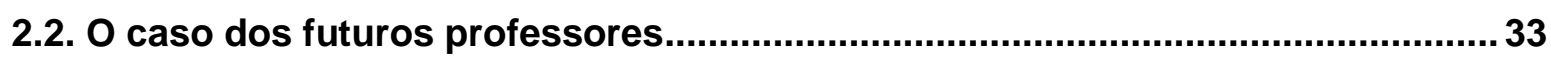

2.3. O método do laboratório de Ensino de Matemática.............................................. 35

3. A GEOMETRIA DAS PAVIMENTAÇÕES DO PLANO ........................................................... 38

3.1. Polígonos, região poligonal e linha poligonal .................................................. 38

3.3. Mosaicos no Plano: Pavimentação e Ladrilhamento .......................................... 49

3.3.1. Pavimentações do plano com polígonos regulares ......................................... 50

3.3.2. Diferentes tipos de Pavimentações ............................................................. 52

3.3.3. As configurações que pavimentam o plano ................................................. 53

3.4. O Caleidoscópio: O que é, como fazer, tipos diferentes ............................................ 56

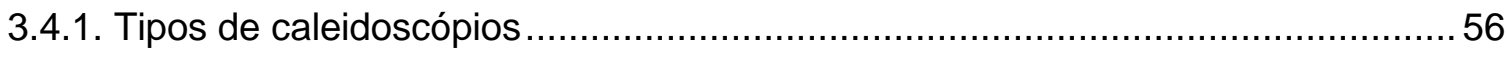

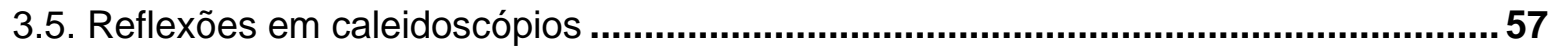

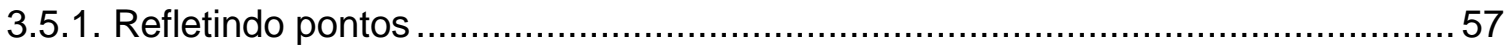

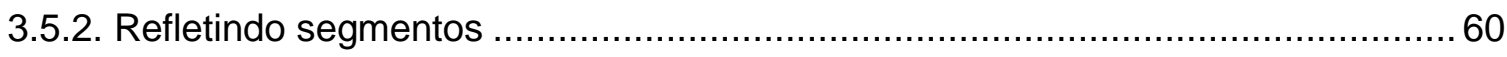

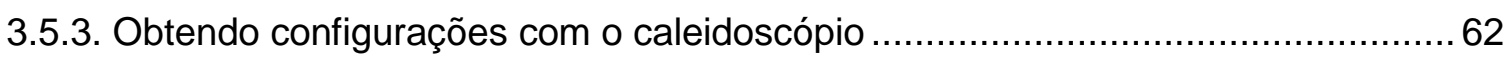

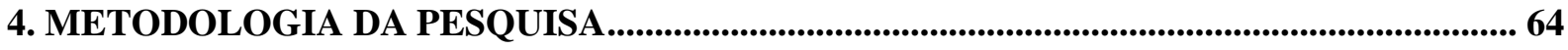

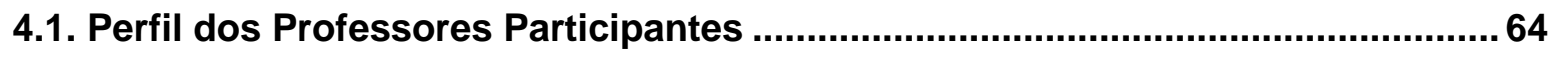

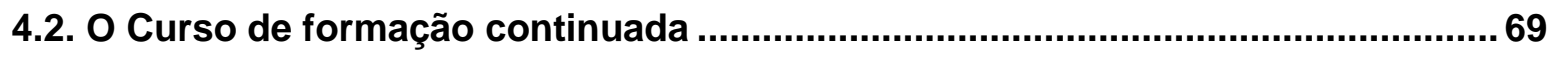

4.3. Cinco Práticas para a Orquestração de Discussões Matemáticas Produtivas ...........72

4.3.1. Investigação Matemática: Tarefas Exploratórias e Tarefas Investigativas ............ 73

4.3.2. As Cinco práticas do Professor ............................................................. 77

5. ANÁLISE DOS ENCONTROS PRESENCIAIS..................................................................... 84

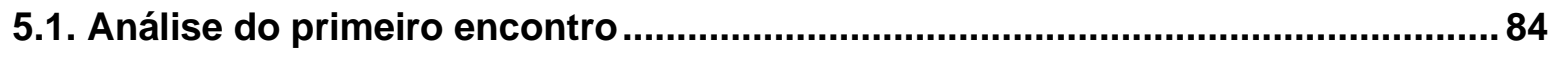

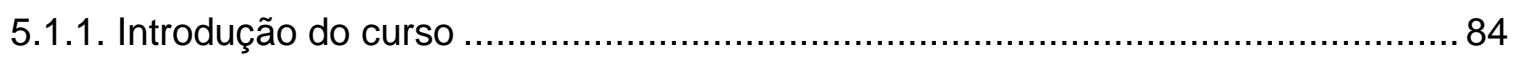

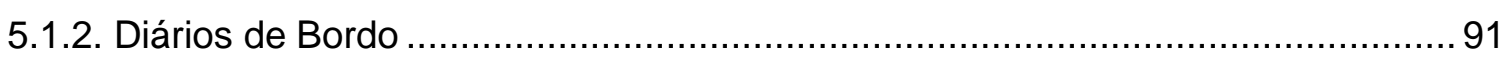

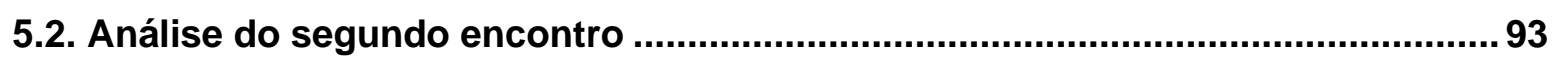




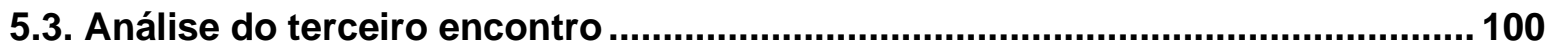

5.4. 0 caso das estrelas poligonais ........................................................................ 102

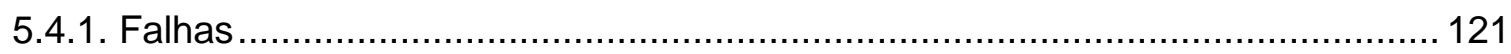

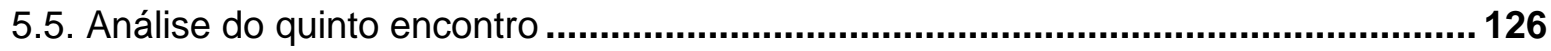

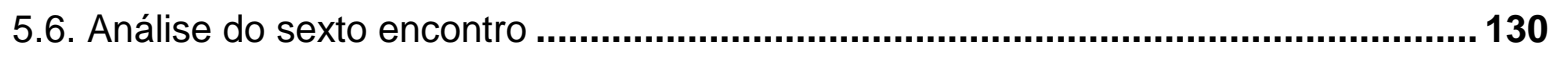

5.6.1. Tarefas da atividade 2 (pavimentações) .................................................... 134

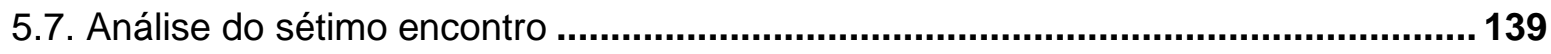

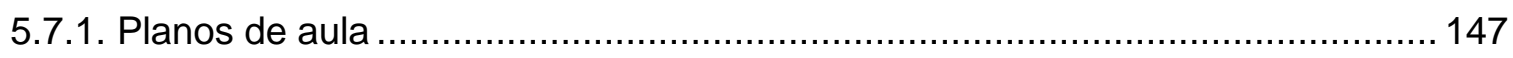

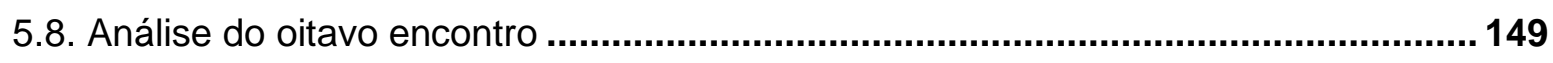

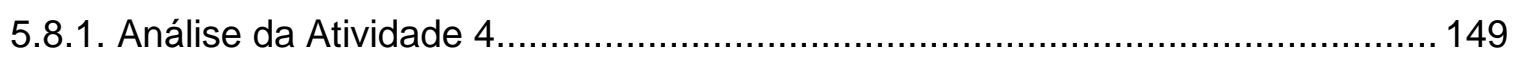

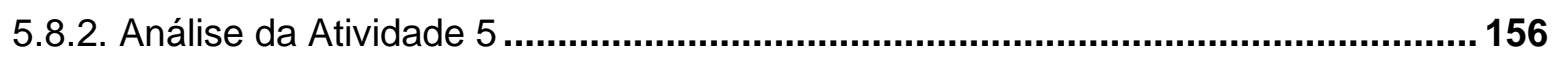

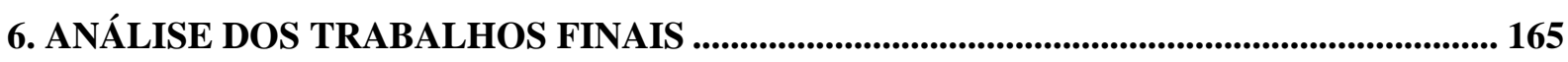

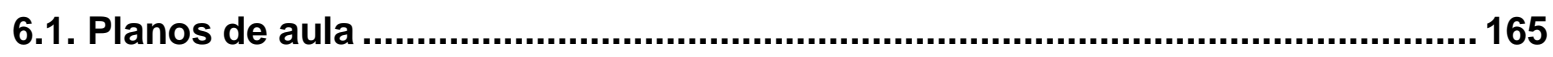

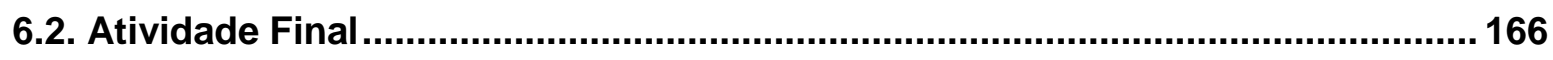

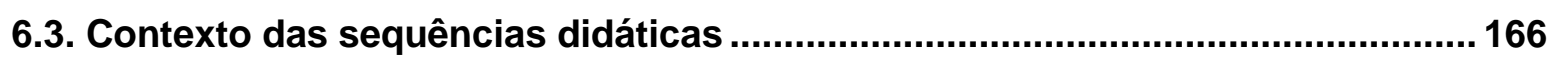

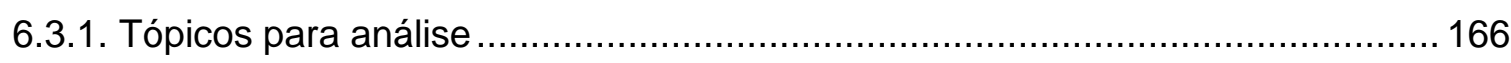

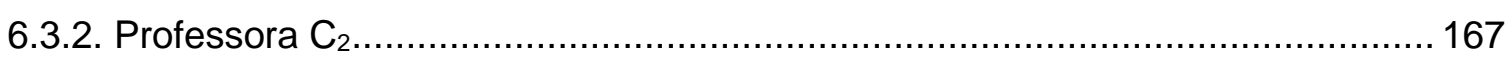

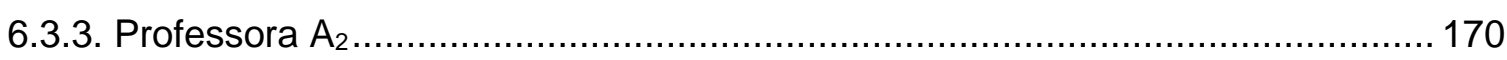

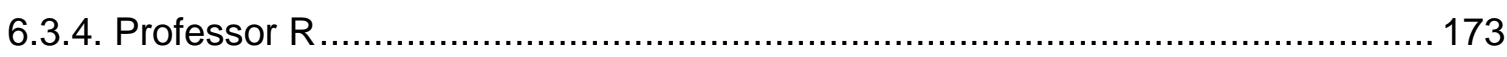

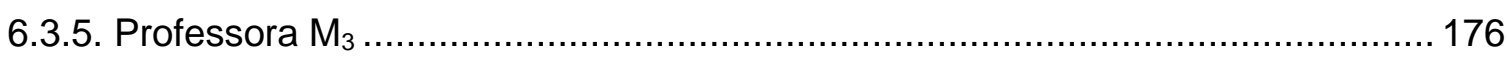

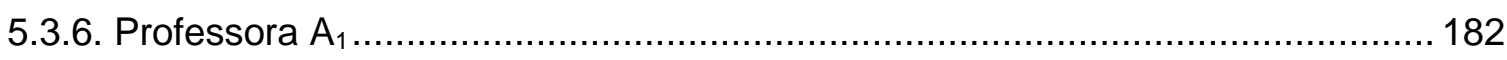

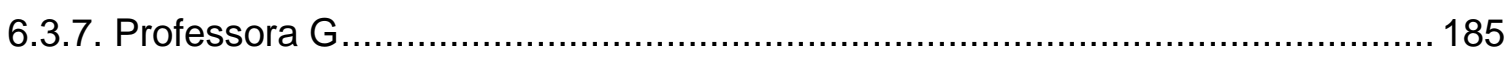

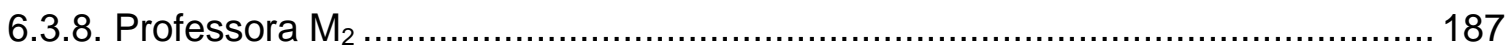

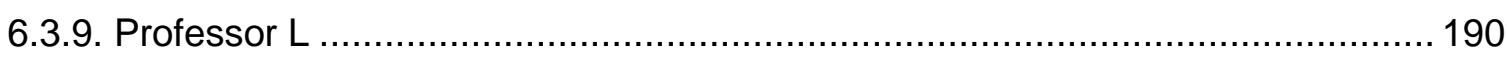

7. AVALIAÇÃO E ANÁLISE DAS SEQUÊNCIAS DIDÁTICAS .................................. 192

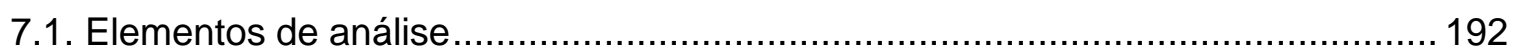

7.2. Padrões: definições de conceitos matemáticos................................................ 196

7.3. Padrões: comparação entre as atividades propostas........................................ 197

7.4. Padrões: desenvolvimento das atividades ........................................................ 199

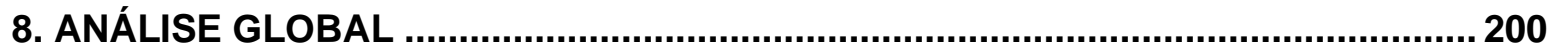

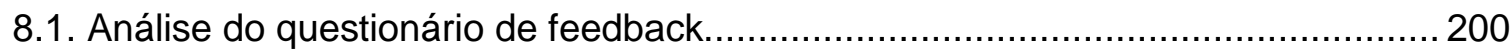

8.2. A importância da Geometria segundo os professores participantes ..................... 207

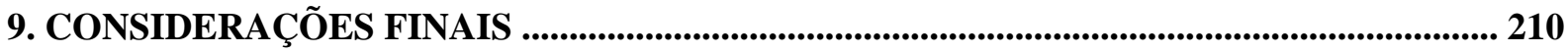

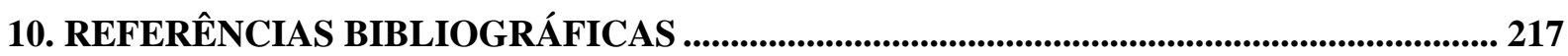

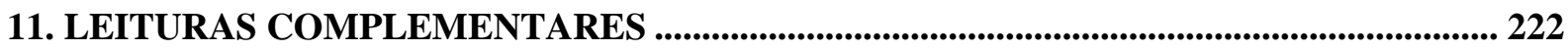


12. APÊNDICES.. 


\section{INTRODUÇÃO}

As lacunas na formação em Geometria são bastante presentes nos alunos tanto nas escolas de Educação Básica como em grande parte das instituições de Ensino Superior e existem por inúmeras razões. Momentos marcantes na história do Ensino de Matemática, como o Movimento da Matemática Moderna, na década de 60, que levou a enfatizar o ensino de Álgebra em detrimento da Geometria, tiveram grande impacto nos currículos e livros didáticos brasileiros. Na sequência, houve um momento em que a legislação - na década de 70 - deu às escolas mais autonomia para a definição de seus programas curriculares e, novamente, a Álgebra fora enfatizada. Com isso, era comum que professores de Matemática passassem a optar por lecionar menos tópicos de Geometria ou mesmo a evitá-los, dado que sua formação não lhes dava subsídios suficientes para trabalhar esse tipo de conteúdo em sala de aula (MARTINS, 2003).

Entretanto, o estudo dessa parte da Matemática tem uma importância inegável na construção do conhecimento matemático e esteve muito presente nos Parâmetros Curriculares Nacionais (BRASIL, 2000) e em outros documentos curriculares mais atuais, tal como a BNCC (BRASIL, 2017). Dessa forma, podemos perceber que existem esforços para manter a Geometria em todos os anos da Educação Básica e que estes vêm se intensificado, combatendo assim, a negligência do Ensino desse assunto, que ocorre nas escolas brasileiras, sobretudo as públicas. As causas desse problema estão relacionadas à carga curricular excessiva, a uma formação de professores insuficiente e a diversas medidas governamentais caracterizadas desde o início do século XX (PAVANELLO, 1993).

Atualmente, a Geometria compõe boa parte dos conteúdos a serem ensinados nas propostas curriculares de Matemática e está presente nos livros didáticos de Ensino Fundamental e Médio que foram aprovados no PNLD de 2017. Na Proposta Curricular do Estado de São Paulo (cujo modelo é fortemente inspirado no que está proposto na BNCC), a Geometria é um dos três blocos da organização dos conteúdos básicos a serem trabalhados em sala de aula. Segundo os autores desse documento,

a Geometria deve ser tratada, ao longo de todos os anos, em abordagem espiralada, o que significa dizer que os grandes temas podem aparecer tanto nas séries/anos do 
Ensino Fundamental quanto nas do Ensino Médio, sendo a diferença a escala do tratamento dada ao tema." (SÃO PAULO, 2012, p.41).

Com isso, acredita-se que as atividades apresentadas neste trabalho podem ser exploradas tanto no Ensino Fundamental II e Ensino Médio, quanto em cursos de formação de professores.

Ao menos em termos institucionais, o ensino da Geometria tem sido reforçado, em particular no Brasil, no sentido de seu papel no reconhecimento do mundo, da natureza e no desenvolvimento de formas específicas de pensamento matemático. Ainda, de acordo com os Direitos de Aprendizagem dos Ciclos Interdisciplinares e Autoral de Matemática, da Secretaria Municipal de Educação de São Paulo (SÃO PAULO, 2016, p. 70), o estudo da Geometria, enquanto eixo do currículo de Matemática, consiste em proporcionar ao educando "participar do espaço em que vivemos (...) e desenvolver capacidades de visualização, representação, identificação e conclusão de propriedades de figuras, sejam elas planas ou tridimensionais".

Muitos professores reconhecem que a Geometria é fundamental para o desenvolvimento do conhecimento matemático ao longo da Educação Básica e que ações realizadas com materiais concretos ou manipulativos têm uma influência significativa no desenvolvimento de visão espacial, noções de perspectiva, capacidade de medição, experimentos físicos, entre outros (SILVA e SILVA, 2014). Entretanto, é comum haver certa insegurança ou mesmo dificuldades no ensino da Geometria, em particular no que diz respeito à grande quantidade de conteúdos que compõem o currículo sob responsabilidade do professor de Matemática; à ausência de disciplinas voltadas à Geometria nos currículos de cursos de Licenciatura, tanto em Pedagogia quanto em Matemática; e a fatores de ordem mais prática como a falta de materiais nas escolas para atividades matemáticas de construções geométricas, tais como régua, compasso, esquadro, malhas quadriculadas, régua e compasso de madeira para o professor, etc.

Podemos perceber que pesquisadores e professores reconhecem que a Geometria é fundamental para o desenvolvimento do conhecimento matemático ao longo da Educação Básica e que ações realizadas com materiais concretos ou manipulativos têm uma influência significativa no desenvolvimento de visão espacial, na capacidade de medição, compreensão de experimentos físicos, entre outros (SILVA; SILVA, 2014). Ainda assim, é comum haver certa insegurança ou mesmo dificuldades da parte do professor no ensino da Geometria nessa perspectiva.

Tal insegurança provém do fato de que muitos professores talvez não tiveram oportunidades de vivenciar a beleza, a lógica e as aplicações da Geometria ao longo da própria 
vida escolar, assim como na formação inicial. Corroborando este fato, até poucos anos atrás, podíamos observar que os livros didáticos, nos quais os professores se apoiavam, apresentavam a Geometria como um conjunto de definições e propriedades "prontas", sem explicações de natureza lógica ou histórica, em capítulos finais dos volumes (LORENZATO, 1995).

\subsection{A trajetória histórica e curricular da Geometria das Transformações}

Mabuchi (2000) verificou que nas décadas de 80 e 90 o ensino de Geometria nas escolas de Educação Básica era negligenciado principalmente porque os professores não aprendiam o suficiente nos cursos de Licenciatura em Matemática. Dessa forma, os estudantes eram afetados pela ausência de Geometria na escola. O pouco que se estudava tinha relação com uma Geometria em uma faceta algébrica, e com a memorização de propriedades em figuras estáticas, o que acabou criando grande distanciamento entre a escola e o estudo da Geometria.

Assim como Mabuchi, acreditamos que, um caminho possível para que essa Geometria esteja presente nas aulas de Matemática da Educação Básica, é o de melhorar a formação inicial e continuada dos professores. No caso do projeto aqui apresentado, a investigação foi orientada para a formação continuada de professores.

Em sua pesquisa, a referida autora teve por objetivo mostrar que a valorização dos aspectos históricos e epistemológicos relativos a esse assunto, amplia os conhecimentos dos professores de Matemática e os motiva em suas práticas de ensino e, por consequência, faz o mesmo com seus alunos.

No que diz respeito à análise epistemológica, discorre sobre o ganho de significado da Geometria, que passou de uma análise lógica do espaço físico para se tornar um estudo abstrato por meio da grande influência que Euclides teve na Matemática como um todo, não apenas na Geometria. Discute também como as manifestações artísticas durante o Renascimento trouxeram ideias que posteriormente caracterizariam a Geometria descritiva e a Geometria projetiva:

A preocupação dos pintores e artistas em representar objetos do espaço fez surgir a ideia de projeções centrais e paralelas e, consequentemente, aparecem as noções de Geometria projetiva e de Geometria descritiva, importantes na gênese do conceito de transformações. (MABUCHI, 2000, p.9) 
Ilustra, em seguida, os aspectos históricos da Geometria projetiva e de seus pioneiros, tais como Jean Victor Poncelet (1788-1867), e expõe alguns casos em que demonstrações de teoremas dessa Geometria demandaram o reconhecimento de propriedades de figuras que ficam invariantes por uma ou mais transformações.

Foi Felix Klein (1849-1925) quem utilizou o conceito de grupo para poder exprimir as Geometrias não-euclidianas desenvolvidas até então, como casos particulares da Geometria Projetiva, numa conferência conhecida como Programa de Erlangen. A partir desse momento, não matemáticos passaram a ter interesse pelos conjuntos de transformações, em especial, das isometrias, como psicólogos e outros estudiosos da Educação devido ao apelo cognitivo (relacionado a "manipulação" de figuras).

Em seguida faz uma análise epistemológica das transformações geométricas, destacando que "a noção de transformação geométrica só aparece claramente durante os séculos XVI e XVII, com o desenvolvimento da álgebra e da análise”, referindo-se a Piaget e Garcia (1987). Para esses autores, a teorização da Geometria das transformações é um indício de que o desenvolvimento cognitivo humano não se dá de forma linear e que demanda uma reorganização de conhecimentos com o acréscimo de novas propriedades.

Em seu processo de investigação, Mabuchi (2000) narra como alguns autores realizaram suas pesquisas a respeito dos conhecimentos de tópicos de Geometria das transformações com atividades envolvendo alunos da Educação Básica, a partir da década de 1970: os estudos eram pouco conclusivos pois não consideravam inúmeras variáveis na forma como foram apresentadas as atividades aos alunos. Já na década de 1980, o maior destaque foi a pesquisa de Hart (1981), pois além de ter trabalhado com uma quantidade significativa de estudantes (cerca de dez mil), havia grande cuidado com a exploração de diferentes variáveis de estudo, tais como tipo de figura (polígono, ponto ou outra figura), o uso de malhas quadriculadas e a posição do eixo de simetria para as atividades de reflexões em reta. Em seguida, outras pesquisas passaram a considerar, em diferentes abordagens e graus de profundidade, não apenas as variáveis de estudo, como também a ação de descrever de forma clara e objetiva quais foram os procedimentos de resolução apresentados pelos estudantes que são, em outras palavras, as características da sequência didática trabalhada.

Houve, nessa década, um aumento do detalhamento dos processos propostos aos estudantes, tornando mais compreensíveis os procedimentos desenvolvidos por esses sujeitos na resolução das atividades envolvendo transformações geométricas. As análises passaram a ter 
menos caráter quantitativo e mais qualitativo, valorizando o modo com que as concepções Matemáticas vão surgindo nos sujeitos em meio à resolução de um problema.

Num estudo realizado em escolas da França e do Japão, por Denys e Garnier (1986), as variáveis de cada problema dado revelaram ser ora um obstáculo, ora um suporte: o uso de malha quadriculada auxilia na resolução de problemas de reflexão em reta nos casos em que o eixo de reflexão é horizontal ou vertical e a figura a ser refletida não intercepta esse eixo; entretanto nos casos em que o eixo é oblíquo e a figura o intercepta, a malha dificulta a visualização da imagem a ser formada. Para tal estudo mais um fator foi levado em consideração: o meio no qual cada perfil de aluno se desenvolveu, no sentido cultural e curricular. Uma conclusão que foi destacada nessa pesquisa, é que o estudo da Geometria Espacial pode afetar a compreensão de reflexão em reta, sobretudo quando esta isometria é percebida ou representada como o efeito de uma dobradura do papel sobre essa reta.

Por fim, a autora cita uma pesquisa de Gutierrez (1996), realizada na Espanha, em que são levadas em consideração as variáveis do contexto da atividade, as formas de resolução que os estudantes apresentam, assim como em que medida determinados métodos de ensino podem influenciar no desenvolvimento de concepções imperfeitas desses estudantes. Tal investigação foi realizada coletando respostas de estudantes a determinadas atividades relativas a reflexões em reta antes e após a realização de um curso.

Essa narrativa apresentada pela autora traz para o leitor quais são as variáveis que devem ser levadas em consideração numa pesquisa de ensino da Geometria das Transformações e as justifica usando argumentos históricos e epistemológicos. Apresenta ainda as propostas curriculares de Matemática para o Brasil e outros países, no período entre as décadas de 1970 a 1990, destacando a forma como o tema transformações geométricas é incluído. Nesse período os impactos do movimento da Matemática Moderna ocorreram em todos os currículos brasileiros e, em especial, em São Paulo as orientações curriculares de Matemática aconselhavam, por meio do documento Guias Curriculares (1975), um ensino dinâmico das estruturas Matemáticas que aparecem nos números e em funções. Mais particularmente, as transformações geométricas apareciam em meio ao tema principal de Geometria que era dividida em diferentes tópicos dentre as séries do antigo $1^{\circ}$ grau, atual Ensino Fundamental.

Para a sexta série, o tópico que aparecia é o de translação e dentre os objetivos, apareciam: "determinar o segmento correspondente a outro por meio de uma translação", "associar o conceito de paralelogramo ao de translação" e "reconhecer figuras congruentes como figuras que se correspondem por uma isometria". 
Para a sétima série, eram trabalhadas outras propriedades da translação, além dos conceitos de simetria axial e central e suas características. Eram diversos os objetivos de aprendizagem e se apoiavam em perceber que a simetria determina uma relação entre duas figuras.

Para a oitava série, em relação às transformações geométricas, os conceitos de a homotetia e de semelhança eram o foco. Um dos objetivos era "traçar diagramas de uma homotetia" e assim como nas demais séries, era sugerido descobrir os pontos invariantes por essa transformação.

Para Mabuchi (2000, p. 74), no Guia Curricular de Matemática "a abordagem das transformações geométricas foi feita a partir da ideia de funções aplicadas a pontos do plano, dando ao aluno uma ideia mais teórica e abstrata do que intuitiva desses conceitos". Porém ainda faz considerações positivas em relação ao documento, pois este sugere a participação ativa do aluno e propõe mais atenção para a metodologia de ensino e o uso de materiais manipuláveis para se concretizar conceitos.

Outro documento curricular apresentado e discutido é o guia "Experiências Matemáticas" (SÃO PAULO, 1994) para as séries quinta a oitava, no qual há indicações didáticas gradativas relacionadas à inserção de tópicos de transformações geométricas que sugerem que o aluno descubra os diversos significados de simetria por meio do uso de materiais manipuláveis e de régua e compasso. Esse documento traz um grande número de propostas de atividades relacionadas ao estudo de propriedades de figuras por meio de isometrias, levando em consideração as mesmas variáveis apresentadas nos estudos da década de 1980, citados anteriormente.

Nos Parâmetros Curriculares Nacionais (PCN), as transformações geométricas aparecem nos anos do Ensino Fundamental I com foco no estudo de simetria axial, enquanto nos anos seguintes, compreende as transformações geométricas (isometrias e homotetias) como recursos para induzir de forma experimental a descoberta de propriedades de objetos do mundo físico.

O objetivo é observar que características, tais como medidas, são preservadas após uma transformação que é identificada por meio de um estudo do espaço, privilegiando a observação e a compreensão de relações e a utilização das noções geométricas para resolver problemas, em detrimento de uma estrita memorização de fatos e nomenclaturas. Este ciclo se caracteriza pelo uso de materiais de desenho geométrico: régua, compasso, esquadro e transferidor. Por fim, o último ciclo busca o ensino de homotetias e a verificação de quais medidas se modificam e 
quais não, após uma ampliação ou redução de uma figura. Os objetos de estudo nesse período escolar são mais representados em figura planas. O papel das isometrias é a de possibilitar a verificação de medidas invariantes e propriedades de uma determinada figura.

Para a autora, os PCN “contribuem para que o professor não trate os conteúdos de forma compartimentada e sim de modo a favorecer e destacar as conexões possíveis entre as transformações geométricas com o cotidiano e com outras áreas." (MABUCHI, 2000, p. 84). Ainda no quarto e último ciclo, uma das orientações dadas é a de que esse ensino deve ocorrer de forma interdisciplinar, envolvendo conteúdos de Artes e de outras áreas.

O fechamento da seção de análise de documentos oficiais se dá no estudo dos padrões curriculares dos Estados Unidos, por meio do documento Estándares curriculares y de evaluación para la educación Matemática (NCTM, 1986), que define que a Matemática deve ter um sentido prático, uma utilidade relacionada em contribuir para se alcançar um determinado objetivo e, além disso, explora o fato de que o conhecimento matemático auxilia na compreensão de modelos e estruturas das demais áreas.

Os destaques são numa aprendizagem de Matemática dividida em três faixas etárias que demandam primeiramente o uso de materiais manipuláveis e parte de um contexto para chegarem a abstrações matemáticas a partir de experiências, seguido de um estudo em que a forma de se estabelecer conexões matemáticas visa processos mais formais e, posteriormente, os conteúdos se caracterizam pela integração de ideias da Álgebra e da Geometria. A autora reconhece que essa integração no processo de aprendizagem representa uma das mais importantes conexões da Matemática:

\footnotetext{
A história da Matemática mostra o impulso considerável produzido no século XVII, quando as ideias geométricas dos antigos foram traduzidas na linguagem da Geometria analítica e se transformaram em novas ferramentas para resolver uma grande variedade de problemas. As transformações e suas ligações com sistemas algébricos podem trazer aos futuros universitários experiências valiosas relacionadas à composição de funções e estruturas de grupo (MABUCHI, 2000, p. 87).
}

Dessa forma, para os estudantes da Educação Básica, as transformações geométricas podem constituir-se tanto como ferramentas na resolução de problemas como também na compreensão dos conceitos de congruência e semelhança. Tais conceitos são estudados em etapas propostas para o estudo da Geometria de forma gradativa, iniciando com o uso de materiais concretos e manipuláveis, passando por um processo intermediário com o uso de instrumentos como régua e compasso e concluindo as etapas com processos mais formais e dedutivos. 
Em relação aos outros currículos apresentados, o destaque dos documentos da Espanha, como os Ensinos Mínimos Nacionais e o Projeto Curricular da Espanha, propostos na década de 1990, é a importância dada ao desenvolvimento de estratégias para a resolução de problemas e um cuidado maior para a percepção de quais são os conhecimentos prévios dos estudantes e por meio de quais processos eles constroem novos conceitos matemáticos. Outras especificidades apresentadas nesses documentos são o cuidado para se ter um olhar estético para a beleza da Matemática e, em especial, da Geometria, além da proposta de que sejam trabalhadas as chamadas "atitudes" dos estudantes, tais como "valorização dos instrumentos de desenho" e "apreciação da beleza de certas configurações geométricas".

A abordagem proposta em tais documentos curriculares oferece uma visão ampla das transformações geométricas, percebendo-as enquanto movimentos de objetos, exploração de semelhanças e de ampliação e redução de figuras e proporcionando um estudo concreto e analítico das simetrias axiais e centrais, aproximando o estudante, inclusive, do conceito de transformação geométrica como uma função aplicada a pontos.

Faz também uma análise mais geral sobre currículo (do final da década de 90) e ensino de Matemática na França e verifica que as transformações geométricas aparecem nos programas franceses com a argumentação de que, pelo ponto de vista pedagógico, a utilização de dobras, de deslizamentos e de rotação de um desenho permite, desde as primeiras séries, introduzir iniciativas de justificação ou argumentação.

Uma consideração que Mabuchi (2000) faz concluindo as subseções relacionadas a análise de documentos curriculares de outros países é que as transformações geométricas se apresentam no currículo francês de forma mais significativa do que no Brasil, justificando, em seguida, por meio de uma análise de como os PCN, após sua última modificação, trazem esse tema para os currículos e mostra em que medida essa ação afetou alguns livros didáticos brasileiros.

No Brasil, o livro didático é um instrumento de apoio didático supervalorizado, pois, inúmeras vezes, o professor não consegue ter condições de aperfeiçoar sua formação e não dispõe de muitos recursos didáticos e suportes curriculares (BRASIL, 1998). Dessa maneira, a forma como os livros didáticos abordam a Geometria e as metodologias utilizadas afetam a maneira segundo a qual esta será ensinada e valorizada na sala de aula pelo professor de Matemática. Para Mabuchi (2000), os livros até o final do século XX caracterizavam-se por uma desvalorização da Geometria, falta de conteúdos importantes e abordagens inadequadas para os níveis de escolarização destinados. Em seu trabalho, a autora busca verificar em que 
medida as ações propostas pelos PCN modificaram significativamente o tratamento da Geometria das transformações em alguns livros didáticos dessa época.

Faz uma análise de quatro livros didáticos do primeiro e segundo ciclo (de $1^{\mathrm{a}}$ a $4^{\mathrm{a}}$ série) e quatro livros didáticos do terceiro e quarto ciclo (de $5^{\mathrm{a}}$ a $8^{\mathrm{a}}$ série). Suas considerações mostram que o estudo das transformações se dava da seguinte forma: no primeiro e segundo ciclo era apresentado apenas o estudo da reflexão e das propriedades de simetrias, enquanto no terceiro apareciam recomendações para o ensino de reflexões em retas, translações, rotações, ampliações e reduções.

No quarto ciclo, o estudo das transformações serve, principalmente, como ferramenta analítica para problemas relativos à congruência e semelhança de figuras. Ainda a respeito dos terceiro e quarto ciclos, categoriza os livros didáticos com uma abordagem para as transformações enquanto ferramentas para a dedução de propriedades geométricas. Outras aplicações em Geometria também aparecem, tais como obtenção de figuras por meio de isometrias, compreensão de transformação geométrica enquanto um movimento no plano etc.

Por meio da trajetória histórica que as transformações geométricas tiveram nas propostas curriculares brasileiras e de outros países influentes, como Estados Unidos e França, o tratamento dessa parte da Geometria evidenciou o significado que a aplicação possui em si mesma, sendo ela uma reflexão em relação a uma reta ou a um ponto, uma translação, uma rotação ou uma homotetia. Estas foram identificadas nas recomendações de documentos curriculares da Educação Básica como ferramentas para análise de características de figuras, de comparação entre figuras, e sobretudo de movimento de figuras e de objetos. O conceito de função aplicada a pontos do plano ou espaço não aparece nas propostas atuais, mas a pesquisa intui que as transformações geométricas poderiam ser apresentadas como correspondência entre pontos do plano ou espaço nas últimas séries do Ensino Fundamental.

Observou então, como as variáveis afetam a observação de uma atividade de reflexão, como aplicar os tópicos de ampliação e redução de figuras e como obter figuras e objetos por meio de outras isometrias, além de comparar casos de congruência, a partir de uma disciplina ministrada em um curso de Licenciatura em Matemática, oferecido pela PUC/SP. O público da disciplina foi composto por 34 participantes dentre professores de Matemática, Ciências e pedagogos. Metade desse grupo relatou que não ensinavam ou que ensinavam pouca Geometria em sala de aula e, além disso, 19\% dos professores não haviam estudado Geometria em nenhum momento de sua vida escolar antes do referido curso. Esse fato forneceu indícios de que a Geometria já era negligenciada em escolas brasileiras desde a década de 1980. 
A estrutura da disciplina deu-se em algumas etapas que consistiram na fonte de dados da pesquisa de Mabuchi (2000). Os objetivos traçados foram de que os professores participantes se apropriassem das noções sobre as transformações geométricas e de possibilidades de trabalhos de sobre as transformações que poderiam ser desenvolvidos no Ensino Fundamental, junto aos alunos.

Grande parte dos professores mostrou, por meio da atividade diagnóstica, compreender o conceito de simetria e reflexão em reta, porém conclui-se que as transformações translação e rotação eram desconhecidas por todo o grupo. A análise apoiou-se nas pesquisas de Diana van Hiele-Geldof e Pierre van Hiele (1957 e 1959) sob a ótica de Gutiérrez e Jaime (1987), que são apresentadas em quatro níveis de compreensão (a teoria original apresenta cinco níveis):

a) Nível 1 - Visualização ou reconhecimento: reconhecem os movimentos das isometrias de maneira global com a observação em objetos e uso de materiais auxiliares, como régua. Utilizam propriedades visuais para identificar e descrever esses movimentos.

b) Nível 2 - Análise: consideram os movimentos mediante suas características e os utilizam de forma explícita na resolução de problemas.

c) Nível 3 - Classificação ou Dedução Informal: generalizam e justificam resultados de composições de isometrias, compreendem as reflexões transladadas; deduzem, argumentam e demonstram proposições. Possuem maior abstração das definições e são capazes de fazer generalizações com argumentos informais.

d) Nível 4 - Dedução formal: fazem demonstrações formais das propriedades mais importantes das isometrias do plano, compreendendo as hipóteses, a tese e as implicações lógicas.

Nesse período, diversos modelos curriculares que estavam estruturados sob a ótica da Matemática Moderna sofreram uma forte influência das pesquisas dos Van Hiele. O principal fator evidenciado é que o foco passou a ser colocado nas necessidades e na forma de aprender dos alunos e não mais no conceito matemático em si.

Os níveis propostos por Van Hiele poderão ser observados implicitamente no processo da nossa pesquisa: a experiência com professores de Matemática inicia-se no nível 1 com a visualização de objetos e segue para a análise de características e generalizações de propriedades. Embora o nível de dedução formal não tenha sido nosso principal objetivo, os professores puderam discutir algumas demonstrações de propriedades da Geometria Plana e de reflexões em reta. 
Em seguida, discute um pouco a teoria das situações didáticas de Guy Brousseau (1986) e, assim como o modelo de Van Hiele, preconiza o processo de aprendizagem com foco no aluno e na sua construção do saber. Segundo ele, o aluno aprende adaptando-se a um determinado meio, a fatores de dificuldades e se deparando a contradições; o meio pode ser caracterizado como uma situação didática ou uma situação a-didática.

Chamam-se situações didáticas as relações que se estabelecem entre o(s) aluno(s), um determinado meio e ao professor, buscando a aquisição de saberes por parte desses alunos, nessas relações o professor tem papel fundamental na forma de aproximação do estudante com o meio.

Por outro lado, uma situação a-didática é caracterizada pelo papel secundário do professor, no qual este é afastado da interação entre o aluno e a situação, e pelas ações e iniciativas do próprio aluno que se relacionam com a lógica interna da situação e que não dependem da intervenção de um professor.

Para Brousseau (1990, p. 51) "na didática moderna, o ensino é a devolução ao aluno de uma situação a-didática e aprendizagem é a adaptação a esta situação”. O papel do professor se modifica com a exploração do conceito de situação a-didática e se caracteriza pela noção de devolução: ato pelo qual o professor faz o aluno aceitar a responsabilidade de uma situação de aprendizagem (a-didática) ou de um problema e aceita ele mesmo as consequências dessa transferência (BROUSSEAU, 1990 apud MABUCHI, 2000, p. 128).

Outro conceito apresentado por Brousseau é o de contrato didático, o qual determina, sobretudo, de forma implícita, quais regras devem ser seguidas durante o trabalho em meio à situação proposta. A forma como os sujeitos concebem esse contrato ou como o aceitam tem relação com os acordos realizados pelo grupo de estudantes e pelo professor, mas também sofre influência dos contratos didáticos vivenciados anteriormente pelo grupo.

Para determinados grupos, o contrato se caracteriza como um modelo em que o professor expõe qual conteúdo será trabalhado, explicitando os conceitos e noções, fazendo as demonstrações e estabelecendo as principais relações, esse modelo se caracteriza por situações didáticas em que o professor tem papel de destaque no processo de aprendizagem, enquanto um modelo em que as discussões entre os alunos são encorajadas, o processo de descoberta de conceitos e padrões se dá em meio à resolução de problemas e que o professor não expõe os principais resultados sem que os alunos tenham conseguido, anteriormente, obtê-los, caracteriza uma situação a-didática. 
$\mathrm{Na}$ resolução de problemas, um aluno que não tenha adquirido a noção esperada de algum tópico de estudo pode ter desenvolvido um obstáculo, ou seja, um conhecimento ou uma concepção que podem atrapalhar a aquisição de novos conceitos. Organizar a superação de um obstáculo consiste primeiramente em identificar quais são os principais erros que o manifestam e, em seguida, de escolher uma situação em que a única resolução satisfatória seja aquela relacionada com os conceitos devidamente aplicados.

Em seu texto, uma relação é estabelecida entre a teoria das situações didáticas de Brousseau e a dialética ferramenta-objeto segundo Régine Douady (1992), mostrando quais aspectos podem ser destacados em uma situação dependendo de qual é o foco e de como é o problema dado, de forma que uma transformação geométrica possa passar a ser uma ferramenta quando utilizada como um conhecimento para se estudar as propriedades de figuras e para a noção de congruência, mas também pode ser compreendida como o objeto de estudo a fim de classificar diferentes tipos de Geometrias. Após construir a narrativa de como os principais conceitos da Geometria das transformações foram concebidos segundo o ponto de vista histórico e epistemológico entre os matemáticos e nos currículos de Geometria de alguns países e apresentar uma fundamentação didática acerca de como se dá o aprendizado em meio a determinadas situações e acerca do tema central deste trabalho, faz a descrição das atividades desenvolvidas em seu curso e do desempenho dos professores participantes.

Dezenove atividades foram propostas, todas relacionadas com o conceito de reflexão (em relação a reta ou a ponto) e simetrias de figuras planas. Apresentada a atividade, a análise deu-se em: descrição do objetivo principal; feita uma análise da atividade em si, dos itens em que se dividiu e das variáveis didáticas evidenciadas nas principais pesquisas de ensino da Geometria das transformações relacionadas com cada item, tais como posição do eixo de reflexão, complexidade da figura, uso de malha quadriculada ou não etc.; uma análise dos resultados detalhando qual foi o desempenho dos professores - que realizaram todas as atividades em pequenos grupos - em cada um dos itens, fazendo conexões entre os principais erros com algum tipo de variável. A análise tanto da atividade como dos resultados foi feita tendo como base os conceitos dos tipos de situações desenvolvidos por Brousseau, na teoria das situações didáticas, e as fases de organização do ensino desenvolvidas na abordagem de Douady, na dialética ferramenta-objeto.

$\mathrm{Na}$ apresentação das atividades e na análise destas, foram descritas, com diferentes níveis de detalhamentos em cada questão, quais foram as intervenções executadas, as 
manifestações dos professores, o que foi discutido, as formas de resolução e tipos de justificativas apresentadas.

Não fica muito evidente como foi feita a formalização ou concretização de conceitos matemáticos, como as atividades foram apresentadas ou expostas, nem em quais ou quantas aulas foram realizadas. No entanto, afirma que antes que as atividades fossem apresentadas para os professores, foi feito um teste diagnóstico para analisar seus conhecimentos prévios com relação aos tópicos da Geometria das transformações. Os itens das atividades que demandaram apenas os conhecimentos prévios, que os professores já haviam obtido em disciplinas anteriores nesse mesmo curso de Licenciatura, são apresentados como a fase da organização do ensino chamada por Douady (1992) de antigo e na fase de conclusão de certas atividades, os resultados matemáticos aparecem como a fase de institucionalização. Nessa fase é feito um filtro dos conhecimentos trabalhados de forma a analisar os que podem ser descontextualizados e expressos como objetos do saber matemático.

Os itens das atividades nos quais os professores fizeram a resolução das atividades por meio de uma discussão em grupo foram caracterizados como situações de formulação (BROUSSEAU, 1990), pois verifica-se a troca de informação entre os sujeitos a fim de explicitar seus modelos ao resolver um problema.

$\mathrm{Na}$ análise de resultados, foram destacados os procedimentos utilizados nas resoluções, bem como as dificuldades que apareceram em meio às atividades, classificando a atividade do estudante em dos níveis de raciocínio geométrico dos Van Hiele (1959). Para a autora, a solicitação da justificação das respostas em todos os itens colabora para o desenvolvimento dos professores em-diferentes níveis. Também faz validações de algumas constatações realizadas por pesquisadores do ensino de Geometria das transformações, que estudou em seu capítulo sobre a evolução das pesquisas dessa área em vários países diferentes.

Nas situações em que os conhecimentos prévios dos professores não eram suficientes para se resolver alguns tipos de problemas que até então não eram comuns para o grupo, foi necessário que se formulassem, ainda que implícita ou informalmente conceitos, propriedades ou procedimentos. caracterizando-se como uma fase da organização do ensino chamada por Douady de "novo implícito".

Um fator que se mostrou impactante no desenvolvimento dos participantes desse curso de Licenciatura é que eles não haviam estudado com certo detalhamento as propriedades da Geometria Euclidiana fazendo com que, segundo relato da autora, houvesse momentos em que os professores tivessem algumas dificuldades em aplicar conceitos aprendidos de forma 
cumulativa. Isso fica evidente pois, numa determinada atividade, trabalhou-se e concretizou-se como resultado matemático, determinado conceito relacionado à preservação de ângulos em uma reflexão em reta, que foi um requisito para a resolução de uma das atividades seguintes, mas que ainda assim um número pequeno de professores conseguiu responder corretamente.

Em algumas das atividades, o objetivo era descrever as principais propriedades e conclusões geométricas obtidas a partir da experimentação em tarefas relacionadas a reflexões em retas e em pontos. Dessa forma havia, primeiramente, atividades em que estava evidente que se buscava a resolução de problemas e, posteriormente, havia atividades em que se buscava escrever explicitamente as generalizações obtidas nesses problemas. As justificativas, argumentações e demonstrações desses resultados gerais foram realizadas e obtidas por meio de várias discussões do grupo.

Após as atividades de simetria por reflexão, o curso oferecido apresentou atividades relacionadas a translação e rotação com o enfoque em aplicações e no estudo de composição de reflexões que produzem tais isometrias. Segundo a autora, os professores participantes haviam demonstrado, na atividade diagnóstica, que desconheciam as propriedades dessas duas isometrias. As atividades sobre esses dois tópicos não foram descritas e detalhadas, pois o foco de estudo foi em reflexões em reta e reflexões em ponto.

Além da resolução de 19 atividades em encontros presenciais, os professores também receberam orientação para que desenvolvessem algumas atividades relacionadas à reflexão em reta e estudo de simetrias axiais com os seus alunos. A maior parte dessas atividades foram oferecidas pela ministrante do curso e, inclusive, eram semelhantes a algumas das atividades desenvolvidas no curso de licenciatura, mas os professores participantes também poderiam apresentar atividades que eles mesmos criassem.

O trabalho com essas atividades deveria incentivar o trabalho mais autônomo dos alunos, de tal forma que os professores deveriam fazer o mínimo possível de intervenções durante as aulas. Mesmo sem descrever em detalhes de que forma os professores deveriam aplicar as atividades, sabe-se que grande parte dos professores propôs trabalhos em grupos, mas não foi explicitado como a discussão e o fechamento dos conceitos matemáticos deveriam ser feitos e como poderiam ser as intervenções do professor e quais materiais deveriam ter utilizado (mas os próprios professores mencionaram que solicitariam aos seus alunos que trouxessem régua, espelhos e outros materiais pertinentes às atividades). Os resultados das aplicações foram descritos em relatórios individuais dos professores. 
De forma geral, nos relatórios de aplicação, os professores afirmaram que houve uma boa interação dos seus estudantes com as atividades propostas e que, apesar de ocorrerem muitos erros, as aulas foram dinâmicas e diversos conceitos relacionados à Geometria Plana puderam ser explorados. Uma conclusão importante que aparece no trabalho de Mabuchi, em relação ao curso oferecido, e que se revela a partir das produções desses professores com as atividades de reflexão e simetria axial, é que as características da Geometria Plana, as propriedades de algumas figuras e o desenho geométrico são muito pouco trabalhados nas escolas de Educação Básica e que, portanto, muitos professores não tiveram a oportunidade de ter esse tipo de contato com a Geometria ou só o tiveram durante o curso de Licenciatura. Nos próprios relatórios os professores mostraram que reconheciam as dúvidas e dificuldades de seus alunos com as suas próprias dúvidas e dificuldades, mostrando que

\footnotetext{
embora grande parte do grupo de professores lecionasse Matemática há um bom tempo e trouxesse alguma bagagem de conhecimentos geométricos, muitos dos docentes apresentaram procedimentos semelhantes aos assinalados em pesquisas feitas com alunos do Ensino Fundamental. Observamos que a escolha de diferentes valores das variáveis didáticas [...] favoreceu ou dificultou a resolução dos problemas, fazendo surgir concepções e erros semelhantes aos dos alunos das pesquisas. (MABUCHI, 2000, p.192)
}

Tal fenômeno também será discutido em nosso trabalho por meio de uma experiência com professores de Matemática. A presença da Geometria na formação docente, inicial e continuada, é um fator que interfere diretamente em nossos estudos e, assim como Mabuchi, buscamos formas de colaborar com o ensino e aprendizagem de tópicos de transformações geométricas planas.

Após a realização de todas as atividades, foi solicitado aos professores que fizessem um tipo de avaliação final com problemas semelhantes aos apresentados na atividade diagnóstica, no início do curso, para que se pudesse fazer uma análise global do aprendizado de determinados conceitos e desenvolvimento na produção de justificativa e argumentação de respostas. Segundo a autora, $71 \%$ dos professores participantes que não conseguiam resolver e/ou justificar os problemas no início do curso passaram a apresentar resoluções e argumentações satisfatórias no final do curso. Verificou-se também uma evidente progressão nos níveis de raciocínio geométrico da teoria dos Van Hiele, mais especificamente, partindo de resoluções classificadas em nível 1, de Análise, até as resoluções do nível 3, de Dedução Informal.

Foi identificado, com este trabalho, que é possível que alguns professores de Matemática da Educação Básica tenham pouca familiaridade com demonstrações e 
justificativas de conceitos matemáticos, fazendo com que apresentem os conteúdos de Geometria, quando os apresentam, de forma convencional, ou seja, com definições, relações, generalizações e propriedades já explicitadas. Por essa razão, além de fortalecer o ensino de Geometria nas escolas, os professores precisam continuar se atualizando em uma formação continuada, refletindo sobre sua própria prática em cursos de extensão e nas suas próprias vivências docentes, desenvolvendo assim a sua forma de comunicar Matemática, assim como a de seus alunos.

Podemos concluir que o estudo das propriedades das transformações geométricas pode colaborar na formação docente, para além do desenvolvimento do pensamento geométrico (PARZYSZ, 2006), no desenvolvimento de argumentações matemáticas, na capacidade de explorar diferentes tipos de representações e na resolução de problemas.

\subsection{Escolha do tema de pesquisa}

No vasto campo da Geometria, escolhemos trabalhar com o tema pavimentações do plano. Uma das principais motivações para essa escolha refere-se a um projeto de ensino que desenvolvemos no final de nossa Graduação (como trabalho de conclusão de curso) intitulado "Pavimentação do Plano usando Espelhos Planos e Caleidoscópios" (SANTOS, 2014). Nesse contexto, elaboramos uma sequência de atividades de Geometria relacionadas ao estudo das propriedades de reflexões em retas e pavimentações do plano com polígonos regulares, mas que não tivemos oportunidade de experimentar, nem com alunos, nem com professores.

Surgiu assim o desejo de aprofundar os estudos dessa temática, e mais, associar ao projeto inicial um estudo experimental com professores de Matemática, uma vez que constatamos, posteriormente, que esse tema é pouco trabalhado em sala de aula bem como recebe pouca atenção em livros didáticos de Matemática do Ensino Fundamental. O referido trabalho nos pareceu servir, então, de subsídio bibliográfico e referencial para as atividades que compõem sequências didáticas a serem reelaboradas, em especial no que se refere a algumas das propriedades Matemáticas de reflexões e das pavimentações do plano.

Consideramos que o uso de espelhos e caleidoscópios para o ensino da Geometria, com ênfase nas pavimentações, é justificado principalmente pelo seguinte aspecto: essas são ferramentas que fornecem destaque à visualização de diversas propriedades e facilitam o levantamento de conjecturas a respeito de conceitos geométricos associados às pavimentações, desenvolvendo certo nível de pensamento, como será descrito mais adiante. Entendemos que a aprendizagem de tais objetos matemáticos é rica em diversos conceitos - como polígonos, estudo de ângulos, retas com propriedades especiais tais como bissetrizes e mediatrizes a partir 
de construções com régua e compasso e reflexões em retas - e que os materiais escolhidos potencializam a exploração deles de forma mais dinâmica e experimental.

\subsection{Questões norteadoras}

Nesta pesquisa fomos guiados por duas questões principais que buscamos refletir durante todo o processo de investigação:

1- Em que medida um curso de formação continuada pode colaborar com a apropriação, por parte de um grupo de professores, de uma abordagem de ensino com foco no desenvolvimento de tarefas exploratórias de Geometria por meio de materiais manipuláveis?

É sabido que a formação de professores é um processo contínuo na carreira docente e que existem diferentes formas de desenvolver uma aula de Geometria. Nossa intenção é avaliar como uma formação específica pode colaborar com a apropriação de uma abordagem de ensino que utiliza a investigação matemática, em especial com tarefas exploratórias.

2- De que(quais) forma(s) a prática dos professores participantes pode ser afetada, no que diz respeito ao planejamento de sequências didáticas e da valorização do ensino de Geometria, a partir das discussões coletivas e do desenvolvimento das atividades de um curso de formação continuada?

O formato do curso de formação continuada desta pesquisa demandou dos professores participantes a elaboração de sequências didáticas. Avaliamos então, durante o processo dessa pesquisa, como essa característica do curso pôde afetar suas práticas docentes.

\subsection{Objetivos}

Tivemos o interesse de colaborar com a formação dos professores participantes, tendo em vista que é provável que poucos tiveram contato com a Geometria das transformações durante sua Graduação, e de apresentar um tipo de abordagem pedagógica para se elaborar e experimentar tarefas de investigação matemática; discutir e vivenciar como o uso de materiais 
concretos pode colaborar com o ensino de Geometria; e sugerir a utilização das atividades desenvolvidas no curso, de forma integral ou adaptada, com os seus alunos, produzindo suas próprias sequências didáticas.

\subsubsection{Objetivos Gerais}

- Produzir e validar uma sequência de atividades compostas por tarefas exploratórias, inseridas em um laboratório de Educação Matemática, sob a ótica do desenvolvimento do pensamento geométrico.

- Na perspectiva de Shulman (1987), contribuir com a formação continuada de professores nos seguintes aspectos:

- Conhecimento do conteúdo: no estudo e aprofundamento de determinados conceitos de Geometria Plana;

- Conhecimento pedagógico do conteúdo: no desenvolvimento de subsídios para apoiar as reflexões sobre suas práticas docentes no que diz respeito à elaboração e desenvolvimento de sequências didáticas e ao uso de materiais diversificados, em particular para abordar conceitos geométricos e de transformações.

\subsubsection{Objetivos Específicos}

No contexto de um curso de formação continuada, cujo tema envolve pavimentações do plano com polígonos regulares, pretende-se:

- Contribuir na formação de professores com relação a conceitos de transformações geométricas planas, em especial de reflexão em reta;

- Discutir e experimentar com professores formas de introduzir a investigação matemática na prática docente;

- Analisar como os professores concebem a validação de conjecturas a partir de evidências materiais, discussões e argumentação;

- Refletir sobre formas de se introduzir o uso de espelhos e caleidoscópios em aulas de Geometria na Educação Básica; 
- Verificar se e como, a partir da proposta de situações específicas, os professores constroem conhecimentos, articulando-os tanto em uma Geometria com referencial concreto quanto em uma Geometria axiomática.

Almejando contribuir para alterar o cenário do ensino de Geometria, acreditamos que o estudo das transformações geométricas planas na Educação Básica oferece ao professor oportunidades de tornar mais interessante o ensino de Geometria, por meio de situações de aprendizagem que envolvem o uso de materiais concretos em atividades experimentais e de caráter investigativo. Nesse contexto, fortemente inspirados pela abordagem proposta por Barbosa (2005), conjecturamos que o uso de espelhos planos e caleidoscópios em sala de aula pode representar uma abordagem de ensino significativa.

Com a intenção de validar e aprimorar algumas condições - em termos de atividades, recursos materiais e estratégias didático-metodológicas - em uma ação de formação, propusemos e ministramos um curso de formação continuada para professores que ensinam Matemática, intitulado Geometria Plana: pavimentações usando espelhos e caleidoscópios.

Visamos, essencialmente, que as atividades do curso que será apresentado em detalhes no capítulo sobre metodologia, resultassem em subsídios para que os professores fizessem uma reflexão de suas práticas acerca do ensino e aprendizagem de alguns tópicos de Geometria, desenvolvendo-se profissionalmente, em especial, a partir do desenvolvimento do conhecimento pedagógico do conteúdo, que, segundo Shulman (1987, p. 9), é um tipo de conhecimento que diz respeito a fazer escolhas dentro de um assunto, a fim de se obter as formas mais úteis de representação de ideias, analogias, ilustrações, exemplos e demonstrações, tornando tal assunto o mais compreensível possível.

Buscaremos depreender então, como é a percepção e aceitação de professores de Matemática ao uso de espelhos e caleidoscópios (sendo estes os materiais didáticos principais desse estudo) por meio de atividades de investigação matemática (às quais o curso oferecido se dedicou) conduzidas por uma abordagem de ensino inspirada nas Cinco Práticas para Orquestração de Discussões Matemáticas (STEIN; SMITH, 2011), que está detalhada mais adiante, e visam o aprendizado de alguns tópicos da Geometria Plana.

A partir de uma experiência com professores, validaremos, sob uma perspectiva de formação, tanto os instrumentos escolhidos e as atividades produzidas (por nós e pelos sujeitos participantes), como a abordagem adotada, formando assim, uma justificativa de um projeto de ensino baseada na experiência, vivência e avaliação de quem efetivamente ensina. 


\section{O DESENVOLVIMENTO DO PENSAMENTO GEOMÉTRICO}

Inspirado fortemente nos estudos de Diana van Hiele-Geldof e Pierre van Hiele, Parzysz (2006) descreve uma forma de estabelecer níveis de desenvolvimento do raciocínio geométrico relacionando-os diretamente com a tangibilidade dos objetos em estudo, bem como de suas representações, e com a capacidade de abstração necessárias para a validação de conjecturas e de resoluções de problemas de Geometria.

Assim como os níveis descritos pelos Van Hiele, aqueles de pensamento geométrico não se apresentam ou se manifestam de forma estática e linear nos sujeitos. Uma pessoa pode utilizar estratégias de mais de um nível de pensamento e elaborar uma discussão que perpasse uma geometria axiomática e uma não-axiomática. Parzysz discute formas de utilizar a tangibilidade dos objetos e suas representações para se produzir conjecturas, mesmo quando o sujeito utiliza uma lógica hipotético-dedutiva com percepção abstrata dos objetos em sua argumentação.

O autor discute ainda a importância da presença de disciplinas obrigatórias de Geometria nos cursos de formação de professores para auxiliar os alunos no processo de transição entre uma Geometria da observação e uma Geometria da demonstração e lidar com os conflitos cognitivos atrelados a esse processo.

Na discussão dessa dualidade de Geometrias, Van Hiele (2002) distingue dois níveis de apreensão das formas geométricas, assim nomeados de nível inferior, em que a visualização é utilizada, quase exclusivamente, para a identificação das formas; e nível superior (descritivo), em que essa identificação depende das propriedades da figura. Partindo de uma perspectiva semelhante, Houdement \& Kuzniak (2003) fazem essa distinção destacando três níveis em que a compreensão do objeto geométrico depende (ou não) da conexão com a realidade e Henry (1999) destaca outros três níveis que consistem na observação da realidade ou de um modelo teórico.

A partir desses estudos, Parzysz cria um quadro teórico com quatro paradigmas do pensamento geométrico (cf. Figura 1).

Figura 1- Paradigmas do pensamento geométrico 


\begin{tabular}{|c|c|c|c|c|}
\cline { 2 - 5 } \multicolumn{1}{c|}{} & \multicolumn{2}{c|}{ Geometrias não-axiomáticas } & \multicolumn{2}{c|}{ Geometrias axiomáticas } \\
\hline $\begin{array}{c}\text { Tipo de } \\
\text { Geometria }\end{array}$ & $\begin{array}{c}\text { Concreta } \\
(\mathrm{G} 0)\end{array}$ & $\begin{array}{c}\text { Espacial-gráfica } \\
(\mathrm{G} 1)\end{array}$ & $\begin{array}{c}\text { Proto-axiomática } \\
(\mathrm{G} 2)\end{array}$ & $\begin{array}{c}\text { Axiomática } \\
(\mathrm{G} 3)\end{array}$ \\
\hline Objetos & \multicolumn{2}{|c|}{ Físicos } & \multicolumn{2}{c|}{ Teóricos } \\
\hline Validações & \multicolumn{2}{|c|}{ Perceptivo-dedutivas } & \multicolumn{2}{c|}{ Hipotético-dedutivas } \\
\hline
\end{tabular}

Fonte: PARZYSZ, B. La géométrie dans l'enseignement secondaire et en formation de professeurs des écoles: de quoi s'agit-il?. "Quaderni di Ricerca in Didattica”, n.17, 2006.

Neste trabalho, utilizaremos chamaremos esses paradigmas de níveis do pensamento geométrico. Cada um dos quatro níveis mostrados representa um modelo de raciocínio geométrico que é determinado pelo tipo de objeto de estudo e por uma determinada forma de se justificar afirmações e de se resolver problemas.

A primeira categorização de Geometria é nomeada como não-axiomáticas e refere-se a observação da realidade e percepção de características e propriedades de objetos geométricos a partir da evidência material em situações concretas. Partindo da Concreta (G0) - que, segundo Parzysz (2006), não é propriamente uma geometria - com a finalidade de desenvolver a capacidade de análise caracterizada pelo uso de desenhos, representações e gráficos, chega-se à Espacial-gráfica (G1).

As Gometrias ditas axiomáticas referem-se ao desenvolvimento de conjecturas e teses que não exigem, necessariamente, alguma evidência material, mas que se baseiam, a princípio, na análise de propriedades de objetos de natureza abstrata que não demandam desenhos ou representação gráfica, partindo da Proto-axiomática (G2) para uma análise da estrutura do modelo teórico, de sua consistência e de seus teoremas, formando a Axiomática (G3).

Para a discussão sobre como são constituídas as atividades de cada tipo de Geometria, axiomática ou não-axiomática, além de como são trabalhadas e seus objetivos, foi tomada como base a estrutura proposta por Chevallard (1991) no que diz respeito a tarefas, técnicas, tecnologias e teorias.

O uso de materiais de construção geométrica tais como régua e compasso, para a resolução de problemas, evidencia que determinada atividade e a forma como se lida com ela pode ser caracterizada como G1. O uso de régua graduada para encontrar o ponto médio de um segmento, por exemplo, ou encontrá-lo por meio do auxílio do compasso e de uma régua (não graduada) são tarefas que dependem do uso de instrumentos e que demandam a construção de uma representação gráfica (ou desenho) do objeto.

Atividades caracterizadas pelo uso explícito de propriedades, axiomas e definições para lidar com objetos puramente geométricos, tais como ponto e reta, caracterizam uma G2. Nesse 
tipo de atividades, o uso de materiais de construção geométrica tem utilidade apenas para representação e ilustração.

O autor descreve uma articulação entre G1 e G2 que parte de situações em que a validação, confirmação ou verificação de propriedades, conjecturas ou conclusões no âmbito G2 demandem análises sob a ótica de G1 e vice-versa. Para ilustrarmos tarefas de G1 e G2 podemos tomar como exemplo a validação de uma conjectura que pode partir de:

a) G2 - uma demonstração seguindo um raciocínio hipotético-dedutivo que pode usar uma figura como suporte visual, mas que depende de axiomas;

b) G1 - construir uma figura ou representação gráfica para se obter uma validação perceptiva da conjectura ou para evidenciar características que a corroborem.

Em outro exemplo destacado por Parzysz (2006), podemos perceber a natureza dos objetos de estudo de cada um desses dois paradigmas e mostrar que um objeto $X$ satisfaz uma propriedade $P$ ao:

a) G2 - realizar uma demonstração puramente axiomática, partindo de definições e aplicando teoremas. Nesse caso X é um objeto teórico e abstrato e pode ser representado figuralmente.

b) G1 - construir X e verificar P de forma analítica ou com outras estratégias; ou construir um objeto $\mathrm{Y}$ em que é sabido que podemos verificar $\mathrm{P}$ e, então, mostrar que $\mathrm{Y}$ pode se sobrepor a $\mathrm{X}$, ou que ambos possuem determinada equivalência. Nesse caso $\mathrm{X}$ é um objeto físico e observável.

Em seu estudo, o autor expôs uma situação proposta para alunos de cerca de 11 anos de idade, de uma escola de Educação Básica da França. Na atividade em que deveriam trabalhar, eram dados alguns triângulos desenhados em uma folha de papel, e era pedido que fizessem marcas em cada lado, ordenando do menor para o maior lado de cada triângulo; para tanto era permitido apenas o uso de um compasso.

Nesse caso, apesar do uso de materiais concretos, tais como a folha de papel e o compasso, indicar um paradigma G0, o triângulo é o objeto de estudo e está dado apenas em 
uma representação gráfica, caracterizando um paradigma G1. Para a resolução esperada (ou idealizada), os alunos usariam um teorema de G3, "se um ponto $P$ pertence ao interior de uma circunferência $\Gamma$, então $P O<R O$, para todo ponto $R$ da circunferência, onde $O$ é o centro de $\Gamma^{\prime}$.

Em outras palavras, bastaria que os alunos tomassem, no triângulo $\mathrm{ABC}$, uma circunferência de centro em $\mathrm{A}$ e raio $\mathrm{AB}$ e verificar se $\mathrm{C}$ estaria em seu interior ou não (cf. Figura 2). No entanto, o mesmo problema pode ser analisado como sendo de natureza teórica: a circunferência, seu interior e exterior podem ser tomados como conjuntos de pontos do plano euclidiano onde a distância de dois pontos dados pode ser associada a um número real positivo.

Figura 2 - Comparação dos lados de um triângulo
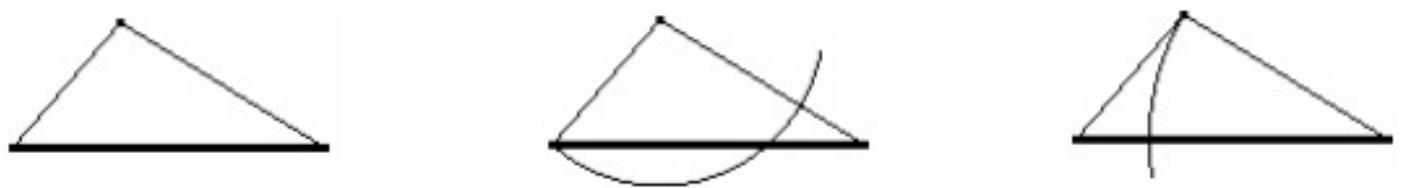

Fonte: PARZYSZ, 2006.

No processo de resolução dessa atividade, são levados em consideração aspectos visuais de G1, destacando primeiramente qual dos três lados do triângulo é o maior, então são aplicadas técnicas de G2 para verificar ou comparar propriedades do objeto geométrico, no caso, usar o compasso para observar visualmente (G1) se determinado vértice do triângulo está fora da circunferência traçada como na figura. As conclusões obtidas permitem ordenar os três lados, do menor para o maior e a justificativa é de natureza hipotético-dedutiva, proto-axiomática, G2.

Este exemplo ilustra o fato de que no trabalho com uma atividade, na realização de tarefas e na resolução de problemas de Geometria, o raciocínio utilizado ora é de natureza física e tem caráter intuitivo, ora é de natureza teórica e tem caráter axiomático, ou seja, o sujeito em questão transita entre os paradigmas G1 e G2 (ou ainda utiliza de um primeiro contato com o concreto G0 e com teoremas desenvolvidos em G3).

Dessa forma, Parzysz afirma que é possível perceber cada paradigma em quatro níveis (ou momentos) diferentes: o nível da tarefa, o nível da demarcação, o nível da ferramenta e o nível da validação. Durante um processo de resolução de problemas, sobretudo ao se lidar com problemas da Educação Básica, os paradigmas mais presentes nesses níveis são G1 e G2 e a transição de um para outro é muito presente (por exemplo, ao usar um desenho para evidenciar uma propriedade, criar uma conjectura e demonstrá-la). 


\subsection{A dialética sabido/percebido}

A necessidade de representar objetos físicos e tangíveis nos faz produzir desenhos que nem sempre são capazes de ilustrar todas as propriedades que o objeto de fato possui. Existem características que são conhecidas - o sabido - mas que não são apresentadas ou visualizadas na representação, pois esta é capaz de discriminar e evidenciar apenas determinados elementos - o percebido - de um objeto. A forma como se lida com o sabido e o percebido ao se ter uma representação de um objeto é chamada de negociação.

Um desenho em suporte bidimensional que representa um objeto tridimensional não conservará todas as suas propriedades espaciais. Em uma representação gráfica desse objeto, as propriedades que podem ser visualizadas habitualmente - o visto - são ilustradas por meio de técnicas de desenho, fazendo remeter àquilo que é conhecido.

\section{2. $O$ caso dos futuros professores}

O meio usado para se explicitar a articulação entre os paradigmas G1 e G2 foi uma pesquisa realizada com mais de 800 estudantes de cursos de formação inicial de professores, na qual foi destacado em que tipo de situações é natural utilizar G2 para regular ações realizadas em G1 e vice-versa.

Os principais objetivos dessa pesquisa foram: obter um inventário de argumentações possíveis para problemas de Geometria; testar o quadro teórico proposto; fazer e testar um trabalho de engenharia didática que desenvolvesse nos alunos a consciência para se distinguir G1 de G2, bem como ampliar seus conhecimentos de Geometria. Para tanto, foram propostas atividades relacionadas como o conceito de mediana.

Em uma das atividades, foi proposto que obtivessem a mediatriz de um segmento MN dado em três situações distintas, com diferentes variáveis (na primeira o segmento estava no centro do papel, na segunda, próximo a borda da folha e na terceira foram dados apenas os pontos $M N$ e dois triângulos isósceles de base $M N$ ). A primeira estratégia, e a mais comum, foi a de traçar duas circunferências de raio $M N$, com centro em $M$ e em $N$, e ligar seus pontos de intersecção, mas nas situações propostas, em que havia um elemento dificultador para essa estratégia, raramente apareciam adaptações de procedimentos de resolução. Com isso percebese que o sujeito pode possuir um conhecimento do tipo "saber-fazer" que não necessariamente implique em ter consciência dos saberes geométricos utilizados. Em outras palavras, foi 
constatado que, em muitos casos, esses futuros professores não sabiam relacionar as técnicas de G1 em construções com régua e compasso e propriedades de G2.

Outra atividade solicitava aos alunos que construíssem uma circunferência de centro $\mathrm{O}$ e diâmetro $\mathrm{AB}$, uma segunda circunferência de centro $\mathrm{O}$ e uma terceira circunferência de centro em A interceptando a segunda em C e D (cf. Figura 3). O problema era verificar e justificar se a reta $\mathrm{CD}$ é mediatriz de $\mathrm{AB}$, sendo que as medidas dos raios das três circunferências foram dadas e eram diferentes números para cada grupo de alunos. Os números escolhidos criaram dois tipos de situações: um caso em que $\mathrm{CD}$ efetivamente era a mediatriz de $\mathrm{AB}$ e outro caso em que $\mathrm{CD}$, apesar de não ser mediatriz de $\mathrm{AB}$, induzia visualmente a concluir-se, erroneamente, que CD era a mediatriz.

As conclusões obtidas mostraram que, dentre os 31 grupos de respondentes, apenas 3 mostraram uma precisa distinção entre G1 e G2, enquanto alguns utilizaram ambos os paradigmas mostrando certa confusão entre uma argumentação por evidência material (como afirmar que C, O e D são colineares sem justificar o porquê) de uma argumentação hipotéticodedutiva (usando algum teorema e provando conjecturas) e outros se detiveram apenas a argumentação de G1 ou apenas de G2.

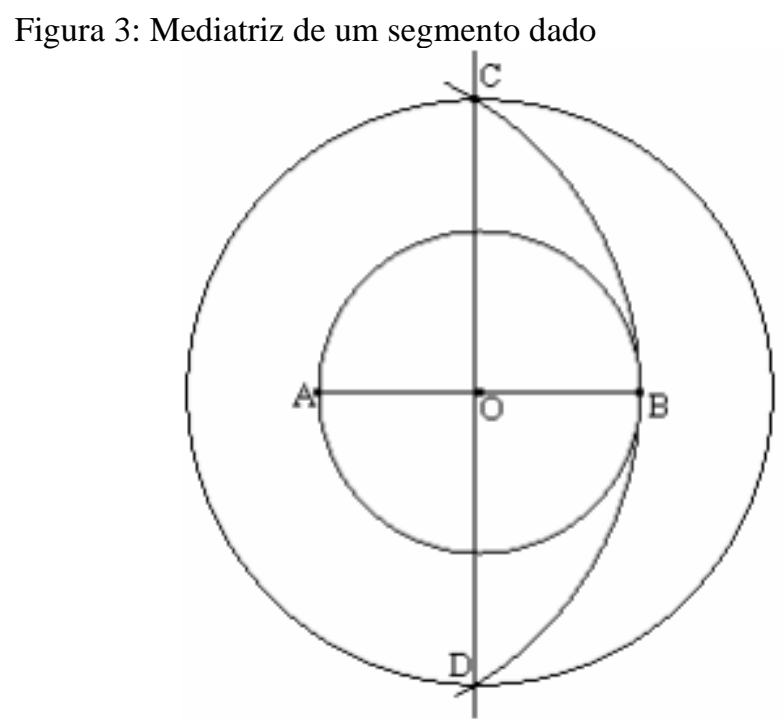

Fonte: Parzysz, 2006

Em outro momento, foram realizadas atividades semelhantes às citadas anteriormente, mas em um ambiente de Geometria dinâmica (Cabri-géomètre) com as ferramentas que possibilitam a "movimentação" de objetos tais como ponto e reta. A pesquisa revelou que, nesse segundo tipo de ambiente, a criação de conjecturas foi facilitada e a maior precisão dos desenhos auxiliou os alunos. Parzysz verificou que os estudantes da pesquisa, futuros 
professores, possuíam relevantes conhecimentos geométricos como teoremas e o simbolismo, mas que grande parte deles não diferenciava uma verificação perceptiva de uma demonstração e não compreendiam que uma figura é apenas uma representação material de um objeto teórico.

A Geometria escolar tem papel fundamental no desenvolvimento dos alunos para terem um uso consciente das ferramentas do raciocínio matemático na resolução de problemas do domínio espacial e físico, por meio do campo teórico e abstrato, garantindo que não se confundam e cometam erros provenientes da percepção visual. Para Parzysz, essa tomada de consciência é o próprio processo de aprender a distinguir bem os quatro paradigmas geométricos propostos em seu quadro teórico.

\subsection{O método do laboratório de Ensino de Matemática}

Dentro do vasto campo de estudos que é o Laboratório de Ensino de Matemática, apresentaremos uma breve revisão de literatura que diz respeito à uma forma de compreender como se caracterizou o ambiente físico e de discussão do curso oferecido nesse estudo e como nosso interesse de colaborar com a formação dos professores participantes foi traduzido em atividades com foco no processo do desenvolvimento do pensamento geométrico e na concepção de uma abordagem didática para a sala de aula da Educação Básica.

O professor Júlio César de Mello e Souza, conhecido como Malba Tahan (1895 - 1974), faz uma discussão no segundo volume de seu livro Didática da Matemática (1962) sobre as potencialidades de se sistematizar conceitos matemáticos por meio do uso dirigido de materiais manipuláveis adequados a situações-problema de diferentes naturezas, além de um ambiente bem equipado. Segundo ele, esse tipo de trabalho motiva mais os estudantes e proporciona-lhes maior segurança para a apropriação de conceitos abstratos. Nessa obra é apresentado e discutido o método do Laboratório de Ensino de Matemática (LEM) que posteriormente viria a ser abordado por outros inúmeros autores.

Malba Tahan apresenta, em seguida, o uso da taquimetria ${ }^{1}$ que é evidenciado em atividades de Geometria Plana, como forma de manter a valorização da Geometria por parte dos professores e seus alunos. Taquimetria é compreendida como o Ensino da Geometria pela evidência material e está relacionada com a resolução de problemas de Geometria de forma prática e concreta.

\footnotetext{
${ }^{1}$ Do grego taqui (rápido) e metria (medir).
} 
Antes que a Geometria fosse compreendida pelo seu caráter de grupo (teoria dos conjuntos) e como Analítica (algebrização), as recomendações do currículo de Geometria no Brasil no período que antecede o MMM são, segundo Matos e Silva (2011) de:

um ensino eminentemente prático e intuitivo nos primeiros anos do curso ginasial e que desperte, aos poucos, no aluno, o sentido da necessidade da justificativa, da prova e da demonstração, introduzindo, ainda no curso ginasial, o método dedutivo, com o cuidado que se exige. (MATOS \& SILVA, 2011, p.7)

Propõe-se então, o trabalho com atividades dirigidas que instigam o processo de descoberta matemática a partir da criação de heurísticas de resolução de problemas que podem ser trabalhados concretamente, resgatando esse aspecto prático e intuitivo do ensino de matemática.

Para Lorenzato (2006), o Laboratório de Ensino de Matemática é definido por:

\footnotetext{
Uma sala ambiente para estruturar, organizar, planejar e fazer acontecer o pensar matemático, é um espaço para facilitar, tanto ao aluno como ao professor, questionar, conjecturar, procurar, experimentar, analisar e concluir, enfim, aprender e principalmente aprender a aprender. (LORENZATO,2006, p.7)
}

No entanto, esse conceito de Laboratório de Ensino de Matemática pode ir muito além do que conhecemos como "sala ambiente", incluindo também todo o desenvolvimento de ideias que antecedem a construção do conhecimento matemático.

Oliveira e Kikuchi (2018) discutem a importância de incentivar a implementação de laboratórios de ensino de Matemática em sala de aula e nos cursos de formação inicial e continuada de professores de Matemática. Destacam que além de conhecer as potencialidades de um Laboratório de Ensino de Matemática e como ele se constitui, é fundamental que o professor conheça as funcionalidades dos materiais e ferramentas, bem como possibilidades de abordá-los de forma adequada em sua prática docente.

Na pesquisa de Rodrigues (2011), são apresentados diferentes tipos de abordagens do Laboratório de Ensino de Matemática, dentre os quais destacamos os dois tipos que mais se aproximam aos objetivos do presente trabalho:

a) Laboratório/ Sala Ambiente - Laboratório de Ensino de Matemática: consiste no local de desenvolvimento de atividades com foco na vivência de processos que auxiliam a construção do conhecimento matemático; trata-se de uma forma de adaptar o Laboratório para a sala de aula, podendo ser explorado na formação de professores e desenvolvido na Educação Básica; é 
um ambiente propício para a sistematização de resultados matemáticos assim como a problematização de uma situação ou de um conceito.

b) Laboratório/Agente de formação - Laboratório de Educação Matemática: um ambiente com foco central na realização de atividades relacionadas ao ensino, à pesquisa e à extensão com ênfase na formação inicial e continuada de professores em Matemática; é propício para que os sujeitos discutam e conheçam como se dá o processo de desenvolvimento do pensamento matemático e da descoberta, vivenciando e explorando atividades que podem ser futuramente promovidas em salas de aula da Educação Básica.

Para Rodrigues (2011), o Laboratório de Educação Matemática contribui para a formação continuada em 10 aspectos, dos quais citamos os que mais se aproximam dos nossos interesses com essa pesquisa:

a) Fornecer aos docentes da Educação Básica subsídios teóricos, práticos e metodológicos como forma de melhoria da prática pedagógica.

b) Promover a reflexão/avaliação das atividades de ensino desenvolvidas.

c) Capacitar os docentes em relação à construção, testagem e à correta utilização do material didático.

d) Criar grupos de estudos e discussões para refletir sobre os problemas educacionais relacionados ao processo ensino aprendizagem na comunidade escolar.

e) Permitir a troca de experiências entre os docentes da universidade e os professores da Educação Básica

f) Assessorar os docentes dos ensinos Fundamental e Médio na pesquisa e organização de material de apoio para o ensino de conteúdos matemáticos vinculados às diretrizes curriculares.

Dentre nossos objetivos, buscamos propor a investigação das atividades, adequando o ambiente de estudo, para que os professores pudessem desenvolver seus próprios conhecimentos geométricos, refletir sobre como as atividades exploradas colaboraram com esse desenvolvimento e discutir formas de adaptar as atividades, conteúdos e objetos estudados para suas próprias salas de aula. 


\section{A GEOMETRIA DAS PAVIMENTAÇÕES DO PLANO}

Neste capítulo, apresentaremos os conceitos matemáticos relacionados com as atividades que foram propostas aos participantes do curso: polígonos, tópicos de Geometria das transformações, pavimentação do plano e a Geometria dos caleidoscópios.

\subsection{Polígonos, região poligonal e linha poligonal}

Como nosso trabalho trata de pavimentações do plano usando polígonos, sentimos a necessidade de discutir primeiramente como podemos caracterizar matematicamente tal objeto. Neste tópico, realizaremos, uma discussão acerca de possíveis definições de polígonos, sob a ótica de livros didáticos, e apresentaremos a definição utilizada neste trabalho e no decorrer do curso que oferecemos (que será apresentado mais adiante).

Em geral, os livros didáticos usados no Brasil trazem diferenças nas definições de polígonos, região poligonal e linha poligonal plana e espacial. Algumas das distinções mais comuns entre as definições de tais entes geométricos estão relacionadas à forma de escrever os enunciados de problemas de Geometria, sobretudo aqueles que envolvem área e perímetro.

Mais precisamente, há definições que afirmam que o polígono é uma linha poligonal que segue determinadas regras, outros afirmam que é a linha poligonal unida com a região interna determinada por essa linha (cf. Figura 4 e Figura 5, respectivamente) e também há aqueles que, apesar de afirmarem que o polígono é apenas a linha poligonal que obedece determinadas regras, posteriormente propõem enunciados do tipo "Calcule a área do triângulo a seguir". A contradição estaria no fato de que uma linha possui sempre área nula, neste caso, podemos dizer que houve certa incoerência com o objetivo dessa tarefa e de seu enunciado, pois, em geral, este tipo de enunciado se refere à área da região delimitada pelo triângulo dado.

Ademais, também acontece de ser feita uma definição que explicita o que é e o que não é polígono, mas apresentando imagens ditas de polígonos que contradizem essa definiç̧ão, produzindo uma inconsistência no conteúdo. Outra situação que pode acontecer, é que ao se decidir por uma definição, podem existir objetos que, apesar de satisfazê-la, não eram pretendidas pelo autor, cuja natureza os faria serem chamados de "monstros" pelo aluno Delta em "A Lógica do descobrimento Matemático: Provas e Refutações" (LAKATOS, 1978), por diferirem muito da essência do objeto imaginado ao se criar uma definição, ainda que o "monstro" satisfaça às condições do que fora definido. 
Figura 4 - Representação de um polígono definido sem a região interna

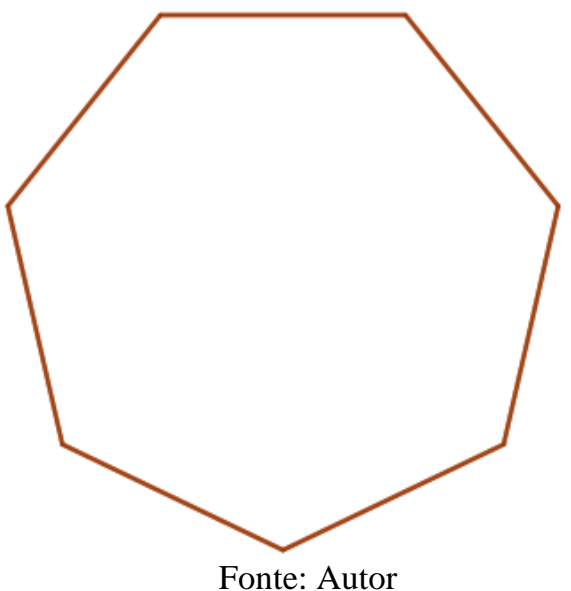

Figura 5 - Representação de um polígono definido incluindo a região interna

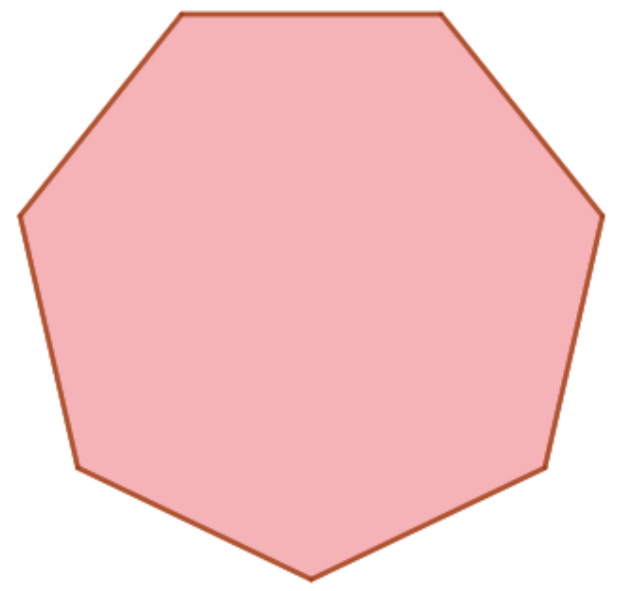

Fonte: Autor

Dentro deste trabalho adotamos a seguinte definição:

Uma figura P é dita polígono se:

1. Existem $\mathrm{n}$ pontos distintos coplanares, chamados de vértices do polígono, $\mathrm{P}_{1}, \mathrm{P}_{2}, \mathrm{P}_{3}, \ldots, \mathrm{P}_{\mathrm{n}-1}$ e $P_{n}$ tais que

$$
P=P_{1} P_{2} \boldsymbol{U} P_{2} P_{3} U P_{3} P_{4} \boldsymbol{U} \ldots \boldsymbol{U} P_{n-1} P_{n} \boldsymbol{U} P_{n} P_{1}
$$

2. A intersecção de cada par de segmentos, chamados de lados do polígono, é nula ou é igual a um extremo em comum. 
Essa definição foi apresentada aos professores participantes durante o quinto encontro do curso oferecido, na primeira atividade desse dia. Até então o termo "polígono" teria sido utilizado seguindo os conceitos que os professores participantes já tinham ou de forma intuitiva (ou seja, mesmo sem saber definir, o sujeito saberia diferenciar o que é polígono do que não é).

A fim de facilitar a convergência entre as imagens produzidas e a linguagem utilizada oralmente e nos enunciados, ao iniciarmos a atividade 2 do quinto encontro, ampliamos essa definição com a seguinte propriedade:

3. O interior da região delimitada pela linha poligonal de $\mathrm{P}$ também pertence a $\mathrm{P}$.

Nesse caso, o conceito de polígono serve como pré-requisito para a compreensão de outro objeto da Geometria, que é a pavimentação do plano. No entanto, o estudo dos polígonos pode ganhar outros significados se nos pusermos em face da questão "Por que estudar polígonos?". Acreditamos que a essência desse estudo se justifica principalmente dentro da arte, da arquitetura, da compreensão de propriedades de faces de poliedros, pelo estudo de ângulos, perímetros e área, entre outras aplicações. Além disso, o estudo de polígonos pode ser visto como uma primeira tentativa de se explorar a transição do nível de pensamento geométrico G1 para o nível proto-axiomático G2, uma vez que, ainda que sejam figuras recorrentes em todos os anos da Educação Básica, é possível que exploraremos diferentes propriedades.

No estudo de áreas, os polígonos são as figuras planas cuja medida pode ser determinada sem muita complexidade. Em geral, na Geometria Euclidiana, podemos decompô-los em triângulos, fazendo com que em diversas situações, encontremos a medida de área de um polígono calculando o valor da área de suas partes triangulares. Além disso, conhecendo uma forma de calcular o valor da área de um triângulo qualquer, podemos deduzir uma forma direta (sem necessidade de decomposição de figuras), ou simplesmente uma fórmula, para calcular o valor da área de outros polígonos.

Nas mais variadas produções artísticas da história da humanidade (e em objetos pertencentes ao cotidiano) e inclusive na natureza, são comuns padrões geométricos envolvendo regiões poligonais. Alguns artistas recorriam a esse tipo de padrão, como o holandês Piet Mondrian (cf. Figura 6) e o português Nadir Afonso, cujas obras representam frequentemente o meio urbano e a disposição de construções. Também existem muitos murais espalhados pelas cidades com mosaicos que, em sua grande maioria, usam peças com contornos de quadriláteros e pentágonos, como os do modernista brasileiro Di Cavalcanti. 
Figura 6: Broadway Boogie-Woogie, Piet Mondrian (1943)

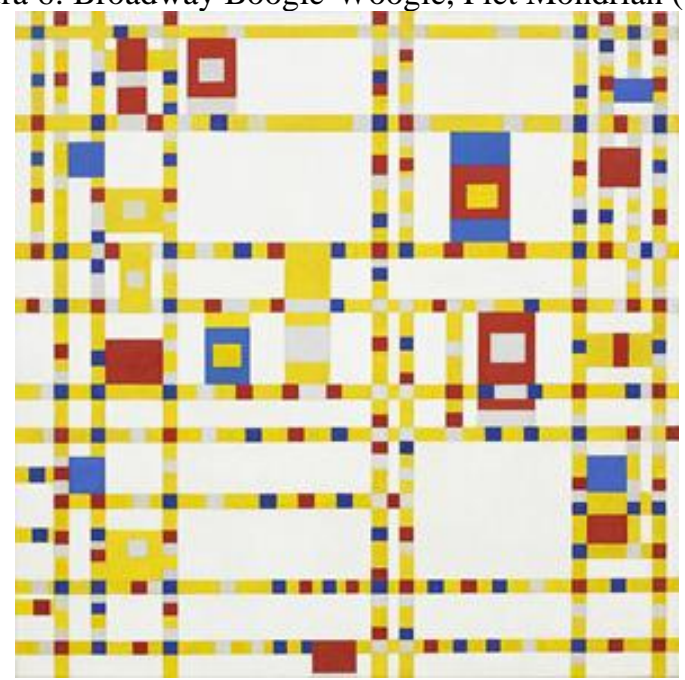

Fonte: http://art-nerd.com/newyork/apartment-of-piet-mondrian/

Os padrões geométricos que se assemelham a regiões poligonais e polígonos também são comuns na natureza, como em colmeias, casco de tartaruga, flocos de neve (ver figura abaixo), escamas de cobras, teias de aranha etc.

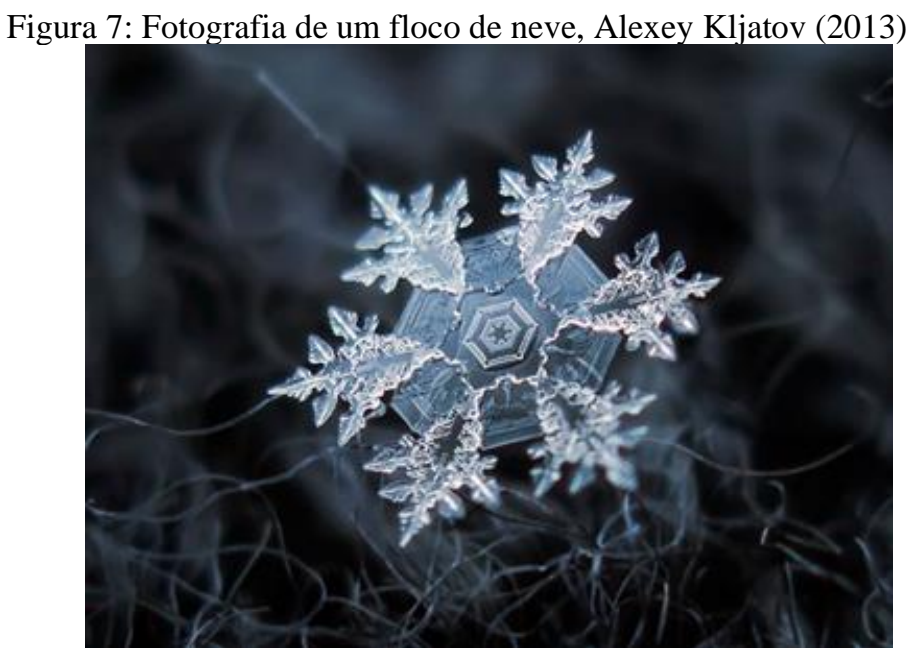

Fonte: http://www.mdig.com.br/index.php?itemid=30190

Em geral, os livros didáticos e o currículo de Matemática da Educação Básica apresentam o conteúdo de polígonos e regiões poligonais posteriormente (ou pouco antes) ao reconhecimento de sólidos geométricos. Tomando como base livros didáticos conferidos, tais como Ribeiro (2009), Bianchinni (2016), Souza e Pataro (2015), Dante (2012), Bonjorno (2010), Barbosa (1970), Bigode (2012) Castrucci Jr. (2012), Giovani (2012), Imenes e Lelis (2010) e Silveira e Marques (2015) , percebemos que isso ocorre, pois no ensino, primeiramente 
é dado aos alunos a oportunidade de reconhecer objetos tangíveis, portanto espaciais, antes que se apresente as figuras planas, seja com secções de objetos, faces de poliedros ou sombras de sólidos. No livro da coleção do projeto Araribá (GAY, 2014), por exemplo, o capítulo que discute sólidos geométricos é apresentado anteriormente ao capítulo de polígonos, enquanto em "Matemática: Ideias e desafios" de Iracema (2012), sólidos geométricos aparecem antes de figuras planas, mas ambos estão no mesmo capítulo (mas há mais dois capítulos referentes às figuras planas e polígonos).

\subsection{Transformações no plano: Reflexão em retas}

Ao prosseguirmos estudando os objetos que cercam a Geometria das pavimentações do plano que podem ser produzidas a partir do uso de caleidoscópios, deparamo-nos com o estudo das propriedades da reflexão em reta, tais como como a preservação de dimensões/distâncias, natureza de figuras etc. Podemos dizer que a reflexão em reta é a isometria "mais importante" ou a isometria primitiva, pois todas as demais isometrias, como a translação e a rotação, são composições de duas ou mais reflexões em retas (para mais detalhes ver Alves \& Galvão, 1996).

Ao se falar de Geometria das transformações, um grande destaque é dado às propriedades das isometrias. A palavra Isometria deriva do grego, isos + metron e significa "mesma medida", ou seja, as isometrias são as transformações geométricas que preservam medidas. A seguir, definiremos dentro de uma Geometria Euclidiana (portanto nos vale o caso LAL de congruência de triângulos), o que é uma transformação geométrica (em especial, a transformação do plano), o que é uma isometria e o que é uma reflexão em reta e mostraremos as propriedades que são interesse deste trabalho. ${ }^{2}$

\section{Definição 1 - Aplicação}

Uma aplicação f de um conjunto A em um conjunto B é uma correspondência na qual cada elemento $a$ de A é associado a um único elemento $b$ de B.

O elemento $b$ é chamado de imagem de $a$ pela aplicação f e podemos escrever:

$$
\mathrm{f}(a)=b
$$

\footnotetext{
${ }^{2}$ Não abordaremos, neste trabalho, os objetos primários como ponto, reta e plano via um olhar axiomático, portanto não os definiremos.
} 


\section{Definição 1.1. - Aplicação Bijetora}

Uma aplicação f de A em B é dita bijetora se ela é injetora e sobrejetora.

Ela é dita injetora se $f(x)=f(y)$, então $x=y$. Podemos dizer que é injetora se cada elemento de B é o correspondente de, no máximo, um único elemento de $\mathrm{A}$.

Ela é dita sobrejetora se para todo elemento $b$ de B, existe um $a$ elemento de A, tal que $\mathrm{f}(a)=b$. Podemos dizer que é sobrejetora se todo elemento de B é o correspondente de algum elemento de A.

\section{Definição 2 - Transformação do Plano}

Uma transformação do plano é uma aplicação bijetora de um plano sobre si mesmo, onde os seus elementos são pontos.

Ao leitor que se interessar, podemos encontrar uma apresentação das definições de uma inversa, de uma composta e de uma identidade de uma transformação do plano em Ribeiro (2016).

\section{Definição 3 - Isometria}

Uma transformação f do plano é dita uma isometria se preserva distâncias entre segmentos de reta. Ou seja, para todo e qualquer par de pontos $\mathrm{P}$ e Q, temos que

$$
\overline{P Q} \equiv \overline{f(P) f(Q)}
$$

Isto é, o segmento de reta de extremos $\mathrm{P}$ e $\mathrm{Q}$ tem o mesmo comprimento que o segmento determinado pelas imagens de $\mathrm{P}$ e de $\mathrm{Q}$ pela transformação f.

A partir dessa definição são concluídas várias propriedades que podem ser assumidas intuitivamente em atividades relacionadas com reflexão em reta. A Figura 8 a seguir mostra 13 propriedades relacionadas com a invariância de características por meio de uma isometria (para demonstrações, ver RIBEIRO, 2016). 
Figura 8 - Propriedades das Isometrias

1. $f$ preserva colinearidade; isto é, se $P, Q$ e $R$ são três pontos colineares, entâo $f(P)$, $f(Q)$ e $f(R)$ são colineares.

2. $f$ preserva estar-entre de pontos; isto é, se $P, Q$ e $R$ são três pontos tais que $P-Q-R$ então $f(P)-f(Q)-f(R)$.

3. $f$ preserva segmentos; isto $\hat{\text {, }}$ se $A$ e $B$ são pontos e $A^{\prime}$ e $B^{\prime}$ sẫo suas imagens por $f$, então $f(\overline{A B})=\overline{A^{\prime} B^{\prime}}$ e $\overline{A B} \cong \overline{A^{\prime} B^{\prime}}$.

4. $f$ preserva ponto médio; isto é, se $P-Q-R$ e $P Q=Q R$, ou seja, $Q$ é o ponto médio do segmento $\overline{P R}$, então $P^{\prime} Q^{\prime}=Q^{\prime} R^{\prime}$, e $Q^{\prime}$ é o ponto médio do segmento $\overline{P^{\prime \prime} R^{\prime}}$.

5. f preserva retas; isto é, se r é uma reta, entâo $f(r)$ é uma reta.

6. f preserva semi-retas; isto é, se $\overrightarrow{O P}$ é uma semi-reta, então $\overrightarrow{O^{\prime} P^{\prime \prime}}$ é uma semi-reta.

7. $f$ preserva estar-entre de semi-retas; isto é, se $\overrightarrow{O P}, \overrightarrow{O Q}$ e $\overrightarrow{O R}$ são três semi-retas tais que $\overrightarrow{O Q}$ está-entre $\overrightarrow{O P}$ e $\overrightarrow{O R}$, então $\overrightarrow{O^{\prime} Q^{\prime}}$ está-entre $\overrightarrow{O^{\prime} P^{\prime \prime}}$ e $\overrightarrow{O^{\prime} R^{\prime \prime}}$.

8. $f$ preserva triângulos; isto é, se $\triangle B A C$ é um triângulo, então $f(\triangle B A C)$ é um triângulo e $f(\triangle B A C) \cong \triangle B A C$.

9. $f$ preserva ângulos; isto é, se $\angle B A C$ é um ângulo, então $f(\angle B A C)$ é um ângulo $e$ $f(\angle B A C) \cong \angle B A C$.

10. f preserva perpendicularismo; isto é. se $\overleftrightarrow{O P}$ é perpendicular a $\overleftrightarrow{O Q}$ em $O$, então $\overleftrightarrow{O^{\prime} P^{\prime \prime}}$ é perpendicular a $\overleftrightarrow{O^{\prime} Q^{\prime}}$ em $O^{\prime}$.

11. f preserva paralelismo; isto é, se $\overleftrightarrow{A B}$ é paralela a $\overleftrightarrow{C D}$, entâo $\overleftrightarrow{A^{\prime} B^{\prime \prime}}$ é paralela a $\overleftrightarrow{C^{\prime} D^{\prime}}$.

12. $f$ preserva cúnculos; isto é, se $\mathscr{C}$ é um círculo com centro $O$ e raio $r$, então $f(\mathscr{C})$ é um círculo de centro $f(O)$ e raio $r$.

13. $f$ preserva áreas; isto é, se $R$ é uma região poligonal, então $f(R)$ é uma região poligonal, e chamando de $\alpha(R)$ a área da regiäo $R$, então $\alpha(f(R))=\alpha(R)$.

Fonte: Ribeiro, 2016

\section{Definição 4 - Reflexão em reta}

Seja $r$ uma reta do plano П. Chamamos de reflexão em relação a reta $r$ a transformação do plano isometria que leva cada ponto $\mathrm{P}$ em seu correspondente $\mathrm{P}$ ', de tal forma que:

- $\quad r$ é mediatriz do segmento $\overline{P P^{\prime}}$, caso $P \notin r$

- $P=P^{\prime}$, caso $P \in r$ (nesse caso, $\mathrm{P}$ é dito invariante) 


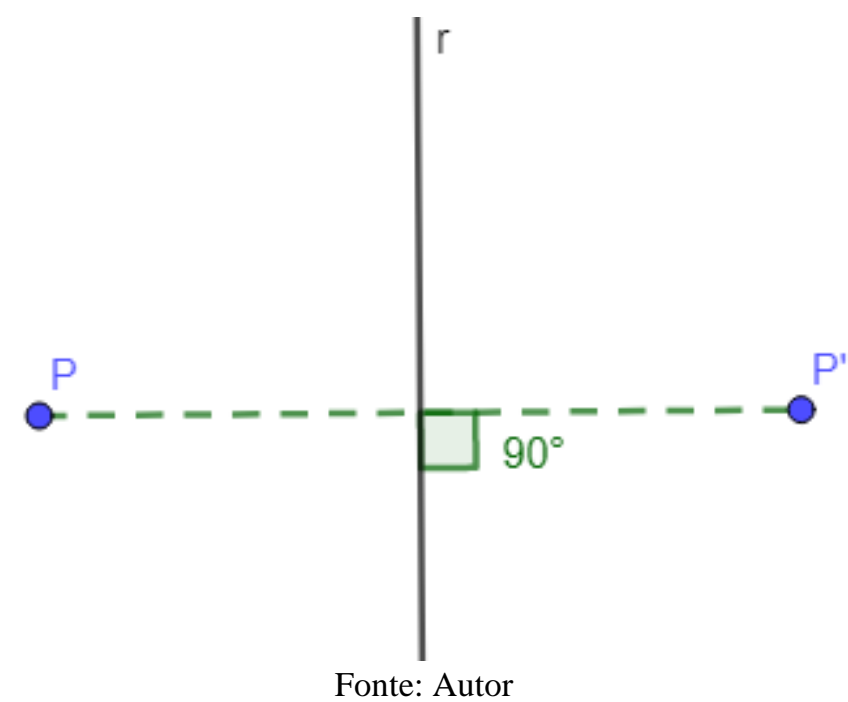

Teorema: A reflexão em reta é uma isometria, ou seja, ela preserva distância entre segmentos de reta.

Demonstração: Analisaremos os três possíveis casos.

1) O segmento $\overline{P Q}$ pertence a reta $r$ : nesse caso, a imagem $P^{\prime}$ do ponto $P$ é igual a $P$ e a imagem Q' do ponto Q é igual a Q e, como todos os pontos do segmento PQ pertencem a reta r, então todos esses pontos também são invariantes, ou seja, temos que $\overline{P^{\prime} Q^{\prime}}=\overline{P Q}, \log \overline{P^{\prime} Q^{\prime}}$ tem a mesma medida que $\overline{P Q}$.

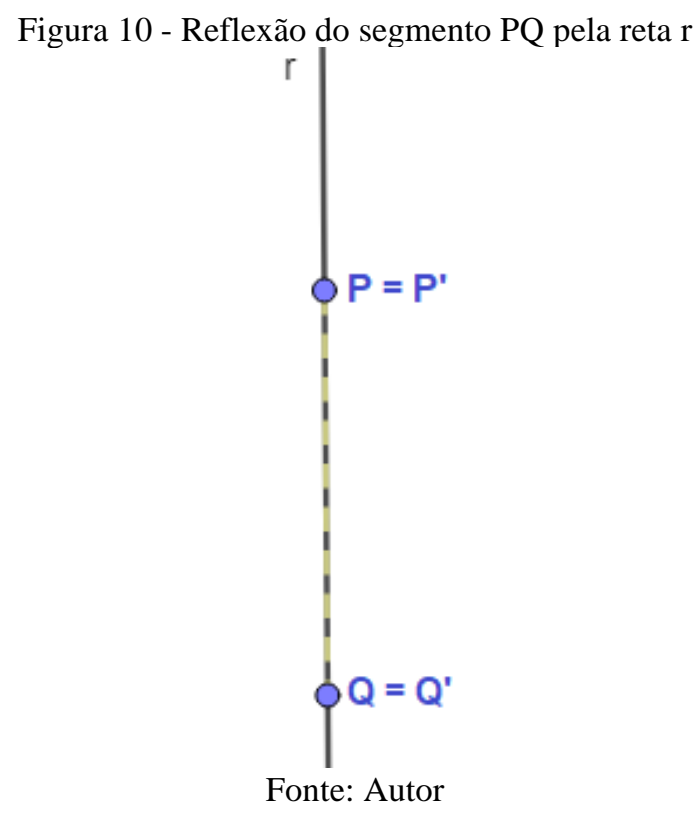


2) $O$ ponto $P$ pertence a reta $\mathbf{r}$ mas o ponto $Q$ não pertence: nesse caso a imagem $P^{\prime}$ de $P$ é igual a $\mathrm{P}$, mas a imagem Q' de Q é diferente de Q. Seja $\mathrm{S}$, tal que $S=\overline{P P^{\prime}} \cap r$. Agora observe os triângulos $\triangle P Q S$ e $\triangle P^{\prime} Q S$ e note que eles são congruentes pelo caso LAL:

- (L) Sabendo que a mediatriz de um segmento passa pelo seu ponto médio, temos que $\overline{P S} \equiv \overline{S P^{\prime}}$

- (A) Sabendo que a mediatriz forma um ângulo reto com o segmento $\overline{P P^{\prime}}$, temos que $Q \hat{S} P \equiv Q \hat{S} P^{\prime}$ e ambos medem $90^{\circ}$;

- (L) O segmento $\overline{Q S}$ é comum aos dois triângulos.

Dessa congruência podemos tirar que os lados correspondentes $\overline{P Q}$ e $\overline{Q P^{\prime}}$ são congruentes.

Observação: note que, enquanto lugar geométrico, qualquer ponto da mediatriz equidista dos extremos do segmento.

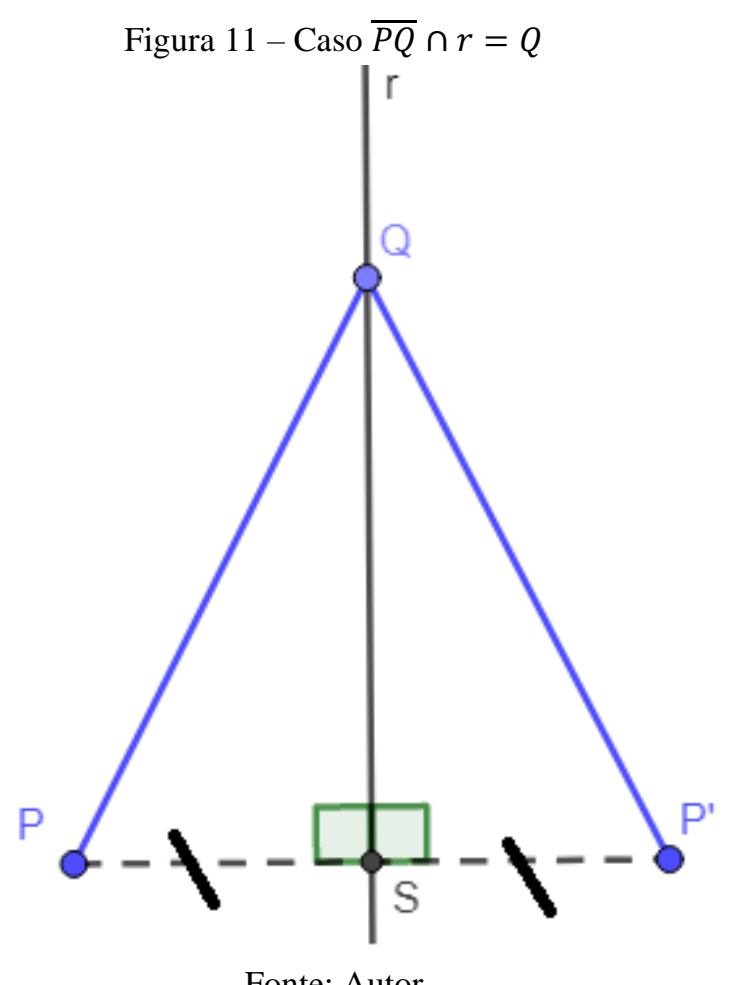

Fonte: Autor 
3) Os pontos $\mathrm{P}$ e $\mathrm{Q}$ não pertencem a reta $\mathrm{r}$ :

\subsection{A intersecção da reta $\mathrm{r}$ com o segmento $\overline{P Q}$ é não vazia e igual a um ponto $S$.}

A demonstração desse caso decorre do caso 2:

- O ponto $S$ é invariante pela reflexão pela reta $\mathrm{r}, \log 0 \overline{P^{\prime} Q^{\prime}} \cap r=S$;

- $\overline{P Q}=\overline{P S} \cup \overline{S Q}$ e $\overline{P^{\prime} Q}=\overline{P^{\prime} S} \cup \overline{S^{\prime} Q}$;

- Como $\mathrm{S}$ pertence aos dois segmentos, podemos dizer que $\overline{P Q} \equiv \overline{P^{\prime} Q^{\prime}}$ pois $\overline{P S} \equiv \overline{P^{\prime} S}$ e $\overline{S Q} \equiv \overline{S Q^{\prime}}$, já que essas duas últimas congruências decorrem do caso 2 .

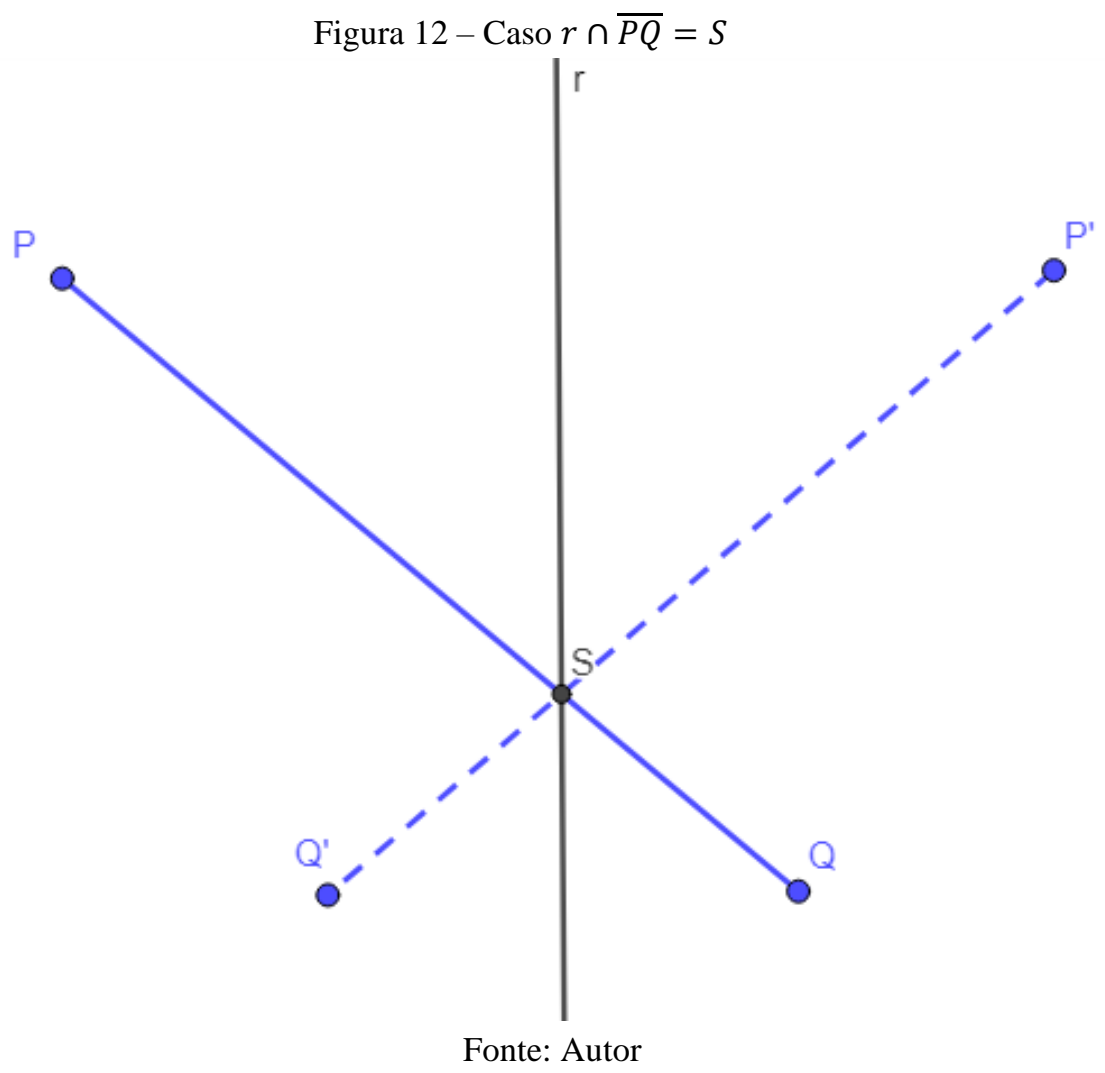

\subsection{A intersecção da reta r com o segmento $\overline{P Q}$ é vazia.}

Uma possível demonstração desse caso pode ser feita com partições em triângulos:

Seja S o ponto médio de $\overline{P P^{\prime}}$ e T ponto médio de $\overline{Q Q^{\prime}}$. Como r é mediatriz desses dois segmentos de reta, então $S \in r$ e $T \in r$. Mostraremos agora, que $\triangle Q P S \equiv \Delta Q^{\prime} P^{\prime} S$, por LAL: 
- (L) Pelo caso 2, sabemos que os triângulos $\Delta Q S T$ e $\Delta Q^{\prime} S T$ são congruentes e, portanto, os lados correspondentes $\overline{Q S}$ e $\overline{Q^{\prime} S}$ são congruentes.

- (A) Além disso, os ângulos correspondentes $<Q S T$ e $<Q^{\prime} S T$ são congruentes. Seja $x$ a medida desses ângulos. Como a mediatriz determina um ângulo reto em relação ao segmento $\overline{P P^{\prime}}$, então os dois ângulos $<Q S P$ e $<Q^{\prime} S P^{\prime}$ são congruentes e medem $90^{\circ}-$ $x$.

- (L) E, por fim, como a reta r é mediatriz de $\overline{P P^{\prime}}$, temos que $\overline{P S} \equiv \overline{S P^{\prime}}$.

Ou seja, $\triangle Q P S \equiv \triangle Q^{\prime} P^{\prime} S$ e, portanto, os lados correspondentes $\overline{Q P}$ e $\overline{Q^{\prime} P^{\prime}}$ são congruentes, como queríamos demonstrar. Uma possível representação dessa demonstração está mostrada na figura a seguir.

\section{Figura 13 - Caso em que $\overline{P Q} \cap r=\emptyset$}

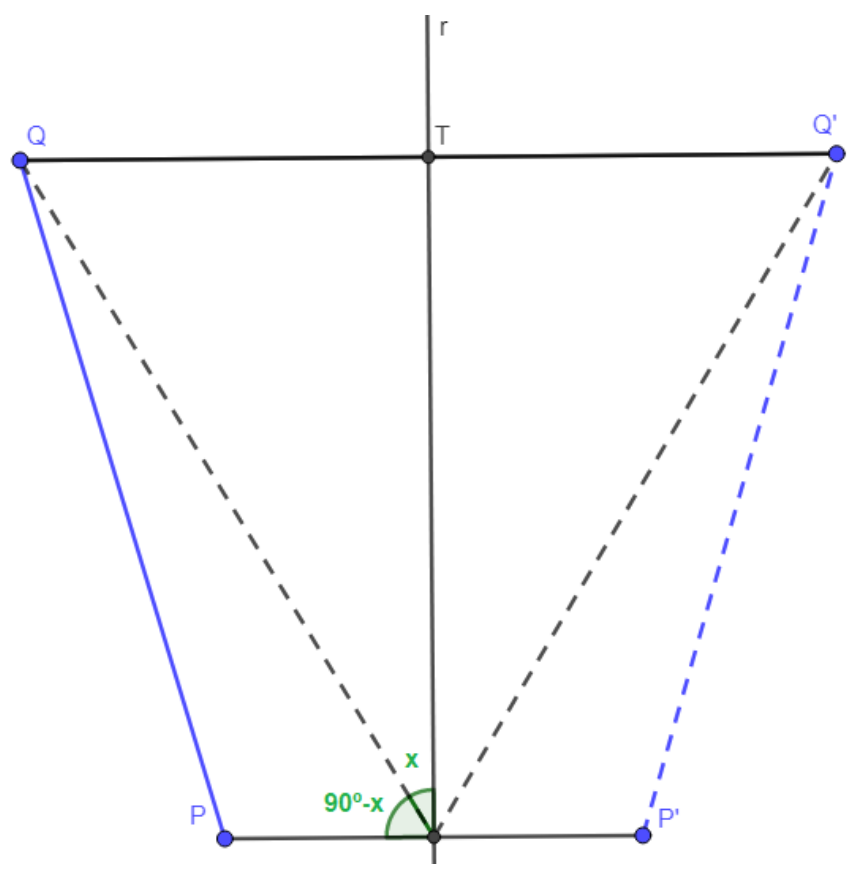

Fonte: Autor 


\subsection{Mosaicos no Plano: Pavimentação e Ladrilhamento}

Podemos chamar de Mosaico o recobrimento ou preenchimento do plano, em geral, sem lacunas e sem sobreposições, formados por peças ou figuras de formatos diferentes ou de formatos iguais. A arte de se criar Mosaicos é antiga na humanidade, sendo que egípcios, persas, árabes, mouros, hindus e chineses já usavam esta técnica para decoração em pisos, tetos, painéis de templos, igrejas, palácios etc.

Em geral, os textos relacionados com este estudo usam "Pavimentação" com o mesmo sentido de "Ladrilhamento". Barbosa (2005) define Pavimentação como todo conjunto de polígonos que cobre o plano sem cruzamentos (compreendemos aqui polígono pela definição linha). Cobrir se refere ao mesmo sentido de preencher descrito anteriormente e não haver cruzamentos significa que a intersecção da região interna de qualquer par de polígonos é nula.

Apresentaremos então, as definições de pavimentação e de ladrilhamento utilizadas por nós em todo o decorrer do curso oferecido: consideramos ladrilhamento a disposição de polígonos sobre o plano de forma a não deixar lacunas e nem haver sobreposições.

Compreendemos como pavimentação do plano, um ladrilhamento em que:

1. Ao redor de cada vértice há um agrupamento de polígonos dispostos lado a lado, de forma a não sobrar lacunas e nem haver sobreposições, (como desenvolvemos um trabalho com polígonos regulares, utilizamos o fato de que todos os lados são congruentes).

Para efeito das atividades desenvolvidas no curso, caracteriza-se ainda com o seguinte padrão:

2. A composição de polígonos ao redor de todos os vértices no plano são todas iguais ou alternadamente iguais.

Em resumo, a principal característica de pavimentar é cobrir o plano com polígonos lado a lado como a imagem de azulejos de banheiro, por exemplo; enquanto ladrilhar é cobrir o plano com polígonos não necessariamente lado a lado, ou seja, poderíamos considerar a imagem de uma parede de tijolos, na qual os tijolos, apesar de terem lados congruentes, não ficam lado a lado. 
Discutiremos na próxima seção, tipos de pavimentações do plano com polígonos regulares seguindo a ordem e formato de apresentação do material de Barbosa (2005) e, em seguida, discutiremos como podemos explorar algumas dessas pavimentações por meio do uso de espelhos e caleidoscópios.

\subsubsection{Pavimentações do plano com polígonos regulares}

\section{Um único tipo}

Uma pavimentação do plano com polígonos regulares de um único tipo pode ser obtida quando é possível agrupar polígonos regulares congruentes ao redor de um vértice de forma a estarem justapostos. Uma maneira de descobrir quais são os polígonos que satisfazem essas condições é considerando seus ângulos internos: se o produto da medida i do ângulo por uma determinada quantidade $\mathrm{k}$ de polígonos for igual a $360^{3}$ podemos garantir que os polígonos poderão ser agrupados ao redor de um ponto.

Existem algumas condições inerentes sobre a quantidade $\mathrm{k}$ de polígonos. Primeiramente, o menor valor possível para k é 3, pois não faz sentido ajustar 2 ou 1 polígono regular ao redor de um ponto. E pelas condições para o produto k.i, isto é $k . i=360$, segue que

$3 \leq \frac{360}{i}$ o que implica $i \leq 120$. Com está condição sobre o ângulo sabemos que o hexágono regular será o polígono com maior número de lados que iremos tentar pavimentar o plano.

Para as tentativas de pavimentar o plano, bastará considerarmos a medida do ângulo interno de cada um dos seguintes polígonos: triângulo equilátero, quadrado, pentágono regular e hexágono regular. Como $k . i=360$, então dado o valor de i saberemos a quantidade de polígonos que devem ser colocados ao redor de um ponto. Apenas os polígonos cujos ângulos internos sejam divisores de 360 poderão se justapor ao redor de um ponto e, por isso, desconsideraremos pavimentar o plano com o pentágono (em vista de 108 não ser um divisor de 360).

a) Triângulos equiláteros:

É possível pavimentar o plano com triângulos equiláteros pois seu ângulo interno de medida $60^{\circ}$ é um divisor de 360 e 6 desses polígonos podem ser justapostos ao redor de cada vértice.

\footnotetext{
${ }^{3} \mathrm{Na}$ seção 3.3 iremos nos referir a ângulos sem utilizar o símbolo o de graus.
} 
b) Quadrados:

O ângulo interno do quadrado (de medida 90) é um divisor de 360 e 4 desses quadrados podem ser justapostos ao redor de cada vértice. Assim, é possível pavimentar o plano com quadrados.

c) Hexágonos regulares:

Com seu ângulo interno tem medida $120^{\circ}$, o hexágono regular também pavimenta o plano com o total de 3 hexágonos ao redor de cada vértice em vista de que $3 \times 120=360$.

Outra forma de verificarmos quais são os polígonos regulares que podemos usar para pavimentar o plano leva em consideração o número $n$ de lados de cada polígono. Primeiramente lembramos que a medida i do ângulo interno de cada polígono é dada por $i=(n-2) \cdot \frac{180}{n}$. Esse resultado pode ser obtida de duas formas.

A partir de qualquer um dos vértices traçamos as diagonais que passam por ele. A quantidade de diagonais é $n-3$ (pois apenas não serão formadas diagonais com os vértices adjacentes e com o próprio vértice considerado), e então teremos formado $n-2$ triângulos no interior do polígono, cada um deles somando $180^{\circ}$ das medidas dos seus ângulos internos. Com isso, temos a soma total dos ângulos do interior do polígono e basta então dividir pela quantidade de ângulos que é n. Portanto, $i=(n-2) \cdot \frac{180}{n}$.

Ou então podemos traçar segmentos unindo o ponto central do polígono aos vértices (cf. figura abaixo). Com isso, teremos formado $n$ triângulos isósceles congruentes, com ângulos internos de medidas $x, y$ e $y$. Temos $x=\frac{360}{n}, y+y+x=180$ e $2 y=i$ (pois a soma da medida dos dois ângulos congruentes de cada triângulo corresponde à medida do ângulo interno do polígono). Então obtemos da equação $2 y+x=180$ que $i+\frac{360}{n}=180$ e $i=180-\frac{360}{n}$ (que é a mesma equação $i=(n-2) \cdot \frac{180}{n}$, mencionada anteriormente) . 
Figura - ângulo interno de polígono regular

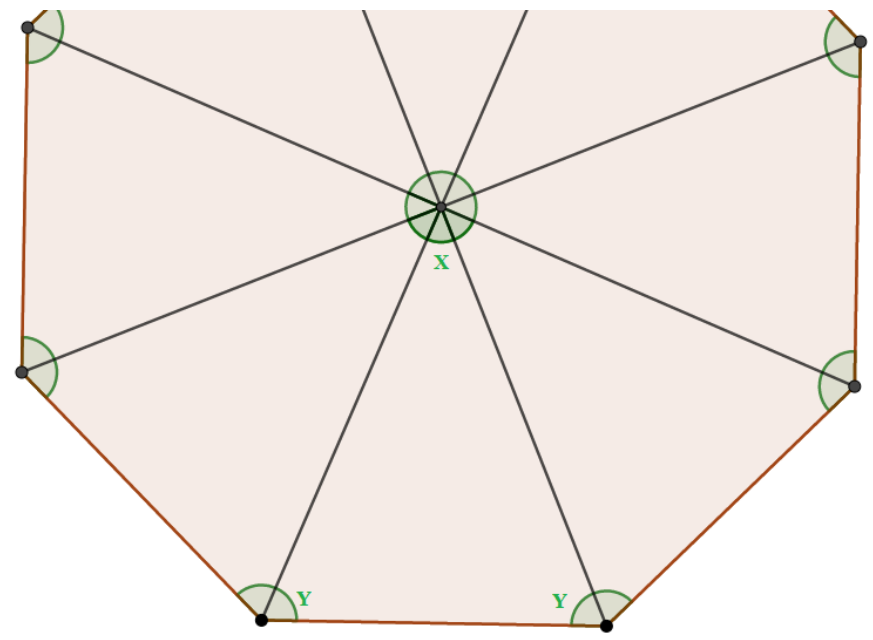

Fonte: autor

Mais do que isso, podemos explicitar o número $k$ de polígonos em função do número de lados usando $k . i=360$, ou seja, $k=\frac{360}{i}$, obtendo $k=\frac{360 \cdot n}{(n-2) \cdot 180}=\frac{2 n}{n-2}$. Entretanto, sabemos que $k \geq 3$; $\log$ o, $\frac{2 n}{n-2} \geq 3$ e $n \leq 6$. Como também é sabido que é necessário $n \geq 3$ (o triângulo é o polígono com menor número de lados) temos o intervalo $3 \leq n \leq 6$ que nos sugere que os polígonos usados deverão ter 3, 4, 5 ou 6 lados.

Então a partir de $n$, ou seja, do mínimo de lados do polígono, calcularemos a quantidade $k$ de polígonos que deverão ser colocadas ao redor de um ponto usando a equação $k=\frac{2 n}{n-2}$. Para $n=6$ teremos $k=3$, isto é, três hexágonos regulares colocados ao redor de cada vértice formam uma pavimentação do plano. Para $n=5$ teremos $k=\frac{10}{3}$ e como $k$ não é um número inteiro, podemos concluir que o pentágono regular não pavimenta o plano. Para $n=4$, teremos $k=4$ de modo que quatro quadrados colocados ao redor de cada vértice formam uma pavimentação do plano. Para $n=3$ temos $k=6$, então seis triângulos equiláteros colocados ao redor de cada vértice formam uma pavimentação do plano.

\subsubsection{Diferentes tipos de Pavimentações}

Para posicionar três ou mais polígonos regulares de tipos diferentes ao redor de um ponto inicialmente devemos notar que a medida de seus ângulos internos devem somar exatamente 360. Entretanto, devemos fazer outras considerações a fim de formalizar metodologias que determinem quais os tipos de polígonos podemos usar. 
Para tais considerações, vários casos devem ser considerados, algumas equações são estudadas e obtém-se como resultado as oito pavimentações do plano com polígonos de diferentes tipos. Tal estudo estenderia por demais esse capítulo e, por isso, decidimos por não o fazer, mas para o leitor que se interessar, ver capítulos 4, 5 e 6 de Barbosa (2005).

\subsubsection{As configurações que pavimentam o plano}

Primeiramente, verifica-se que é impossível pavimentar o plano usando um triângulo equilátero e outros dois polígonos regulares (não congruentes). Isso ocorre, pois ao tentarmos dispor em um dos lados desse triângulo um polígono regular de n lados e em outro lado desse triângulo um polígono regular de m lados não podemos definir qual será o polígono regular que será disposto (se é o de m lados ou de $\mathrm{n}$ lados) no terceiro lado do triângulo a fim de que em cada vértice da pavimentação tenhamos sempre a mesma distribuição de polígonos regulares.

A partir disso, concluímos facilmente que as configurações $(3,7,42),(3,8,24),(3,9,18)$ e $(3,10,15)$ não pavimentam o plano, apesar de poderem ser dispostas ao redor de um vértice.

O argumento para pentágonos é análogo ao de triângulos equiláteros. Ao tentarmos dispor ao redor do pentágono regular outros dois polígonos regulares de $m$ e $n$ lados, $m \neq n$, não conseguiremos concluir qual é o polígono a ser disposto no último lado para preservar a distribuição, pois não há como o fazer. E com isso, também não podemos utilizar as configurações $(4,5,20)$ e $(5,5,10)$ para pavimentar o plano.

Feita a exclusão das configurações que não pavimentam o plano, ficamos com apenas 8 possibilidades: $(3,12,12),(4,6,12),(4,8,8), \quad(3,3,4,12),(3,3,6,6), \quad(3,4,4,6), \quad(3,3,3,3,6)$, $(3,3,3,4,4)$. Na Figura 14, seguem exemplos de tais configurações. 
Figura 14: Configurações que pavimentam o plano

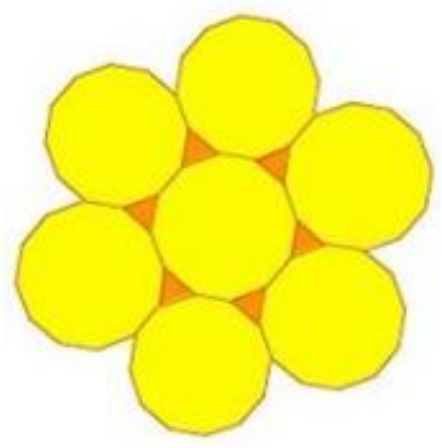

$(3,12,12)$

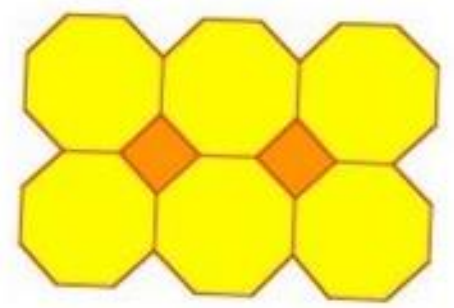

$(4,8,8)$

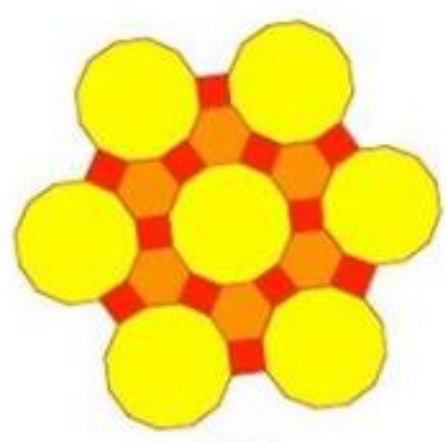

$(4,6,12)$

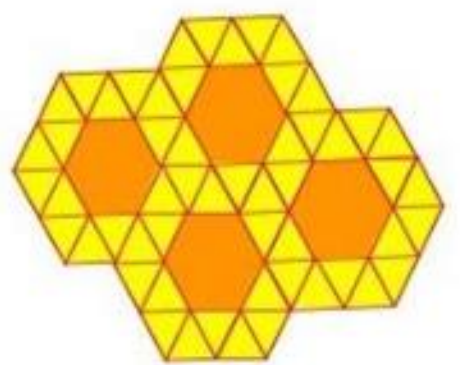

$(3,3,3,3,6)$

Fonte: Sallum, 2015

Neste trabalho, para representar as possíveis configurações de polígonos regulares que pavimentam ou não o plano, é usada a notação com os números de lados de cada polígono disposto ao redor de um vértice em parênteses. Por exemplo. $(4,8,8)$ é a configuração com um quadrado e dois octógonos, dispostos nessa ordem.

Há ainda configurações que não se estendem por todo o plano igualmente em cada vértice e se dispõe de forma alternada, como é o caso da configuração formada por dodecágonos regulares, triângulos equiláteros e quadrados que se dá por $(3,4,3,12)$ e $(3,12,12)$, como na figura abaixo.

Figura 15 - Configurações $(3,4,3,12)$ e $(3,12,12)$

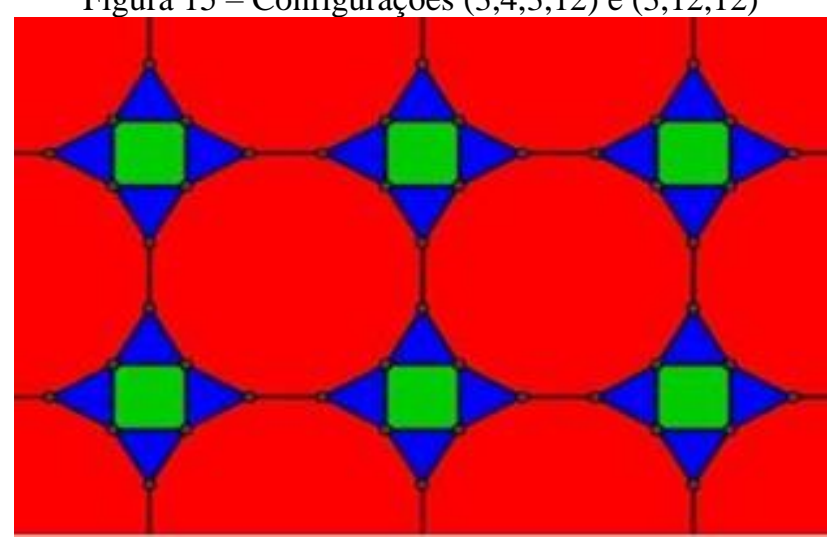

Fonte: Autor 
Figura 16a - Configuração $(3,4,4,6)$ e $(3,4,6,4)$

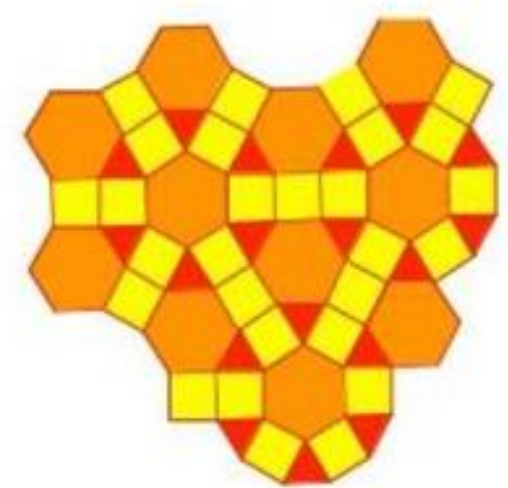

Fonte: Sallum, 2015

Figura 16b - Configuração $(3,4,6,4)$

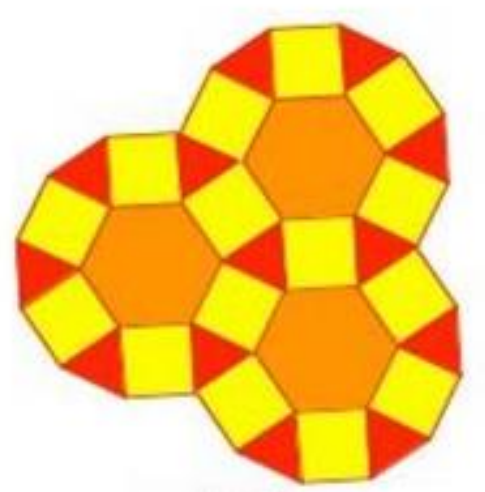

Fonte: Sallum, 2015

O mesmo pode ser observado na configuração $(3,4,4,6)$, que se estende como $(3,4,4,6)$ em alguns vértices e como $(3,4,6,4)$ em outros. Entretanto, também é possível dispor uniformemente a configuração $(3,4,6,4)$, conforme ilustrado nas Figuras 16a e 16b.

Figura 17 - Configurações com hexágonos e triângulos

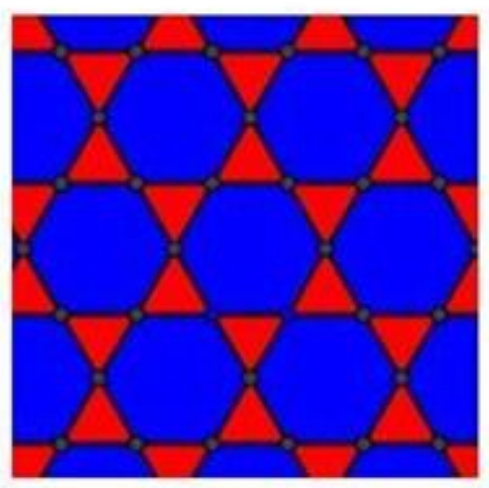

$(3,6,3,6)$

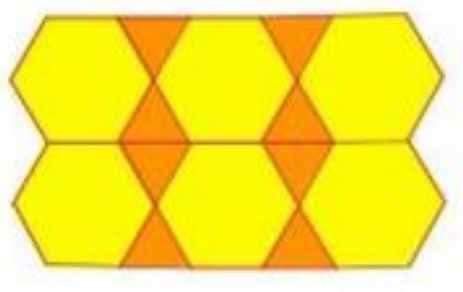

$(3,6,3,6)$ e $(3,6,6,3)$

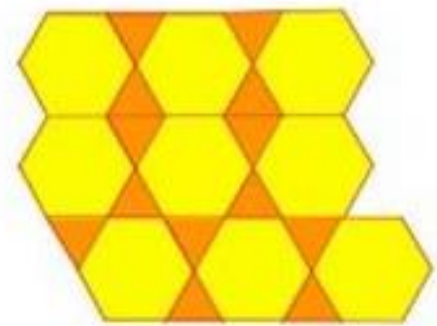

$(3,6,3,6)$ e $(3,6,6,3)$

Fonte: Sallum, 2015 
A configuração $(3,6,3,6)$ pode ser estendida uniformemente pelo plano com $(3,6,3,6)$ em alguns vértices e $(3,3,6,6)$ em outros (cf. figura 17). Já a configuração $(3,4,3,3,4)$ pode se estender uniformemente pelo plano, tanto como a configuração $(3,3,3,4,4)$ e ambas no mesmo mosaico, conosco de $(3,4,3,3,4)$ e $(3,3,3,4,4)$, conforme figura abaixo.

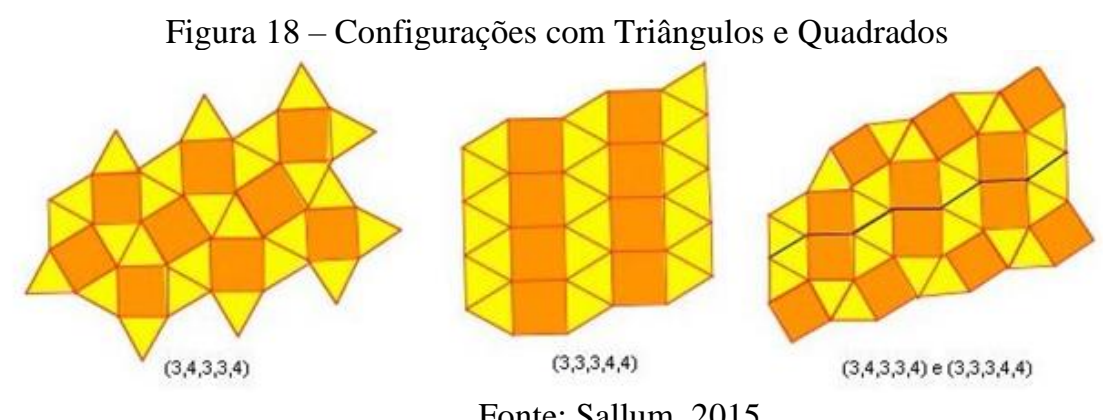

Fonte: Sallum, 2015

Em resumo, podemos destacar que é possível, não apenas colocar ao redor de um vértice, mas estender a pavimentação por todo o plano com oito configurações diferentes: $(3,12,12),(4,6,12),(4,8,8),(3,3,3,3,6),(3,4,6,4),(3,6,3,6),(3,4,3,3,4),(3,3,3,4,4)$.

\subsection{O Caleidoscópio: $O$ que é, como fazer, tipos diferentes}

Buscaremos responder às seguintes questões: qual o potencial do caleidoscópio, sobretudo sob a ótica do professor de Matemática? Quais tipos existem e como podemos fazer cada um, adaptando-os aos materiais de sala de aula?

\subsubsection{Tipos de caleidoscópios}

Os caleidoscópios mais comuns são formados por três espelhos planos com o lado espelhado para dentro, posicionados perpendicularmente a uma base de forma a constituírem as faces laterais de um prisma triangular. A base inferior é feita com um papel que possa transmitir a luz e a superior fechada (vedada à entrada de luz), com um orifício para observação. São construídos de forma que $2 \mathrm{z}$ divida 360 , ou seja, cada par de espelhos forma um ângulo z cujo dobro seja um divisor de 360 . 
Se chamarmos de a, b e c esses ângulos internos, então bastará que a|180, b|180 e c|180. Sendo $n_{1}=\frac{180}{a}, n_{2}=\frac{180}{b}$ e $n_{3}=\frac{180}{c}$ e sabendo quea $+b+c=180$, temos que $\frac{a}{180}+\frac{b}{180}+\frac{c}{180}=1$ e dessa forma $\frac{1}{n 1}+\frac{1}{n 2}+\frac{1}{n 3}=1(*)$. Supondo, sem perda de generalidade, que $n_{1} \leq n_{2} \leq n_{3}$ temos que, para que exista triângulo, $\mathrm{n}_{1}$ é no mínimo 2 (pois o maior ângulo de um triângulo cuja medida divide 180 é o ângulo de medida 90) e, da equação (*), conclui-se que $\mathrm{n}_{1}$ é no máximo 3 (dessa forma $\mathrm{n}_{1}$ é 2 ou 3 ).

Primeiramente, a única solução para a equação (*) com $n_{1}=3$ é aquela em que $\mathrm{n}_{1}, \mathrm{n}_{2} \mathrm{e}$ $\mathrm{n}_{3}$ são todos iguais. Assim $n_{1}=n_{2}=n_{3}=3 e$, dessa forma, obtém-se a configuração do caleidoscópio equilátero, ou seja, aquele que possui o triângulo da base com medidas dos ângulos internos iguais a 60 .

Em seguida, se $n_{1}=2$ então $n_{2}=n_{3}=4$, ou seja, é a configuração do caleidoscópio isósceles (e retângulo), com o triângulo da base com medidas dos ângulos internos iguais a 90, 45 e 45. Ou então, $n_{1}=2, n_{2}=3$ e $n_{3}=6$, que é a configuração do caleidoscópio escaleno (e retângulo), no qual as medidas dos ângulos internos do triângulo são 90, 60 e 30. Em resumo, temos três possibilidades de caleidoscópios triangulares com imagens coincidentes para os dois sentidos de reflexões de um ponto em cada par de espelhos: equilátero, escaleno e isósceles (cf. Figura 19).
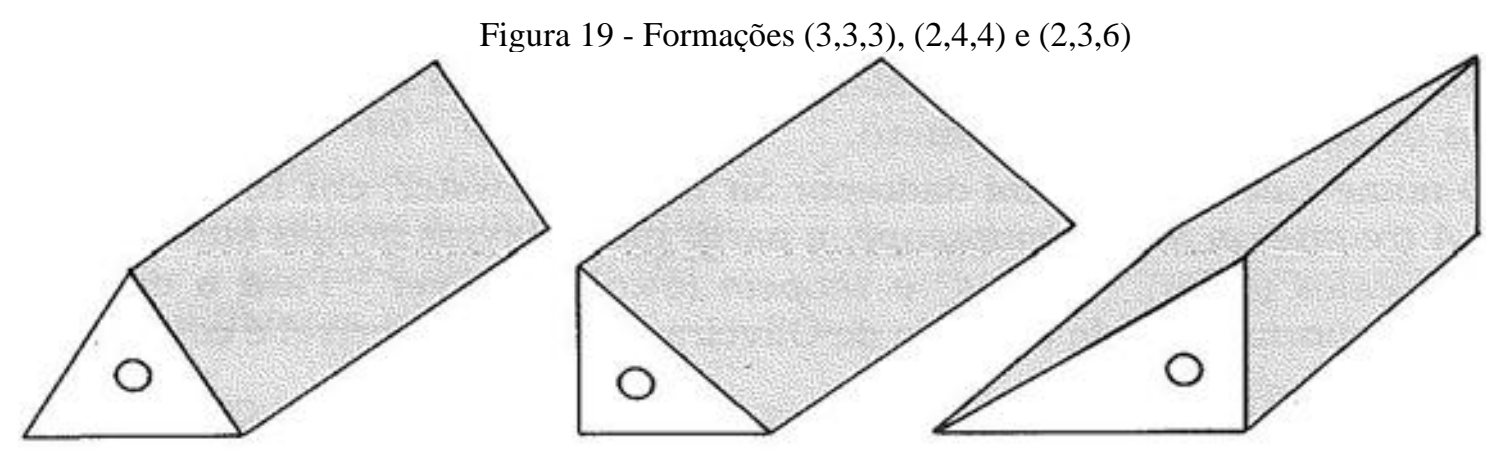

Fonte: Barbosa, 2005

\subsection{Reflexões em caleidoscópios}

\subsubsection{Refletindo pontos}

Inicialmente, vejamos as possibilidades para as imagens de um ponto $\mathrm{P}$ entre um par de espelhos, utilizando a construção citada anteriormente, obtemos, a partir da medida angular 60, a quantidade de cinco imagens que constituem, com $\mathrm{P}$, uma configuração denominada 
hexavértice. Tal hexavértice será regular (Figura 20) se o ponto pertencer a bissetriz do ângulo interno entre os espelhos ou alternadamente regular (Figura 21), caso o ponto não pertença a esta bissetriz.

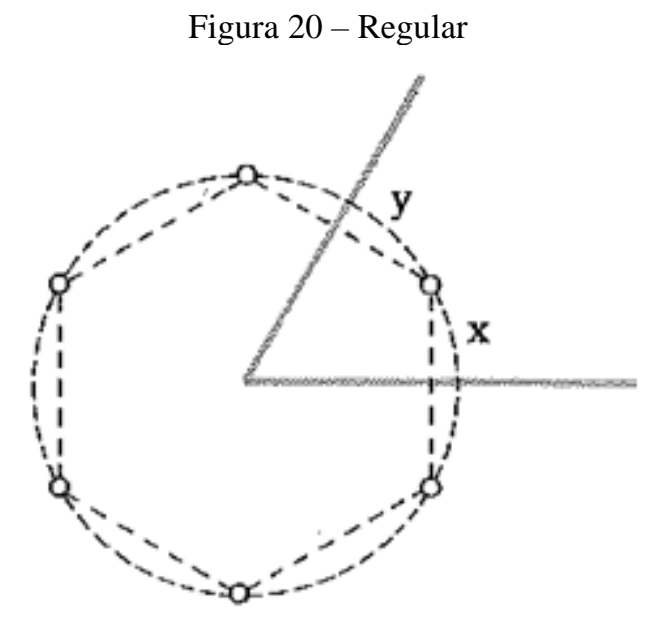

Fonte: Barbosa, $200 \overline{5}$

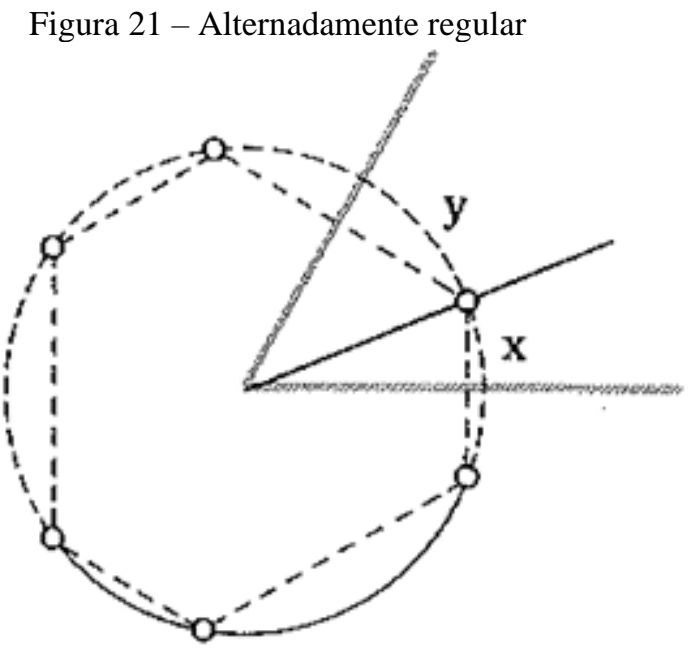

Fonte: Barbosa, 2005

Uma abordagem para esse tipo de experimentação pode ser vista na nossa atividade 2 , de reflexões em retas com espelhos concorrentes.

Caso o ponto $\mathrm{P}$ esteja muito próximo de um dos espelhos (o valor da medida do ângulo determinado por $\mathrm{P}$ e um dos espelhos é muito próximo de zero), três dos vértices do hexavértice tendem a desaparecer, e obtém-se uma configuração chamada trivértice regular (cf. figura 22). 
Figura 22 - Trivértice regular

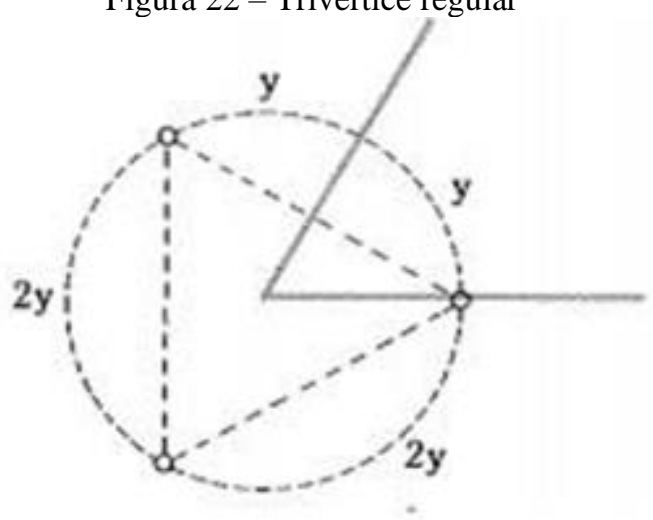

Fonte: Autor

Para três espelhos (usando o mesmo tipo de modelo), alguns casos devem ser destacados: se o ponto $\mathrm{P}$ não pertence a nenhuma bissetriz, então serão formados três hexavértices alternadamente regulares e distintos entre si, e com um lado em comum dois a dois (cf. Figura 23). Caso P pertença a todas as bissetrizes ou algumas delas, serão formadas, respectivamente, somente hexavértices regulares ou regulares e alternadamente regulares.

Figura 23 - Hexavértices por pontos em bissetrizes
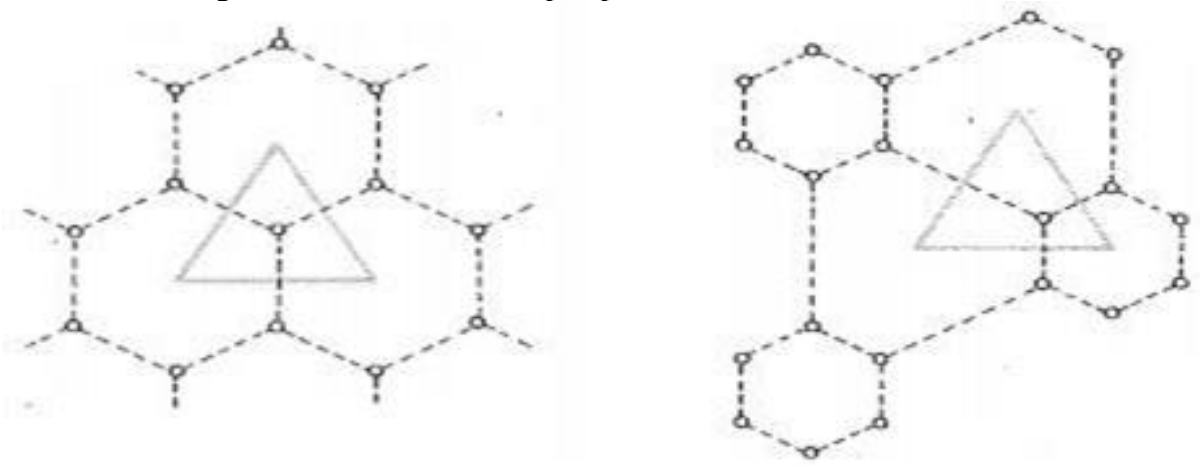

Fonte: Barbosa, 2005

Se o ponto P não está no interior do triângulo determinado pela base do caleidoscópio e sim em um dos seus lados, então serão formadas, para cada par de segmentos concorrentes que contenham este ponto, trivértices regulares (distintos, se P não é o ponto médio do lado a que pertence e congruentes, caso $\mathrm{P}$ seja ponto médio) e para o par de segmentos concorrentes que não contenham o ponto $\mathrm{P}$ será formado naturalmente um hexavértice.

Caso passemos a considerar os pontos médios de dois lados do triângulo, então serão formados dois trivértices regulares para o par de segmentos que contém esses dois pontos e com isso teremos formado um conjunto de dois trivértices, portanto, um hexavértice regular. Para os outros dois pares de segmentos, a imagem da reflexão dos dois pontos médios formarão normalmente dois trivértices regulares. Note que a reflexão dos dois pontos no espelho que não 
contém estes pontos formará uma configuração de pontos chamada quadrivértice retangular (cf. Figura 24).

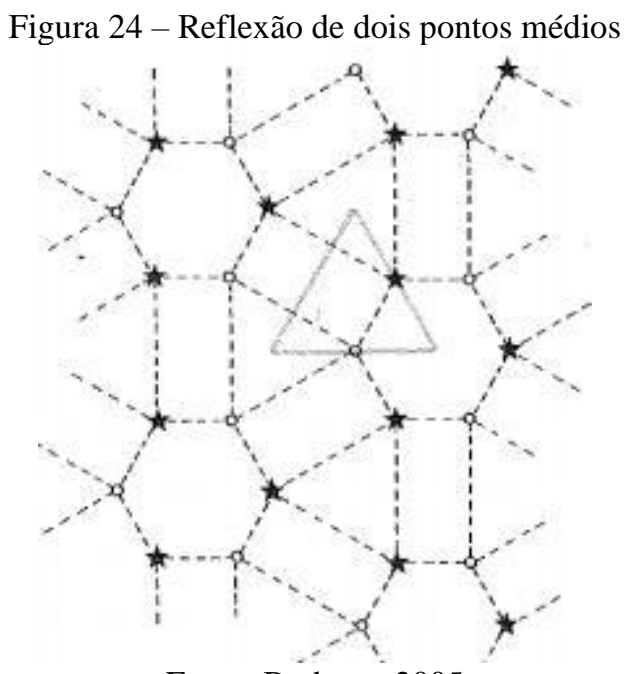

Fonte: Barbosa, 2005

\subsubsection{Refletindo segmentos}

Utilizando uma bissetriz do triângulo, obtemos um segmento pela reflexão em cada um dos três espelhos. Sucessivamente, esses segmentos formarão novos segmentos a partir da reflexão nos espelhos. Com uma figura podemos observar que esses segmentos formarão uma pavimentação de triângulos semelhantes à base.

Podemos utilizar segmentos que ligam cada vértice até o incentro para formar uma figura cujas reflexões serão losangos. Caso usemos dois desses segmentos, ficam destacados os losangos apenas, e se usarmos três segmentos poderemos perceber mais losangos formando uma figura de estrela (neste caso em especial, se pintarmos cada uma das três regiões formadas com esses segmentos com uma cor poderemos observar uma formação de imagens que se assemelham a cubos em perspectiva, cf. Figura 25). 
Figura 25 - Reflexões sucessivas de segmentos

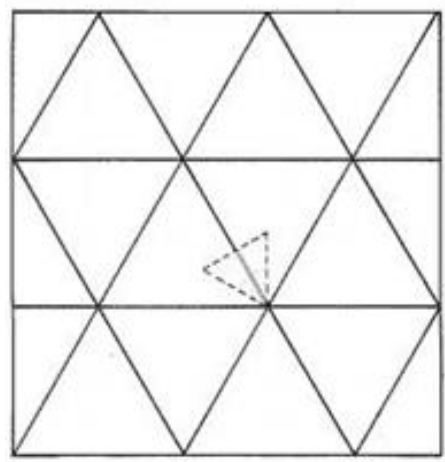

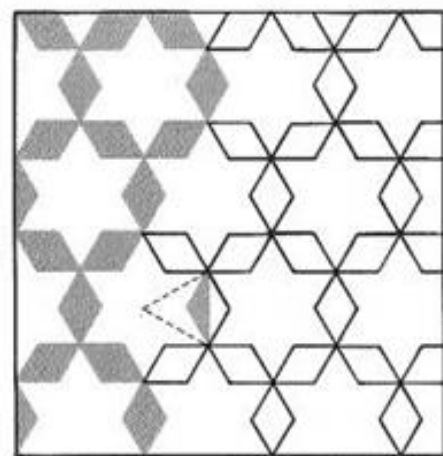

Fonte: Barbosa, 2005

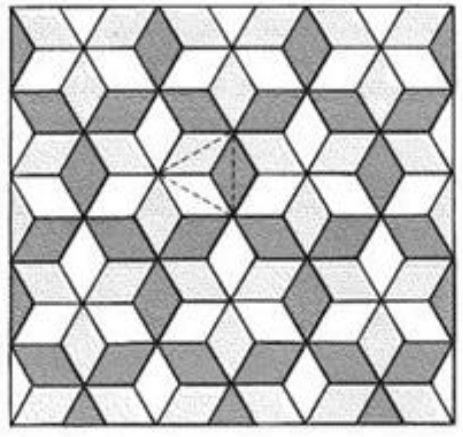

Traçando um segmento sobre um dos lados do triângulo, obtemos hexágonos regulares. Traçando segmentos sobre dois dos lados, obteremos losangos. Se traçarmos segmentos sobre os três lados, obtemos novamente a configuração de pavimentação formada por triângulos equiláteros e congruentes à base (cf. Figura 26).

Figura 26 - Reflexões sucessivas de lados
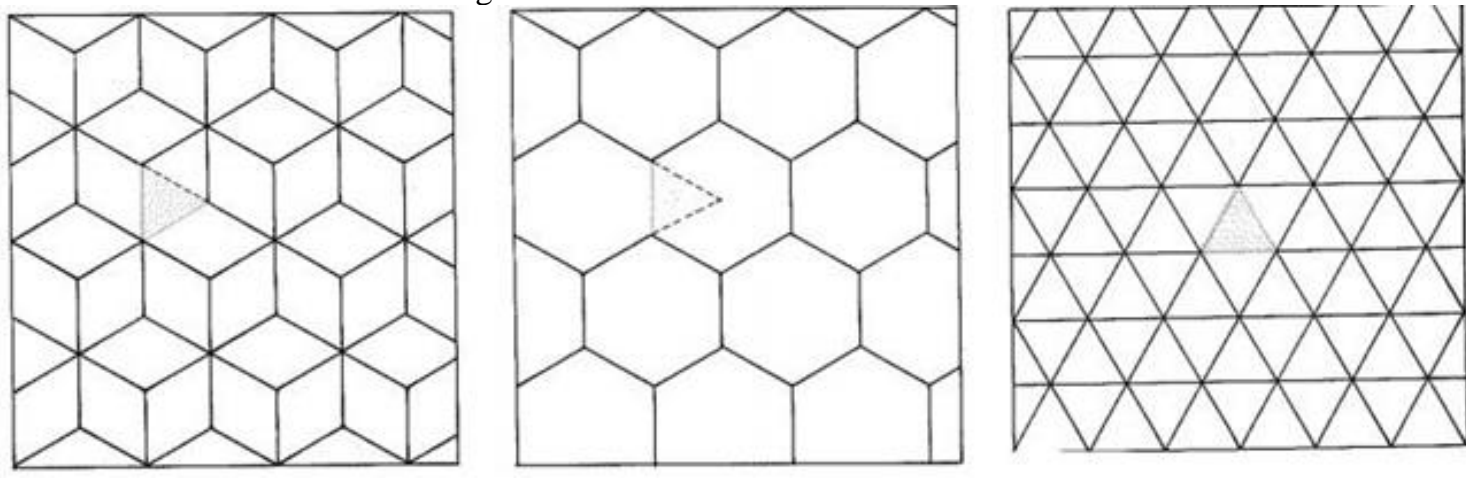

Fonte: Barbosa, 2005

Tomando dois segmentos unindo pontos médios dos lados do triângulo, obtemos um hexágono para cada ângulo correspondente (o ângulo do triângulo cujos lados contém os dois pontos médios) já no ângulo em que não está desenhado o segmento de reta média correspondente teremos a reflexão de losangos formando uma estrela de seis pontas (que pode ser ressaltado caso o interior do losango formado esteja pintado). Se ao invés disso tomarmos três segmentos de retas médias do triângulo (ligando cada ponto médio aos outros dois) será formado um hexágono regular para cada lado do triângulo, mas pela reflexão do triângulo formado pelos três segmentos descritos haverá também triângulos em cada lado dos hexágonos formados (tal configuração também pode ser obtida traçando-se de um ponto médio, os dois segmentos perpendiculares aos demais lados, cf. Figura 27). 
Figura 27 - Reflexões sucessivas de segmentos médios
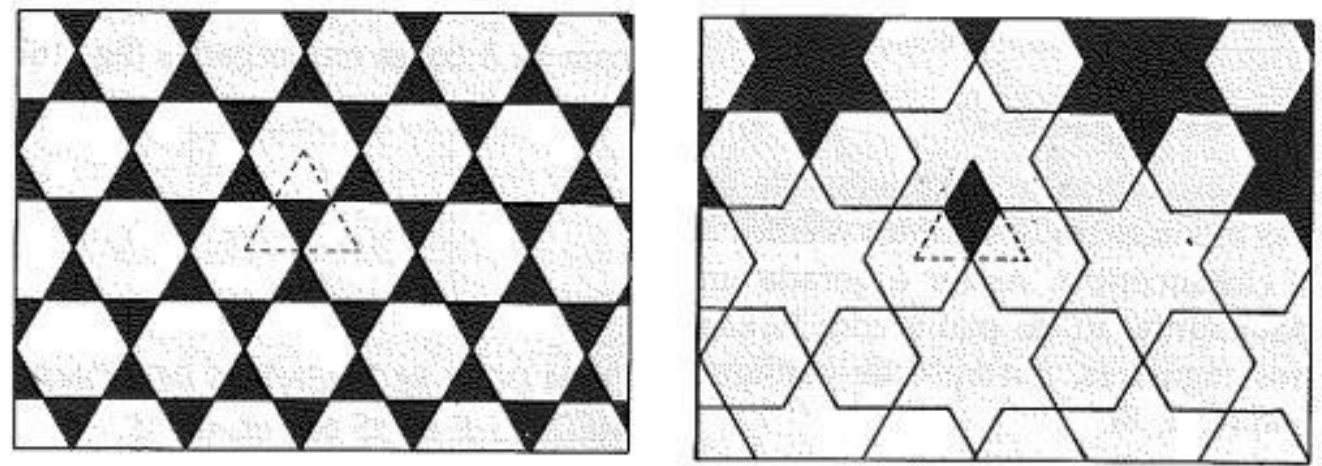

Fonte: Autor

Podemos desenhar os três segmentos formados pela ligação do incentro até os pontos médios dos lados e com isso cada par de espelhos formará um hexágono regular, todos congruentes entre si. A partir das reflexões sucessivas destes hexágonos pelos espelhos, podemos observar uma pavimentação que se assemelha a favos de mel numa colmeia (Figura 28).

Figura 28 - Pavimentações de hexágonos por reflexões sucessivas

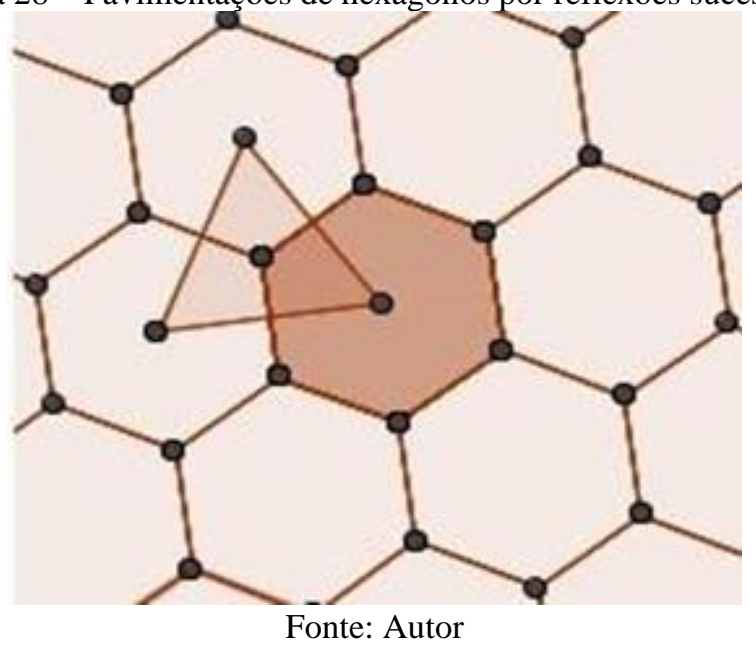

\subsubsection{Obtendo configurações com o caleidoscópio}

- Configuração $(3,4,6,4)$ e $(4,6,12)$ no caleidoscópio equilátero

Podemos obter uma pavimentação do plano do tipo $(3,4,6,4)$, ou seja, com nós formados por dois quadrados, um triângulo equilátero e um hexágono regular (semelhante as imagens de quadrivértices, trivértices e hexavértices obtidas anteriormente a partir de dois pontos médios) basta considerarmos a partir de $\mathrm{A}$, um dos pontos médios, semirretas com o ângulo de medida 
de 45 com o lado que contém A, tendo essas semirretas, consideramos os pontos B e C sendo como a intersecção destas semirretas com cada um dos outros dois lados do triângulo.

A configuração desejada é obtida pelo segmento $\mathrm{BC}$ e a partir de $\mathrm{B}$ e C tomamos os segmentos perpendiculares ao lado que contém A.

Podemos obter uma pavimentação do plano do tipo $(4,6,12)$, ou seja, com nós formados por um quadrado, um dodecágono e um hexágono regulares basta considerarmos a partir de X, um dos pontos médios, semirretas com o ângulo de medida de 45 com o lado que contém $\mathrm{X}$ e as duas bissetrizes desse lado com cada um dos outros dois. Consideremos como $\mathrm{Y}$ e $\mathrm{Z}$ os pontos de intersecção das semirretas de ângulo de medida de 45 com essas duas bissetrizes.

A configuração desejada é obtida pelo segmento $\mathrm{YZ}$, a partir de $\mathrm{Y}$ e $\mathrm{Z}$ tomamos os segmentos perpendiculares aos outros lados que formam sua correspondente bissetriz.

- Outras configurações no caleidoscópio equilátero:

a) $(6,6,6)$ pode ser obtida a partir do traçado das três bissetrizes até o incentro ou então construindo uma faixa grossa sobre um dos lados da base triangular do caleidoscópio;

b) $(3,6,3,6)$ pode ser obtida a partir de um ponto médio e suas respectivas alturas ou então ligamos cada ponto médio aos outros dois;

c) $(3,3,3,3,3,3)$ pode ser obtida facilmente construindo faixas grossas sobre os lados na base triangular do caleidoscópio;

d) $(3,12,12)$ pode ser feita quando chamamos os vértices do triângulo como $\mathrm{A}, \mathrm{B}$ e C, tomamos o ponto médio $\mathrm{M}$ de $\mathrm{AB}$, e tomamos os pontos médios $\mathrm{N}$ de $\mathrm{MA}$ e $\mathrm{O}$ de $\mathrm{MB}$. De $\mathrm{N}$ traçamos a altura a $\mathrm{AC}$ e de $\mathrm{O}$ traçamos a altura a $\mathrm{BC}$.

No desenvolvimento em nosso curso, exploramos essas formas de se obter pavimentações por meio de caleidoscópios equiláteros nas atividade 3,4 e 5 , no sétimo e no oitavo encontro.

Outras pavimentações podem ser obtidas por meio dos outros tipos de caleidoscópios, tais como a pavimentação $(4,4,4,4)$ no caleidoscópio isósceles. Segundo Murari (1999), as mesmas configurações que podem ser obtidas com o caleidoscópio equilátero, podem ser obtidas também com o caleidoscópio escaleno. Um estudo de Kingston (1957) nos mostra que podemos descobrir as bases para os caleidoscópios a partir da observação dos eixos de simetria que podem ser encontrados nas figuras e que coincidem com as mediatrizes dos lados dos polígonos. 
Podemos encontrar no trabalho de dissertação de Martins (2003), um estudo qualitativo com professores e seus alunos de $7^{\mathrm{a}}$ série (equivalente ao atual $8^{\circ}$ ano do Ensino Fundamental atual). Nesse estudo, foram abordados conceitos de Geometria como pavimentação e padrões geométricos com atividades que envolviam objetos espaciais e planos, acessados por materiais concretos e digitais. Dentre as atividades que foram desenvolvidas e experimentadas pela autora, existem algumas relacionadas à simetria e à pavimentação que mostraram que os alunos têm maior potencial de aprendizado nas aulas de Geometria quando são introduzidos materiais como espelhos e caleidoscópios para formação de padrões.

\section{METODOLOGIA DA PESQUISA}

A metodologia desta pesquisa é de cunho qualitativo, de natureza interpretativa, na qual realizamos um estudo exploratório com professores, visando validar a nossa sequência de atividades concebida com base em uma abordagem de ensino inspirada nas cinco práticas.

Inicialmente, foi feito um estudo sobre o conteúdo matemático da pesquisa a fim de descrever os aspectos relativos ao ensino e aprendizagem dos tópicos matemáticos acerca do tema pavimentações do plano, bem como a organização e finalização do conjunto de atividades.

Em seguida, para a coleta de dados, foi concebido e ministrado um curso de formação continuada para professores de Matemática ${ }^{4}$. Os instrumentos usados foram as produções dos professores participantes, em particular, as resoluções das atividades, os relatos dos sujeitos e áudio-gravação de sessões, visando descrever em que medida os objetivos traçados foram alcançados e quais elementos de respostas foram obtidos para a questão norteadora.

\subsection{Perfil dos Professores Participantes}

No primeiro encontro, compareceram 12 professores; no segundo 9 e, a partir, do quinto encontro 8 que permaneceram até o final. Apesar de termos utilizado, de forma explícita ou não, as produções dos professores que não concluíram o curso para as discussões e análises do capítulo seguinte, trouxemos nesta sessão apenas o perfil dos outros 8 professores. Para apresentarmos o perfil dos professores utilizaremos as respostas dadas a questões colocadas em

\footnotetext{
${ }^{4}$ Tal curso foi divulgado pelos meios de comunicação utilizados pelo CAEM-IME-USP, tais como página web do Centro, redes sociais virtuais, e-mail e telefone.
} 
um tipo de questionário de perfil, que pode ser visto na figura abaixo. A professora $A_{1}$ não o respondeu mas suas produções compõem uma parte importante de nossas análises.

Figura 29 - Questionário de Perfil

1 - Qual sua formação acadêmica?

Graduação - Curso: Ano de conclusão:

Pós-graduação - Curso: Ano de conclusão:

2 - Qual o nome e a localização da(s) instituição(ões) em que atua?

3 - Qual(is) disciplina(s) leciona?

( ) Matemática ( ) Outra(s):

4 - Em qual(is) nível(is) atua?

( ) EF I ( ) EF II ( ) E médio ( ) E Superior ( ) Outro(s):

5 - Em qual (is) rede (s) atua?

() Municipal () Estadual () Federal ()Particular () Outra:

6 - Em relação aos conteúdos de Geometria que são ensinados na Educação Básica, você diria que sua formação acadêmica foi:
( ) Insuficiente
( ) Razoável
( ) Suficiente
( ) Ótima

7 - Quais disciplinas ou tópicos de Geometria você estudou em sua Graduação?

8- Quais conteúdos de Geometria você já ensinou?

9- Para você, qual a importância do ensino de Transformações Geométricas?

10 - Costuma adotar livro didático? ( ) Não

A) Em caso afirmativo, qual(is)? Indique título e/ou autor(es).

B) Nesses livros, são abordados tópicos de Transformações Geométricas? Comente.

Fonte: Autor

A maioria dos professores participantes tinha formação em Licenciatura em Matemática e alguns, inclusive, já haviam participado de cursos de formação continuada para professores de Matemática. As professoras $\mathrm{G}, \mathrm{M}_{3}$ e $\mathrm{M}_{2}$ cursavam ou já haviam concluído cursos de pósgraduação em Educação Matemática. Apenas duas professoras não tinham formação na área de Matemática: a professora $A_{1}$ e a professora $\mathbf{J}$ (que também não respondeu ao questionário).

No item 6 do questionário do Perfil do Participante, solicitamos que indicassem uma classificação para os conteúdos de geometria estudados durante a graduação e relacionados ao currículo da Educação Básica. No quadro a seguir podemos observar as respostas dadas entre "Insuficiente", "Razoável", "Suficiente" e "Ótima" e a última coluna, "N de disciplinas", se refere à quantidade de disciplinas de tópicos de geometria estudadas durante a graduação (número obtido a partir das respostas do item 7). 
Quadro 1- Conteúdos de Geometria Estudados pelos Participantes

\begin{tabular}{|c|c|c|}
\hline Professor & Respostas à questão 6 & $\mathbf{N}^{\mathbf{0}}$ de disciplinas escritas na questão 7 \\
\hline $\mathbf{M}_{\mathbf{3}}$ & Razoável & 3 \\
\hline $\mathbf{G}$ & Suficiente & 4 \\
\hline $\mathbf{M}_{\mathbf{2}}$ & Ótima & 7 \\
\hline $\mathbf{R}$ & Ótima & 3 \\
\hline $\mathbf{C}_{\mathbf{2}}$ & Insuficiente & 2 \\
\hline $\mathbf{L}$ & Suficiente & 4 \\
\hline $\mathbf{A}_{\mathbf{2}}$ & Razoável & 1 \\
\hline
\end{tabular}

Fonte: Autor

Até o início do curso, todos os professores participantes lecionavam no Ensino Fundamental II e/ou Ensino Médio, com exceção da professora $\mathrm{M}_{3}$ que trabalhava em uma universidade particular da cidade de São Paulo, atundo em um curso de Licenciatura em Matemática (mas com experiência em lecionar para Ensino Médio também).

Dentre as respostas do item 8 , todos os professores participantes falaram que já haviam trabalhado com tópicos de Geometria plana e espacial, enquanto a Geometria das transformações foi destacada apenas por dois professores: a $\mathbf{M}_{2}$ afirmou que, ao seguir $\mathrm{o}$ programa curricular de sua escola (se trata de uma escola particular com seu próprio programa curricular) desenvolve poucos tópicos da Geometria das transformações e o R que disse lecionar transformações geométricas aos seus alunos. O quadro abaixo mostra os conteúdos de Geometria desenvolvidos por cada um dos professores participantes.

Quadro 2 - Respostas da questão 8 do Questionário de Perfil

\begin{tabular}{|c|c|c|}
\hline Professor & $\begin{array}{c}\text { Estudou Geometria das } \\
\text { Transformações }\end{array}$ & Outros Conteúdos Ensinados \\
\hline M3 & Não & $\begin{array}{c}\text { Desenho Geométrico, Geometria Plana, Espacial e } \\
\text { Analítica. }\end{array}$ \\
\hline G & Não & $\begin{array}{c}\text { Desenho Geométrico, Geometria Plana, Espacial e } \\
\text { Analítica.. }\end{array}$ \\
\hline $\mathbf{M}_{2}$ & Pouco & $\begin{array}{c}\text { Segue o programa curricular } \\
\text { R }\end{array}$ \\
\hline
\end{tabular}




\begin{tabular}{|c|c|c|}
\hline $\mathbf{C 2}$ & Não & $\begin{array}{c}\text { Congruência e Semelhança, Trigonometria e } \\
\text { circunferência. }\end{array}$ \\
\hline $\mathbf{L}$ & Não & Geometria Plana, Espacial e Analítica. \\
\hline $\mathbf{A} 2$ & Não & Ângulos e Planificação de Sólidos. \\
\hline
\end{tabular}

Fonte: Autor

A questão 9 foi respondida de forma diferente por todos os professores participantes. É possível que eles nunca tenham tido que responder essa pergunta antes ou que não haviam feito uma reflexão maior sobre a importância e, por isso, algumas respostas ficaram superficiais ou genéricas. No quadro abaixo apresentamos as respostas dadas pelos professores participantes.

Quadro 3-Respostas do item 9

\begin{tabular}{|c|c|}
\hline Professor & Resposta do item 9 \\
\hline $\mathbf{M}_{3}$ & $\begin{array}{l}\text { Essa é uma falha grande na minha formação, acredito que nunca aprendi esse } \\
\text { tópico de maneira satisfatória. Assim, não me vejo em condição de avaliar. }\end{array}$ \\
\hline G & $\begin{array}{l}\text { É importante para que o aluno entenda um pouco sobre o que acontece ao seu } \\
\text { redor. }\end{array}$ \\
\hline $\mathbf{M}_{2}$ & Muito importante. \\
\hline $\mathbf{R}$ & Outra abordagem para entender conceitos sobre alguns polígonos. \\
\hline $\mathbf{C}_{2}$ & $\begin{array}{l}\text { É importante para a descrição e interrelação do homem com o espaço em que } \\
\text { vive, as transformações geométricas estão no dia a dia e podem ser } \\
\text { consideradas como Matemática concreta, ligada com a realidade. }\end{array}$ \\
\hline $\mathbf{L}$ & Acho muito importante, porém nos livros didáticos temos pouco conteúdo. \\
\hline $\mathbf{A}_{2}$ & $\begin{array}{l}\text { A importância de transformações geométricas é para que o aluno possa aprender } \\
\text { sobre reflexão e rotação. }\end{array}$ \\
\hline
\end{tabular}

Fonte: Autor

A professora $\mathrm{G}$, apresentou uma resposta um pouco geral sem falar de que forma a geometria das transformações pode realmente colaborar com o entendimento do aluno e a professora $\mathrm{M}_{2}$ escreveu apenas que acredita ser "Muito importante.", sem falar o porquê dessa importância. 
A professora $\mathrm{M}_{3}$ mostrou ainda que, por haver lacunas na sua formação, em relação à geometria das transformações, não conseguiria avaliar sua importância. Ao observar as respostas do item 7 , em que nenhum professor afirmou já ter estudado a geometria das transformações durante a graduação, percebemos que há uma ligação direta com as respostas obtidas no item 9.

Assim como o professor R, também acreditamos que a geometria das transformações pode colaborar com o estudo de algumas propriedades de polígonos, no entanto a sua importância vai muito além disso, desenvolvendo também conceitos como o de relação e de função, congruência e semelhança, estando conectada com a percepção do real e do concreto por estudar movimentos geométricos (como rotação e translação).

Segundo os Parâmetros Curriculares Nacionais (BRASIL, 1998), o estudo das transformações isométricas "é um excelente ponto de partida para a construção das noções de congruência" e o estudo das simetrias pode estar relacionado com a análise de diversos objetos do mundo físico, podendo justificar, por exemplo, as respostas da professora $\mathrm{G}$ e da professora $\mathrm{C}_{2}$. Para a relação com o mundo físico é discutido o conceito de planos de simetria:

Em inúmeros objetos físicos ocorrem aproximações de planos de simetria de reflexão. Em representações planas desses objetos, tais planos de simetria reduzem-se a eixos de simetria. No corpo humano pode-se observar (aproximadamente) um plano de simetria. [...] Há eixos de simetria em diversas criações do homem, como desenhos de aeronaves, edifícios e móveis (BRASIL, 1998, p. 124).

Além disso, também são expostos exemplos de quais padrões geométricos que podem ser observados no dia-a-dia poderiam ser reproduzidos por meio de simetrias:

\footnotetext{
As simetrias centrais e de rotação também surgem em diversas situações: desenhos de flores, logotipos de empresas, desenhos de peças mecânicas que giram, copos, pratos, bordados etc. Os exemplos de translação também são fáceis de encontrar: grades de janelas, cercas de jardins, frisos decorativos em paredes, azulejos decorados etc. (BRASIL, 1998, p. 124).
}

No Currículo da Cidade de São Paulo (SÃO PAULO, 2017), é descrito que o estudo da geometria está vinculado a ideias matemáticas fundamentais, sobretudo a interdependência intimamente ligada ao estudo da geometria das transformações enquanto uma aplicação ou relação entre conjuntos de pontos -, a variância, a equivalência e a representação. Ainda nesse documento é sugerido o estudo de tópicos de geometria das transformações do $7^{\circ}$ ao $9^{\circ}$ ano do Ensino Fundamental (o documento não aborda o Ensino Médio). 
A resposta do professor L à questão 9 nos leva a pensar em relacionar com a questão 10, a respeito do uso do livro didático e dos tópicos de geometria das transformações nele contidos e refletir em que medida a importância que o professor participante dá à geometria das transformações está relacionado com a valorização já apresentada pelos livros didáticos adotados em sua escola. Tal reflexão não cabe nesta análise e foge do objetivo deste trabalho, então prosseguiremos para discutir os comentários do item 10-B.

Três dos professores, $\mathrm{M}_{2}, \mathrm{~A}_{2} \mathrm{e} \mathrm{R}$, afirmaram que não utilizam/adotam o livro didático em suas escolas e os demais, apesar de terem o livro didático presente em suas práticas docentes afirmaram, em sua maioria, que a abordagem é dada de forma resumida e/ou superficial (o que reforça a pertinência dessa pesquisa). No entanto, a professora $\mathbf{M}_{2}$ afirmou já ter utilizado o livro didático anteriormente e que ele abordava tópicos de simetria e translação, mas de maneira informal e que rotação estava presente em capítulos de geometria analítica, com rotação em torno de um eixo.

A professora $\mathrm{G}$ disse que tópicos da geometria das transformações "aparecem apenas em curiosidades ou atividades extras" do livro didático que utilizava em suas práticas docentes.

Já a professora $\mathrm{M}_{3}$ afirmou que esses tópicos nem aparecem nos livros didáticos utilizados, pois a geometria das transformações não está presente no programa curricular do curso de Licenciatura em Matemática da universidade em que leciona.

Acreditamos que o grupo pode ser percebido como misto, de certa forma, no sentido de experiências profissionais e acadêmicas, pois contamos com professores de Ensino Fundamental Anos Finais, Ensino Médio e Ensino Superior, dos quais há quem já tenha feito cursos de formação continuada, quem tenha feito cursos em outras áreas e quem não tenha feito cursos além de sua Licenciatura. Mas também notamos no grupo que há um padrão com relação à sua formação inicial: nenhum professor afirmou ter tido uma disciplina específica de geometria das transformações em sua graduação, embora acreditemos que alguns possam ter estudado em meio às disciplinas de Geometria Plana ou de Geometria Euclidiana.

\subsection{O Curso de formação continuada}

O curso oferecido e que constituiu o contexto para a coleta de dados do estudo exploratório intitulou-se Geometria Plana: Pavimentações do plano a partir de Espelhos e Caleidoscópios (CAEM-IME-USP, 2018). 
Buscamos contribuir na formação de professores, desenvolvendo a sua autonomia em produzir e planejar atividades, além da criação de estratégias para o uso de diferentes instrumentos e materiais manipuláveis relacionados a situações de aprendizagem de Geometria.

O conteúdo matemático desse curso envolveu, principalmente: polígonos e suas propriedades, pontos notáveis de triângulos, construções com régua e compasso, isometrias (com maior foco em reflexão em reta), pavimentações do plano e simetrias.

O objetivo global do curso foi envolver os professores participantes em atividades exploratórias e investigativas, com ênfase no uso de materiais concretos (espelhos e caleidoscópios) para o desenvolvimento de tarefas específicas (de pavimentações do plano) e na (re)elaboração de atividades didáticas, por parte dos professores participantes, a partir das experiências com o curso e as discussões sobre as Cinco Práticas para o Orquestração de Discussões Matemáticas (STEIN \& SMITH, 2011) que serão melhor descritas na subseção 4.3.

A carga horária foi de 30 horas e o curso foi oferecido no âmbito das atividades regulares do CAEM-IME-USP e ministrado por nós, autores dessa pesquisa, compreendendo 8 encontros presenciais com duração de 3 horas e 45 minutos cada. Foi realizado também, um encontro extra para apresentação do trabalho final na forma de seminário, no qual os professores participantes relataram a experiência realizada ao explorar suas respectivas sequências didáticas inspiradas nas atividades do curso, com seus alunos.

Em cada um dos encontros, foram trabalhados tópicos específicos a partir de um conjunto de atividades, realizadas em grupo ou individualmente. Podemos descrever o material que compõe os dados coletados para a pesquisa como: para cada encontro participado, os professores escreveram em seus diários de bordo; todos os registros das atividades realizadas que foram entregues; foram feitas apresentações orais no início do curso tratando-se de atividades em grupo e nos últimos dois encontros, para as discussões sobre os trabalhos finais que serão apresentados no capítulo seguinte.

No Quadro 4, temos registrado um panorama geral da organização do curso com os tópicos estudados, atividades realizadas e quais dados foram coletados. 
Quadro 4: Encontros do curso

\begin{tabular}{|c|c|c|c|}
\hline Encontro & Tópicos Estudados & Atividades Realizadas & Dados Coletados \\
\hline 1 & $\begin{array}{l}\text { Tipos de Caleidoscópios, } \\
\text { Pavimentações do Plano }\end{array}$ & $\begin{array}{l}\text { Exploração das mesas } \\
\text { temáticas em grupos }\end{array}$ & $\begin{array}{l}\text { Vídeo, diário e } \\
\text { questionário. }\end{array}$ \\
\hline 2 & $\begin{array}{c}\text { Composição de } \\
\text { Reflexões em Retas }\end{array}$ & $\begin{array}{c}\text { Atividades } 1,2 \text { e } 3.1 \\
\text { (análise da formação de } \\
\text { imagens) }\end{array}$ & $\begin{array}{c}\text { Diário, Produção } \\
\text { escrita das atividades } \\
1 \text { e } 2 .\end{array}$ \\
\hline 3 & Estrelas Poligonais & $\begin{array}{l}\text { Atividade } 3.2 \text {. Síntese } \\
\text { das atividades } 1 \text { e } 2\end{array}$ & $\begin{array}{c}\text { Diário e Síntese } \\
\text { escrita das atividades } \\
1 \text { e } 2 .\end{array}$ \\
\hline 4 & $\begin{array}{l}\text { Convexidade, } \\
\text { Regularidades e } \\
\text { Bissetrizes }\end{array}$ & $\begin{array}{c}\text { Atividade } 3.3 \\
\text { (individual) e } 3.3 . \mathrm{d} \\
\text { (duplas) }\end{array}$ & $\begin{array}{c}\text { Diário, Produção } \\
\text { escrita das atividades } \\
\text { 3 e 3.3.d. }\end{array}$ \\
\hline 5 & $\begin{array}{l}\text { Transformações do } \\
\text { Plano e Definição de } \\
\text { Polígonos }\end{array}$ & $\begin{array}{c}\text { Atividade de } \\
\text { Transformações do } \\
\text { Plano (1 a 5) }\end{array}$ & $\begin{array}{l}\text { Diário e Produção } \\
\text { escrita da atividade de } \\
\text { Transformações. }\end{array}$ \\
\hline 6 & $\begin{array}{c}\text { Simetrias, Polígonos, } \\
\text { Pavimentação e } \\
\text { Ladrilhamento }\end{array}$ & $\begin{array}{l}\text { Atividade } 4 \text { e } 5 \\
\text { (polígonos e } \\
\text { pavimentação) }\end{array}$ & $\begin{array}{c}\text { Diário, Produção } \\
\text { escrita das atividades } \\
4 \text { e } 5 .\end{array}$ \\
\hline 7 & $\begin{array}{c}\text { Configuração de } \\
\text { Pavimentações do Plano } \\
\text { e as } 5 \text { práticas }\end{array}$ & $\begin{array}{l}\text { Atividade } 6 \text { e } 7 \\
\text { (pavimentações com } \\
\text { caleidoscópios) }\end{array}$ & $\begin{array}{c}\text { Diário, Produção } \\
\text { escrita das atividades } \\
6 \text { e } 7 \text { e Plano de Aula. }\end{array}$ \\
\hline 8 & $\begin{array}{l}\text { Pavimentações com o } \\
\text { Caleidoscópio Equilátero }\end{array}$ & $\begin{array}{l}\text { Atividade } 8 \text { (duplas) e } \\
\text { Apresentação Final }\end{array}$ & $\begin{array}{c}\text { Diário, Produção } \\
\text { escrita da atividade } 8 \\
\text { e Sequência Didática. }\end{array}$ \\
\hline
\end{tabular}

Fonte: Autor

Além das atividades de cada encontro, cada professor participante foi acompanhado e avaliado pela entrega de uma sequência didática, na qual devia constar alguma(s) da(s) atividade(s) vivenciadas no curso, em sua totalidade ou de forma adaptada. Junto a essa atividade, havia o plano de aula, cujos elementos, além do objetivo global, conteúdo e tempo de duração, foram apresentados da seguinte forma:

1. Descrição e Enunciados: questões a serem trabalhadas e intervenções previstas;

2. Expectativas de Aprendizagem: o que se espera, principais dificuldades e ações;

3. Possibilidades de Resoluções: comuns e incomuns;

4. Objetivos de Aprendizagem: noções, conceitos, técnicas e habilidades;

5. Propostas de Continuação: tarefas para uma sequência didática. 
Após a realização dessa experiência, cada professor participante - com sua(s) própria(s) turma(s) - elaborou um relatório de aplicação, destacando o que foi discutido e as intervenções necessárias e, por fim, uma conclusão descrevendo se, e como, os objetivos foram alcançados.

Os dados coletados são compostos por instrumentos diversificados, em particular as produções dos professores participantes em torno das atividades propostas, relato de cada encontro no diário de bordo (especificando os pontos positivos e negativos de cada etapa proposta), trabalho final composto por plano de aula com as atividades exploradas com seus alunos e um relatório do desenvolvimento da sequência didática, questionários (de perfil e de feedback) e vídeo-gravação de algumas duplas selecionadas em função de alguns critérios de formação e experiência profissional.

As sequências didáticas apresentadas pelos professores participantes foram bem diferentes e é importante ressaltar que dois dos professores participantes não conseguiram explorar as atividades em suas salas de aula, mas todos apresentaram um plano de aula adequado aos critérios estabelecidos. Essas produções se referem aos oito professores que puderam acompanhar e concluir o curso.

\subsection{Cinco Práticas para a Orquestração de Discussões Matemáticas Produtivas}

Momentos propícios para a exposição e discussão de ideias são fundamentais para a compreensão da Matemática e cabe ao professor colaborar com a produção de um ambiente adequado para que ocorram discussões produtivas no decorrer das aulas, bem como guiar devidamente o decorrer dessas. O desenvolvimento do pensamento geométrico, sobretudo em nível axiomático (PARZYSZ, 2006), no qual se busca justificar ou refutar afirmações, reconhecendo e utilizando propriedades e conceitos já aprendidos, pode ser explorado por meio das discussões em sala de aula.

Stein e Smith (2011) apresentam um modelo que descreve as ações que os professores podem desenvolver a fim de tornar as discussões em sala de aula mais produtivas, alinhando as ideias e estratégias dos alunos à compreensão de determinado tópico da Matemática. Essa abordagem consiste em utilizar as respostas dadas pelos alunos para conduzir a discussão encaminhando a sistematização de conceitos.

As ações partem da elaboração prévia de um conjunto de tarefas ou uma sequência didática relacionadas ao aprendizado de determinado tópico da Matemática.

Diferentemente das ações de ensino em que o professor expõe ideias e conceitos já sistematizados, com foco no aprendizado pela reprodução de técnicas para resolução de 
exercícios, as práticas que serão descritas a seguir estão relacionadas com um processo de ensino e aprendizagem com foco em atividades de investigação matemática e sistematização de conceitos de forma colaborativa a partir de discussões coletivas.

\subsubsection{Investigação Matemática: Tarefas Exploratórias e Tarefas Investigativas}

Ao discutirmos a presente abordagem de ensino, estamos considerando uma aula de Matemática em que os alunos são colocados em um processo de investigação matemática a partir das tarefas apresentadas pelo professor, visando desenvolver um ou mais conceitos. Para Ponte, Brocardo e Oliveira (2003)

\footnotetext{
O conceito de investigação Matemática, como atividade de ensino- aprendizagem, ajuda a trazer para a sala de aula o espírito da atividade Matemática genuína, constituindo, por isso, uma poderosa metáfora educativa. $\mathrm{O}$ aluno é chamado a agir como um matemático, não só na formulação de questões e conjecturas e na realização de provas e refutações, mas também na apresentação de resultados e na discussão e argumentação com os seus colegas e o professor. (PONTE, BROCARDO E OLIVEIRA, 2003, p.23)
}

Essa aula então, é compreendida por momentos de descoberta, de discussão e de experimentações, momentos esses em que os alunos buscam formas de organizar e expressar ideias, verificar padrões e apresentar suas conclusões.

Para classificar o tipo de investigação matemática que é realizada, deve-se analisar se a atividade ou a sequência didática apresentada é constituída de tarefas com estrutura de maior ou menor abertura para a reflexão de um problema ou objeto. Para Ponte (2003), essa estrutura pode caracterizar investigações matemáticas com dois tipos diferentes de tarefas:

a) Tarefas investigativas: demandam do aluno a resolução de um problema sem que sejam explicitadas as ferramentas ou técnicas a serem utilizadas e sem indicações diretas do que o aluno deve descobrir ou testar.

$\mathrm{Na}$ tarefa apresentada na figura seguir, temos um exemplo de uma tarefa investigativa, em que os alunos são colocados a investigar padrões em uma sequência numérica sem uma direção, especificando o que poderia ser realizado ou que tipo de padrão poderia ser buscado. 
Figura 30 - Tarefa investigativa

Discuta e investigue um ou mais padrões que podem ser encontrados na sequência de números a seguir:

$1,1,2,3,5,8,13,21,34,55,89, \ldots$

Fonte: Autor

Essa tarefa, na qual estão expressos alguns dos termos da sequência de Fibonacci, os alunos podem encontrar diferentes tipos de padrões como, por exemplo, o fato de que sempre aparecem dois números ímpares seguidos de um número par, que precede novamente dois ímpares seguidos de um par, podem tentar ampliar a quantidade de termos representados para analisar padrões relacionados aos algarismos que aparecem, ou podem falar sobre a lei de formação, na qual cada termo é igual à soma dos dois termos anteriores. Para tanto, é interessante que os alunos já estejam habituados a buscar padrões em atividades investigativas, que detenham conhecimentos prévios, tais como paridade e que o professor tenha um plano para lidar com os tipos diferentes de respostas que podem surgir.

a) Tarefas exploratórias: fazem com que o aluno busque resolver um problema indicando um caminho mais evidente do que pode ser feito, podendo ser inclusive, dividido em etapas e com maiores enunciados.

Na tarefa apresentada na figura a seguir, temos um exemplo de uma tarefa exploratória, em que os alunos são colocados em uma situação de descoberta guiada por alguns enunciados direcionando-os a pensarem a tarefa da sequência numérica das potências de 2 de uma determinada forma, com etapas especificadas. 
Figura 31 - Tarefa exploratória

Observe a sequência numérica e responda os itens a seguir:

$$
1,2, \ldots, 8,16, \ldots
$$

a) Qual é o terceiro número dessa sequência? Explique como você o obteve.

b) Qual é o sexto número dessa sequência? E o sétimo? Justifique suas ideias.

c) Existe uma lei de formação para determinar todos os números da sequência? Descreva-a.

d) Escreva a sequência dos números que são potências de 3 .

e) Qual é o segundo termo de uma sequência de potências em que o primeiro termo é 1 e o quarto termo é 216 ? Justifique suas ideias.

Fonte: Autor

As etapas colocadas nessa tarefa levam o aluno a descobrir, primeiramente (nos itens a e b), alguns termos da sequência numérica que não estão explicitados, fazendo com que ele tenha que exercitar a lei de formação antes de descrevê-la, que é o que se pede no item seguinte (item c). Já os dois últimos itens levam o aluno a tentar pensar em sequências com outros números, podendo colaborar com a generalização de outras propriedades.

Em uma investigação matemática, um elemento muito presente é o exercício da autonomia do estudante, uma vez que os resultados matemáticos não lhes são apresentados de antemão, mas devem ser descobertos por ele por meio do processo investigativo. Em se tratando de tarefas investigativas, esse exercício está mais presente ou em grau maior de dificuldade, sobretudo quando o estudante não está habituado a tarefas de investigação matemática, enquanto as tarefas exploratórias conduzem um pouco mais às formas de pensar e discutir os problemas colocados, exigindo menos autonomia do estudante. É possível ainda, que o professor desenvolva e explore tarefas com seus alunos que possam ter um grau de dificuldade não muito grande sem que direcione muito as resoluções dos alunos.

Em uma pesquisa realizada por Foss, Wichnoski e Bassoi (2018), foi feito um levantamento de quantidade de tarefas exploratórias e de tarefas investigativas propostas em trabalhos publicados nas edições XI e XII do Encontro Nacional de Educação Matemática (ENEM) visando analisar em quais contextos elas foram inseridas, bem como destacar suas especificidades. 
A quantidade de tarefas exploratórias encontradas foi maior do que a quantidade de tarefas investigativas e, para os autores, "isso pode encontrar justificativas na insegurança do professor no trabalho com a investigação matemática ou na pouca experiência dos professores e alunos nesse tipo de trabalho". É discutido também que, “o grau de abertura das tarefas investigativas, em relação às exploratórias, permitem aos alunos percorrer diferentes caminhos e, consequentemente, chegar em resultados diferentes dos previstos pelo próprio professor".

Ou seja, a ausência de ações de uma investigação matemática em sala de aula pode ser reflexo de uma falta de hábito ou também pode ser reflexo de um currículo que se pretende seguir, que faz com que o professor apresente conceitos já prontos, de forma fechada, incentivando pouco a discussão e garantindo que os alunos tenham contato com maior número de conteúdos em detrimento de um estudo mais aprofundado.

É certo que a investigação matemática exige do professor um planejamento que o prepare para lidar com diversos tipos de respostas e desdobramentos das discussões entre os alunos; para Ponte (2006, p.14) "uma aula com tarefas de natureza exploratório-investigativa é mais complicada de gerir do que uma aula baseada na exposição de matéria e na realização de exercícios, dada a imprevisibilidade das propostas e questões que os estudantes podem colocar."

Enquanto a imprevisibilidade é posta como um elemento dificultador do trabalho com a investigação matemática, o estudo da Geometria parece colaborar com o desenvolvimento do pensamento matemático por meio desse tipo de tarefa. Na pesquisa de Foss, Wichnoski e Bassoi (2018), foram encontradas muito mais publicações com o conteúdo de Geometria do que os outros conteúdos. Para Abrantes (1999),

\footnotetext{
Fazendo apelo à intuição e à visualização e recorrendo, com naturalidade, à manipulação de materiais, a Geometria torna-se [...] especialmente propícia a um ensino fortemente baseado na realização de descobertas e na resolução de problemas, desde os níveis escolares mais elementares. Na Geometria, há um imenso campo para a escolha de tarefas de natureza exploratória e investigativa, que podem ser desenvolvidas na sala de aula, sem necessidade de um grande número de prérequisitos e evitando, sem grande dificuldade, uma visão da Matemática centrada na execução de algoritmos e em "receitas" para resolver exercícios (ABRANTES, 1999, p.4)
}

As possibilidades de se apropriar de conceitos de geometria por meio do uso de materiais concretos e manipuláveis, o que amplia o uso dos sentidos perceptivos do estudante sobre o objeto matemático, faz com que atividades de investigação matemática sejam naturalmente adotadas pelos professores e pesquisadores da área de Educação Matemática. 


\subsubsection{As Cinco práticas do Professor}

Em meio às investigações matemáticas, em que o processo é determinado não apenas pelo trabalho individual do estudante com as tarefas, mas também pela forma como ele apresenta suas conjecturas e como concorda ou refuta as ideias dos demais, torna-se um desafio para o professor de matemática orquestrar a forma segundo a qual as discussões ocorrem e colaborar para que todos os alunos estejam integrados e envolvidos nas tarefas.

As cinco práticas descritas por Smith e Stein (2011) oferecem ao professor de matemática sugestões de como proceder na orquestração das discussões, elencando as ações em um esquema com cinco práticas diferentes. Tal modelo pedagógico consiste na fundamentação para a elaboração do curso de formação continuada presente nessa pesquisa.

O planejamento das tarefas e da atividade, a escolha de currículo e cuidados com o tipo de público envolvido determina a prática de antecipar. Após a apresentação da(s) tarefa(s) aos alunos é realizado um trabalho sem interferência direta do professor, que assume um papel semelhante ao de observador, classificando a prática de monitorar. Durante o trabalho autônomo dos alunos, o professor, que observou as respostas e levantamentos feitos pelos alunos, escolhe alguns que considere convenientes para serem expostos a toda a turma, caracterizando a prática selecionar. Para o momento da discussão, que deve ocorrer logo em seguida, o professor, que selecionou ideias dos alunos, decide uma ordem para que essas sejam apresentadas a todos da turma; é a prática de sequenciar. Após a exposição das ideias e discussão, o professor deve sistematizar os conceitos apresentados, que é a prática nomeada de estabelecer conexões.

Cada uma das práticas se beneficia do trabalho realizado na prática anterior. Apresentaremos, a seguir, em que consiste o papel de professores e alunos em cada uma dessas práticas e como elas se conectam em ações que permeiam a investigação matemática.

\section{Antecipar}

Com os planejamentos, os professores são capazes de imaginar quais serão os possíveis erros e acertos mais comuns dos alunos e quais respostas mais particulares podem aparecer, inclusive em meio a tarefas investigativas, além de pensar como poderão usá-las para promover uma boa discussão e apresentação de resoluções dos alunos. Ao antecipar como os alunos reagirão cognitivamente às tarefas, o professor deve ficar preparado para saber responder a 
questionamentos e para ajudar os alunos com dificuldades específicas, bem como guiá-los em função do objetivo da tarefa.

Portanto, antecipar consiste em uma reflexão realizada pelo professor sobre como os alunos se comportarão em resposta às tarefas propostas, além de pensar em maneiras de agir e de lidar com os possíveis comportamentos, abordagens e pensamentos dos alunos. Em relação ao papel do professor de Matemática, essa antecipação deve contemplar os aspectos descritos no quadro a seguir.

Quadro 5 - Aspectos da prática Antecipar

\begin{tabular}{|c|c|}
\hline $\begin{array}{l}\text { Adquirir confiança com } \\
\text { a Matemática da tarefa }\end{array}$ & $\begin{array}{l}\text { Determinar qual conceito está envolvido na } \\
\text { tarefa e saber relacioná-lo com os } \\
\text { documentos curriculares seguidos. } \\
\text { Resolver a tarefa sozinho para sentir a } \\
\text { clareza do enunciado e evidenciar as } \\
\text { possíveis estratégias de resolução. }\end{array}$ \\
\hline $\begin{array}{c}\text { Determinar expectativas de interpretação } \\
\text { dos alunos e possíveis estratégias, } \\
\text { corretas ou não }\end{array}$ & $\begin{array}{l}\text { Tentar pensar nas dificuldades de se } \\
\text { desenvolver a tarefa com determinada(s) } \\
\text { turma(s), imaginar o tempo gasto para a } \\
\text { realização do que se pede e da discussão de } \\
\text { sistematização também, além de garantir } \\
\text { que haja os materiais desejados, etc. }\end{array}$ \\
\hline Explorar todo o potencial da tarefa & $\begin{array}{c}\text { Tentar envolver todos os estudantes na } \\
\text { tarefa, discutir com eles todos os possíveis } \\
\text { desdobramentos que suas ideias implicam. } \\
\text { Decidir se o ideal seria promover o } \\
\text { trabalho individual, em duplas ou grupos. }\end{array}$ \\
\hline $\begin{array}{l}\text { Desenvolver expectativas sobre a } \\
\text { interpretação e o envolvimento } \\
\text { dos alunos na tarefa }\end{array}$ & $\begin{array}{c}\text { Pensar na coerência e clareza dos } \\
\text { enunciados escritos de acordo com } \\
\text { ano/série escolar, pensar em como tornar a } \\
\text { atividade ou a tarefa mais interessante, } \\
\text { provocadora ou desafiadora. }\end{array}$ \\
\hline
\end{tabular}




\begin{tabular}{|c|c|}
\hline $\begin{array}{c}\text { Elencar uma diversidade de estratégias } \\
\text { corretas ou não, que os alunos poderão } \\
\text { fazer com diferentes graus de sofisticação }\end{array}$ & $\begin{array}{c}\text { Supor quais ideias, resoluções e } \\
\text { proposições podem surgir. O ideal é que o } \\
\text { professor já conheça bem a turma, assim } \\
\text { como seu programa curricular. }\end{array}$ \\
\hline $\begin{array}{c}\text { Relacionar as interpretações e estratégias } \\
\text { com os conceitos, representações, } \\
\text { procedimentos, práticas etc., que são o } \\
\text { objetivo de aprendizagem }\end{array}$ & $\begin{array}{c}\text { Pensar em como as possíveis estratégias } \\
\text { processo de sistematização de conceitos. }\end{array}$ \\
\hline
\end{tabular}

Fonte: Autor

\section{Monitorar}

Durante a fase de investigação, o professor deve acompanhar as respostas dadas pelos alunos, identificando as estratégias utilizadas e o desenvolvimento do pensamento matemático e, sobretudo quando o trabalho não é individualizado, analisar as discussões locais (em pares ou grupos de alunos). Busca-se identificar o potencial para o desenvolvimento do pensamento matemático e a aprendizagem de determinado conceito a partir das estratégias ou representações usadas pelos alunos (neste trabalho autônomo não há interferências do professor). Nesse momento, o professor deve assumir as funções expostas no quadro a seguir.

Quadro 6-Aspectos da prática monitorar

\begin{tabular}{|c|c|}
\hline Observar e ouvir os alunos e grupos & $\begin{array}{c}\text { Observar as respostas que são importantes de } \\
\text { serem compartilhadas com a turma, valorizar o } \\
\text { esforço dos alunos e sua forma de expressar } \\
\text { ideias, tomar nota durante o monitoramento. }\end{array}$ \\
\hline $\begin{array}{c}\text { Avaliar a validade Matemática } \\
\text { das ideias, respostas e representações }\end{array}$ & $\begin{array}{c}\text { Perceber como é o raciocínio do aluno, } \\
\text { identificando quais suas intenções, que } \\
\text { dos estudantes }\end{array}$ \\
$\begin{array}{c}\text { Auxiliar na interpretação e } \\
\text { pensamentas utilizou e o porquê. }\end{array}$ \\
$\begin{array}{c}\text { Fazer questionamentos, pedindo que o aluno } \\
\text { justifique o que afirmou, solicitando que ele } \\
\text { tente expor para um colega suas ideias. }\end{array}$ \\
\hline
\end{tabular}




\section{Selecionar}

Após monitorar e, então, identificar os grupos/alunos cujas respostas são mais interessantes de serem compartilhadas durante cada etapa da discussão, o professor seleciona alunos ou grupos para apresentarem suas estratégias de tal forma que as respostas sirvam como peças para compor o conhecimento matemático em questão.

Ao fazer uma seleção criteriosa de alunos/grupos e ideias que serão apresentadas, o professor inicia a discussão com os alunos com o foco nas estratégias que eles mesmos elaboraram, fazendo com que a discussão da atividade e/ou tarefa seja mais acessível para todos os alunos e auxiliando para que possam perceber e corrigir seus erros, assim como se apropriar do conceito matemático focado. Para a exposição, o professor pode solicitar que alunos se voluntariem ou chamar um ou mais alunos, de acordo com sua seleção, para apresentarem, dependendo do momento da discussão coletiva. No quadro a seguir apresentamos alguns critérios relacionados com essa seleção.

Quadro 7 - Aspectos da prática Selecionar

\begin{tabular}{|c|c|}
\hline $\begin{array}{c}\text { Respostas da } \\
\text { maioria/minoria }\end{array}$ & $\begin{array}{c}\text { Expor para a turma uma resposta comum pode colaborar para } \\
\text { que todos sejam incluídos na discussão, assim como mais à frente } \\
\text { durante a discussão, levantar respostas incomuns para que } \\
\text { reflitam sobre sua validade. }\end{array}$ \\
\hline $\begin{array}{l}\text { Respostas com } \\
\text { erro recorrente }\end{array}$ & $\begin{array}{c}\text { Mostrar respostas com erros recorrentes, pois são representativos } \\
\text { de uma ideia comum entre a turma. }\end{array}$ \\
\hline $\begin{array}{l}\text { Respostas com } \\
\text { diferentes graus } \\
\text { de sofisticação }\end{array}$ & $\begin{array}{l}\text { Para a exposição pode ser interessante solicitar a apresentação de } \\
\text { estratégias diversas, com diferentes tipos de representações e ideias, bem } \\
\text { como tentar trazer para a discussão respostas mais simples e mais } \\
\text { sofisticadas para auxiliar no desenvolvimento do pensamento matemático. }\end{array}$ \\
\hline $\begin{array}{l}\text { Definir se os } \\
\text { alunos poderão } \\
\text { se voluntariar } \\
\text { ou se o professor } \\
\text { escolherá }\end{array}$ & $\begin{array}{l}\text { O que faz o professor decidir se irá escolher o chamar um voluntário é a } \\
\text { ideia que está em discussão. Se é um momento de discussão sobre uma } \\
\text { determinada ideia que pode ser traduzida pela estratégia de um grupo, é } \\
\text { interessante que esse grupo apresente. Mas se a ideia que está sendo } \\
\text { discutida compõe boa parte das estratégias utilizadas, pode ser } \\
\text { interessante chamar um voluntário. O ideal é que o professor tente } \\
\text { alternar entre escolher propositalmente e chamar um voluntário. }\end{array}$ \\
\hline $\begin{array}{l}\text { Tentar fazer } \\
\text { com que todos os } \\
\text { alunos/grupos } \\
\text { possam } \\
\text { apresentar suas } \\
\quad \text { ideias }\end{array}$ & $\begin{array}{l}\text { É fundamental tornar a sala de aula um ambiente favorável para o } \\
\text { desenvolvimento da argumentação matemática e da confiança de todos os } \\
\text { alunos. Para isso, uma estratégia para que a discussão contemple as ideias } \\
\text { de todos e ainda assim considerar o tempo limite da aula, é que eles já } \\
\text { estejam separados em grupos. }\end{array}$ \\
\hline
\end{tabular}




\section{Sequenciar}

Depois de escolher as respostas que serão apresentadas, o professor pode decidir uma ordem de apresentação que considere mais adequada visando o desenvolvimento do pensamento matemático por parte dos alunos acerca do objetivo da atividade ou tarefa. Iniciar a discussão com a estratégia de resolução que mais apareceu (ou a mais simples), por exemplo, pode fazer com que mais alunos não apenas se sintam representados e tenham seu trabalho valorizado como também torna a discussão mais acessível a todos, antes que a discussão inclua resoluções mais incomuns (ou mais sofisticadas). Isso permite que os alunos construam um melhor entendimento do problema e de suas formas de resolução, quando suas ideias e as de seus colegas são confrontadas e/ou conectadas.

Alguns aspectos que podem nortear a elaboração da sequência são apresentados no quadro a seguir.

Quadro 8-Aspectos da prática Sequenciar

\begin{tabular}{|c|c|}
\hline $\begin{array}{l}\text { Começar com } \\
\text { resposta com erro } \\
\text { frequente para } \\
\text { esclarecimento } \\
\end{array}$ & $\begin{array}{c}\text { Uma primeira reflexão que pode ser feita é em relação a algum erro } \\
\text { cometido por vários alunos, fazendo com que possam compreender } \\
\text { melhor suas próprias estratégias. }\end{array}$ \\
\hline $\begin{array}{l}\text { Caminhar do mais } \\
\text { informal ao mais } \\
\text { formal, em termos de } \\
\text { representação }\end{array}$ & $\begin{array}{c}\text { Assim como Parzysz (2009) fala sobre o desenvolvimento do } \\
\text { pensamento geométrico axiomático, o pensamento matemático em } \\
\text { si também demanda que a investigação matemática perpasse um } \\
\text { crescente nível de complexidade. }\end{array}$ \\
\hline $\begin{array}{l}\text { Guiar as } \\
\text { apresentações } \\
\text { buscando a } \\
\text { generalização de } \\
\text { conceitos }\end{array}$ & $\begin{array}{l}\text { Tendo como objetivo a sistematização conjunta de determinado } \\
\text { conceito, os conhecimentos desenvolvidos durante a discussão } \\
\text { devem ser conduzidos visando uma apropriação do significado } \\
\text { desse conceito por meio da generalização de um procedimento, de } \\
\text { uma estratégia ou de uma propriedade matemática. }\end{array}$ \\
\hline
\end{tabular}

Fonte: Autor

\section{Estabelecer Conexões}

As apresentações das respostas selecionadas devem se conectar por meio da discussão: os alunos veem como suas respostas são refletidas pela turma, comparam o que fizeram com o que os demais colegas fizeram, discutem validando ou refutando resoluções de seus colegas, participam da discussão elaborando uma argumentação que se desenvolve no processo, analisam e transitam por diferentes tipos de representações. 
Quadro 9 - Aspectos da prática Estabelecer Conexões

\begin{tabular}{|c|c|}
\hline $\begin{array}{c}\text { Analisar, comparar e } \\
\text { confrontar as diferentes } \\
\text { resoluções apresentadas }\end{array}$ & $\begin{array}{c}\text { Fazer os alunos perceberem o que é comum/distinto } \\
\text { nas diferentes resoluções apresentadas, instigá-los a } \\
\text { apresentar suas respostas e validar as respostas dos } \\
\text { colegas também. }\end{array}$ \\
\hline $\begin{array}{c}\text { Pensar sobre as principais } \\
\text { potencialidades das } \\
\text { diferentes soluções }\end{array}$ & $\begin{array}{c}\text { Ao circular por entre os alunos, fazer os registros } \\
\text { necessários, durante o monitoramento, o professor } \\
\text { pode pensar sobre como conduzir a discussão acerca } \\
\text { de cada tipo de estratégia (dar foco ao tipo de } \\
\text { representação, à explicação descritiva do aluno, ao } \\
\text { procedimento realizado etc.). }\end{array}$ \\
\hline $\begin{array}{c}\text { Sempre propor uma } \\
\text { extensão da tarefa }\end{array}$ & $\begin{array}{c}\text { Mesmo após o momento de sistematização de } \\
\text { conceitos, o professor pode propor uma continuidade } \\
\text { da discussão, mostrando que ainda é possível } \\
\text { questionar mais e pensar mais sobre o problema ou } \\
\text { sobre o conceito que ele envolve. }\end{array}$ \\
\hline $\begin{array}{c}\text { Ter o registro das } \\
\text { estratégias utilizadas }\end{array}$ & $\begin{array}{c}\text { Registrar as estratégias utilizadas ou solicitar que os } \\
\text { alunos entreguem um registro de suas respostas à } \\
\text { tarefa ou atividade para poder acessar, posteriormente, } \\
\text { os tipos de resoluções propostas pelos alunos. }\end{array}$ \\
\hline
\end{tabular}

Fonte: Autor

Cada uma das práticas se beneficia e se sustenta da prática anterior (seguindo a ordem apresentada) e, além disso, há intersecções entre os momentos das práticas. Fazer uma antecipação de como os alunos agiriam durante a resolução da tarefa permite um monitoramento mais preciso das ações dos estudantes, um monitoramento cuidadoso durante a investigação dos alunos colabora com uma possível seleção de respostas que surgem; um sequenciamento de respostas e exposição de comentários, representações ou respostas muito recorrentes depende da seleção prévia; e, por fim, a forma e ordem de exposição das ideias e estratégias dos alunos atrelados a uma discussão em que os alunos são instigados a justificarem e argumentarem suas respostas, permite que o professor estabeleça conexões entre as ideias dos alunos e entre suas ideias e o conceito matemático que é o objetivo da tarefa.

As habilidades e as competências associadas aos objetivos poderão ser adquiridas pelos alunos se estes fizerem a conexão, a apresentação e a representação de suas resoluções de situações problemas confrontados na aula. Estes momentos podem ser construídos, mais especificamente, a partir de uma exposição para a turma, pois dar ao aluno a oportunidade e necessidade de buscar meios (expressão oral, representações numéricas ou geométricas, esquemas, tabelas, equações, gráficos, etc.) de explicitar suas ideais e responder a questões e comentários de colegas, faz com que seus argumentos sejam aprimorados e seu raciocínio refinado. Para o fechamento, é importante solicitar aos alunos que justifiquem o que fora 
concluído (por expressão oral, registro de ideias principais ou a partir do artifício de desafios, lição de casa etc.).

Levando em consideração, a todo momento e inclusive ao final da tarefa, os objetivos que já estavam pré-definidos, o professor precisa avaliar quais foram alcançados. Para Abrantes (1995), que assume as diversas facetas de avaliar, assim como Hadji (2001) que também as descreve, a avaliação não é apenas um meio de constatar a quantidade de conhecimento acumulado, mas uma forma de observar "até que ponto vai a capacidade do estudante e disposição para usar e comunicar uma informação". Para o aluno ter oportunidades de demonstrar tal capacidade, são necessários meios distintos, assim como discussões, desafios, relatórios descritivos e argumentativos etc. 


\section{ANÁLISE DOS ENCONTROS PRESENCIAIS}

Apresentaremos, a seguir, a descrição do desenvolvimento de cada um dos encontros e uma análise das atividades desenvolvidas pelos professores participantes, mostrando, de certa forma, o desempenho global deles e em que medida sua prática pode ter sido afetada com relação as aspectos pertinentes a esta pesquisa: uso de materiais concretos e manipuláveis no ensino da Geometria Plana, construção colaborativa de definições, conceitos e resultados matemáticos obtidos a partir de discussões coletivas, desenvolvimento do pensamento geométrico em nível axiomático e organização de sequências didáticas a partir da proposta das cinco práticas.

Nota-se que cada uma das atividades desenvolvidas é composta por uma ou mais tarefas exploratórias (indicadas como item a, b, c, etc.), separadas em etapas cada uma (indicadas como I, II, III, etc.).

\subsection{Análise do primeiro encontro}

\subsubsection{Introdução do curso}

Primeiramente houve uma apresentação de todos os presente e breve exposição de experiências, tanto dos ministrantes como dos 12 professores participantes. Em seguida foram apresentados os principais objetivos do curso, que estão relacionados com o desenvolvimento de um Laboratório de Educação Matemática e na colaboração com a formação dos professores participantes com atividades compostas por tarefas exploratória. Foram apresentadas as etapas do curso, os tópicos de conteúdos matemáticos que seriam estudados, o cronograma de trabalho e a metodologia de avaliação, além de algumas das bibliografias básicas do curso.

O objetivo desse primeiro encontro era, principalmente, sensibilizar o grupo de professores com a potência do caleidoscópio, enquanto material que instiga a criatividade e seu uso para o estudo das pavimentações do plano, bem como tentar colaborar com a adaptação dos professores participantes para a abordagem do curso com ações como o trabalho em grupos, a exposição de ideias e a discussão coletiva.

Em seguida, os professores participantes foram divididos em cinco grupos (quatro grupos com duas pessoas e um grupo com três pessoas) e levados a uma das cinco mesas da nossa exposição. As mesas são totalmente baseadas nas mesas da exposição que produzida pelo autor deste trabalho em parceria com o CAEM. Cada grupo ficou por 20 minutos, aproximadamente, em se apropriando das atividades e experiências de uma das cinco mesas, 
sendo colocados a refletir cada grupo uma das seguintes questões, de acordo com a mesa em que estavam:

1 - O que é um Caleidoscópio?

2 - A partir da escolha de dois Caleidoscópios diferentes, que mudanças ocorrem ao observar uma mesma figura?

3 - O que é uma Pavimentação do plano?

4 - Por que essas posições do caleidoscópio produzem as duas pavimentações observadas?

5 - Escolham um dos desenhos e determinem uma posição do Caleidoscópio. O que ocorre com a figura desenhada? Por quê?

A primeira pergunta se refere a mesa 1: mesa que contém quatro caleidoscópios de brinquedo (o prisma dentro de um tubo fechado para observação); um caleidoscópio de brinquedo desmontado, com um manual de instruções sobre como montá-lo; um cartaz do filme "O menino e o mundo"; um computador com este filme, que se projetava em uma tela.

Nesta mesa as instruções são: observar livremente os caleidoscópios, discutir sobre como ele é construído e observar no filme o trecho entre 44 min 30 seg até 46 min 30 seg, no qual há um menino brincando com um caleidoscópio recebido de seu pai.

Observações: Uma professora sugeriu que o filme ganhasse mais destaque, ou mesmo que este fosse passado com um trecho maior e ressaltar que é uma produção brasileira. A admiração pelos caleidoscópios ocorreu com todo o grupo de professores, da mesma forma como o menino do filme se encantou com as imagens vistas.

A segunda pergunta se refere a mesa 2: mesa que contém seis caleidoscópios - sendo 2 equiláteros, 2 isósceles e 2 escalenos, com as duas faces triangulares abertas; alguns desenhos produzidos de alunos que participaram de exposições anteriores; algumas placas de papelão com desenhos de pavimentações.

Nesta mesa, as instruções são: utilizar diferentes caleidoscópios para observar, nessa ordem, a sala, os colegas, os objetos sobre a mesa, a borda da própria mesa - primeiro com uma 
ponta do caleidoscópio para fora da mesa e as outras em cima da mesa e depois apenas uma em cima da mesa (cf. figura 33) -, os desenhos de alunos e, finalmente, as placas de pavimentação. Toda observação deve ser feita movimentando os caleidoscópios de um lado para outro e girando o mesmo.

Observações: Uma professora participante notou que, por exemplo, mirando o caleidoscópio à parede era possível ver os colegas que estavam ao lado, "Da pra ver a sala inteira", afirmou; no outro professor teve muita dificuldade em observar padrões durante a etapa desta mesa.

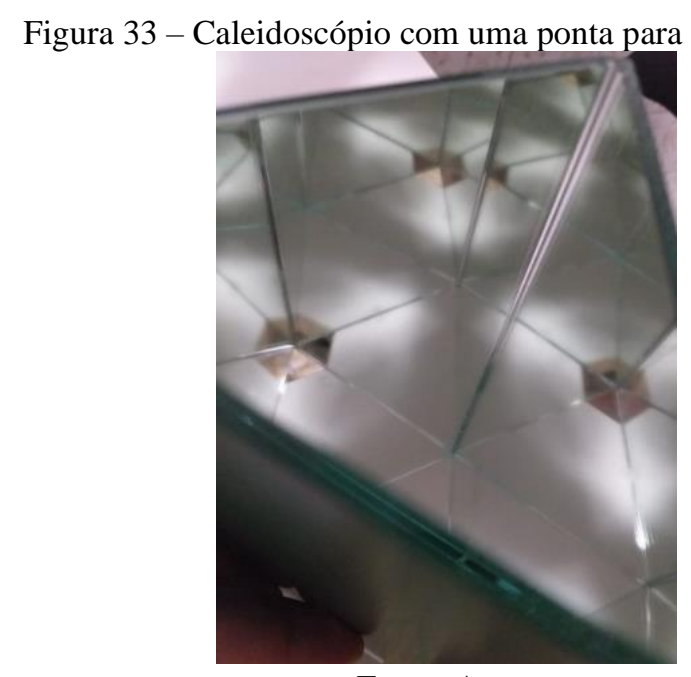

Fonte: Autor

A terceira pergunta se refere a mesa 3: mesa que contém um tablado branco, de dimensões de 1 metro de largura, 2 metros de comprimento e 15 centímetros de altura; conjuntos de peças de acrílico representativas de polígonos regulares, todos com uma mesma medida fixa de lado - triângulos equiláteros (laranjas), quadrados (vermelhos e roxos), pentágonos (azuis), hexágonos (amarelos), heptágonos (pretos), octógonos (roxos), eneágonos (pretos), decágonos (azuis) e dodecágonos (verdes), cada tipo em uma caixinha (cf. figura 34).

Nesta mesa, as instruções são: construir pavimentações diferentes e, em seguida, olhar as folhas de gabarito para verificar suas construções, para isso devem ser dispostas as peças lado a lado - é dito "um tipo de quebra-cabeças" -, para que a configuração seja chamada de pavimentação, primeiramente, é necessário que, ao redor de um vértice, sejam dispostos os polígonos sem haver sobreposição de peças e sem deixar lacunas e, além disso, é necessário que a mesma configuração (mantendo inclusive a mesma ordem dos polígonos ao redor do vértice) se repita em todos os outros vértices. É sugerido que os participantes façam o maior número possível de pavimentações que puderem encontrar. 
Observações: Em geral as pavimentações apareceram, mas aquelas que permitem duas configurações (como triângulos com hexágonos) apareciam ou só de um jeito ou só de outro para cada grupo. Algumas configurações causam, segundo vários dos professores participantes, a ilusão de padrões circulares que, segundo uma professora, podem ser "quebrados" ao usar cores diferentes de um mesmo tipo de polígono (na configuração $(3,4,6)$ ela usou, alternadamente, as duas cores de quadrados).

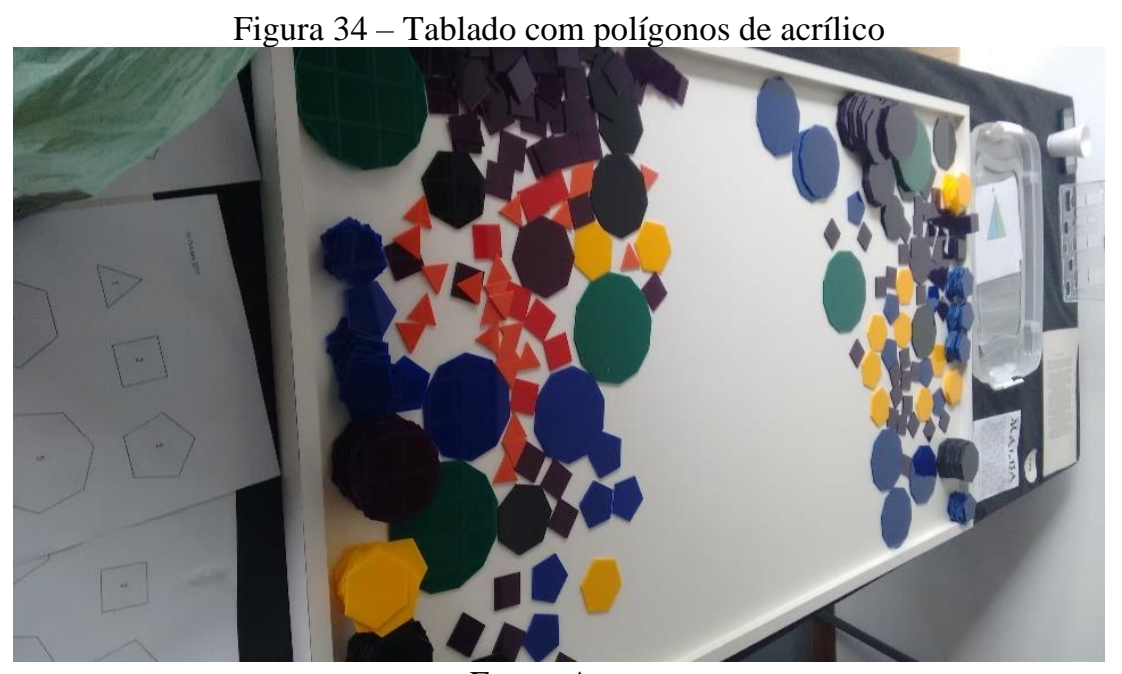

Fonte: Autor

A quarta pergunta se refere a mesa 4: mesa que contém quatro caleidoscópios equiláteros de base com lado de 10 centímetros e altura de 15 centímetros; 6 folhas de tamanho A4 com a pavimentação de triângulos equiláteros verdes e azuis, dispostos alternadamente; 6 folhas de tamanho A4 com a pavimentação de triângulos equiláteros verdes e hexágonos regulares, azuis, laranjas e vermelhos, alternadamente, e dispostos na configuração $(3,6,3,6)$; folhas com as bases geradoras dos dois padrões das folhas A4 e outras três diferentes bases geradoras de pavimentações.

Nesta mesa as instruções são: observar as folhas com as duas pavimentações utilizando o caleidoscópio equilátero sobre a folha e movimentá-lo afim de encontrar a posição em que o caleidoscópio deve estar para que a imagem dentro dos espelhos seja a mesma imagem da folha e, depois de encontrada a posição correta, observar as folhas com as bases geradoras, comparar os gabaritos com as imagens obtidas e discutir quais são as pavimentações formadas com as outras três bases geradoras.

Observações: Uma professora participante reparou que havia duas bases distintas que formavam, cada uma de uma forma diferente, um hexágono regular. A primeira base formava a partir de uma um segmento ligando dois pontos médios, enquanto na outra base o hexágono 
era formado a partir de um quadrilátero pipa dentro da base. Concluiu, com nossos questionamentos, que existem diferentes eixos de simetria em um hexágono regular.

A quinta pergunta se refere a mesa 5: mesa que contém cinco caleidoscópios equiláteros de base com lado de 10 centímetros e altura de 15 centímetros; alguns desenhos produzidos de alunos que participaram de exposições anteriores; folhas em branco para se desenhar; réguas, compassos, lápis coloridos, borracha, apontador, canetinha, giz de cor e fita adesiva colorida.

Nesta mesa as instruções são: observar as folhas com os desenhos visando perceber os efeitos das reflexões com cada tipo de figura, buscar padrões em desenhos e tentar despertar algum olhar artístico para o caleidoscópio. Em seguida, fazer um desenho livre usando os materiais da mesa e explorando a criatividade para, na sequência, observar com o caleidoscópio o que ocorre com o desenho.

Observações: Uma professora observou os desenhos e notou que faltavam figuras com traços curvilíneos ou circunferências e quis descobrir o que aconteceria com esse tipo de desenho. Assim sendo, ela fez um desenho inspirada nos anéis das olimpíadas. Ainda assim, o efeito foi parecido com alguns que ela havia visto, semelhante a uma flor.

\section{Após um intervalo, ocorreu o rodízio das mesas.}

O grupo 1 foi para a mesa 2, o grupo 2 foi para a mesa 3, o grupo 3 foi para a mesa 4, o grupo 4 foi para a mesa 5 e o grupo 5 foi para a mesa 1. E, assim por diante, até que todos os grupos tivessem passado por todas as mesas (ver Apêndice 1). Na figura a seguir podemos ver a experimentação de um dos grupos na mesa 4. 
Figura 35 - Trabalho em grupo na mesa 4

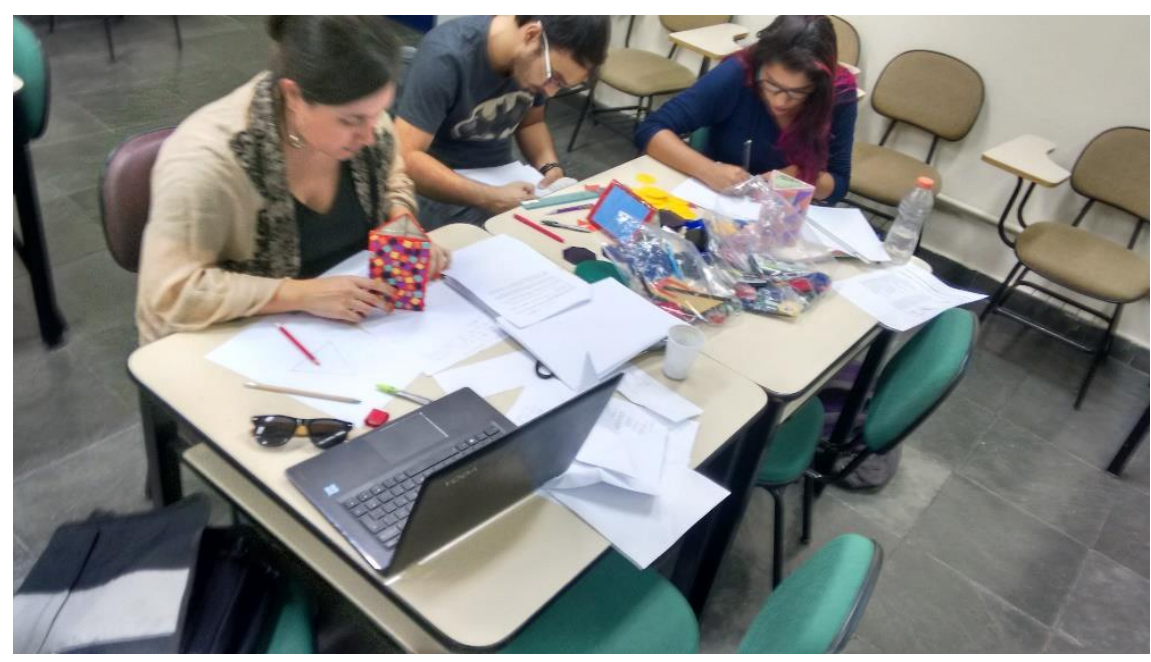

Fonte: Autor

Por fim os grupos apresentaram suas percepções sobre as vivências norteados por uma questão norteadora correspondente e focando sua resposta em três pontos:

1. impressão geral da mesa, apropriação dos materiais e da experiência;

2. conceitos Matemáticos que podem ser explorados;

3. aplicabilidade em sala de aula e sugestões de melhoria, ampliação, críticas e sugestões.

\section{Cada grupo entregou a sua ficha de resposta.}

Grupo 1: Segundo o grupo, foi observada uma pavimentação do plano com os caleidoscópios de brinquedo, mas não afirmaram qual era a configuração. Com relação aos conceitos matemáticos relacionados com a mesa: o grupo foi além do esperado, pois tiveram um olhar bem sensível ao filme, percebendo que poderia ser trabalhado:

- $\quad$ Figuras e formas.

- Matemática no cotidiano (dinheiro, divisão etc.).

E, a partir do caleidoscópio, sugeriram a exploração de:

- Reflexão.

- Simetria.

- $\quad$ Prismas.

- Padrões. 
O grupo sentiu falta de maior exploração e descrição sobre o filme, falaram que o texto da mesa (cada mesa continha um texto explicativo, baseado nos textos das exposições realizadas anteriormente - o Apêndice 1) foi bem complementar aos caleidoscópios de brinquedo.

Grupo 2: Segundo o grupo, o caleidoscópio escaleno dá um efeito de "expandir e retrair" a imagem das pavimentações nas plaquinhas ao arrastá-lo e visualizaram um quadrilátero formado por triângulos e um hexágono ao girá-lo, enquanto o equilátero produz uma imagem composta por triângulos equiláteros.

Grupo 3: Para o grupo, pavimentação é o preenchimento do plano com figuras geométricas sem deixar lacunas. A estética deixou a atividade mais interessante. Sugeriram que seja trabalhado os conteúdos de polígonos regulares e irregulares e seus ângulos internos e externos de, áreas, perímetros, decomposição de polígonos e posição. Há um aspecto de interdisciplinaridade com artes, sugeriram, também, que façamos polígonos irregulares e outros polígonos regulares.

Grupo 4: O grupo encontrou rapidamente as posições corretas do caleidoscópio, mas dependeu de nossa ajuda e de nossas instruções diretas, mas não justificaram a questão norteadora. Sugeriram o trabalho com ângulos em polígonos regulares, pontos notáveis em triângulos equiláteros, áreas, simetrias e grupos cíclicos. Destacaram a possibilidade de as tarefas da mesa serem colocadas em uma sequência didática.

Grupo 5: O grupo ressaltou que estrelas e hexágonos são facilmente formados com os caleidoscópios equiláteros, destacou que os principais conceitos são geométricos: reflexão, simetria, rotação e ângulos, com relação a aplicabilidade, sugeriram o trabalho com o $6^{\circ}$ ano do Ensino Fundamental Anos Finais:

a) Cada aluno faria o seu desenho e observaria no caleidoscópio, compararia com os dos colegas e destacaria semelhanças entre as imagens formadas com o seu desenho e com a de seus colegas;

b) Construção de mandalas, juntamente com o professor de artes. 
A reflexão feita pelo grupo mostrou que foi percebido o número de imagens produzidas por cada par de espelhos, afirmando que cada figura é refletida cinco vezes no caleidoscópio equilátero, como em uma mandala de seis partes.

\subsubsection{Diários de Bordo}

Apresentaremos agora, uma análise de como foram escritos os primeiros diários de bordo pelos professores participantes, destacando pontos em comum, pontos em destaque, dificuldades, sugestões, apropriação de conceitos matemáticos, expectativas e observações gerais.

\section{Pontos em comum:}

- $\quad$ O tempo foi suficiente em cada mesa;

- o trabalho com materiais concretos é um bom artifício para um ensino de Matemática para além do giz e lousa;

- $\quad$ o filme desperta o interesse pelo assunto de caleidoscópios.

\section{Pontos em destaque:}

- A professora $\mathrm{G}$ descreveu todas as etapas do encontro 1, incluiu fotos, destacou suas impressões, críticas e elogios. Ela apreciou o grupo de professores e demonstrou entusiasmo. Foi a primeira a entregar o diário de bordo. Em sua visão geral, prefere a apresentação das mesas seguindo a ordem crescente a partir da mesa 1 pois, segundo ela, é por onde alunos que não sabem o que é um caleidoscópio deveriam começar. Para ela os textos das mesas foram de grande importância para nortear as tarefas. Disse também que a mesa 3 traz alegria para quem participa.

\section{Dificuldades}

- Um professor destacou que um grupo pequeno de participantes, como no nosso curso com doze pessoas presentes, pode dificultar o debate e a troca de ideias; 
- $\quad$ esse mesmo professor teve muita dificuldade em perceber padrões com o caleidoscópio e não conseguiu destacar muitas propriedades geométricas;

- dificuldades em perceber as diferentes características das imagens refletidas nos três tipos de caleidoscópios (escalenos, isósceles e equiláteros);

- $\quad$ alguns materiais não são de fácil acesso aos professores participantes;

- a bibliografia do curso não evidenciou suficientemente como se trabalhar com os materiais em sala de aula, afirmou uma professora.

\section{Sugestões}

- Um professor pediu que tivessem mais explicações expositivas, pois ele sozinho teve dificuldades em se apropriar das atividades e mostrou-se mais dependente de instruções diretas;

- uma professora disse que para aplicar as atividades das mesas com seus alunos demandaria outras pessoas para ajudarem a conduzir as tarefas;

- $\quad$ essa mesma professora afirmou ser importante adaptar e "tentar procurar um espelho uma textura mais plástica e menos pesada para evitar acidentes, tentar cortar as peças geométricas em papelão e talvez plastificar.”;

- relacionar as formas geométricas com a natureza;

- colocar mais figuras (bases geradoras) na mesa 4;

- fazer dois desenhos na mesa 5: um livre e um com algum padrão geométrico.

\section{Apropriação Matemática}

- $\quad$ Propriedades de reflexões sucessivas: formação de polígonos;

- O Caleidoscópio equilátero forma cinco cópias da figura em seu interior, ao redor de um vértice;

- pavimentar o plano com polígonos regulares requer conhecimentos a respeito da soma de ângulos internos dos polígonos;

- os conceitos matemáticos vistos, segundo a participante que é professora de Geografia, podem ser ampliados para outra disciplina: 
"Na geografia, pensando na interdisciplinaridade, é possível trabalhar a (re)produção de paisagens utilizando apenas formas geométricas, também pode solicitar que os alunos produzam duas pavimentações utilizando diferentes escalas como conteúdo procedimental para compreender esse conteúdo. Além disso, o filme "O Menino e o Mundo" tem um grande potencial, pois apresenta as temáticas de espaço urbano e Rural e a questão da visão do indivíduo em relação ao mundo.”.

\section{Expectativas}

- $\quad$ Esperam se apropriar de abordagens de ensino de áreas, ângulos internos e externos de polígonos;

- $\quad$ Aplicar com seus alunos as atividades vivenciadas no encontro;

- $\quad$ O principal desafio será a aplicação de atividades com as suas turmas.

\section{Observações:}

- $\quad$ Alguns professores participantes, como o professor $\mathrm{R}$ e a professora $\mathrm{A}_{2}$ tiveram dificuldades em se apropriar da proposta no primeiro contato com as mesas e pediram uma sequência didática detalhada e mais clara do que fazer; nossa proposta é permitir que os professores explorem os materiais, atividades e as mesas de todas as formas possíveis, ou seja, em certa medida era um momento mais aberto mesmo e os participantes, possivelmente, irão se apropriar e se adaptar com essa abordagem com o decorrer do curso.

- Também houve críticas com relação a ordenação das mesas, mas não houveram sugestões a esse fator, com exceção de uma, sugerida por uma professora, que seria fazer com que cada mesa tivesse uma parte das cinco mesas da exposição, o que acreditamos ser inviável.

\subsection{Análise do segundo encontro}

Começamos retomando com os professores participantes as impressões que eles tiveram das suas vivências no primeiro encontro, alguns dos grupos formados no encontro anterior terminaram suas exposições e discutiram suas respostas com os demais. 
Em geral, no início de cada um dos encontros, realizamos uma discussão sobre o encontro anterior, atividades para casa (quando houveram) e reflexões acerca dos diários de bordo e dos trabalhos finais.

Nesse encontro, foram desenvolvidas as atividades 1 e 2, acerca do tema composição de reflexões em retas usando espelhos paralelos e espelhos concorrentes. Nosso objetivo era o de desenvolver as atividades 1, 2 e 3.1., explorando composições de reflexões em retas visando formar polígonos. Esperávamos também, poder desenvolver as tarefas da atividade 3.2., mas não foi possível pois o grupo gastou mais tempo do que o previsto nas atividades 1,2 e 3.1. A seguir, temos o enunciado da atividade 1

Atividade 1 - Composição de reflexões em retas

Em uma folha, desenhe dois segmentos de reta paralelos que distam, ao menos, $12 \mathrm{~cm}$ um do outro e posicione perpendicularmente à folha um espelho sobre cada segmento. Entre os espelhos, coloque as duas caixinhas fornecidas (azul e vermelha). Feito isso, observe as imagens formadas nos espelhos e discuta a quantidade de imagens e a disposição de cores das imagens das caixinhas. Justifique suas afirmações.

I - Existe alguma relação entre o ângulo dos espelhos com a folha e a quantidade de imagens observadas? (manipule os materiais e discuta com seus colegas)

II - Quais outros fatores você diria que influenciam na quantidade de imagens observadas?

Alguns professores participantes discutiram o que perceberam com relação a variação da quantidade de imagens observadas de caixinhas dependendo da posição dos espelhos, como o professor L: se deixados ambos perpendiculares à base, infinitas imagens; se deixados com um ângulo "inclinado para fora", ou seja, o ângulo entre o espelho e a base, que está do lado das caixinhas, seria obtuso, as imagens aparecem inclinadas; se esse mesmo ângulo é "inclinado para dentro" só aparecem duas imagens. Nós questionamos, mais precisamente, o que ocorreria com as imagens de acordo com essas três posições dos espelhos e ele respondeu baseado também nessa colocação. 
Em geral, os professores participantes perceberam e descreveram de que forma as cores se alternavam. Alguns professores trabalharam com a posição dos espelhos como mostra a figura abaixo (um apoiado sobre o lado maior e o outro espelho apoiado sobre o lado menor).

Figura 36 - Reflexões sucessivas de caixinhas coloridas

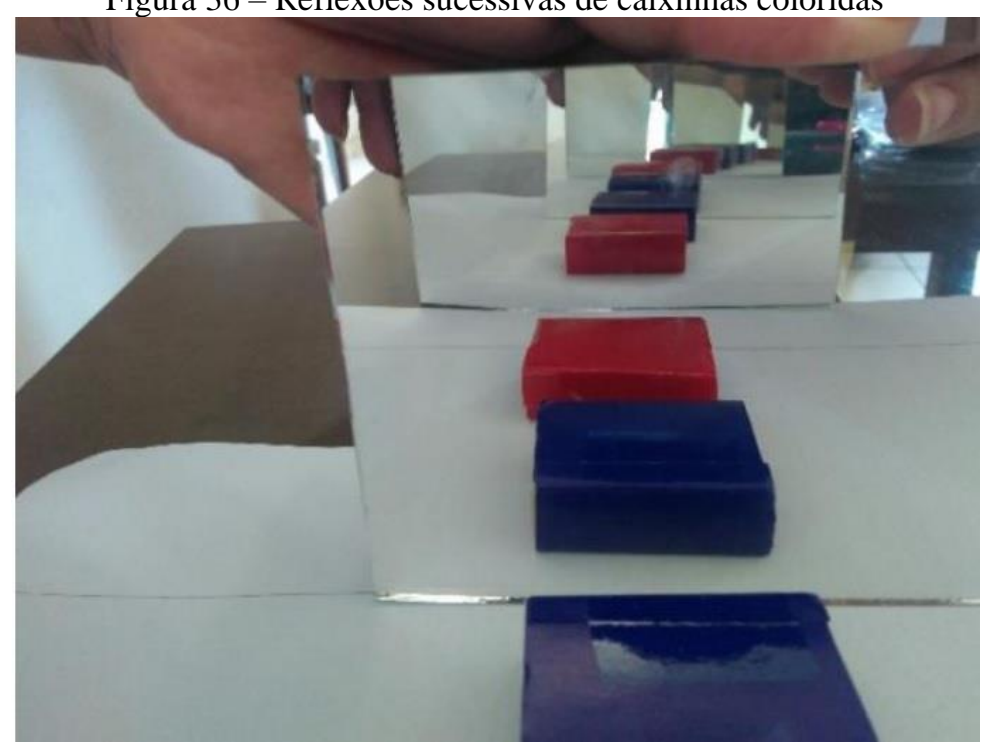

Fonte: Autor

$\mathrm{O}$ professor $\mathrm{R}$ disse que "quanto maior a distância das linhas menor o número de imagens", ou seja, quando os espelhos estão mais longe um do outro, menos imagens das caixinhas aparecerão.

A professora $\mathbf{J}$ afirmou que essa atividade pode ser boa para introduzir o uso de materiais como a régua e espelhos, que devem ser adaptados para a sala de aula; a professora $\mathrm{A}_{2}$ sugeriu que essa atividade fosse aplicada a turmas de $7^{\circ}$ ano.

A professora $\mathrm{M}_{2}$ notou que cada reflexão cria um novo eixo de simetria.

\section{Atividade 2}

Desenhe dois segmentos de reta a fim de formar um ângulo agudo arbitrário, meça-o com o transferidor e sobre eles disponha os espelhos.

a) Entre os espelhos, coloque a bolinha de modo que seja equidistante dos dois segmentos e registre o que observou quanto ao número de imagens obtidas. 
b) Em outra parte da folha, obtenha outros ângulos, fazendo novos pares de segmentos de reta com uma extremidade em comum. Registre o que foi percebido quanto ao número de imagens com cada ângulo usado e medido.

c) Usando a Folha 1, disponha os espelhos sobre o ângulo verde e, novamente, entre os espelhos, coloque a bolinha na sua bissetriz. Movimente, simultaneamente, ambos os espelhos (de forma a usar sempre a mesma bissetriz) sobre os outros ângulos e descreva o que ocorre com esses movimentos. Registre, ao menos, 2 polígonos regulares formados com as reflexões sucessivas e justifique porque são regulares. Justifique suas afirmações.

Em seguida, colocamos duas questões para reconhecer como os professores participantes argumentam a respeito das propriedades das reflexões em retas.

I - Todas as imagens produzidas nos espelhos são congruentes?

II - Reconhecendo as propriedades das reflexões em retas, você diria que as imagens da bolinha, nos itens a, b e c, estão todas à mesma distância umas das outras?

Utilizando a folha 1, após a realização da atividade 2, os professores participantes receberam a tabela com os ângulos para preencherem com suas respostas ao item b e c.

Grande parte dos professores errou a tabela, colocando S para o polígono que não era regular e $\mathrm{N}$ erroneamente. A professora $\mathrm{C}_{2}$ acertou apenas um entre dez polígonos. Isso é um indício de que, primeiramente, nossa exposição do problema (oral, escrita e via materiais) foi ineficiente ou insuficiente e, além disso, pode significar que os professores participantes não tenham muita familiaridade com ângulos centrais de polígonos regulares e com reflexão em reta.

Acreditamos que esse tipo de erro, também pode ter ocorrido pelo seguinte fato: alguns professores disseram que mediam e encontravam, por exemplo, o valor de $70^{\circ}$ e, depois, encontravam $72^{\circ}$; nesse caso pedimos para considerarem que o polígono é regular (pentágono) e que estávamos fazendo uma aproximação; entretanto, na tabela, eles preencheram sem aproximar para o valor que produz o polígono regular, mas afirmaram que era regular; dizendo, por exemplo, que $70^{\circ}$ forma um polígono regular. 
Ainda nesse encontro, reforçamos que eles deveriam pensar, a todo momento, em como desenvolver as atividades do curso em suas próprias salas de aula, pois o trabalho final demandava a elaboração e experimentação de uma sequência didática. Dessa forma, a professora $\mathrm{J}$ destacou os conceitos que acredita ser mais importantes nessas atividades, para trabalhar com seus alunos, são medidas de ângulos e bissetriz.

Já nessa atividade, apareceu a seguinte discussão: quando o ângulo entre os espelhos não era um ângulo cujo valor era próximo ou igual ao de um ângulo central de polígono regular, então aparecia uma falha no fundo das imagens que, geralmente era apenas as duas imagens no fundo mais distantes do que as demais, mas ocorria de aparecer apenas um pedaço da bolinha, quando observada de determinada posição. Em especial, quando se utiliza um ângulo de 70 graus não fica evidente se é formado um polígono de 5 lados com quatro ângulos centrais de 70 graus e um de 80 graus, ou se são 6 lados com cinco ângulos centrais de 70 graus e um de 10 graus (a professora $\mathrm{M}_{2}$ afirmou essa segunda conjectura).

A professora $\mathrm{M}_{2}$ escreveu uma conclusão de como prever a regularidade:

. Se L.a $=360^{\circ}$, o polígono é regular

. Se L.a > $360^{\circ}$, o polígono não é regular

Onde a é o ângulo entre os dois espelhos e L é o número de lados do polígono. Essa conjectura seria, de fato, uma propriedade importante para todas investigações Matemáticas das atividades seguintes.

Em seguida, iniciamos a atividade 3.1, com o seguinte enunciado:

\section{Atividade 3.1}

Obtenha um ângulo agudo arbitrário com dois segmentos de reta com mesma extremidade, meça esse ângulo com o auxílio do transferidor e coloque, de forma transversal (interceptando os segmentos), um pedaço de fita adesiva de modo que a bissetriz do ângulo coincida com a mediatriz da fita. 
a) Sobre os segmentos (representando os lados do ângulo) disponha os espelhos. Registre que polígono foi formado com as reflexões da fita e se é regular ou não, sempre justificando.

b) Com outros ângulos diferentes, traçados em partes diferentes da folha, repita o procedimento buscando formar polígonos regulares tais como um triângulo equilátero, um pentágono regular, um quadrado ou um hexágono regular. Registre como conseguiu obter esses polígonos. Por que são regulares?

c) Monte uma tabela com o nome de cada polígono obtido e a medida do ângulo inicial utilizado (entre os espelhos) e escreva considerações sobre o que acontece quando o ângulo é "grande" e quando ele é "pequeno", com relação ao número de lados do polígono formado. Por fim, tente obter outros tipos de polígonos regulares e diga que ângulos entre os espelhos permitem formar esses polígonos.

I - Qual a diferença dos polígonos formados com a fita nessa posição para os polígonos formados com a fita em outras posições? Em especial, o que ocorre se a fita estiver disposta perpendicularmente a um dos espelhos?

II - O comprimento das imagens da fita são todos iguais? Esse fato depende da posição da fita com relação ao ângulo entre os espelhos.

Nesse dia nem todos os professores participantes conseguiram finalizar essa atividade, a professora $\mathrm{A}_{2}$, por exemplo, entregou suas folhas com as tarefas da atividade 3.1., com respostas bem resumidas dos itens dessa atividade e ela não respondeu as questões I e II;

Foi definido para o grupo, a partir da resposta ao item a, do professor $\mathrm{R}$, que um polígono é regular se tem todos os lados congruentes entre si e todos os ângulos internos congruentes entre si. Em comparação a atividade 2, nessa atividade, houve maiores acertos ao se relacionar medida de ângulos entre os espelhos e regularidade de polígonos;

Fizemos questionamentos a respeito do que ocorre quando a fita é perpendicular a um dos lados, ressaltando que a intersecção da fita com o lado do ângulo não seria mais um vértice de polígono, então alguns perceberam que se tornara um ponto médio de um lado, mas não justificaram por escrito. 
Com relação a questão I, alguns professores disseram que o polígono formado tem mais lados quando a mediatriz da fita coincide com a bissetriz do ângulo do que quando a fita é colocada perpendicularmente a um dos lados do ângulo. Esperávamos que especificassem, que poderia formar o dobro de lados, ou que discutissem alguma relação entre essas duas quantidades, mas isso foi feito superficialmente devido a quantidade de tarefas desenvolvidas nesse encontro.

Com o item II, esperávamos que verificassem que o polígono só é regular quando o ângulo traçado é ângulo central de polígono regular. Uma professora mostrou como obter esse valor de ângulo e apresentou suas ideias para o grupo.

O professor R fez uma comparação entre formação de polígonos com a bolinha e com a fita, concluindo que a bolinha representava um vértice dos polígonos e a fita um lado, o que fez com que refletisse sobre as especificidades da atividade 3.1. Esse professor descreveu o que acontece com o ângulo entre a fita e o espelho: se for um ângulo reto, sua imagem será outro reto, compondo um raso e, portanto, formando um segmento.

A professora $\mathrm{J}$ fez uma discussão sobre o que ocorre com a fita na posição como da figura abaixo (aparentemente sobre a bissetriz do ângulo). Ela também discutiu que, quando a fita está perpendicular ao lado do ângulo que, nesse caso, mede $53^{\circ}$, o polígono tem uma "parte côncava" e uma "parte convexa".

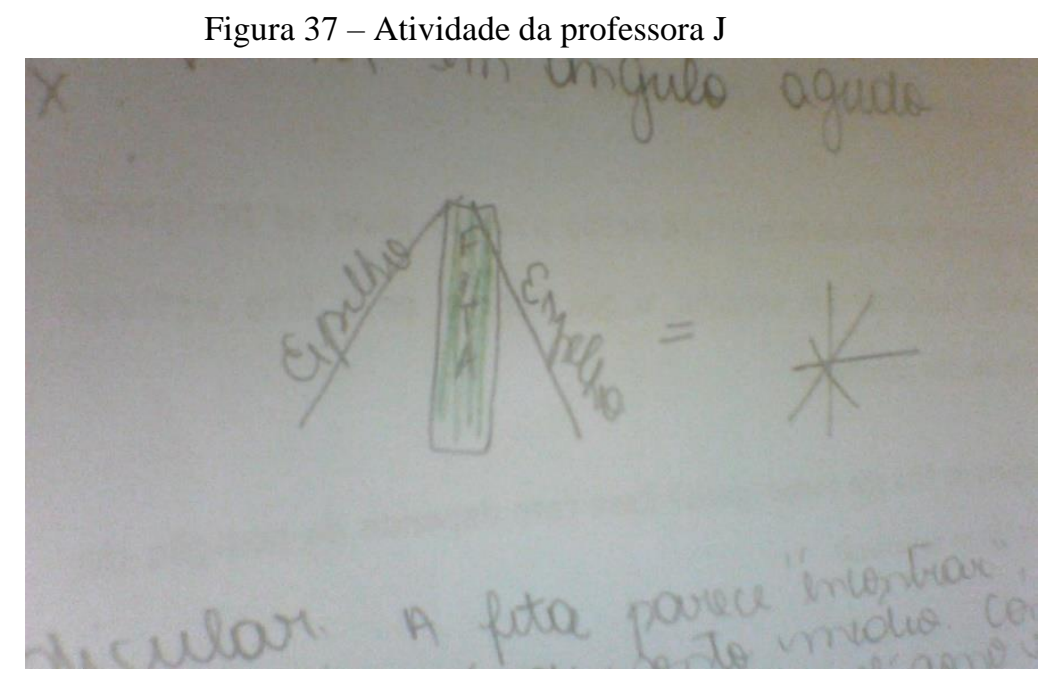

Fonte: Autor

Essa construção possibilitaria outros desdobramentos como, por exemplo, eixos de simetria para o caso de ser formado um polígono regular, as bissetrizes dos ângulos de um polígono formado com essa construção ou ainda as mediatrizes dos lados. Decidimos não explorar esse tipo de discussão e focamos na construção de polígonos. 


\subsection{Análise do terceiro encontro}

No início desse encontro, exploramos uma síntese do que foi desenvolvido nas atividades 1 e 2, fazendo ilustrações na lousa e levantando as respostas dadas pelos professores participantes oralmente e por escrito.

\section{Síntese da Atividade 1}

Mostramos, na lousa, uma representação da situação das caixinhas entre os dois espelhos para ilustrar o que ocorre com as imagens.

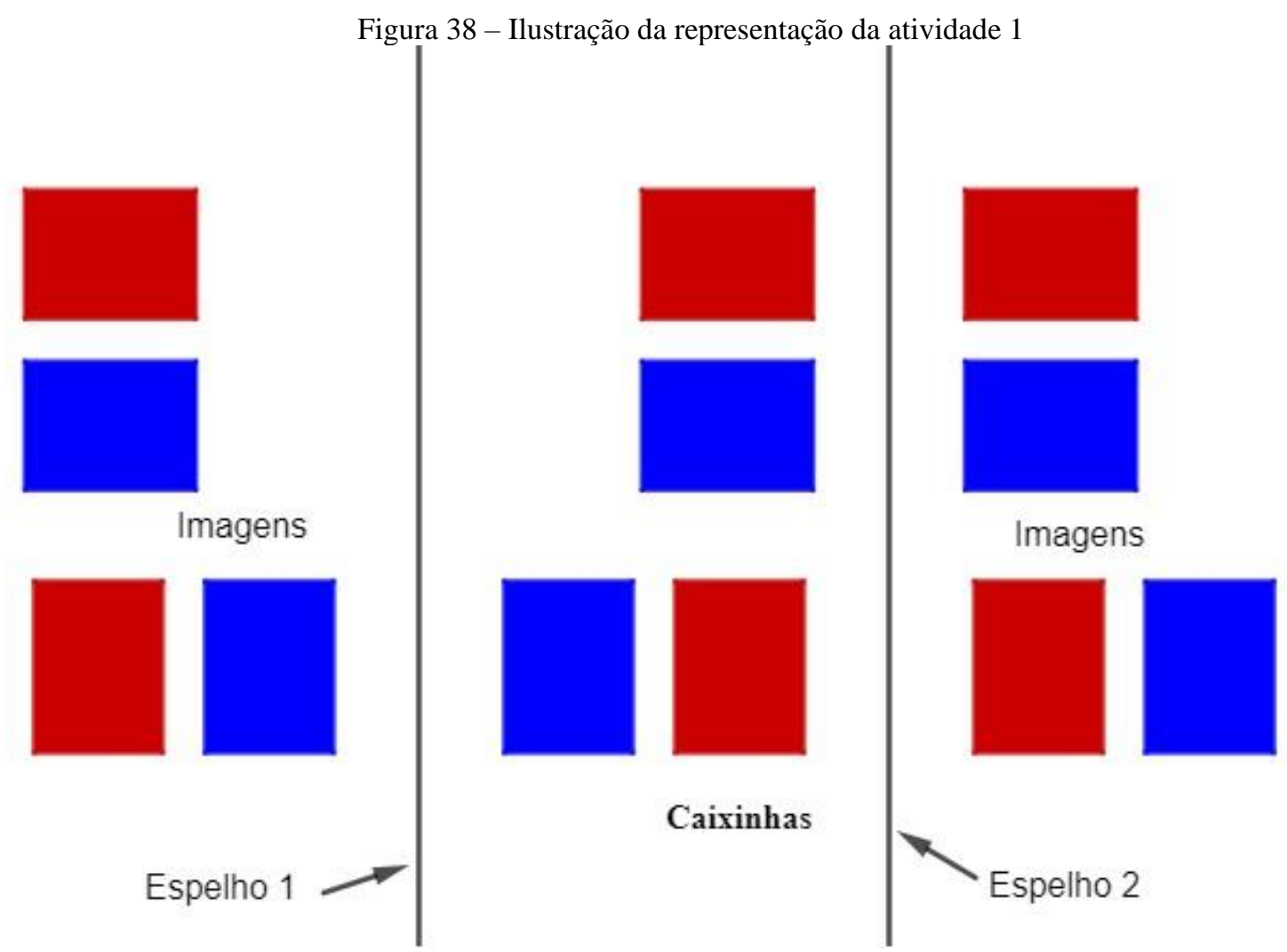

Fonte: Autor

Discutimos que as imagens das caixinhas teriam cores alternadas se fossem dispostas como na figura 38, na posição inferior. Questionamos a razão de acontecer tal alternância e, em seguida, desenhamos as caixinhas em outra disposição, como na figura 38 , na posição superior para que vissem um caso em que as cores se alternam e um caso em que as cores não se alternam. 
Concluímos que, o que faz esse efeito de cores é que as caixinhas estão lado a lado e a diferentes distâncias dos espelhos e, mais especificamente, os professores participantes afirmaram que a caixinha vermelha está mais próxima do espelho 2 e a caixinha azul está mais distante e, por isso, a imagem vermelha aparece antes da azul. Os professores tiveram certa dificuldade em justificar esse efeito e poucos escreveram, posteriormente, essa conclusão em seus diários de bordo.

Falamos brevemente sobre a composição de reflexões em retas paralelas e deixamos como uma provocação. A professora $\mathrm{M}_{3}$ afirmou que seria uma translação, então pedimos que ela pensasse por qual vetor e justificasse.

\section{Atividade 2}

Primeiramente discutimos os erros nos preenchimentos das tabelas, que foi muito comum dentre os professores e fizemos uma discussão sobre a imprecisão da medida do transferidor.

Reafirmamos que a contagem das imagens da bolinha de gude (sugeriram a substituição por uma calota de bolinha com alguma cor mais forte, facilitando tanto a visualização como a manipulação, já que a bolinha de gude pode escorregar) deveria ser feita apenas com as imagens enxergadas. Então, tivemos que discutir a respeito do que acontece quando o ângulo entre os dois espelhos não é um ângulo central de polígono regular: existem situações em que vemos as duas últimas imagens, no fundo dos espelhos, mais distantes entre si do que cada outro par de imagens (ou bolinha) consecutivas e existem situações em que vemos as duas últimas imagens mais próximas entre si.

Fizemos determinada provocação para o ângulo de $70^{\circ}$, colocamos algumas sugestões e posteriormente elaboramos uma argumentação para explicar o que acontece e levamos no encontro seguinte. Nossa provocação foi: o que acontece com as imagens da bolinha com o ângulo entre os espelhos de $70^{\circ}$ ? São formadas quatro imagens, com as duas últimas mais distantes ou são formadas cinco imagens com as duas últimas mais próximas?

\section{Observações}

Em um polígono regular, o ângulo central é o ângulo formado entre as semirretas que ligam o centro do polígono com dois vértices consecutivos. Nesta atividade, estamos analisando 
o ângulo entre as duas semirretas que ligam o centro a dois pontos médios consecutivos e, no caso do polígono regular, pode-se verificar que esse ângulo é congruente ao ângulo central.

Um polígono irregular, com mais de três lados, não tem centro geométrico (não existe uma circunferência que seja tangente a todos os lados), portanto o ponto de origem do ângulo entre os espelhos não é um centro do polígono. Em relação ao polígono irregular formado nesta atividade, cujos vértices são a bolinha e suas imagens, o ponto de origem do ângulo entre os dois espelhos é apenas a intersecção de duas retas perpendiculares a dois pontos médios consecutivos.

Em seguida, falamos brevemente sobre a composição de reflexões em retas concorrentes e deixamos como mais uma provocação para a turma. Novamente a professora $\mathrm{M}_{3}$ afirmou que seria uma rotação, então pedimos que ela pensasse no centro da rotação e no ângulo.

Fizemos ainda, sugestões de como fazer os diários de bordo: justificar as afirmações Matemáticas; falar sobre a aplicabilidade das atividades nos diários, explicando se fariam adaptações, modificações, atividades prévias etc.; especificar melhor o que cada um aprendeu, compreendendo que o diário é um material individual e subjetivo. No final desse encontro, apresentamos um questionário para que os professores pudessem dar um feedback geral a respeito do curso (cf. Apêndice 3)

\section{4. $O$ caso das estrelas poligonais}

As atividades aqui apresentadas foram desenvolvidas nos terceiro e quarto encontros. No terceiro encontro, o foco foi dado à Atividade 3.2 e no quarto à Atividade 3.3, cada um caracterizando uma forma diferente de se conceber figuras a partir de manipulações de dois espelhos concorrentes e de outros materiais. Nesses dois encontros presenciais, as atividades eram realizadas pelos participantes que apresentavam suas resoluções após discussões em duplas e/ou coletivas.

O desenvolvimento das atividades 1,2 e 3.1 permitiu que o grupo descobriu como os ângulos utilizados entre os espelhos e entre os objetos (bolinha de gude, fita adesiva ou traçados) poderiam determinar imagens de polígonos convexos ou polígonos côncavos. Mas durante esse processo foi produzido o seguinte questionamento por parte dos professores participantes: "e se a mediatriz da fita não coincidir com a bissetriz do ângulo?”. Além disso, durante a realização das atividades propostas anteriormente, ocorria que, ao manipular os espelhos, foi observado um tipo especial de polígono côncavo que se mostrou muito presente como resultado dessa investigação que intitulamos de estrelas poligonais. 
Antes definir esse tipo de polígono, ressaltamos que há um termo semelhante a esse nos estudos de Geometria Plana, conhecido como polígono estrelado. Tal termo assume mais de uma definição diferente, dependendo do material didático e autor que o apresenta, mas em geral se referem a objetos como o representado na figura 39 abaixo, enquanto a estrela poligonal está representada na figura 40 .

Figura 39 - Polígono estrelado

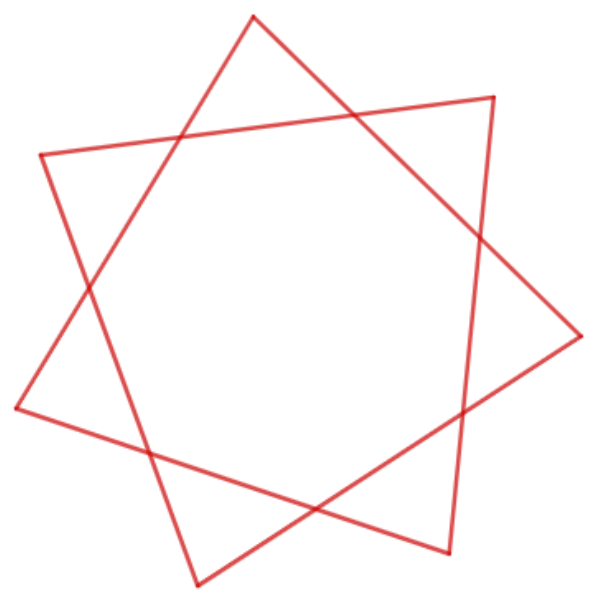

Fonte: Autor
Figura 40- Estrela poligonal

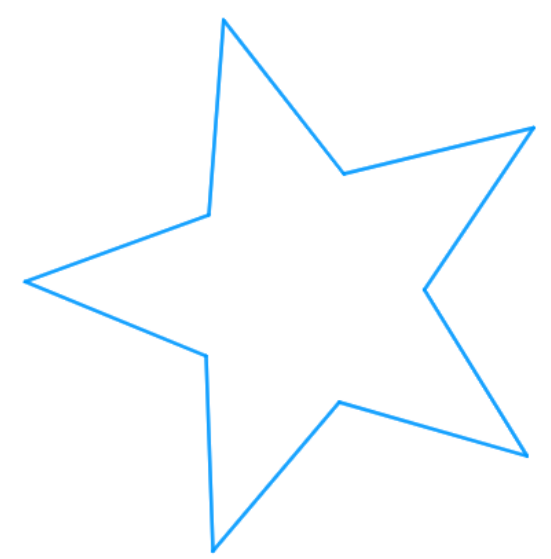

Uma forma de distinguir objetivamente a natureza desses dois objetos da Geometria Plana é que o polígono estrelado, como podemos notar, é determinada por uma linha poligonal não-simples (possui cruzamento de lados) enquanto a estrela poligonal é uma linha poligonal simples.

Para que o grupo definisse o que é uma estrela poligonal foi necessário que analisassem as propriedades necessárias e suficientes para caracterizá-las. Com questionamentos como "o que podemos dizer com relação aos ângulos internos" e "que tipo de polígono é?”, a discussão caminhou para a seguinte definição: estrela poligonal é um polígono côncavo com ângulos internos alternadamente agudos e maiores do que $180^{\circ}$. As imagens que foram formadas em meio a esse estudo eram, em geral, de estrelas poligonais com todos os ângulos alternadamente congruentes e todos os lados congruentes, que chamamos de estrelas poligonais regulares.

$\mathrm{Na}$ Figura 41, podemos observar uma estrela poligonal produzida por uma professora participante, na qual podemos ver um polígono côncavo com ângulos internos de, aproximadamente, $60^{\circ}$ e $255^{\circ}$. Mais adiante, discutiremos como foi o processo investigativo dos professores participantes. 
Figura 41 - Estrela poligonal produzida pela professora A

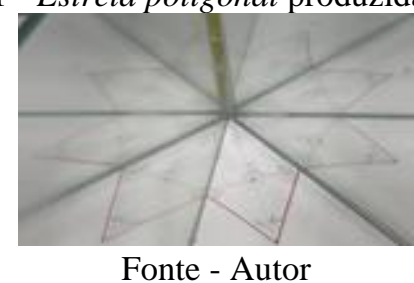

Apresentaremos a seguir, as atividades 3.2. e 3.3., cujo objeto de estudo foram as estrelas poligonais e podem ser identificadas por serem compostas por tarefas exploratórias (PONTE, 2003) e tal exploração guiou os professores participantes em direção sentido-a refletirem e concluírem a respeito de como produzir uma estrela poligonal regular e a desenvolvemos com os seguintes objetivos:

a) propor a exploração de padrões nas características das estrelas poligonais;

b) instigar a descoberta de como produzir uma estrela poligonal regular (equilátera e com ângulos alternadamente congruentes);

c) desenvolver o uso de argumentação Matemática por meio de definições e propriedades;

d) promover o uso de argumentação Matemática a partir de uma análise de separação em casos e subcasos;

e) desenvolver o pensamento geométrico axiomático e a articulação entre os níveis G1 e G2 por meio da elaboração de justificativas conduzidas pela evidência figural;

f) fazer com que os professores participantes se habituassem com os efeitos, tanto da angulação entre pares de espelhos como das construções geométricas, que produz uma imagem por meio das reflexões (efeitos que se tornam ainda mais presentes ao utilizar um caleidoscópio).

Na Figura 42 reproduzimos parte da Atividade 3.2, que foi realizada durante o terceiro encontro, na qual estrelas poligonais são obtidas a partir da reprodução de imagens de um de seus lados, que é representado pela fita. Nessa atividade, o ângulo entre os dois espelhos determinaria a quantidade de lados obtidos, o que representa o dobro da quantidade de pontas. Dentre os conceitos abordados nos itens dessa atividade, temos o estudo de simetrias das figuras, convexidade, ângulos internos e centrais de polígonos regulares. 
Figura 42 - Atividade 3.2.

Obtenha um ângulo agudo arbitrário com dois segmentos de reta com mesma extremidade, meca esse ângulo com o auxilio do transferidor e coloque, de forma transversal (interceptando os segmentos de forma obliqua), um pedaço de fita adesiva de modo que a bissetriz do âng ulo não coincida com a mediatriz da fita.

a) Sobre os segmentos (representando os lados do angulo), disponha os espelhos, registre que poligono foi formado com as reflex ões da fita e se é regular ou não.

I-Ele pode ser convexo? E côncavo? Justifique.

b) Com outros angulos diferentes, traçados em partes diferentes da folha, repita o procedimen to bus cando formar diferentes estrelas poligonais. [...]

III- Pode-se formar estrelas com número par de pontas e tambèm estrelas com número impar de pontas? Em caso afirmativo, explique como; se não, justifique o porquê.

IV - Quais propriedades a posição da fita tem, com relação aos lados do ângulo, para que seja formada uma estrela e não um poligono convexo?

V - Quais propriedades devem ter o ângulo entre os espethos e a posição da fita, com relação aos lados do ângulo, para que seja formada uma estrela com lados congruentes?

Fonte: Autor

Para cada item era feita a leitura coletiva do enunciado antes de iniciarem a investigação. Após a leitura do item I perguntamos aos participantes o que era a convexidade e escrevemos na lousa uma definição de polígono convexo e polígono côncavo dado por eles: o convexo tem todos os ângulos internos menores do que $180^{\circ}$ enquanto um côncavo "tem ao menos um vértice para dentro", ou seja, ao menos um dos ângulos internos é maior do que $180^{\circ}$. Para o grupo, foi uma tarefa complexa, pois primeiro tiveram que fazer as construções geométricas solicitadas, analisá-las e só então pensar em como responder aos itens sobre convexidade dos polígonos e quantidade de pontas de estrelas poligonais.

Durante o momento em que monitoramos a investigação dos professores participantes, trouxemos provocações sobre que tipo de imagens os dois ângulos entre a fita e os espelhos poderiam produzir. Dois professores apresentaram voluntariamente suas ideias e chegaram, juntamente com nossas intervenções, à seguinte ideia: se esses ângulos são agudos, seu dobro é menor do que $180^{\circ}$ e, portanto, é formado um ângulo interno de um polígono convexo, mas se esses ângulos são obtusos, seu dobro é maior do que $180^{\circ}$ e, portanto, é formado um ângulo interno de um polígono côncavo. Então os alunos deveriam usar essa informação para tentar produzir estrelas poligonais (a definição precisa de estrelas poligonais só foi mostrada no encontro 4).

Indagamos o grupo com relação ao número de pontas e regularidade do polígono obtido e cada professor participante expressou essa ideia de uma forma diferente, mas em geral, sem 
muita segurança. Ficou evidente que para formar uma estrela poligonal regular de $\mathrm{n}$ pontas seria necessário usar um ângulo congruente a um ângulo central de um polígono regular de 2n lados, com n natural maior do que 2.

Os professores participantes expressaram bem como construir um polígono côncavo e convexo a partir da reflexão de dois espelhos concorrentes, mas não justificaram totalmente e falaram pouco sobre ângulos internos. Quando questionamos sobre "como são os ângulos?", "são agudos, retos ou obtusos?", logo conseguiram destacar que o polígono côncavo é produzido ao se formar um ângulo obtuso entre a fita e um espelho com a fita formando um ângulo obtuso com um dos espelhos - sendo $\mathrm{O}$ a origem do ângulo entre os espelhos e $\mathrm{A}$ e $\mathrm{B}$ as intersecções da fita com os lados desse ângulo, então o ângulo OAB ou OBA deve ser obtusoe que para ser convexo deveriam ter dois ângulos agudos e uma professora disse que poderia ser um agudo e outro reto.

Dessa forma, sistematizamos as ideias exploradas nesse encontro a partir de indagações e das ideias levantadas pelo grupo e, por fim, solicitamos que realizassem em casa os itens VI e VII da atividade 3.2 e que trouxessem no encontro seguinte para a discussão em grupo a respeito dos eixos de simetria (cf. Figura 43).

Figura 43 - Itens VI e VII para casa

VI - Quais das estrelas formadas no item anterior possuem eixos de simetria?

VII - Quais relações existem desse fato com o ângulo entre os dois espelhos? Explique.

Fonte: Autor

\section{Análise do quarto encontro}

Primeiramente pedimos que algum professor participante falasse de alguma estrela que observou a quantidade de eixos de simetria. O professor L falou da estrela de 4 pontas (chamamos de "ponta" o vértice que compõe o ângulo interno agudo) e quis mostrar o que havia pensado em casa (cf. figura a seguir). $\mathrm{O}$ auxiliamos a representar uma estrela de 4 pontas regular na lousa, que contava com uma malha quadriculada para suporte e então discutimos os eixos de simetria dessa estrela, em especial. O professor L traçou, inicialmente, dois dos os quatro eixos (ilustrado pela figura 45) e, ao questionarmos se havia mais, ele percebeu que havia mais dois. 
Observando essa representação e a turma fez a conjectura que as estrelas poligonais regulares de $\mathrm{n}$ lados possuem $\mathrm{n}$ eixos de simetria.

Figura 44 - Representação dos eixos de simetria pelo professor L

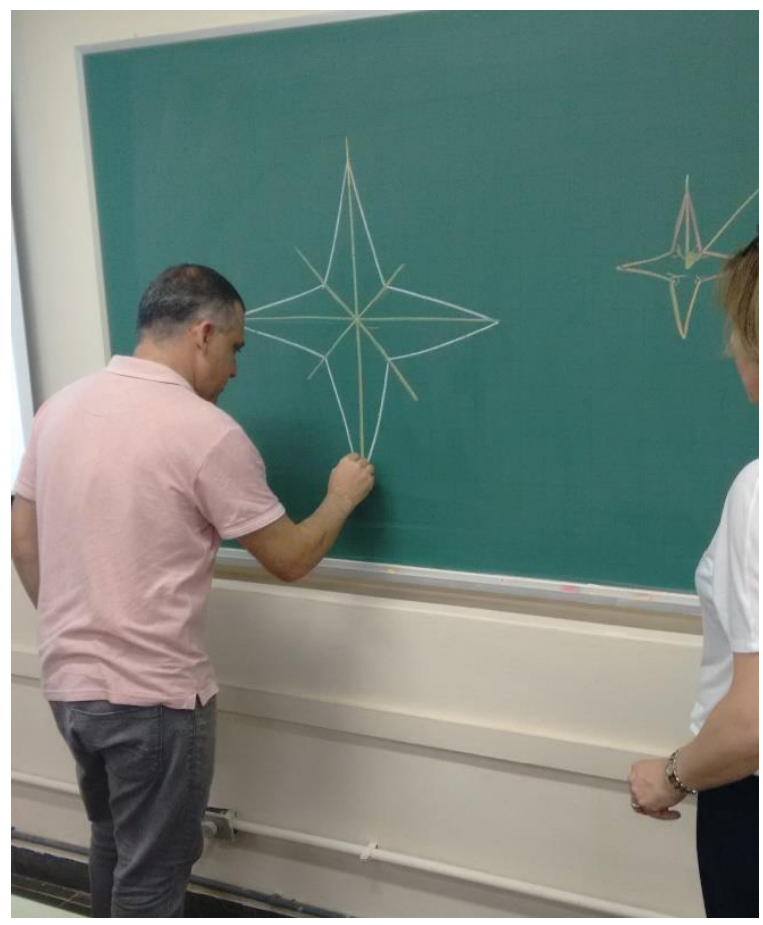

Fonte: Autor

Figura 45 - Eixos de simetria de uma estrela poligonal regular de quatro pontas

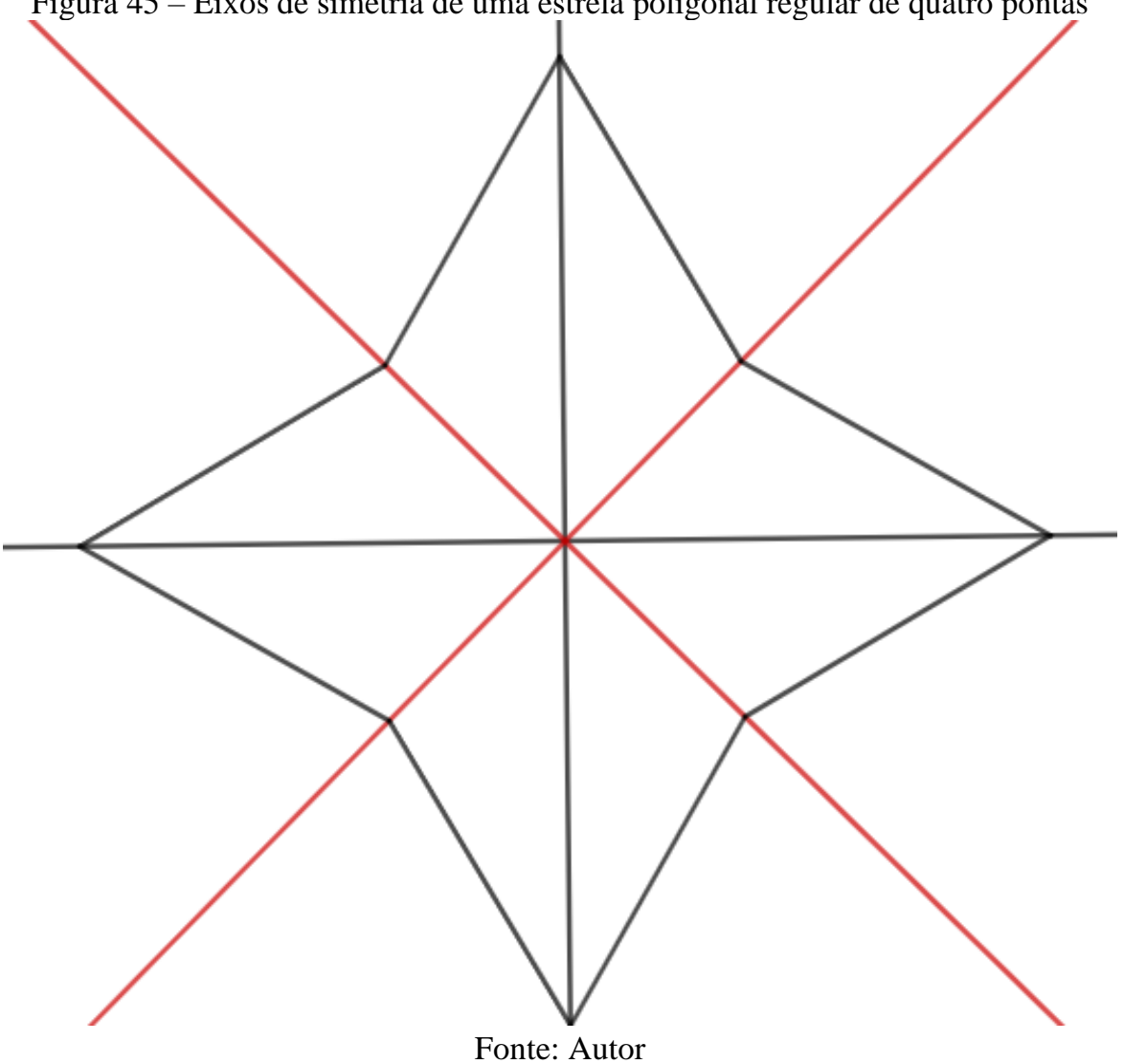

Fonte: Autor 
Falamos brevemente sobre as estrelas irregulares formadas fazendo uma "aproximação" sobre a figura formada com um ângulo entre os dois espelhos que não seja congruente a nenhum ângulo central de polígono regular. Consideramos que os ângulos seriam alternadamente congruentes e os lados seriam todos congruentes, com exceção a ponta formada atrás dos espelhos e seus dois lados. Seguimos a sugestão da professora $\mathrm{M}_{3}$ para fazermos essa consideração. A figura formada parecia admitir sempre um único eixo de simetria, que passa pela ponta menor, atrás dos espelhos, no entanto, a professora $\mathrm{M}_{2}$ fez questionamentos que nos fizeram refletir a respeito de como essa ponta menor se formava e, ao analisarmos fora do encontro, percebemos que se trataria de uma falha e que sequer formaria um polígono.

Em seguida, buscando certo nível crescente de complexidade, a professora $\mathrm{M}_{3}$ desenhou na lousa a estrela poligonal regular de cinco pontas. Dessa vez a turma verificou a conjectura e a justificou separando em dois casos que podem ser sintetizados da seguinte forma:

1 - Quando existe um número par de pontas os eixos de simetria passarão por duas pontas ou por dois vértices que não são pontas, cada eixo formado assim divide a estrela em duas figuras que são simétricas em relação ao eixo, devido as medidas dos lados e dos ângulos entre os lados serem as mesmas;

2 - Quando existe um número ímpar de pontas os eixos de simetria passam por uma ponta e por um vértice que não é ponta, a justificativa é de mesma natureza e foi realizada oralmente (comparando os ângulos e lados que eram congruentes).

A partir dessa investigação foi concluído uma estrela poligonal de n pontas, formada pelas imagens entre os dois espelhos planos, cuja construção tem uma das pontas entre os dois espelhos, terá n eixos de simetria se o ângulo entre os dois espelhos for congruente ao ângulo central de algum polígono regular, caso contrário não poderíamos afirmar o número de eixos de simetria (a discussão sobre esse caso será feita mais à frente e não foi apresentada em detalhes aos professores participantes). Além disso, se a estrela poligonal de $\mathrm{n}$ pontas for formada com apenas um lado no interior dos espelhos, então o ângulo entre os dois espelhos deve medir a metade de um ângulo central de polígono regular, para que haja $\mathrm{n}$ eixos de simetria. Após a apresentação dessa conclusão, unindo as ideias apresentadas pelo grupo, cada um escreveu individualmente suas respostas ou complementou o que já havia escrito anteriormente.

Apresentaremos agora, com a Figura 46, a atividade 3.3., que foi realizada durante o quarto encontro. 
Figura 46 - Atividade 3.3. Parte I

\section{Atividade 3.3 (estrelas poligonais)}

Obtenha um ângulo agudo arbitrário com dois segmentos de reta com mesma extremidade, meça esse ângulo com o auxílio do transferidor. Faça os traçados dos itens a seguir, preferencialmente, com canetinha colorida.

a) Marque um ponto arbitrário no interior do ângulo $e$, em seguida, trace um segmento que liga o ponto a um lado do ângulo $e$ outro segmento que ligue o ponto ao outro lado. Disponha os dois espelhos sobre os dois segmentos e observe a imagem formada.

I - É uma estrela poligonal? Tente justificar sua resposta.

b) Trace um ângulo congruente ao anterior, em outra parte da folha, e nomeie seu vértice de $O$. Marque outro ponto arbitrário no interior do ângulo, nomeie-o de $A e$, em seguida, trace os segmentos $A B$ \& $A C$ (diferentes do item $a$ ), com $B$ pertencendo $a$ um lado do ângulo e $C$ ao outro lado. Com o auxílio de um transferidor meça os ângulos $A B O$ e $A C O$. Pinte o interior do quadrilátero $A B O C$ e disponha os dois espelhos sobre os dois segmentos e observe a imagem formada.

II - Agora compare com as construções de seus colegas e respondam: A medidas dos ângulos $A B O$ \& $A C O$ produzem que tipo de imagem? $O$ que ocorre quando esłes ângulos são agudos, retos ou obtusos? Se necessário, faça novos desenhos.

III - Que relação existe entre as medidas dos ângulos $A B O . A C O$ e $C A B$ e a convexidade do polígono obtido?

IV - Foram formadas estrelas poligonais? Justifique sua resposta. Fonte: Autor

Para a atividade 3.2, existe apenas um tipo de formação de estrelas poligonais, com a fita transversal com determinada angulação em relação aos espelhos e para a 3.3 foram formadas estrelas poligonais a partir da reprodução de imagens de dois lados consecutivos. Diversos casos diferentes foram apresentados e discutidos dentre alguns polígonos que são estrelas poligonais e alguns que não são. Dentre as propriedades das construções, podemos analisar, por exemplo, se o vértice formado pela intersecção desses dois lados pertence ou não a bissetriz do ângulo entre os espelhos (como mostra a figura 47 e a figura 48). 
Figura 47 - Construção com vértice na bissetriz

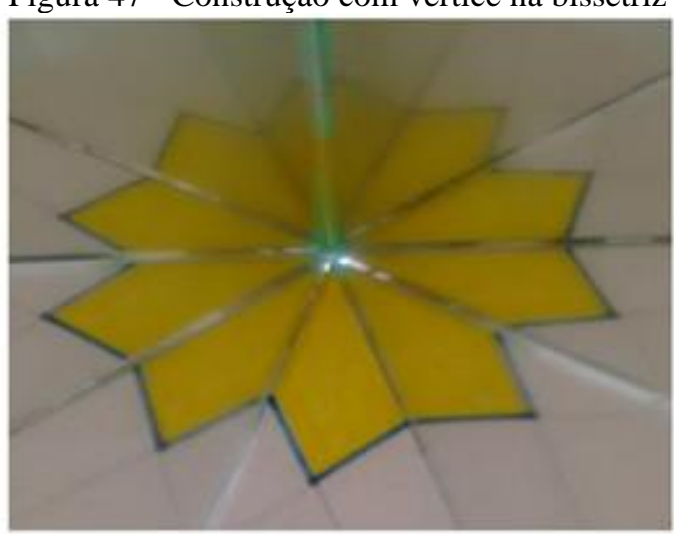

Fonte: Autor

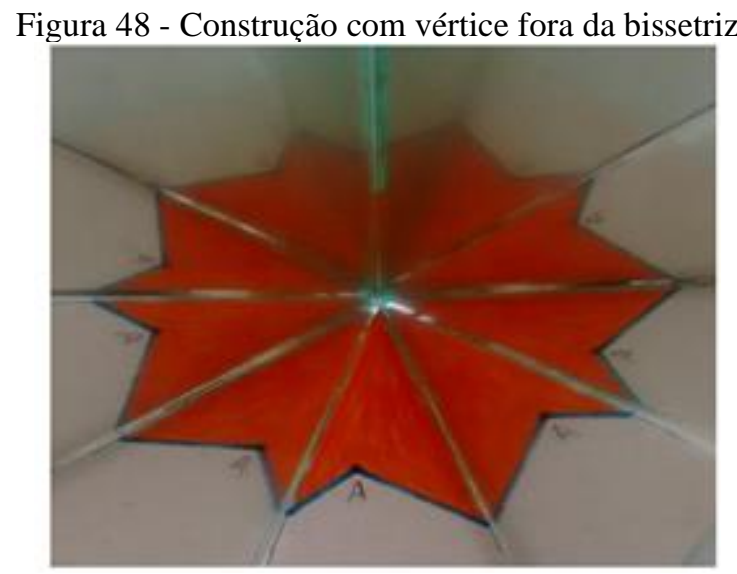

Fonte: Autor

$\mathrm{Na}$ figura abaixo, apresentamos a construção da professora $\mathrm{M}_{2}$, que fez a divisão em dois casos: quando é formado uma estrela poligonal regular (dividido em 3 subcasos diferentes) e quando é formado uma estrela poligonal que não é regular (dividido em 2 subcasos diferentes).

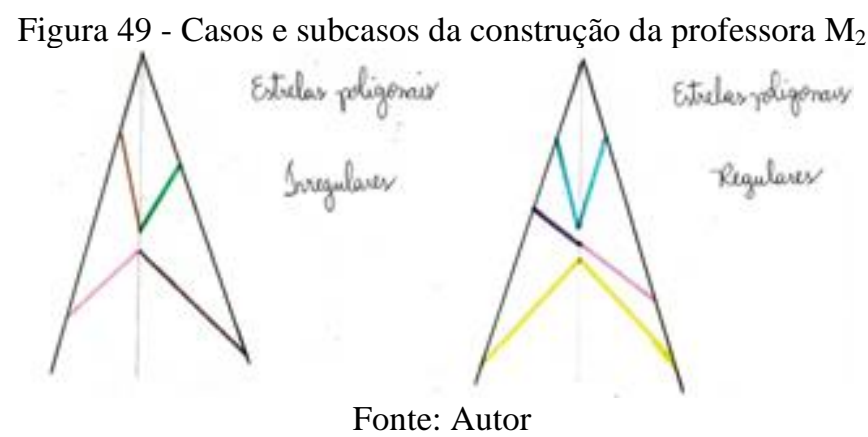

Nas construções realizadas nessa atividade, os professores participantes foram levados a utilizar seus conhecimentos para realizar uma representação figural (o desenho de um quadrilátero no interior dos espelhos), pensar em suas propriedades (vértice na bissetriz ou não 
e medidas dos ângulos) para então utilizarem a evidência material de uma Geometria nãoaxiomática para deduzirem propriedades de uma Geometria axiomática ao justificarem se o polígono formado é côncavo ou não e se foi formada uma estrela poligonal utilizando a definição que fora produzida anteriormente.

As justificativas dos professores participantes foram, em geral, satisfatórias, entretanto nem todos destacaram a medida de todos os ângulos do quadrilátero formado no interior do ângulo entre os dois espelhos, como ilustrado na representação do professor L, na figura 50, enquanto outros tiveram esse cuidado, assim como a professora $A_{1}$, cuja resposta $\mathrm{e}$ representação encontram-se na figura 51.

Figura 50 - Representação do Professor L Ângulo central de 38*

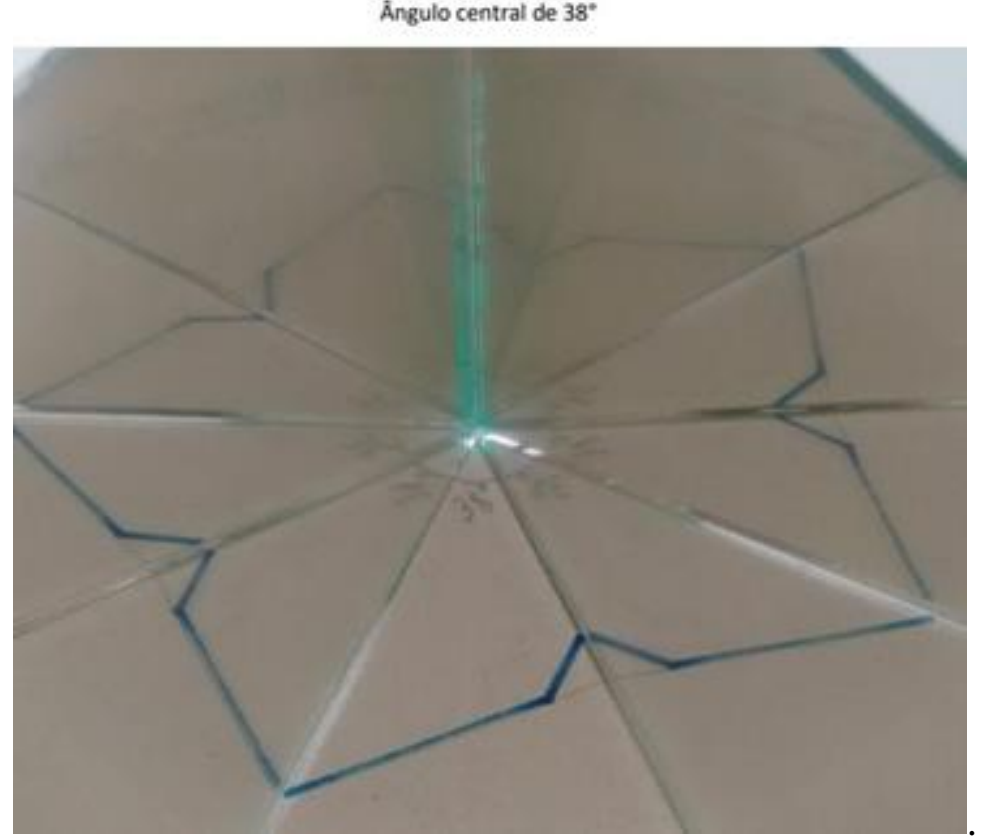

Fonte: Autor 
Figura 51 - Representação da Professora $A_{1}$

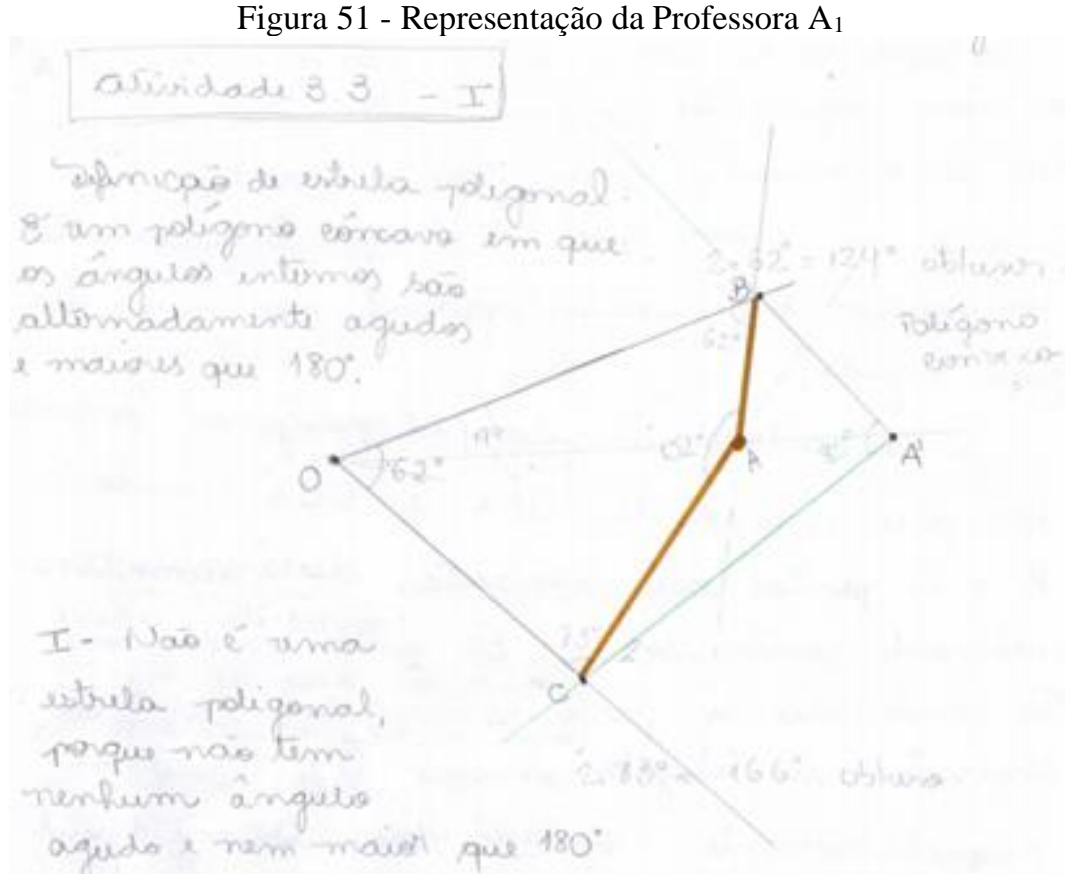

Fonte: Autor

Em sua resposta ao item I, utilizou a definição sistematizada para justificar o porquê de sua construção não produzir uma estrela poligonal. Nesse caso, a professora pôde justificar sem precisar verificar experimentalmente colocando o par de espelhos sobre os lados do ângulo, de tal forma que essa construção serve apenas como suporte para destacar as propriedades principais desse estudo: os ângulos formados por meio da reflexão. Em seguida, no desenvolvimento do item II, nosso objetivo era que os professores participantes descrevessem como os ângulos de uma estrela poligonal podem ser formados, analisando cada tipo de ângulo (agudo, reto e obtuso).

Em vista de que as questões dessa tarefa exploratória se deram acerca de como descobrir se foi obtida uma estrela poligonal, surgiram respostas separadas por itens e respostas unificadas. A professora G respondeu as questões II, III e IV em uma explicação única, enquanto a professora $A_{1}$ fez cada questão separadamente, mas ambas fizeram a separação em casos para cada tipo de ângulo e deram exemplos com figuras. Ou seja, novamente o uso das representações figurais serviu de suporte para ilustrar a argumentação própria do pensamento geométrico axiomático.

A figura abaixo foi feita pela professora G; a primeira construção mostra as duas formas de se obter estrelas poligonais da atividade 3.3, que são mostradas com espelhos nas duas representações seguintes, enquanto a última representação é um exemplo de uma construção que não produz uma estrela poligonal. 
Figura 52 - Estrelas poligonais da atividade 3.3
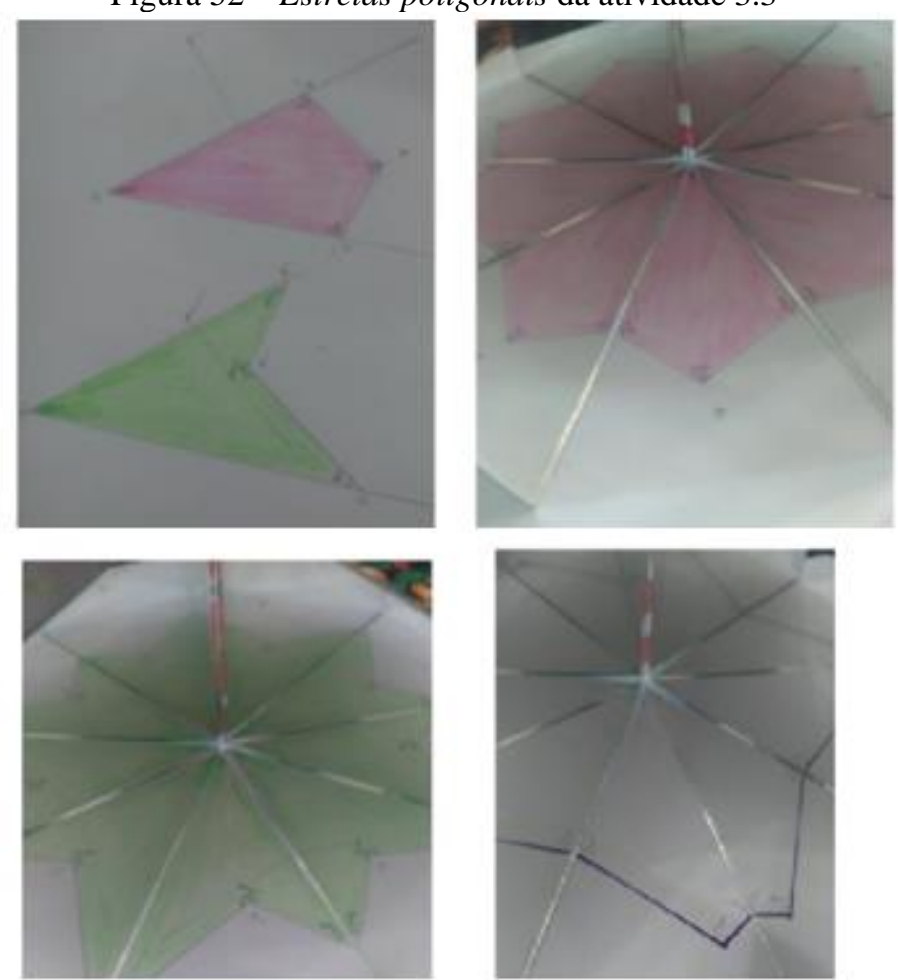

Fonte: Autor

Para além da justificativa dos resultados obtidos, os professores também foram levados a pensar, no item V (cf. Figura 53), sobre uma forma de abordar o conceito de estrela poligonal com seus alunos. Nosso propósito foi primeiramente de instigá-los a pensarem em como desenvolver esse tipo de tarefa em sua própria prática docente e também, de observar quais representações e qual linguagem seria utilizada para adaptar essa tarefa para se realizar uma investigação Matemática com alunos da Educação Básica acerca de estrela poligonal e bissetriz (item V e VI, respectivamente). 
Figura 53 - Atividade 3.3. Parte II

V - Como você explicaria a um aluno qual construção, no interior do ângulo, produzirá uma estrela poligonal? Como você justificaria a esse aluno essa construção?

c) Trace um ângulo congruente ao anterior, em outra parte da folha, $e$ trace sua bissetriz. Marque um ponto arbitrário na bissetriz e, em seguida, trace um segmento ligando o ponto a um lado do ângulo $e$ um segmento congruente ao anterior ligando o ponto ao outro lado. Pinte o interior do ângulo, como indicado no item anterior, $e$ disponha os dois espelhos sobre os dois segmentos e observe a imagem formada.

VI - Como você explicaria a um aluno a construção da bissetriz do ângulo? Como você justificaria a esse aluno essa construção?

VII - Foi formada uma estrela poligonal? Justifique sua resposta.

VIII - Quais propriedades você observa nas imagens formadas? Essas propriedades tem alguma relação com as propriedades da bissetriz do ângulo traçado?

d) Discuta com seus colegas $\varepsilon$, juntos, façam uma construção que produza, a partir das reflexões em dois espelhos, uma estrela poligonal regular (com todos os lados congruentes $e$ ângulos internos alternadamente congruentes)

IX - Que regularidade você consegue observar entre a quantidade de "pontas" e a quantidade de vértices em uma estrela poligonal? Explique?

Fonte: Autor

Os resultados do item $\mathrm{V}$ mostraram que eles apresentariam a tarefa utilizando a definição por meio de um passo a passo, a professora $\mathrm{M}_{3}$ disse que discutiria propriedades das pontas. As respostas do item VI mostraram duas formas de se trabalhar com alunos: por dobradura e por régua e compasso. A professora $\mathrm{G}$ fez sua justificativa, por régua e compasso, da bissetriz de um ângulo e apresentou a representação no Geogebra (cf. Figura 54). Por outro lado, notamos que a professora $\mathrm{A}_{1}$ escreveu em seu diário de bordo, referente ao encontro relativo a essa atividade, que teve dificuldades em acompanhar os encontros devido a suas faltas e que não lembrava como fazer essa justificativa. Acreditamos que isso decorre não apenas de ausências nos encontros do curso, mas também de uma formação inicial com pouco enfoque em Geometria Plana e construções com régua e compasso. 
Figura 54 - Representação da professora $\mathrm{G}$ de uma reta bissetriz
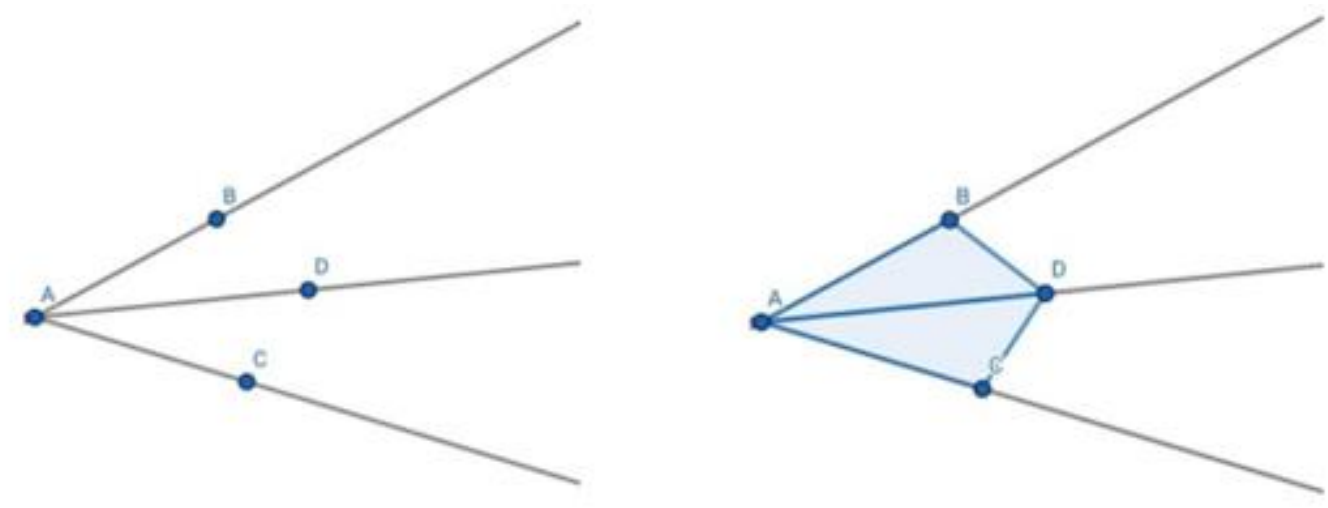

Fonte: Autor

Com o item VIII, gostaríamos que os professores participantes percebessem que é possível utilizar a bissetriz como suporte para a construção de estrelas poligonais regulares. Durante a investigação alguns professores apresentaram respostas curtas e justificativas rasa, mas durante a exposição de ideias a professora $\mathrm{A}_{1}$ afirmou: "os lados são congruentes, porque foram gerados por segmentos congruentes a partir do ponto tomado da bissetriz". Em seguida fizemos o questionamento: "mas os dois segmentos traçados precisavam ser congruentes?" e pedimos que outros expusessem suas construções, ajudando-nos a chegar à conclusão de que apenas com determinadas propriedades seria uma estrela poligonal regular.

O item d foi realizado em duas duplas e um trio e entregue durante o próprio encontro, sem que houvesse interferíssemos. Esse item nos serviu como parâmetro para que os professores apresentarem sua própria sistematização de conceitos. Os três grupos realizaram a construção e a justificativa, no entanto, apenas um dos três grupos usou uma argumentação clara sobre o que fizeram, enquanto os demais se detiveram a apenas destacar as propriedades.

Tratamos como ângulo central o ângulo entre os dois espelhos com a intenção de fazer referência ao ângulo central de polígonos regulares, que comumente eram observados ou tidos como referência para o estudo. Dessa forma, a respeito do estudo das pontas das estrelas poligonais, a Professora J afirmou que "foi possível verificar que o ângulo central é fundamental para (determinar) o número de pontas das estrelas [...]. O ponto central dessa atividade é que se o ângulo central da folha é $40^{\circ}$, o ângulo (central) da ponta da estrela é $80^{\circ}$ ". Nessa afirmação podemos perceber que ela concluiu que o ângulo entre os dois espelhos determinaria o ângulo central de cada ponta e nosso interesse é que ela notasse que, apesar de que $40^{\circ}$ dividir $360^{\circ}$ e ser ângulo central de um polígono regular, seu dobro, a medida de $80^{\circ}$, não divide $360^{\circ}$, fazendo com que possíveis falhas aparecessem, como visto na figura 55. 
Figura 55 - Possível estrela poligonal observada a partir do ângulo central de $40^{\circ}$

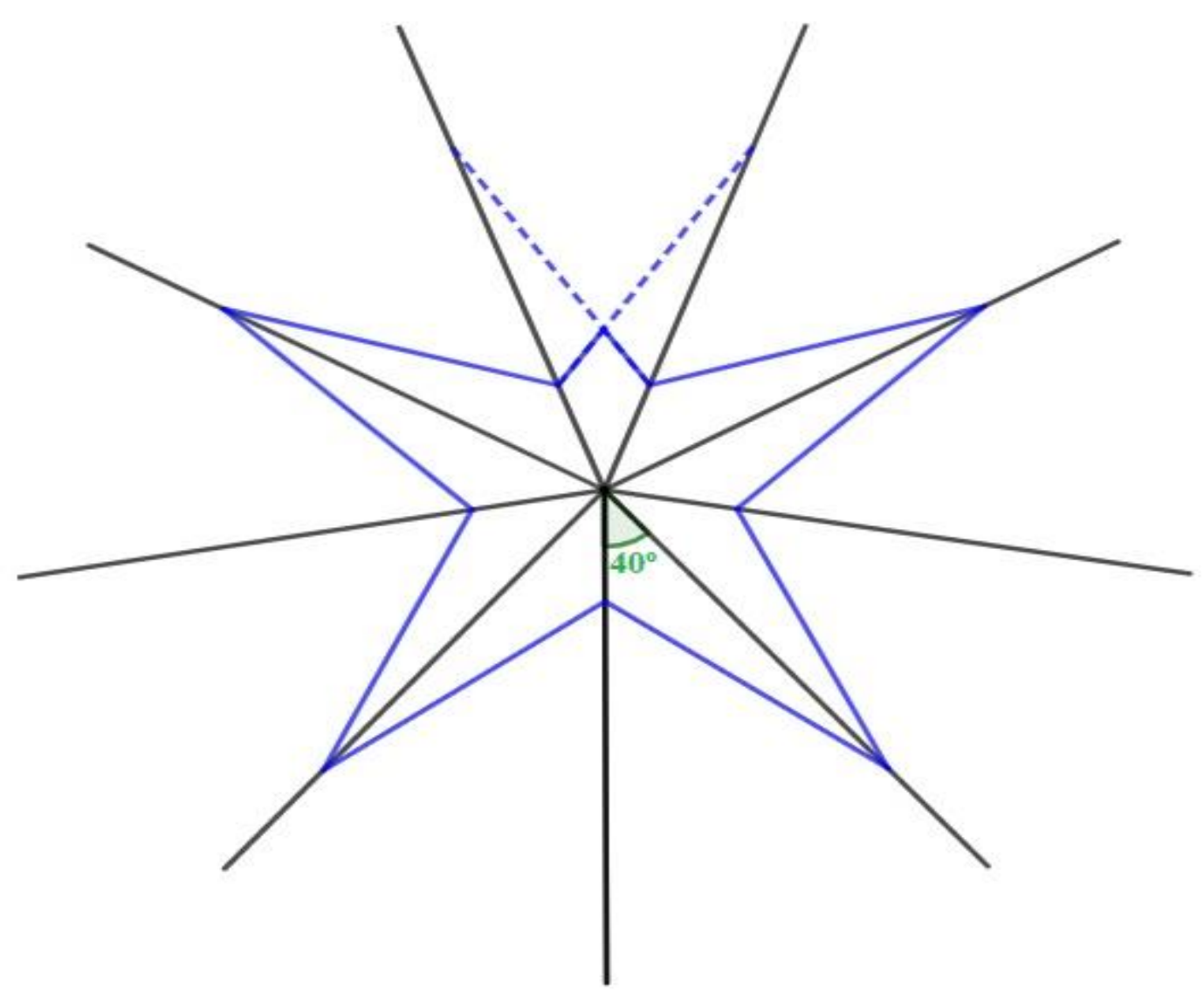

Fonte: Autor

\section{O Desenvolvimento do pensamento geométrico em 3.2. e 3.3.}

A composição dos enunciados das tarefas sobre estrelas poligonais levou os participantes a fazerem uma investigação Matemática que os auxiliassem no desenvolvimento do pensamento geométrico axiomático da seguinte forma:

a) primeiramente analisaram a convexidade dos polígonos obtidos, argumentando a respeito da definição de polígono convexo e côncavo;

b) foi justificado a convexidade analisando como os ângulos foram formados, no caso em que a posição da fita entre os espelhos determinaria esses ângulos, concluíram então, que se o ângulo entre os espelhos e a fita é agudo, seria produzido um polígono convexo, caso contrário seria côncavo; 
c) nas atividades 3.2 e 3.3, foi necessária a divisão em casos e subcasos em diversos dos itens, ou ainda, situações que necessitavam de uma decomposição de figuras;

d) as discussões coletivas fizeram com que os professores participantes tivessem que argumentar suas ideias para os seus colegas, inclusive colaborando para que eles mesmos percebessem possíveis erros em suas estratégias.

Após finalizarmos o quarto encontro, propusemos uma reflexão a respeito da definição de estrelas poligonais e os professores perceberam (em especial, a professora $\mathrm{M}_{3}$ ) e verbalizaram que "polígonos côncavos com ângulos medindo, alternadamente, menos que $180^{\circ}$ e mais do que $180^{\circ}$ ", poderiam ampliar nossa definição inicial. Apesar desse tipo de polígono não ser tão comum quanto aquele que segue o que propomos, respeita as mesmas propriedades com relação a ângulos centrais, número de pontas e de eixos de simetrias como também por estar bem presente nas imagens de polígonos obtidas pela reflexão dos espelhos. De certa forma, isso nos mostra um domínio do significado da definição de estrelas poligonais e de suas propriedades.

Além de auxiliar na ambientalização da sala em um laboratório de Matemática, com as mesas de grupos, materiais concretos e manipuláveis e as folhas com enunciados, as nossas ações e intervenções, enquanto ministrantes, visando colaborar com esse processo, se caracterizaram em algumas das cinco práticas:

a) Antecipar: visamos explorar todo o potencial da tarefa, aproveitando todos os conceitos desenvolvidos durante o estudo das estrelas poligonais e o próprio desenvolvimento do conceito de estrela poligonal foi pensado para auxiliar os professores participantes a elaborarem definições de objetos matemáticos a partir de uma discussão em que todos colaboram/participam; optamos por utilizar grande parte dos terceiro e quatro encontros para desenvolvermos as atividades 3.2 e 3.3 e explorar as propriedades das estrelas poligonais ao percebermos padrões nas construções dos professores, ainda que não tenha sido o planejado no início do curso.

b) Monitorar: assim como nas atividades anteriores, o nosso papel, durante o processo de investigação dos professores participantes, se deu em observar as resoluções elaboradas, as etapas da construção das figuras, bem como analisar possíveis erros ou construções incompletas (em que faltava medir determinado ângulo). Intervimos pouco nesse momento, embora não 
tenha havido muito tempo para a investigação autônoma que antecede a discussão das ideias estratégias produzidas.

c) Selecionar: como a quantidade de professores participantes não era grande, foi possível solicitar que todos apresentassem sua colaboração durante a discussão. No entanto, fizemos uma seleção criteriosa apenas em poucos dos itens das duas atividades quando, por exemplo, a professora $\mathrm{M}_{2}$ questionou sobre o que ocorria nas falhas quando não se formava uma estrela poligonal, quando solicitamos que o professor L representasse na lousa os eixos de simetria e quando a professora $\mathrm{M}_{3}$ fez o esboço de uma estrela poligonal de cinco pontas e contou como a construiu.

d) Sequenciar: no que diz respeito a ordenar as apresentações ocorreram alguns cuidados. Como percebemos que alguns professores tiveram dificuldades em utilizar o transferidor ou cometeram erros a respeito de seu uso, utilizamos o início do quarto encontro para convidar um dos participantes para fazer na lousa (voluntariamente) a medição de ângulos com o transferidor de madeira. Em seguida, observamos que os professores participantes haviam feito algumas estrelas poligonais e para discutirmos os eixos de simetria, solicitamos primeiramente que o professor $\mathrm{L}$ fosse a lousa fazer os eixos de uma estrela de quatro pontas, na sequência, com uma construção mais complexa, a professora $\mathrm{M}_{3}$ fez a de cinco pontas. As etapas seguintes da discussão não foram realizadas em uma sequência proposital, mas decidimos discutir as falhas que a professora $\mathbf{M}_{2}$ havia indagado, apenas após a sistematização de conceitos.

e) Estabelecer conexões: antes da elaboração do curso, não imaginávamos que as construções produziriam imagens de polígonos com um potencial de estudo tão interessante quanto o das estrelas poligonais. Acreditamos que nos aproximamos mais dos nossos objetivos por meio desse estudo, pois os professores puderam explorar mais as construções geométricas dentro dos ângulos entre os dois espelhos, puderam se apropriar melhor de conceitos fundamentais para o estudo das pavimentações (como a reflexão em reta, bissetriz de ângulo, classificação de ângulos, propriedades de polígonos etc.) e discutiram como a medida dos ângulos formados entre os espelhos e os objetos no interior afetam as imagens produzidas. 
Quando apresentamos para a atividade 3.1. item I, os professores participantes que até então utilizavam uma fita cuja mediatriz coincidia com a bissetriz do ângulo (itens a, b e c) foram levados a explorarem o que aconteceria em outras posições e ainda que nosso objetivo fosse que eles concluíssem que seria possível produzir um polígono regular ao se posicionar a fita perpendicularmente a um dos espelhos, aparecem outras figuras de polígonos côncavos e, dentre eles, as estrelas poligonais.

De certa forma, o estudo das estrelas poligonais nos permitiu estabelecer conexões entre as construções produzidas pelos professores e nosso objeto de estudo, as pavimentações do plano com polígonos regulares, bem como auxiliar no desenvolvimento de um pensamento geométrico próprio do nível G2.

Parzysz (2006) descreve que a passagem de um pensamento de G1 para um pensamento de G2 utiliza de evidências materiais em que o sujeito produz justificativas perceptivas. Ele descreve ainda, alguns tipos de tarefas que permeiam a articulação entre G1 e G2, das quais destacaremos duas, a saber:

1. Provar que um objeto $X$ satisfaz uma propriedade $P$ : pode-se construir uma representação do objeto $\mathrm{X}$ e perceber visualmente se ele satisfaz a propriedade $\mathrm{P}$ e então utilizar as definições do objeto $\mathrm{X}$ para a prova.

As questões colocadas nos enunciados da atividade 3.2 apresentam um exemplo que se aproxima desse primeiro tipo de tarefa. Os professores participantes buscaram mostrar que suas construções representavam objetos que satisfaziam propriedades de convexidade, de congruência de lados e de eixos de simetria eram e argumentaram suas respostas por meio da caracterização do que foi percebido (se deveriam ser utilizados só ângulos agudos, se sempre apareceriam eixos de simetria ou não etc.).

O item V dessa atividade "Quais propriedades devem ter o ângulo entre os espelhos e a posição da fita, com relação aos lados do ângulo, para que seja formada uma estrela poligonal com lados congruentes?" apesar de não sugerir nenhuma construção geométrica, os professores tomaram como evidências materiais as figuras produzidas nos itens anteriores, buscando identificar as características que satisfariam a congruência de lados das estrelas poligonais. 
2. Validar uma conjectura dada: utilizar a construção de um objeto gráfico (ou seja, uma figura) utilizando propriedades próprias de uma construção geométrica (aproximada ao nível G2) associadas a validação perceptiva de nível G1.

Em diversos momentos, os professores participantes foram colocados a confrontar conjecturas observando as suas representações figurais e utilizando uma argumentação relativa a propriedades, definições e conceitos apresentados ou construídos nos encontros. O item c (VI, VII e VIII) da atividade 3.3, colocou os professores a pensar em desenvolver conjecturas e argumentá-las a respeito da relação entre a bissetriz do ângulo entre os dois espelhos e propriedades em relação a possível estrela poligonal obtida, podendo conjecturar, por exemplo, que ela teria lados congruentes (outras propriedades seriam necessárias para garantir isso). $\mathrm{Na}$ Figura 56 temos um exemplo de uma figura que se assemelha a uma estrela poligonal com vértice na bissetriz.

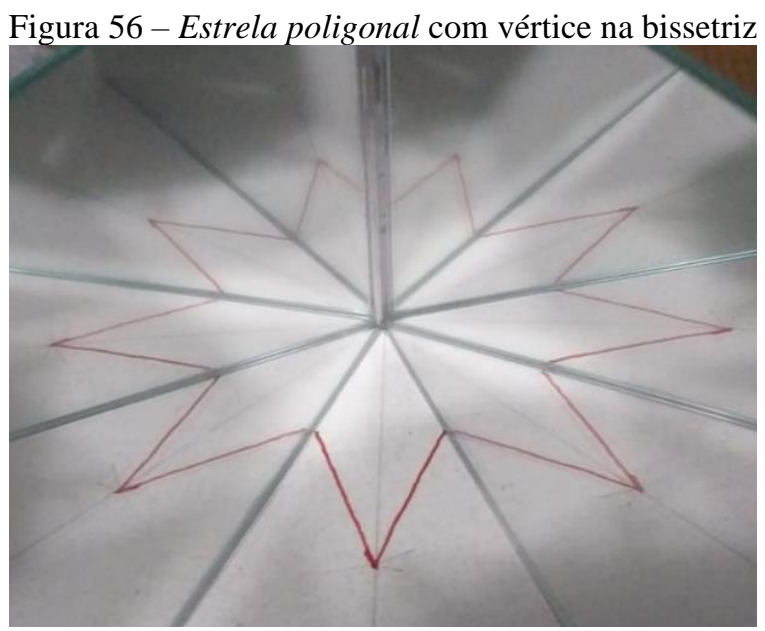

Fonte: Autor

Fazemos uma observação aqui de que, desde a primeira atividade do curso, os professores participantes utilizam as imagens produzidas apenas para representar, com certa aproximação, um objeto ideal. De tal forma que as "falhas" podem não ficar evidentes ao se usar um ângulo próximo de um ângulo interno de polígono regular, como quando se usa, por exemplo, um ângulo de $62^{\circ}$ entre os dois espelhos, sendo que $60^{\circ}$ é o ângulo central de um hexágono regular. Nesse caso, muito provavelmente não será percebido visualmente que se produz uma imagem de um polígono irregular ou de uma figura que não é polígono. Por isso a última tarefa da atividade 3.3. faz com que os professores tenham que utilizar meios que não sejam apenas visuais para construir uma imagem de estrela poligonal. 
Acreditamos que se tomarmos como contexto o trabalho na Educação Básica, as estrelas poligonais são objetos que podem estar presentes em atividades ou situações específicas a serem investigadas, permitindo a abordagem e exploração de conceitos em sala de aula como polígonos, ângulos, bissetriz, simetria, entre outros. Tal investigação ganha não apenas mais sentido para os alunos, mas também há ganho em atratividade - o que foi apontado de forma unânime pelos professores participantes - ao se utilizar materiais concretos e manipuláveis tais como os espelhos planos, promovendo assim, o desenvolvimento argumentativo, de análise de diferentes casos, atividades de composição/decomposição de figuras e melhor capacidade de visualização e dedução.

\subsubsection{Falhas}

Falamos com mais detalhes sobre as "falhas" das imagens observadas nas atividades realizadas com a bolinha, com a fita e com traçados de canetinha, nos casos em que o ângulo entre os dois espelhos concorrentes não era congruente a um ângulo interno de algum polígono regular e, em especial na atividade 3.2, no caso em que o ângulo entre os dois espelhos concorrentes não media metade de um ângulo interno de polígono regular (que é, por consequência, um ângulo cuja medida é um divisor de $360^{\circ}$ ).

Para o caso das tarefas com a bolinha de gude afirmamos que os polígonos formados tinham como vértices a bolinha e suas imagens e como lados os segmentos que as uniam. Dessa forma, a falha ocorria quando não se via nos espelhos uma bolinha completa. Afirmamos que consideramos que contaria como um vértice, mesmo que aparecesse apenas uma parte da bolinha, mas que a bolinha falhada significa um pedaço de imagem produzida em um dos dois espelhos e que, ao olharmos de frente, podemos não vê-la, ou seja, essa parte de imagem pode ser vista em determinado ponto de observação e não visto em outro ponto de observação. Mostramos no Geogebra que, ao olharmos de frente (com o olhar alinhado a bissetriz do ângulo entre os dois espelhos), nunca se observa que o ângulo entre as duas últimas bolinhas observadas nos espelhos seria maior do que o ângulo entre os dois espelhos e a justificativa é que, ao olharmos em um dos espelhos, conseguimos observar, no máximo, as imagens formadas até $180^{\circ}$ com relação à posição inicial da bolinha de gude. 
Na figura 57, temos uma representação da atividade da bolinha feita pela professora $\mathrm{M}_{2}$, usando um ângulo de $70^{\circ}$ entre os dois espelhos. Na representação os segmentos OA e OB são os eixos de simetria e ilustram onde foram colocados os espelhos. Pelas reflexões sucessivas, os ângulos AOB', B'OA', BOA' e A'OB' são todos congruentes ao ângulo inicial, AOB e medem $70^{\circ}$. O ponto $\mathrm{Q}$ representa a bolinha sobre a bissetriz do ângulo entre os dois espelhos. Ao olhar, de forma alinhada a bissetriz, ao espelho que ficou sobre o segmento BO, veremos os pontos $\mathrm{Q}_{2}$ e $\mathrm{Q}_{4}$, enquanto ao olhar, da mesma forma, ao espelho que ficou sobre o segmento $\mathrm{AO}$, veremos os pontos $\mathrm{Q}_{1}$ e $\mathrm{Q}_{3}$. O segmento $\mathrm{A}^{\prime} \mathrm{O}$ foi obtido pela reflexão do segmento $\mathrm{AO}$ pelo eixo BO; B' 'O foi obtido pela reflexão de BO pelo eixo A'O; B'O foi obtido pela reflexão de BO pelo eixo AO; A”O foi obtido pela reflexão de AO pelo eixo B'O (mas são apenas segmentos auxiliares, não fazem parte do polígono que desejamos observar).

Notamos que o ponto $Q_{5}$ não poderia ser enxergado pois: ele representa a reflexão do ponto $\mathrm{Q}_{3}$ pelo eixo $\mathrm{OA}$ ” e o ângulo $\mathrm{QOQ}_{5}$, (observado no sentido anti-horário) é maior do que $180^{\circ}$. Analogamente não enxergamos o ponto Q6, ao olharmos de frente para os dois espelhos, na posição alinhada a bissetriz, as imagens produzidas no espelho do lado direito não podem se sobrepor as imagens observadas no espelho do lado esquerdo, então em cada lado podemos ver no máximo, imagens até $180^{\circ}$ (somando $360^{\circ}$ de campo de observação). Nesse caso, como o nosso objetivo (nós afirmamos isso mais de uma vez) era de que compreendessem que cada imagem da bolinha de gude (e a original) enxergada fosse um vértice de polígono, formou-se um pentágono (pois são cinco vértices verdes) irregular e convexo.

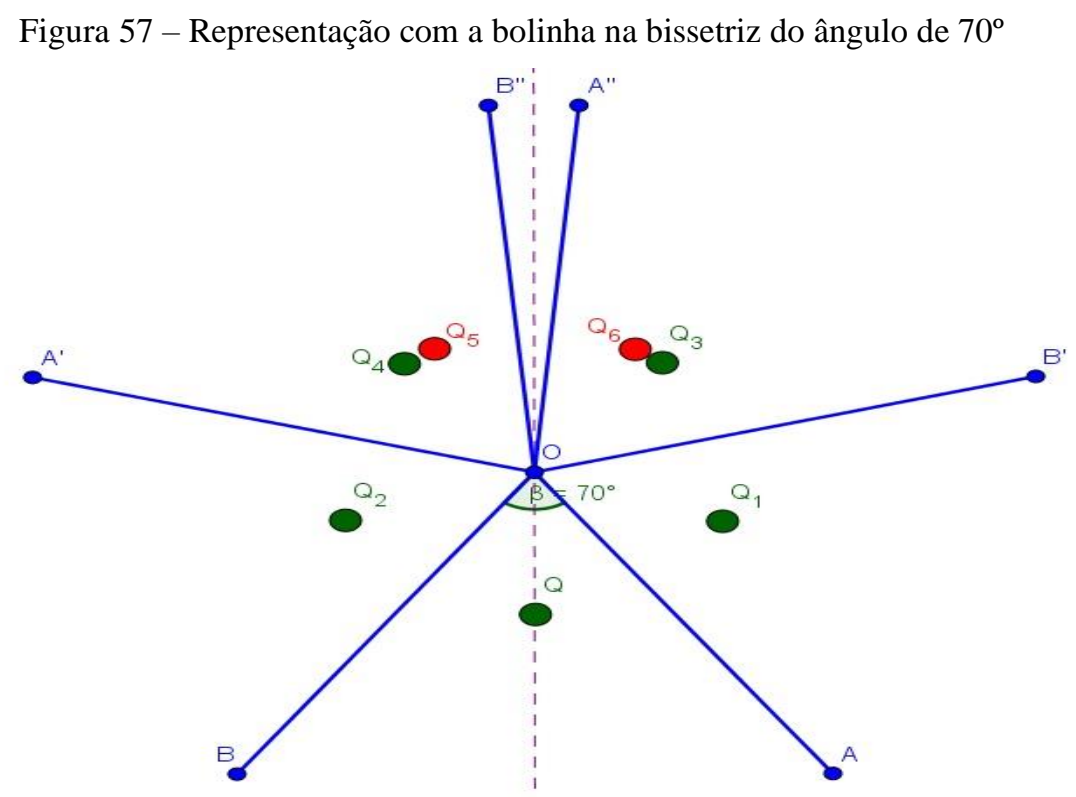

Fonte: Autor 
Na Figura 58, temos uma representação da falha que ocorreu quando usamos a fita posicionada sobre a mediatriz da reta bissetriz do ângulo entre os dois espelhos que, no caso, mede $70^{\circ}$. A construção de segmentos azuis foi feita da mesma forma como foi descrita anteriormente. A faixa roxa entre os dois eixos iniciais representa a fita adesiva colorida usada. Suas imagens, também roxas, são o que conseguimos observar ao olhar de frente para o espelho na posição alinhada com a bissetriz do ângulo entre os dois espelhos. A parte das imagens que é formada por segmentos vermelhos são as imagens que já não podem mais ser observadas pelo mesmo motivo discutido com a Figura 58, em relação ao ângulo de $180^{\circ}$ e, em outras palavras, podemos dizer que a imagem que "passar" da reta bissetriz do ângulo entre os dois espelhos (tracejado cinza) não pode mais ser observada.

Nesse caso foi formado um heptágono (sete lados roxos) irregular e côncavo.

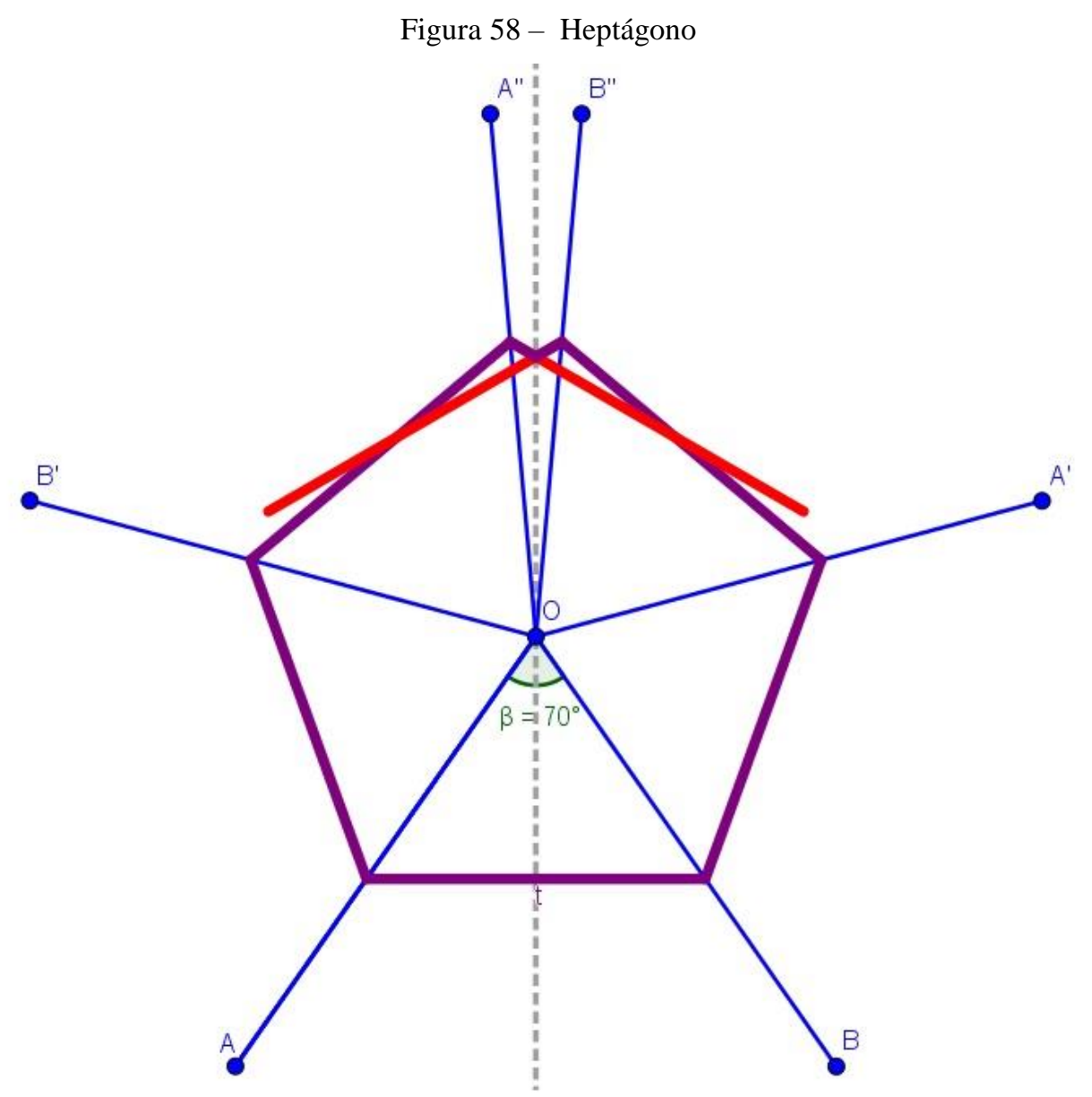

Fonte: Autor 
Em um caso mais especial que, inclusive, foi observado pelos professores participantes, na atividade de estrelas poligonais (3.2. e 3.3.) havia a clara impressão que era formada uma figura que "não fechava" quando era utilizado um ângulo cujo dobro não divide 360 (na atividade 3.3 as estrelas poligonais que "fechavam" eram formadas usando ângulos que dividissem 360, enquanto na 3.2, o dobro do ângulo deveria dividir 360). No nosso exemplo da Figura 26, o ângulo usado foi de $70^{\circ}$, assim como nas duas figuras anteriores.

O segmento amarelo entre os dois eixos iniciais representa a posição da fita adesiva colorida, fixada no interior do ângulo entre os dois espelhos. Essa posição tem a seguinte propriedade: o segmento amarelo forma um ângulo obtuso e outro agudo em relação aos lados do ângulo inicial. Como podemos observar na Figura 58, depois de certa quantidade de reflexões dessa faixa amarela, os segmentos "se fecharam", entretanto a figura não se fecha em um extremo da imagens pelas reflexões do segmento inicial e, além disso, essa intersecção de imagens que não é no extremo ocorre com a parte do segmento que está em vermelho. A parte dos segmentos em vermelho representa a parte da reflexão que já não pode mais ser enxergada quando nos pusermos na posição de observar alinhando o olhar à bissetriz do ângulo entre os dois espelhos. Dessa forma, só conseguimos ver, da representação da Figura 57, o que está em amarelo, ou seja, uma linha que "se desencontra". Para esse caso, apesar de vermos que a falha não produz um polígono, afirmamos que consideraríamos, para a atividades 3.2 e 3.3 , em especial para a discussão de eixos de simetria, que a linha se fecha, mas que era produzido um polígono que não era uma estrela poligonal.

Observação: fazemos aqui a utilização de uma linguagem em que "ângulo dividir 360" ou “dobro do ângulo", entre outros, se refere a medida do ângulo. 
Figura 59 - Reflexão de segmento pelo ângulo de $70^{\circ}$

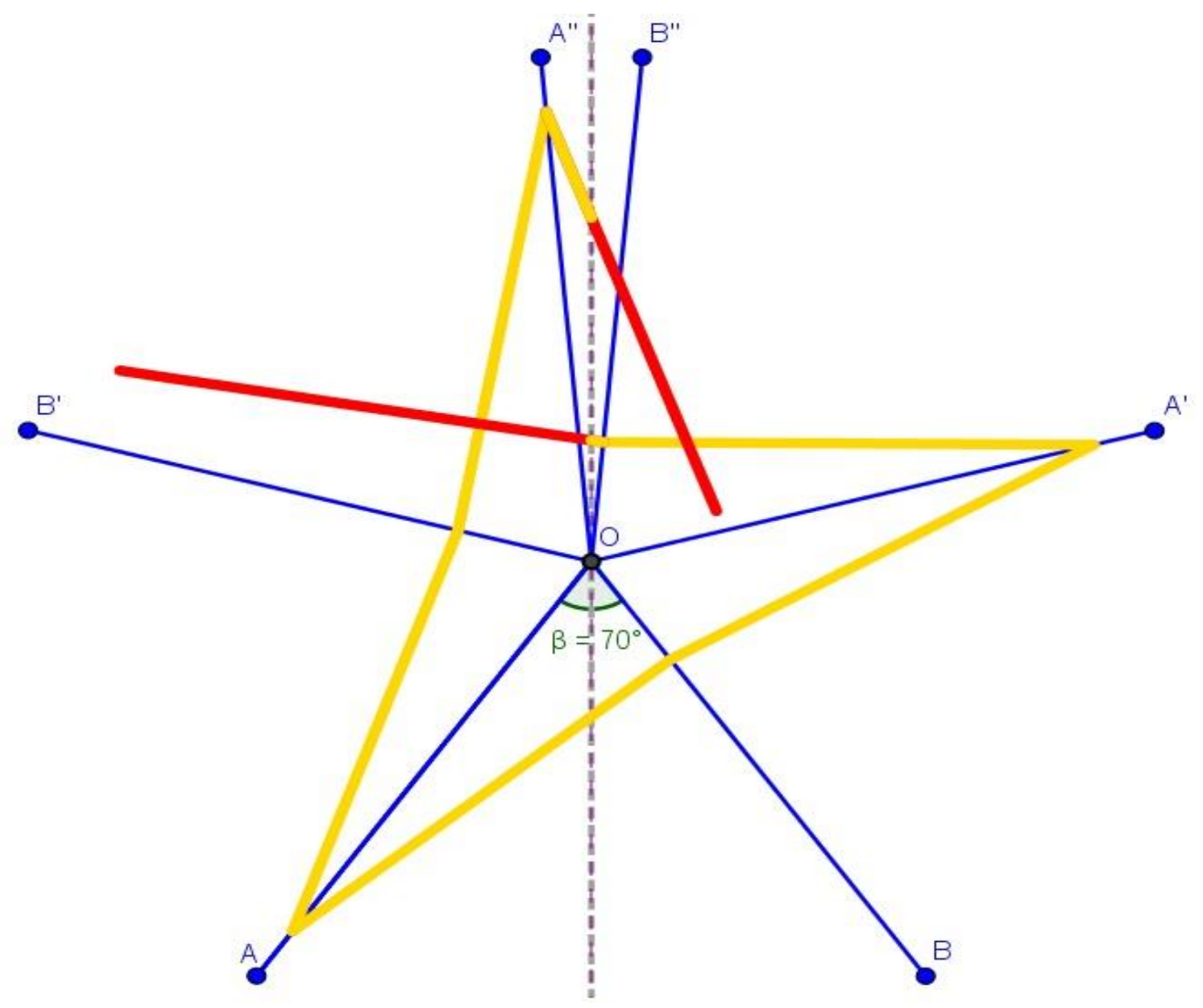

Fonte: Autor

Em nossas discussões, não falamos com estes detalhes acima e nem tivemos tempo de ilustrar separadamente cada um dos três casos das Figuras 57, 58 e 59. Então fizemos determinada construção no Geogebra para dar uma noção de como essas falhas ocorrem, por que ocorrem e quando são formados polígonos ou não, além de reforçar nossos objetivos em cada atividade.

\section{Transformações}

Em seguida fizemos, brevemente, uma criação de conjecturas com os professores participantes a respeito de isometrias: falamos que, assim como na atividade das caixinhas coloridas, podemos verificar que as reflexões sucessivas em dois espelhos paralelos (dois eixos) pode ser feita com uma outra isometria (a professora $\mathrm{M}_{3}$ afirmou translação, que era a isometria 
que esperávamos que falassem) e que, assim como nas atividades da fita adesiva colorida, reflexões sucessivas em dois espelhos concorrentes pode ser feita com uma outra isometria (a professora $\mathrm{M}_{3}$ afirmou rotação, que era a isometria que esperávamos que falassem).

Nosso objetivo era de que pensassem se existe uma isometria diferente da reflexão que seja igual a uma composta de duas reflexões sucessivas. No caso da translação, perguntamos “de qual vetor?” e no caso da rotação "de qual centro e de qual ângulo?”.

Pedimos aos professores participantes que tentassem pensar para o Encontro 5 quais eram as isometrias que são iguais a uma composta de duas reflexões em retas paralelas e concorrentes e que buscassem justificativas.

\subsection{Análise do quinto encontro}

Transformações no Plano

Começamos o encontro perguntando aos professores se haviam conseguido finalizar as atividades que deveriam ser feitas em casa (enviadas via e-mail após o quarto encontro): “Transformações Geométricas Planas: Alguns conceitos" e fizemos uma discussão inicial com todos sobre suas experiências com o tema. As figuras abaixo mostram cada uma das atividades.

Figura 60.1

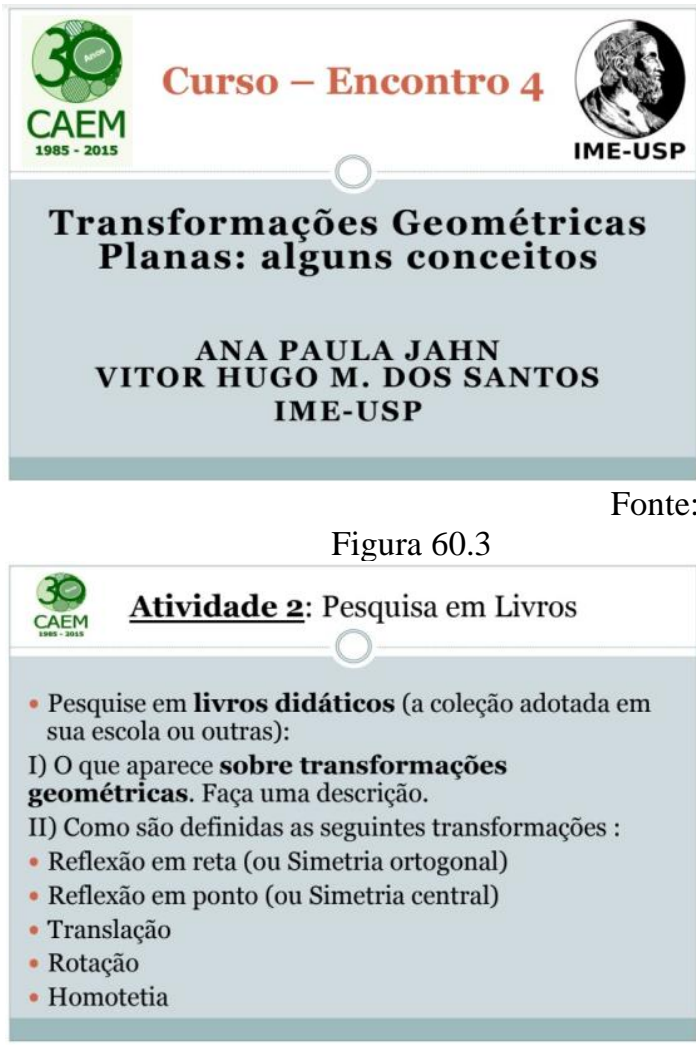

Figura 60.2

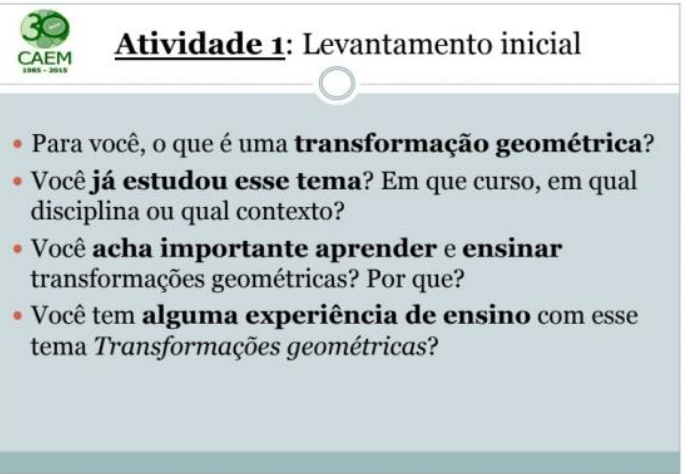

Figura 60.4

Atividade 3: Explorando Isometrias

Exemplos de isometrias no menu "transformações" do Geogebra.

- Explore essas isometrias, obtendo as imagens de diferentes figuras geométricas.

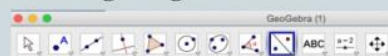

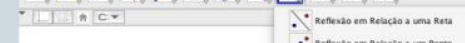

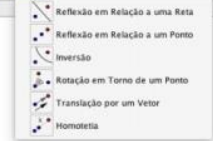

Fonte: Autor 
Figura 60.5

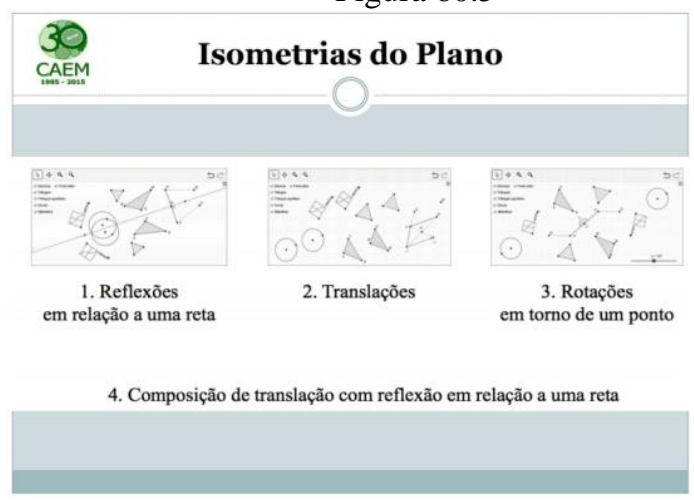

Figura 60.6

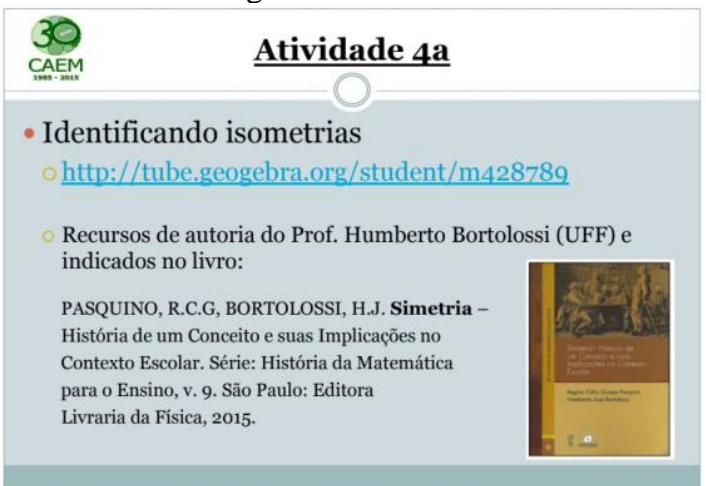

Fonte: Autor

Figura 60.7

30 Atividade 4b
CAEM
- Reflexões em relação a uma reta
http://tube.geogebra.org/student/m429027
- Translações
http://tube.geogebra.org/student/m429983
- Rottp://tube.geogebra.org/student/m430217 em torno de pontos
http://tube.geogebra.org/student/m430353

Figura 60.8

CAO Atividade 5: Levantamento inicial
- O que é simetria para você?
- Na sua opinião, o que significa dizer que uma figura é
simétrica ou tem simetria?
- Você acha importante aprender simetria? Por
que?
- Você conhece aplicações da simetria no mundo real
ou em outras áreas?
- Você já estudou simetria? Em caso afirmativo, em
qual curso, disciplina ou experiência?

Fonte: Autor

Essas atividades puderam ser entregues por e-mail ou por escrito, neste dia.

\section{Atividade 1}

A primeira questão (figura 60.2) teve respostas mais genéricas, no sentido de que tinham, em sua maior parte, alguma semelhança com as definições dadas em livros e materiais teóricos como, por exemplo, a resposta da professora $\mathrm{C}_{2}$ : "É uma correspondência, um a um, entre pontos de um mesmo plano ou de planos diferentes." e a resposta da professora $\mathrm{M}_{3}$ : "Uma transformação geométrica é uma operação que realizamos com um ponto ou conjunto de pontos, que pode alterar algumas de suas propriedades e manter outras.”.

Os professores participantes responderam usando ideais parecidas, destacando principalmente aspectos de uma transformação do plano.

A segunda questão mostrou que os professores ou não viram conteúdos de os viram superficialmente e com maior enfoque na representação algébrica das transformações. 
A terceira questão teve respostas diversas, tendo em comum apenas o fato de que todos concordam ser importante aprenderem esse tópico da Matemática (alguns não falaram nada sobre a importância do ensino).

A quarta questão mostrou que os professores não têm contato com o ensino de transformações do plano ou não o tem de forma significativa. A professora $\mathrm{M}_{3}$ afirmou que: "achei que o tema era irrelevante, me lembro de um aluno perguntando para que eles estavam aprendendo aquilo, e eu dei a triste resposta: 'Eu também não sei.”

\section{Atividade 2}

No primeiro item os professores de Ensino Fundamental afirmaram que não encontraram nos seus livros didáticos, uma definição para transformação do plano, entretanto houve exemplos de situações em que o livro usava o conceito de simetria. A professora de Ensino Superior (professora $\mathrm{M}_{3}$ ) escreveu a definição de transformação do plano dada por um material do seu curso de mestrado (ProfMat). No segundo item os professores participantes, em sua maioria, disseram que não haviam definições dessas transformações em seus materiais didáticos.

\section{Atividade 3}

Nessa atividade o objetivo era explorar as isometrias utilizando as ferramentas do Geogebra. Não apareceram dificuldades, mas, em especial, na versão de Geogebra utilizada pela professora $\mathrm{G}$ não havia a opção de translação e, por conta disso, ela não obteve as imagens produzidas por translação ou por reflexão transladada.

\section{Atividade 4a}

Nessa atividade aparecem oito aplicações que levam um segmento de reta (cujos extremos podem ser manipulados livremente pelo plano cartesiano) em outro segmento de reta e é solicitado que se identifique quais delas são isometrias.

A maioria dos professores não acertou completamente essa atividade, mas a professora $\mathrm{M}_{3}$ identificou quais itens eram isometrias e discriminou a isometria de cada caso. Um erro recorrente foi acreditar que $\mathrm{F}(\mathrm{x}, \mathrm{y})=(|\mathrm{x}|,|\mathrm{y}|)$ era uma isometria. 


\section{Atividade 4b}

Nessa atividade os professores participantes precisavam apenas explorar as ferramentas já selecionadas no Geogebra para fazer a reflexão, translação e rotação de pontos, segmentos e outros objetos já construídos.

\section{Atividade 5}

Na primeira questão, apareceram respostas bem diferentes, mas cada professor destacou algum ponto que mostra que ele sabe destacar alguns elementos da simetria, pois apareceram os termos: "igual”, “sobrepor...e coincidirem”, “igualdade de duas partes”. Entretanto ninguém falou que é uma isometria que mantém um conjunto de pontos invariável.

A segunda questão trouxe respostas com potencial para o desenvolvimento de um pensamento geométrico axiomático:

- "Quando a figura pode ser dividida em duas partes iguais" (professora G)

Substituindo "iguais" por "congruentes" poderíamos identificar, por exemplo, uma simetria por reflexão em reta ou uma rotação.

- “É uma figura igual” (professora $\mathrm{C}_{2}$ )

Como a simetria de uma figura, deve deixar essa figura invariante, então o conjunto de pontos inicial e a imagem são iguais por meio de uma isometria.

$\mathrm{Na}$ terceira questão, os professores mostraram que acreditam que é importante aprender simetrias pois, segundo eles: podemos aprender sobre as regularidades que existem na natureza; é uma aplicação de transformações no plano; torna possível se trabalhar diversos elementos de objetos geométricos, tais como os ângulos e medidas de segmentos.

$\mathrm{Na}$ quarta questão, todos os professores afirmaram que existem aplicações em arquitetura e dois deles falaram que existem aplicações em artes.

Na quinta questão os professores responderam terem visto com poucos detalhes ou não terem visto, mesmo no curso de Licenciatura em Matemática. 
Nesse momento do quinto encontro, fizemos um levantamento de dúvidas e dificuldades, alguns falaram que já haviam estudado transformações do plano, mas bem superficialmente na graduação e que, por conta disso, tiveram algumas dificuldades nas atividades.

Realizamos a correção das atividades, com a participação dos professores e fizemos uma sistematização do conceito de isometria por meio da caracterização: preserva segmentos de reta e, por consequência, preserva ângulos e retas, por exemplo.

Destacamos em seguida, que cada isometria pode ser decomposta em uma quantidade finita de reflexões em retas:

a) Uma reflexão em relação a um ponto A pode ser decomposta em reflexões em duas retas perpendiculares que concorrem nesse ponto A;

b) Uma rotação de ângulo de medida $\theta$ pode ser decomposta em reflexões em duas retas que concorrem no vértice do ângulo de rotação

Nos últimos minutos do encontro iniciamos a atividade 1 de polígonos. Pedimos que os professores lessem a definição de polígonos e falassem suas ideias. Então resolvemos oralmente o item I e II (veja os enunciados na seção seguinte) e pedimos que escrevessem em casa suas respostas, com maior precisão.

\subsection{Análise do sexto encontro}

Inicialmente, fizemos uma discussão sobre a definição de Polígonos para alunos do Ensino Fundamental para a retomada do item I da Atividade 1 (cf. Figura 59 e Figura 60) e sugerimos que cada professor falasse sua sugestão de definição.

O item II foi feito oralmente: cada figura foi descrita como polígono ou não polígono (e justificada) por um dos professores presentes.

Da mesma forma foi feito o item III, mas dessa vez escrevemos na lousa a conclusão de cada figura:

a) Não é formado somente por segmentos de reta;

b) Não é uma figura fechada;

c) Não possui todos os segmentos num mesmo plano;

d) Existem segmentos que se interceptam fora dos extremos; 
e) Não possui apenas uma região interna.

Com isso concluímos que, com relação a polígonos, é correto afirmar que são figuras que:
a) São formadas apenas por segmentos de reta;
b) são fechadas;
c) são planas;
d) possuem segmentos cuja intersecção, dois a dois, é vazia ou um extremo;
e) possuem uma única região interna.

Por meio da tarefa II, acreditamos que podemos colaborar com o desenvolvimento do pensamento geométrico do aluno, auxiliando em produzir uma argumentação acessível e não tão rigorosa quanto a que utilizamos no início da atividade 1 de polígonos.

Analisamos também, algumas definições dadas em livros didáticos e, em conjunto, decidimos e registramos qual definição utilizaríamos no decorrer do curso, sendo que essa deveria ser análoga a definição apresentada no início da atividade e ainda assim fosse adaptada para ser de fácil compreensão.

Figura 61 - Atividade 1 de pavimentações (primeira parte)

\section{Atividade 1 - Polígonos}

Uma figura P é dita polígono se:

1) Existem $n$ pontos distintos coplanares (chamados de vértices do polígono) $P_{1}, P_{2}, P_{3}$ .... $P_{n-1}, P_{n}$. não todos colineares, com $n$ natural maior que dois, tais que $\mathrm{P}=\mathrm{P}_{1} \mathrm{P}_{2} \cup \mathrm{P}_{2} \mathrm{P}_{3} \cup \mathrm{P}_{3} \mathrm{P}_{4} \cup \ldots \cup \mathrm{P}_{n-1} \mathrm{P}_{4} \cup \mathrm{P}_{\mathrm{n}} \mathrm{P}_{1}$

2) A intersecção de cada par segmentos (chamados de lados do polígono) é nula ou é igual a um extremo em comum.

I - Discuta com seus colegas a definição acima $e$ escreva uma que seja equivalente e que você acredita que seria mais adequada/acessível a um aluno de Ensino Fundamental II.

II - Verifique se cada um dos itens a seguir é um polígono ou não, justificando.

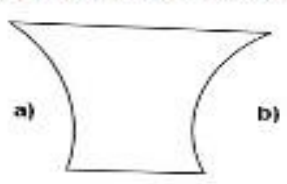

b)
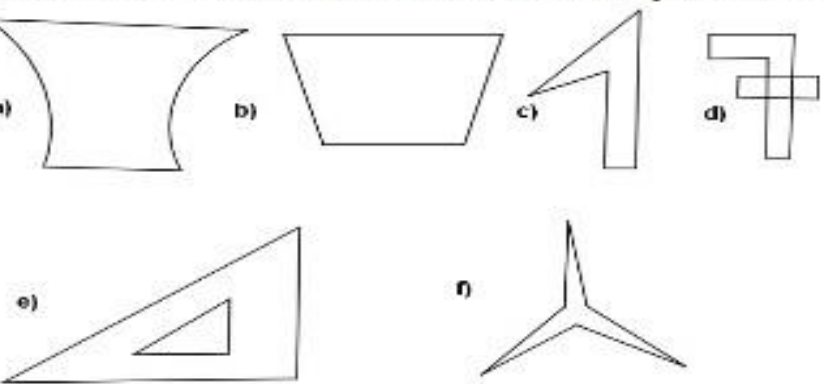

Fonte: Autor 
Figura 62 - Atividade 1 de pavimentações (segunda parte)

III - Escreva ao menos uma característica de cada uma das figuras a seguir que a difere de um polígono.

a)

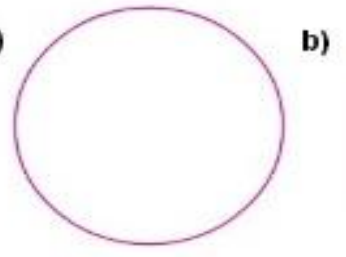

b)
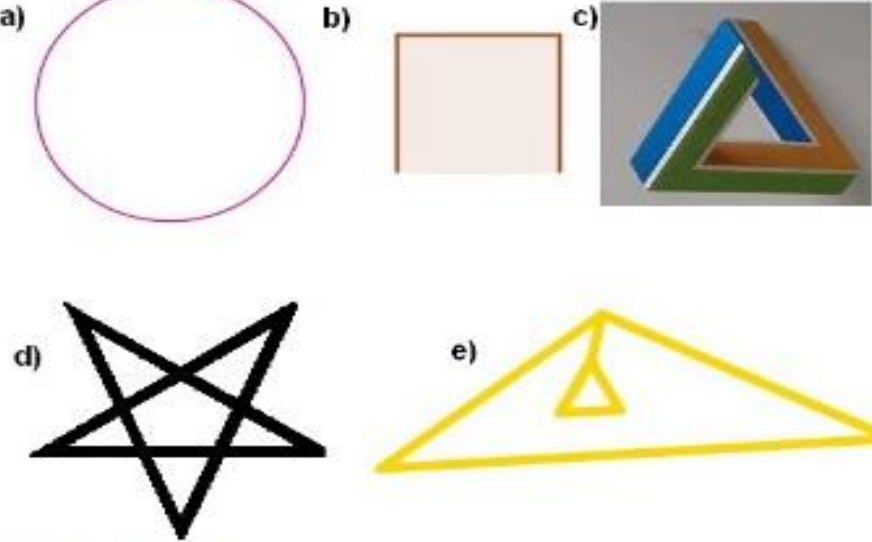

e)

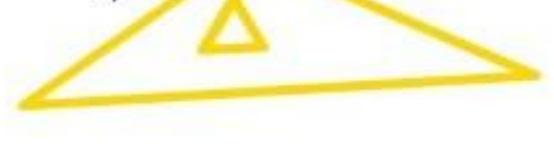

Um polígono é dito regular se:

1) Todos os seus lados são congruentes

2) Todos os seus ângulos internos são congruentes

IV - Use seus conhecimentos de desenho geométrico para desenhar um triângulo equilátero. Justifique sua construção.

$V$ - Use seus conhecimentos de desenho geométrico para desenhar um hexágono regular.

Justifique sua construção.

Fonte: Autor

Os itens IV e V tinham como objetivo exercitar e verificar alguns conhecimentos de desenho geométrico dos professores participantes. A construção do triângulo equilátero $\mathrm{ABC}$ foi feita, pela maioria do grupo, partindo de um segmento de reta $\mathrm{AB}$ qualquer: tomando a intersecção $\mathrm{C}$ de dois arcos de circunferência de raio $\mathrm{AB}$, com centro em $\mathrm{A}$ e em $\mathrm{B}$. A justificativa foi feita em conjunto. Já a construção de um hexágono regular fizemos a partir de um método que já era conhecido por alguns professores, que é: dada uma circunferência de raio $\mathrm{x}$, traçar arcos de raio x "consecutivos" com a ponta do compasso partindo de qualquer ponto da circunferência e depois ligá-los

\section{Atividade 2}

Em sequência, ainda no sexto encontro, realizamos a Atividade 2 e decidimos ampliar a definição de polígonos a fim de utilizar as peças de acrílico e poder compreender suas superfícies como representações concretas de polígonos. E, assim como indicamos oralmente durante o encontro, a professora $\mathrm{G}$ escreveu em seu respectivo diário de bordo: "Começamos falando sobre polígono ser a figura com sua região interior, e não só o contorno, pois se considerarmos só o contorno da figura, nunca haverá sobreposição.” 
As respostas apresentadas pelos professores foram escritas a partir das conclusões encontradas após a discussão coletiva de tal forma que apresentamos aqui, nossas principais intervenções. A primeira parte da atividade foi realizada com certo nível de abstração, utilizando provas com argumentações algébricas, onde as figuras representativas só serviam para dar um suporte visual.

Figura 63 - Atividade 2 de pavimentações

Atividade 2 - Pavimentações de único tipo

Para efeito das atividades de pavimentações do plano, ampliaremos a definição de polígono P: o interior da região delimitada por $\mathrm{P}$ faz parte do polígono.

Compreendemos uma pavimentação do plano:

1) Ao redor de cada vértice há um agrupamento de polígonos dispostos lado a lado, com todos os lados congruentes, de forma a não sobrar lacunas $e$ nem haver sobreposições.

2) A composição de polígonos ao redor de todos os vértices no plano são todas iguais ou alternadamente iguais.

I - Existe uma quantidade mínima de polígonos regulares que podem ser dispostos ao redor de um vértice? Justifique (dica: pense em como são os ângulos internos de poligonos regulares).

II - Existe uma quantidade máxima de poligonos regulares que podem ser dispostos ao redor de um vértice? Justifique.

III - Crie uma hipótese a respeito de quais são os polígonos regulares que pavimentam o plano, de um único tipo.

a) Utilize os polígonos recebidos, um tipo por vez, e tente validar experimentalmente sua hipótese.

IV - Registre quais são os poligonos que pavimentam o plano, de um único tipo, e justifique sua resposta.

$V$ - Dado um polígono regular de $n$ lados, como você calcularia o seu ângulo interno? Justifique.

VI - $O$ que os ângulos internos dos polígonos regulares que você citou possuem em comum?

b) Considere que um ladrilhamento é a disposição de poligonos sobre o plano de forma a não deixar lacunas e nem haver sobreposições.

VII - Usando quadrados, você consegue fazer mais de um ladrilhamento? E triângulos equiláteros? Justifique.

VIII - Usando hexágonos regulares quantos ladrilhamentos são possiveis? Justifique.

c) Em uma folha em branco desenhe um triângulo congruente a base do caleidoscópio (triângulo equilátero de lado $10 \mathrm{~cm}$ ). Repita o procedimento numa segunda follha.

IX - Na primeira folha contorne seu triângulo com uma canetinha e pinte seu interior com um lápis de cor. Em seguida, com a mesma canetinha, ligue todos os pontos médios. Observe com o caleidoscópio sobre o triângulo, se foi formada uma pavimentação. Justifique.

$X$ - Na segunda folha pinte o interior do seu triângulo com um lápis de cor. Ligue, com uma canetinha, os três pontos médios ao incentro. Observe com o caleidoscópio sobre o triângulo, se foi formada uma pavimentação. Justifique.

Fonte: Autor

Durante a discussão do item I da atividade 2 (cf. Figura 63), foi justificado o porquê de não ser possível dispor ao redor de um vértice apenas dois polígonos regulares (mostramos exemplos de que pode ser possível, quando um dos dois polígonos é côncavo). Como já havíamos estudado configurações de três polígonos, mesmo que apenas experimentalmente, os professores participantes puderam concluir que a quantidade mínima de polígonos regulares que podem ser dispostos ao redor de um vértice é igual a 3. Alguns deles inclusive, discutiram 
configurações específicas; a professora $\mathrm{G}$ afirmou que é possível formar uma configuração com três hexágonos regulares pois a soma das medidas dos seus ângulos internos seria igual a $360^{\circ}$.

Depois de deixarmos os professores participantes debaterem entre si e refletirem sobre a resposta do item II, fizemos uma discussão em torno da relação entre o ângulo interno do polígono regular com a quantidade destes ao redor de um vértice; concluímos que, quanto menor é esse ângulo interno, maior será a quantidade de polígonos que podem ser colocados ao redor de um vértice. Logo, como o triângulo equilátero é o polígono regular de menor ângulo interno, a quantidade máxima é 6 , sendo necessariamente 6 triângulos equiláteros.

Nessa etapa do curso a transição do nível G1 para o G2 foi feita de forma dirigida. O nível de G1 foi caracterizado pelo uso de representações gráficas e desenhos realizados na lousa por nós e pelos professores participantes, algumas respostas faziam referência ao estudo desenvolvido com os materiais concretos (as peças de acrílico) de G0 e as conclusões e resultados matemáticos eram apresentados por meio de generalizações do nível G2, tais como a resposta escrita da professora G ao item III: "São polígonos cujo ângulo interno é divisor de $360^{\circ}$ e que tenham, no mínimo, 3 lados e, no máximo, 6 lados”. Essa e as demais respostas foram justificadas oralmente, destacando propriedades de lados e ângulos de polígonos. Deduzimos em conjunto, posteriormente, a forma de se obter o valor de ângulo interno de um polígono de $\mathrm{n}$ lados, mas nos primeiros quatro subitens essa forma foi tida como sabida.

Incluímos o item III pois, dentre outras razões, o professor $\mathrm{R}$ havia solicitado, em seu diário de bordo de encontros anteriores, que pudessem ter mais tempo para desenvolver suas ideias e criar suas conjecturas, sendo assim, incentivamos os professores a criarem suas hipóteses primárias antes de descobrirem resultados matemáticos experimentalmente.

\subsubsection{Tarefas da atividade 2 (pavimentações)}

Descreveremos aqui como foram desenvolvidas as tarefas da atividade 2, de pavimentações do plano, e analisaremos o desempenho geral dos professores participantes em cada um dos itens.

a) Utilize os polígonos recebidos, um tipo por vez, e tente validar experimentalmente sua hipótese.

Essa tarefa teve como principal característica a verificação experimental por meio de materiais concretos, sendo estes as peças de acrílico. Como as peças de acrílico que dispomos 
eram triângulos, quadrados, pentágonos, hexágonos, heptágonos, octógonos, eneágonos, decágonos e dodecágonos (todos regulares), pedimos que tentassem validar suas hipóteses apenas para esses polígonos (não apareceram hipóteses com polígonos diferentes dos citados). Nenhum professor afirmou que seria possível pavimentar o plano com polígonos regulares de um único tipo que possuam maior quantidade de lados do que o dodecágono.

IV - Registre quais são os polígonos que pavimentam o plano, de um único tipo, e justifique sua resposta.

Apesar de descobrirem experimentalmente quais dos 9 tipos diferentes de peças representam uma pavimentação de um único tipo, eles justificaram que apenas o triângulo equilátero, o quadrado e o hexágono regular podem ser usados devido ao fato de que seus ângulos internos possuem medidas que dividem $360^{\circ}$ e que então, poderiam dispor polígonos regulares do mesmo tipo, uma quantidade inteira de vezes.

V - Dado um polígono regular de n lados, como você calcularia o seu ângulo interno? Justifique.

Nosso objetivo aqui era de incentivar os professores participantes a construírem mais argumentos para a resposta do item anterior. Alguns professores sabiam a fórmula, mas poucos sabiam justificá-la. Portanto indicamos uma justificativa utilizando a medida do ângulo central do polígono regular de $\mathrm{n}$ lados, que é igual a $\frac{360}{n}$, obtida após se seccionar o polígono em triângulos, cada um com vértice no centro e em dois vértices consecutivos do polígono. Como o polígono regular é inscritível numa circunferência de mesmo centro, esses triângulos são todos isósceles, então os ângulos de sua base são congruentes, logo o ângulo interno (que é a união de dois desses ângulos de base) mede a diferença entre 180 e o ângulo central (usando que a soma das medidas dos ângulos internos de um triângulo qualquer da Geometria Euclidiana é igual a 180), ou seja, $180-\frac{360}{n}$.

Essa justificativa foi construída em meio a discussão coletiva e com anotações e representações na lousa, usando inclusive exemplos de alguns polígonos regulares.

VI - O que os ângulos internos dos polígonos regulares que você citou possuem em comum? 
A professora C escreveu, a respeito dos ângulos internos: "são divisíveis por $360^{\circ}$ ", ao invés divisores de $360^{\circ}$, mas mesmo assim ela mostrou compreender que as medidas dos ângulos internos de qualquer polígono regular divide $360^{\circ}$; discutimos alguns exemplos, tais como quadrado e hexágono regular.

b) Considere que um ladrilhamento é a disposição de polígonos sobre o plano de forma a não deixar lacunas e nem haver sobreposições.

Nesse momento, caracterizamos uma distinção entre a palavra ladrilhamento e pavimentação, sendo a pavimentação um tipo especial de ladrilhamento em que há a disposição lado a lado e o padrão descrito na característica 2 dessa atividade.

VII - Usando quadrados, você consegue fazer mais de um ladrilhamento? E triângulos equiláteros? Justifique.

Em ambos os casos são possíveis fazer mais de um ladrilhamento, efetivamente existem infinitas possibilidades de dispor os polígonos. Mas é importante se fazer uma observação: nos ladrilhos com quadrados cada quadrado deve estar disposto lado a lado com outros dois quadrados, caso contrário haverá lacunas e pelo mesmo motivo nos ladrilhos com triângulos cada triângulo também deve estar disposto lado a lado com outros dois triângulos. (cf. Figura 64 e Figura 65)

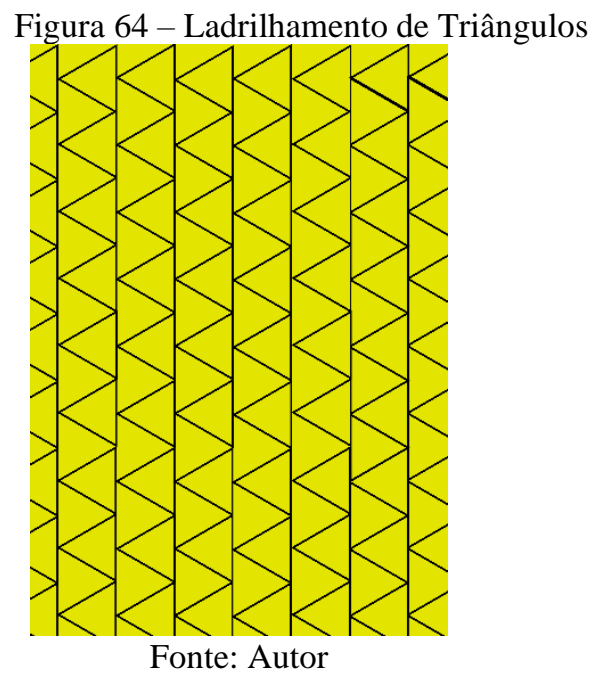




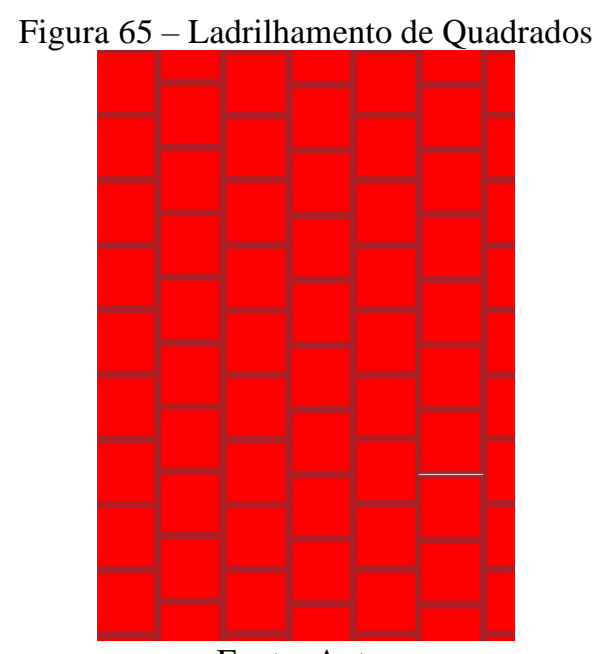

Fonte: Autor

Os professores mostraram além da configuração lado a lado, duas ou três formas de se ladrilhar, mas não afirmaram, antes da discussão, que havia infinitas possibilidades. Mostramos experimentalmente como formar diferentes ladrilhos com arrastamento das peças de acrílico. Nesse momento utilizamos a câmara de documentos para expor esse movimento das peças e ilustrar as diferentes formas de se obter ladrilhamentos.

VIII - Usando hexágonos regulares quantos ladrilhamentos são possíveis? Justifique.

As respostas foram acertadas, afirmando que não seria possível se fazer mais do que um tipo de ladrilhamento diferente, mas houve respostas em que o professor afirmava não conseguir encontrar mais de uma forma de se ladrilhar com hexágonos, enquanto outros afirmavam que não havia mais de uma forma possível (também houve respostas mais simples, como só uma figura representando esse ladrilho). Nosso objetivo era que eles percebessem que não seria possível outra formação de ladrilhamento com hexágonos regulares, mas tal percepção só ficou clara para todos após a discussão geral. A justificativa também foi obtida de forma coletiva, compreendendo que o deslizamento que foi possível com os quadrados e com os triângulos equiláteros ocorre devido ao fato de que os ângulos internos desses polígonos podem compor $180^{\circ}$, permitindo assim, um deslizamento horizontal.

c) Em uma folha em branco desenhe um triângulo congruente a base do caleidoscópio (triângulo equilátero de lado $10 \mathrm{~cm}$ ). Repita o procedimento numa segunda folha. 
IX - Na primeira folha contorne seu triângulo com uma canetinha e pinte seu interior com um lápis de cor. Em seguida, com a mesma canetinha, ligue todos os pontos médios. Observe, utilizando o caleidoscópio sobre o triângulo, se foi formada uma pavimentação. Justifique.

Destaca-se no item IX, o fato de que a mesma construção pode formar, visualmente, configurações diferentes, caso decida-se fazer ou não, o contorno do triângulo original, à canetinha (cf. Figura 66). Nosso objetivo era de se produzir uma configuração de pavimentação composta exclusivamente por triângulos equiláteros e estudar suas propriedades principais, como a congruência dos triângulos formados no interior do triângulo original.

A resposta esperada era que seria formada uma pavimentação de triângulos equiláteros, no entanto, a partir das discussões os professores identificaram a formação de hexágonos regulares também, ao imaginarem a composição formada por seis triângulos equiláteros ao redor de um vértice.. Fizemos representações na lousa e pedimos que os professores justificassem essa formação de imagens, dando destaque aos ângulos internos e centrais e as partições do hexágono regular em triângulos equiláteros.

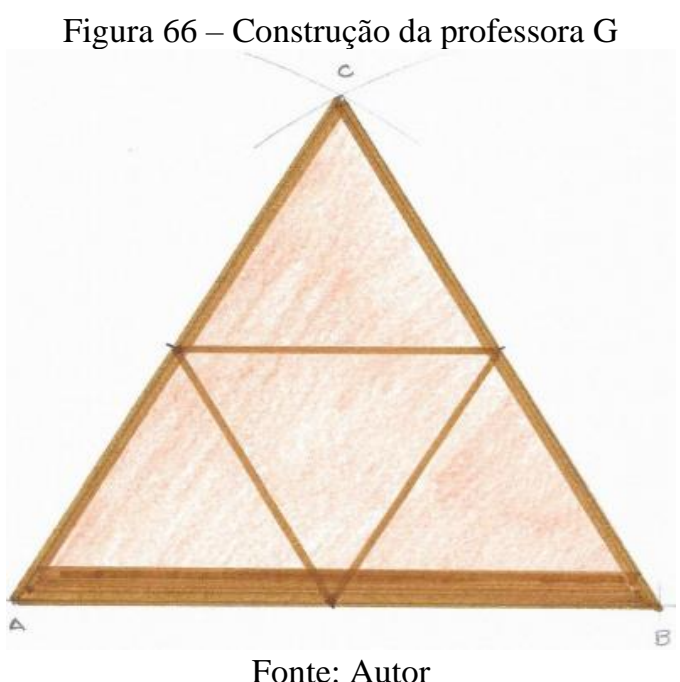

$X$ - Na segunda folha pinte o interior do seu triângulo com um lápis de cor. Ligue, com uma canetinha, os três pontos médios ao incentro. Observe com o caleidoscópio sobre o triângulo, se foi formada uma pavimentação. Justifique. 


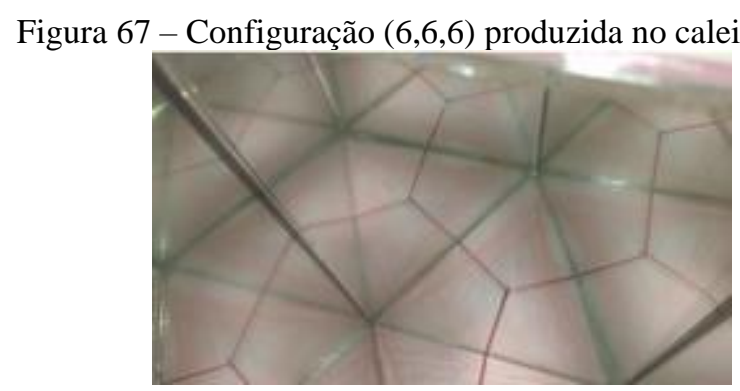

Fonte: Autor

A maioria dos professores participantes acertou a construção (cf. Figura 67) e verificaram que se formava uma pavimentação de hexágonos regulares. Relacionamos esse item com os resultados discutidos no item anterior no que diz respeito à formação de hexágonos regulares e suas propriedades relacionadas à ângulos internos e centrais.

\subsection{Análise do sétimo encontro}

Logo no início do sétimo encontro fizemos uma breve retomada das resoluções dos itens IX e $\mathrm{X}$ da atividade 2. Foi discutido porque é possível formar hexágonos regulares com um triângulo posicionado no interior da base para o caleidoscópio como também com um tipo de quadrilátero pipa. A conclusão é que, observando de outra forma, é possível verificar que o hexágono regular pode ser partido em seis triângulos equiláteros congruentes ou em seis quadriláteros pipa congruentes (cf. figura a seguir). A primeira partição é obtida fazendo-se "cortes" sobre os segmentos determinados por vértices opostos enquanto a segunda é obtida fazendo-se "cortes" sobre os segmentos determinados pelos pontos médios opostos. A forma como apresentamos essa ideia aos professores participantes foi de imaginar que é possível, dado uma figura de um hexágono regular, posicionar o caleidoscópio com os espelhos sobre dois vértices consecutivos ou posicioná-lo sobre dois pontos médios consecutivos, nos dois casos com o vértice do caleidoscópio sobre o centro do hexágono regular.

Figura 68 - Hexágono Regular partido em seis triângulos equiláteros

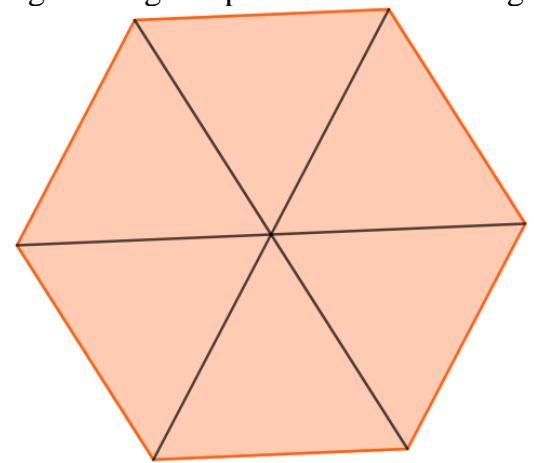

Fonte: Autor 
Figura 69 - Hexágono Regular partido em seis quadriláteros pipa

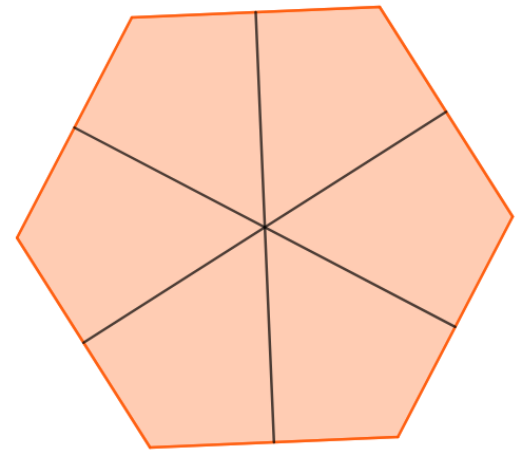

Fonte: Autor

Para a Atividade 3 (cf. Figura 70), foram entregues as peças de acrílicos para que os professores pudessem descobrir algumas pavimentações e suas propriedades a partir da manipulação de materiais concretos que representassem alguns tipos de polígonos regulares. Podemos caracterizar uma articulação entre os níveis G0 e G2 a partir do uso de materiais concretos para auxiliar no processo de produção de conjecturas e de se verificar experimentalmente determinados padrões com o uso de peças de acrílico e, posteriormente, justificar o que foi observado por meio de argumentação sobre as propriedades de pavimentações do plano.

Os professores participantes foram levados a pensar em padrões geométricos determinados por configurações de pavimentações. Além disso, uma discussão importante que permeou essa atividade foi a existência de configurações que podem ser formadas ao redor de um vértice mas que não podem se estender pelo plano. Fatos como esses eram inicialmente percebidos com a manipulação dos materiais, explorando suas características a partir de uma discussão coletiva e concluídos como resultados matemáticos.

Foi solicitado o registro de configurações de pavimentações e para esse registro fizemos a sugestão de que utilizassem a escrita tal como faz Barbosa (1993), em que, nas palavras de uma professora participante, está determinado a: quantidade de polígonos, quantidade de lados de um polígono e a ordem da qual os polígonos estão dispostos. Por exemplo, uma configuração com quatro quadrados ao redor de um vértice é denotada por $(4,4,4,4)$, mas podemos dispor outras configurações ao redor dos demais vértices, como a $(3,4,3,3,4)$. No entanto só se diz pavimentação um ladrilhamento em que todas as configurações ao redor de cada vértice são iguais, ou alternadamente iguais. 
Figura 70 - Atividade 3 (pavimentações), tarefas de a até $\mathrm{f}$

\section{Atividade 3}

Ao receber os conjuntos de polígonos regulares, tente colocar ao redor de pelo menos um vértice, polígonos diferentes sem que haja sobreposição ou lacunas.

a) É possível obter uma pavimentação em que apareçam pentágonos? E hexágonos? $E$ heptágonos? Quais? Justifique.

b) Podemos fazer uma pavimentação usando, simultaneamente, quadrados e triângulos equiláteros? De que forma(s)?

c) Utilize os polígonos recebidos para dispor, ao redor de um vértice, uma configuração sem deixar lacunas e sem sobreposições, formada por:

$\begin{array}{ll}\text { I) } 3 \text { polígonos regulares; } & \text { II) } 4 \text { polígonos regulares; }\end{array}$

III) 5 polígonos regulares; IV) 6 polígonos regulares;

Justifique porque cada configuração obtida é possível.

d) Existe mais de uma configuração possível, usando diferentes polígonos recebidos, para os itens I, II, III e IV? Escreva, quando existir, pelo menos mais um tipo de configuração para cada um dos itens.

e) De todas as configurações obtidas, escolha uma que seja possivel de se estender pelo plano, pavimentando-0. Justifique.

f) De todas as configurações obtidas, escolha uma que não seja possível de se estender pelo plano. Justifique porque essa extensão não pode ser feita.

Fonte: Autor

Para o item a, eles conseguiram encontrar, por meio da manipulação das peças, mais de uma configuração para hexágonos, nenhuma para heptágonos e para pentágonos uma configuração que não pode ser estendida pelo plano como uma pavimentação. A professora $\mathrm{A}_{2}$. afirmou que se tivéssemos uma estrela poligonal regular que encaixasse poderíamos formar uma pavimentação (ela produziu o padrão da Figura 71). A verificação das pavimentações foi dada de forma experimental e concreta assim como as combinações que não formam pavimentações.

Sabendo que, para pavimentar, deve haver um padrão que se repete em cada um dos vértices ou de forma alternada, precisaríamos verificar se é ou não, possível pavimentar o plano dessa forma. Nas respostas foi colocado que os heptágonos não podem ser combinados com outros dos polígonos que dispunham com a justificativa que reconhecesse que os ângulos internos não dividem $360^{\circ}$ e não somam $360^{\circ}$ com nenhuma combinação de outros dos polígonos, caracterizando respostas no nível G2, com o uso de propriedades da Geometria Plana. Para a configuração $(5,5,10)$ discutimos uma justificativa mostrada por Barbosa $(2005)$, 
usada para polígonos com número ímpar de lados em configurações com três polígonos regulares. Uma professora disse, num relato de seu diário de bordo, que gostaria de ter estudado mais justificativas como essa, nos itens da atividade seguinte.

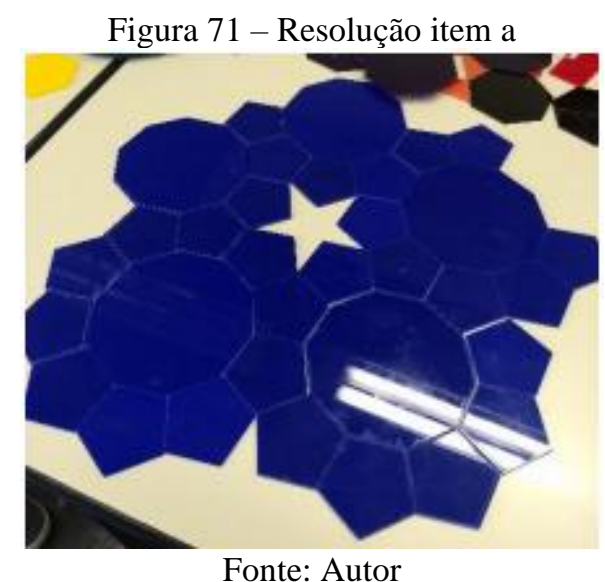

Nosso objetivo no item b foi de conduzir os professores a concluírem que existem pavimentações de uma ou duas configurações, além disso, uma curiosidade é que se forem utilizadas pelo menos três configurações diferentes é possível conseguir diversas pavimentações diferentes com quadrados e triângulos equiláteros. Todos os professores encontraram, a partir da manipulação das peças, alguma pavimentação e a descreveram nas suas respostas. No entanto, algumas justificativas ficaram incompletas ou mostraram que o conceito de pavimentação não estava totalmente compreendido por todos, de tal forma houve alguns momentos em que alguns professores se mostraram mais preocupados em produzir uma configuração local, sem discutir, com alguma profundidade, como estendê-la pelo plano. Na discussão os professores expuseram as configurações obtidas, a maioria deles encontrou a configuração $(3,3,3,4,4)$. Nesse item percebemos algumas dificuldades em se trabalhar com o nível G2, ao se utilizar as definições e propriedades de pavimentações para argumentações nas justificativas.

No item c incentivamos os professores a tentarem formar, manualmente, diferentes configurações com diferentes polígonos. Notemos que configurações com $\mathrm{N}$ polígonos regulares implica que é formada uma configuração tal que, ao redor de um vértice existe $\mathrm{N}$ polígonos regulares dispostos. Por exemplo, a configuração $(3,3,3,4,4)$ possui cinco polígonos regulares ao redor de um vértice, mesmo que só haja apenas dois polígonos diferentes, o quadrado e o triângulo equilátero.

No item I, o professor L confundiu essa indicação do exercício ao responder com a configuração $(3,4,3,12)$ na qual, apesar de serem utilizados apenas três polígonos regulares 
diferentes, é uma configuração em que há quatro polígonos regulares ao redor de um vértice.

Enquanto boa parte dos professores participantes deu apenas uma resposta para cada item (como solicitado no enunciado), a professora $\mathrm{M}_{2}$ escreveu todas as configurações que conseguiu encontrar (cf. Figura 72). Ela pediu para terminar de responder em casa e entregar por e-mail durante a semana, então essas respostas ela obteve com um trabalho mais detalhado em cada questão, dado em vista que já havia sido compartilhado nas discussões do encontro 7 , algumas dessas respostas e como obtê-las. A conclusão final colocada por ela foi ressaltada pelos próprios professores em aula, quando os questionamos "o que essas configurações obtidas possuem em comum?". Para essa pergunta apareceram respostas como "são todos polígonos regulares", "não deixam lacunas e nem sobreposições".

Quando questionamos “como justificamos matematicamente?”, a professora G afirmou que "os ângulos fecham $360^{\circ}$, uma volta completa". Essa discussão já havia sido iniciada em questões anteriores, de tal forma que sempre retomávamos os elementos e características já destacadas pelos professores durante os encontros.

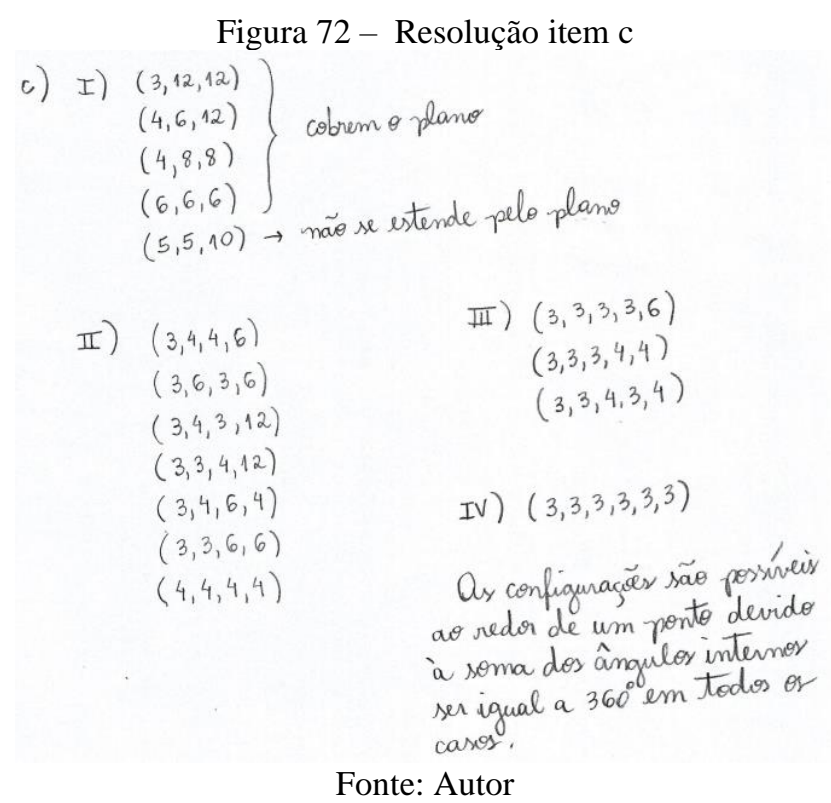

Para responder a questão d, pedimos para os professores falarem as configurações que encontraram, que era reproduzida por eles usando a câmara de documentos, ou apenas explicando oralmente. Dessa forma os demais puderam acrescentar mais configurações às suas respostas. No item IV todos perceberam que a única resposta era a configuração $(3,3,3,3,3,3)$.

No item e, os professores mostram-nos que já haviam pensado sobre como estender as configurações pelo plano, utilizaram algumas das justificativas obtidas na discussão anterior e escolheram uma das configurações obtidas no item c). Em suma, as justificativas, além de 
ressaltarem que a soma dos ângulos internos dos polígonos regulares resultava em $360^{\circ}$, descreviam que é possível reproduzir nos demais vértices o mesmo padrão de configuração. Ficou um pouco mais evidente o porquê de ser possível essa reprodução de um padrão quando observamos quais configurações não podem ser reproduzidas, como nos itens $\mathrm{f}$ e g ou a discussão dos pentágonos no item a. No entanto não exigimos que essa conclusão fosse descrita com todos esses detalhes nas respostas escritas, mas a reforçamos na discussão.

Algumas das respostas dadas estavam incompletas ou sem justificativas, em especial os professores L e $A_{2}$ não justificaram grande parte dessa atividade. O professor L escreveu em alguns dos diários (e relatou oralmente), inclusive no que é respectivo a esse encontro, que estava tendo algumas dificuldades em compreender os conceitos relacionados a pavimentação do plano, apesar de que obteve respostas satisfatórias na maioria das atividades propostas. Ressaltamos também que a professora $\mathrm{C}_{2}$ escreveu em suas respostas que precisou fazer uma pesquisa na internet para estudar mais o significado de pavimentação do plano.

A partir dessas percepções dos professores com relação aos conceitos de pavimentação percebemos que havia certa dificuldade no registro escrito - dificuldade essa que aparecera já em outros encontros, pois era muito comum que concluíssemos uma discussão em que todos participavam e ficava clara a conclusão de uma tarefa, no entanto quando pedíamos para que escrevessem era gasto um tempo maior do que o previsto - se comparado a outras representações, como figuras e esquemas, uso de materiais concretos e discussões, o que pode significar que, ou eles não estão muito habituados com esse tipo de justificativa por escrito, ou que transpor os resultados matemáticos obtidos via manipulação de materiais e construção de significado em conjunto para diferentes tipos de registros é difícil, mostrando que alguns conceitos podem não ter sido compreendidos em sua totalidade, mesmo com a apreensão de significados.

Com essa sequência de itens da atividade 3, formou-se uma proposta que pode encaminhar os professores a tirarem conclusões sobre pavimentações do plano e seus padrões geométricos, em especial, formando um caminho para chegarem às onze pavimentações do plano com polígonos regulares.

No item f, uma justificativa que apareceu foi observar o ângulo formado ao redor dos outros vértices e quais polígonos regulares poderiam se "encaixar" nas lacunas. O resultado era que ou o polígono mudava a configuração inicial, formando uma segunda configuração num vértice diferente, ou não seria possível "encaixar" nenhum polígono regular, por esse ângulo dessa lacuna não ser ângulo interno de polígono regular. Tais justificativas foram por nós 
incentivadas e encaminhadas, sugerimos que tentassem observar quais polígonos conseguiriam colocar nos demais vértices e notarem porque não poderiam ser os mesmos do vértice com a configuração inicial. Foi citado nas respostas, e discutido como um dos exemplos, a configuração $(3,4,3,12)$, na qual é possível preencher as lacunas ao redor dos outros vértices se for utilizada a configuração $(4,3,4,6)$.

O item g (cf. figura 73.1) foi resolvido em duplas e entregue em uma folha separada nesse mesmo dia, compondo parte da avaliação dos professores. Nesse dia havia 8 professores presentes, portanto cada dupla realizou um subitem diferente. A figura 73.2 a seguir mostra a resolução dada no subitem (i).

Figura 73.1 - Item g da atividade 3 (pavimentações)

g) Analise as seguintes configurações abaixo e verifique se pavimentam o plano.

Justifique sua resposta:

(i) triângulo equilátero, heptágono regular e 42-ágono regular:

(ii) triângulo equilátero, octógono regular e 24-ágono regular;

(iii) quadrado, pentágono regular e icoságono regular;

(iv) triângulo equilátero, eneágono regular e octodecágono regular.

Fonte: Autor

Figura 73.2 - Resolução subitem (i)

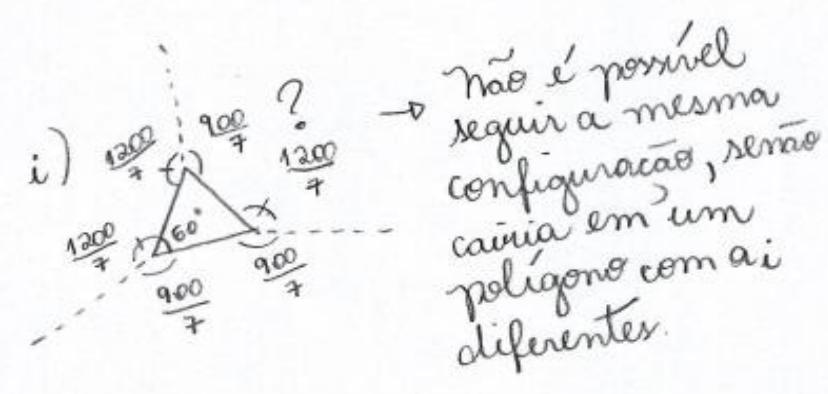

Fonte: Autor

Essa dupla usou frações de denominador sete para representar os valores dos ângulos internos dos três polígonos regulares desse subitem. Na figura 71.2, em que está indicado a resposta dada pela dupla composta pelas professoras $\mathrm{M}_{2}$ e $\mathrm{M}_{3}$, apresenta-se uma representação por meio de um desenho com indicação dos possíveis ângulos internos unida a uma conclusão escrita.

Notemos que elas inseriram o heptágono abaixo do triângulo e o 42-ágono no lado esquerdo desse triângulo e no terceiro lado escreveram as medidas dos ângulos que deveriam 
ser usados para que a configuração $(42,7,3)$ pudesse se repetir, formando um polígono com dois ângulos internos diferentes, que elas nomearam de " $\mathrm{a}_{\mathrm{i}}$ ".

Em outra parte da sua folha de resolução, mostraram o que aconteceria se optassem por utilizar como terceiro polígono um heptágono em uma argumentação própria do nível G2, ilustrado na figura abaixo.

Figura 74 - Resolução subitem (i)

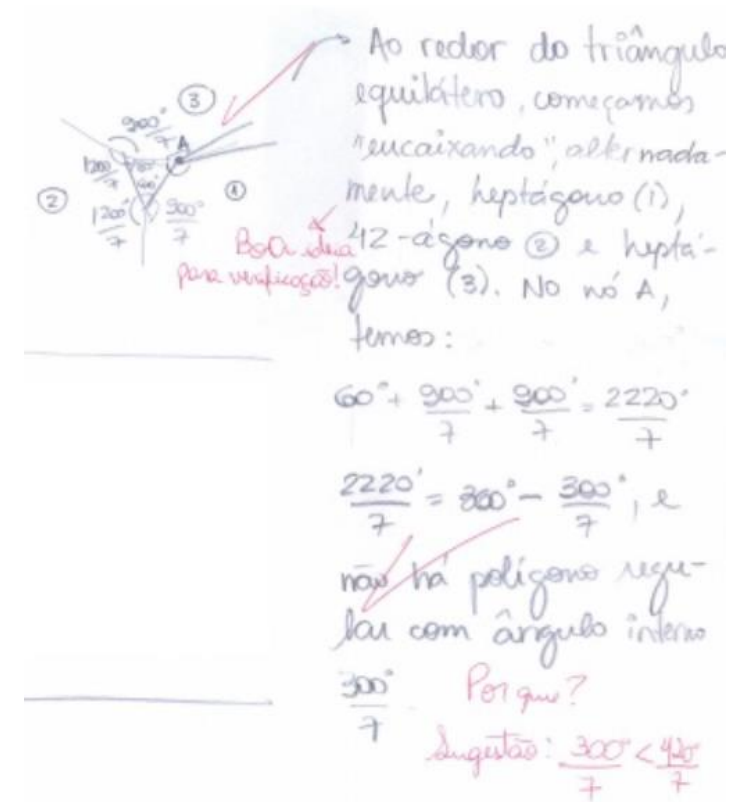

Fonte: Autor

Na semana anterior a este encontro os professores entregaram via e-mail um esboço do plano de aula respectivo à aplicação das atividades com os seus alunos. Nos comprometemos a oferecer apoio na formulação desse plano de aula e que o mesmo poderia ser corrigido antes da entrega final, no último encontro.

Neste último momento do $7^{\circ}$ encontro fizemos alguns comentários a respeito dos planos de aula que haviam sido entregues. Cada um recebeu uma orientação com comentários via email, no sentido de uma devolutiva dos planos de aula entregues. Mas para além disso, fizemos observações gerais sobre as atividades propostas, tentamos oferecer alternativas para uso de materiais e adaptações de atividades, além de propor melhorias nos planos de aula entregues.

Até então metade da turma ainda não tinha conseguido terminar esse esboço de plano de aula, apesar de terem trabalhado em sua preparação durante a semana anterior a este encontro, seguindo nossas orientações por e-mail (consistindo nos elementos do plano de aula e nos slides da apresentação sobre as cinco práticas). Os demais enviaram nos dias seguintes.

Quem não conseguiu entregar antes do sétimo encontro ficou com menos tempo de 
receber o nosso feedback e, inclusive, alguns não conseguiram preparar uma segunda versão desse trabalho.

\title{
Observações
}

Após lermos os diários de bordo, alguns comentários nos chamaram mais a atenção e, dentre eles, o da professora $\mathrm{G}$ nos faz considerar que, de certa forma, não houve muito tempo para que os professores participantes pudessem se apropriar das últimas atividades e adaptá-las para a aplicação. A maioria das atividades propostas e aplicadas pelos professores são de atividades dos cinco primeiros encontros. No entanto, não foram aplicados temas diferentes nos últimos encontros (sétimo e oitavo), o que ocorreu foi uma imersão maior ao tema de pavimentações do plano, sendo que os encontros anteriores compuseram subtópicos desse tema principal: compreensão de algumas propriedades das isometrias, características dos polígonos regulares, ângulos internos e centrais, configurações de pavimentações, etc.

O comentário da professora $\mathrm{G}$, realizado no seu diário de bordo, ilustra as dificuldades de se apropriarem do tema principal com antecedência:

\begin{abstract}
Achei o tema do 7o encontro muito interessante e fácil de utilizar em sala de aula, o que me deixou um pouco frustrada, pois cada aula nova acho o tema mais interessante para a aula que teremos de aplicar. Infelizmente os temas mais pertinentes com o conteúdo do ensino fundamental foram abordados nos encontros finais e ficamos com o tempo apertado para criar outro plano de aula e adaptá-las. Para finalizar o encontro, os professores falaram um pouco sobre o esboço do plano de aula que enviamos e deram dicas de como adaptar as atividades. Foi bem esclarecedor.
\end{abstract}

\section{Lição de Casa}

A atividade 4, sobre pavimentações ficou como lição de casa para ser entregue e discutida na semana seguinte, no oitavo encontro. Para tanto, os professores puderam pegar emprestado espelhos e caleidoscópios para auxiliar na resolução dos exercícios.

\subsubsection{Planos de aula}

Desde o início do curso já era de conhecimento de todos os participantes que, como componente de avaliação individual, cada um deveria elaborar e experimentar uma sequência didática com 
seus alunos utilizando atividades, desenvolvidas por eles mesmos, inspiradas nas atividades estudadas nos encontros presenciais.

Além das atividades realizadas no decorrer do curso, os professores tiveram que elaborar um plano de aula, onde descreveriam o planejamento de uma ou mais aulas nas quais buscariam explorar outras atividades, por eles desenvolvidas, que consistiriam uma adaptação do que foi estudado e explorado nos encontros presenciais com os formadores.

No sexto encontro apresentamos (via slides e discussão de um caso) e discutimos as cinco práticas para orquestração de discussões Matemáticas produtivas em sala de aula e solicitamos que os professores participantes fizessem as descrições em seus planos de aula a partir delas. Foi acordado que cada um dos professores produziria seus planos de aula e nos enviariam por e-mail para receberem o devido feedback antes do sétimo encontro.

Até este momento, os professores participantes desenvolveram seus planos de aula baseados em nossas instruções, dadas oralmente no sexto encontro. Tais instruções foram em direção a auxiliar os professores a pensarem uma forma de desenvolver uma atividade, ou sequência didática, inspirada em suas experiências dos encontros anteriores do presente curso. Deveriam pensar em atividades para uma ou mais aulas, para serem desenvolvidas com seus próprios alunos; dispusemo-nos a ir às suas escolas para auxiliar na aplicação assim como a emprestar os materiais utilizados no decorrer dos encontros (fornecidos pelo CAEM).

Para nós, a importância da elaboração e aplicação desse plano de aula está em analisar e avaliar em que medida os professores se apropriaram do conhecimento pedagógico do conteúdo desenvolvido nos encontros do curso. Dessa forma, pudemos analisar, com certa nitidez, a aplicabilidade dos contextos explorados, supondo que o público-alvo das atividades poderia ser composto por alunos da Educação Básica ou do Ensino Superior.

O trabalho final entregue pelos professores consistiu em entregar, além do plano de aula com as devidas modificações, o relatório descrevendo as intervenções, o processo de aplicação e uma reflexão sobre os resultados e sobre sua própria prática, analisando também, se os objetivos de aprendizagem foram alcançados.

Entre o sétimo e oitavo encontro alguns professores participantes já haviam realizado suas atividades com seus alunos e começaram a analisar os resultados obtidos. Por outro lado, alguns professores não haviam conseguido o tempo hábil para fazê-lo ainda. Dessa forma, dois dos professores fizeram uma exposição oral dos resultados de sua sequência didática, enquanto os demais fariam nos dias seguintes. 
Como estava previsto, inclusive no cronograma oficial do curso, que seria realizado um total de oito encontros presenciais, mas não havíamos conseguido alcançar essa etapa final com todos os professores participantes, decidimos em conjunto que haveria um encontro extra para que as exposições dos trabalhos dos demais professores pudessem ocorrer e para que eles tivessem mais tempo para experimentarem suas atividades em suas escolas. Tal encontro ocorreu duas semanas após o oitavo encontro. A análise dos trabalhos finais será apresentada após a análise do oitavo encontro.

\subsection{Análise do oitavo encontro}

Durante o início do oitavo encontro fizemos a discussão sobre a atividade 4, incentivando os professores a apresentarem como foram suas resoluções, quais dificuldades tiveram, bem como críticas e comentários.

Em meio à discussão, alguns professores puderam perceber seus erros e como corrigilos, além disso nos atentamos a um detalhe no enunciado do item 4-c que o deixava, de certa forma, incoerente, fazendo com que uma errata desse item fosse proposta, posteriormente, via e-mail.

\subsubsection{Análise da Atividade 4}

Embora as respostas do item a (cf. figura 75) tenham sido dadas a partir da observação visual de imagens produzidas no interior do caleidoscópio, caracterizando uma análise no nível G1, os professores participantes utilizaram argumentos baseados em conceitos e propriedades de Geometria, caracterizando o paradigma G2 ao descrever a representação produzida. 
Figura 75 - Atividade 4, tarefa a

\section{Atividade 4}

Escolha um dos caleidoscópios equiláteros e faça, em três folhas diferentes, um triângulo equilátero que seja congruente a base do caleidoscópio escolhido (de lado $10 \mathrm{~cm}$ ). Dica: para facilitar a construção dos triângulos você pode fazer o contorno por dentro do caleidoscópio.

a) Na primeira folha faça a seguinte construção: usando uma canetinha, ligue os pontos médios, dois a dois; note que foram formados 4 novos triângulos; pinte 0 triângulo determinado pelos pontos médios com uma cor e os demais com outra cor. Observe com o caleidoscópio sobre o triângulo, se foi formada uma pavimentação. Justifique.

I) $O$ que os 4 triângulos formados tem em comum? Justifique.

II) Por que a reflexão sucessiva de 4 triângulos congruentes pode formar polígonos diferentes?

III) Na atividade 2, item c) X, foram produzidos hexágonos regulares a partir da reflexão sucessiva de quadriláteros, enquanto na presente atividade os hexágonos regulares foram produzidos a partir da reflexão de triângulos equiláteros. Por que é possível se produzir hexágonos regulares a partir dessas duas maneiras diferentes? Existe(m) outra(s)? Justifique.

IV) Discuta com seus colegas e responda: é possível produzir a configuração $(3,6,3,6)$ com outro tipo de construção para a base do caleidoscópio? Comente.

Fonte: Autor

Foi concluído por todo o grupo que a construção produz uma pavimentação do plano e suas justificativas foram utilizando argumentos axiomáticos de G2 sem demonstrá-los. A título de exemplos das respostas apresentadas, reproduzimos na figura a seguir o que as professoras $\mathrm{G}$ e $\mathrm{C}_{2}$ escreveram.

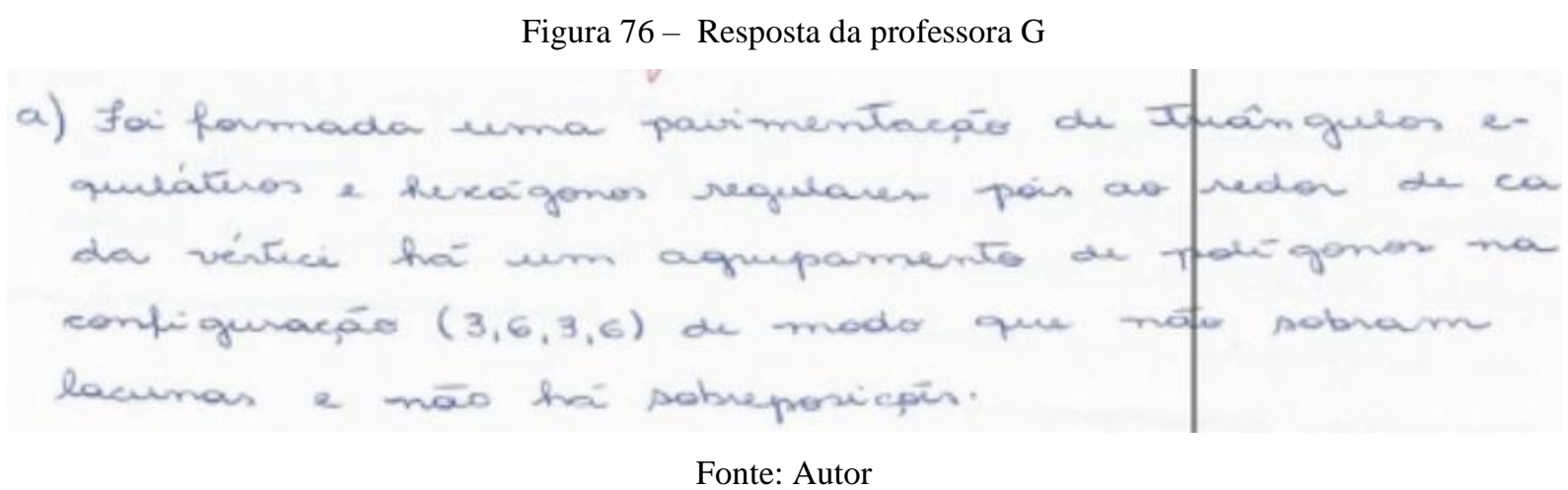

A professora $\mathrm{G}$ afirmou, utilizando a simbologia adequada, que a configuração formada foi $(3,6,3,6)$ e que os polígonos estavam agrupados sem sobrar lacunas e sem sobreposições. 
Figura 77 - Resposta da professora $\mathrm{C}_{2}$

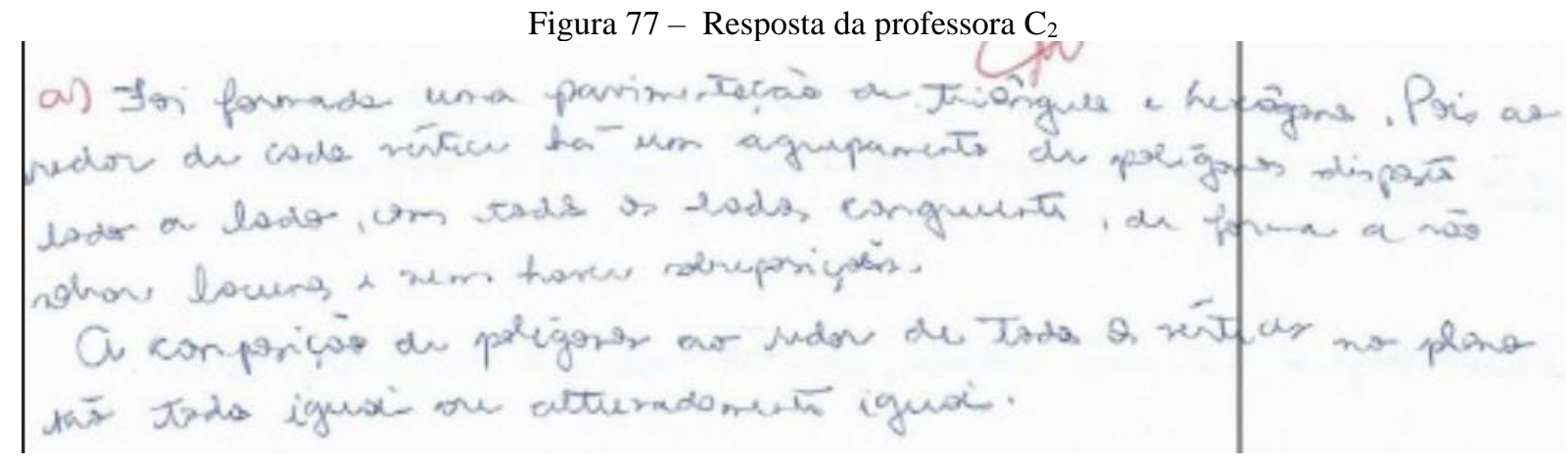

Fonte: Autor

A professora $C_{2}$ justificou dizendo que, além de não haver lacunas e sobreposições, os polígonos estavam dispostos lado a lado com todos os lados congruentes.

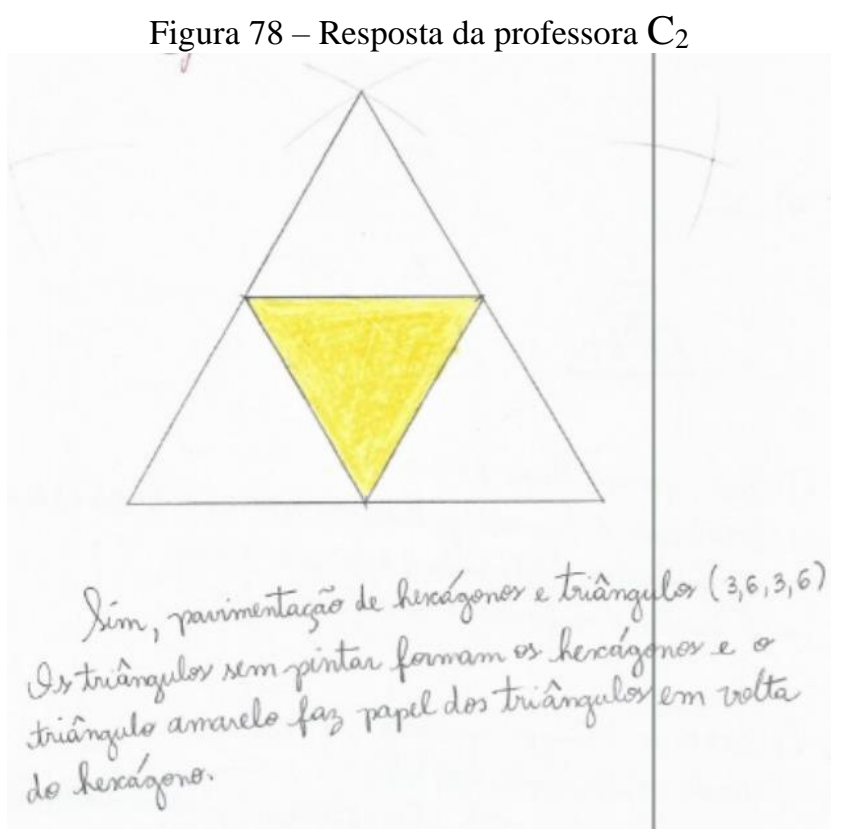

Fonte: Autor

Todos os professores conseguiram identificar, inicialmente, que foi formada uma pavimentação do plano com triângulos equiláteros e hexágonos regulares. A professora $\mathrm{M}_{2}$ discutiu (cf. figura 78) de que forma a base para o caleidoscópio pôde produzir os polígonos que compõem essa pavimentação.

Os itens da construção a (I a IV) têm por objetivo auxiliar os professores a buscarem uma argumentação hipotético-dedutiva e perceberem que após a etapa de se trabalhar com os materiais concretos que produzem, visualmente, uma pavimentação, ainda é necessário fazer uma justificativa considerando uma pavimentação como um objeto geométrico ideal e abstrato. 
Nota-se que a visão humana nos permite identificar uma determinada quantidade de polígonos, mas a pavimentação descrita e idealizada nessas atividades é formada por infinitos polígonos regulares.

No item I, a professora $G$ afirmou que os 4 triângulos são congruentes e justificou demonstrando, primeiramente, que eram triângulos equiângulos utilizando propriedades e resultados da Geometria Plana (tais como, ângulos alternos internos) e, em seguida, demonstrou que são equiláteros. Assim concluiu a congruência, conforme figura abaixo.

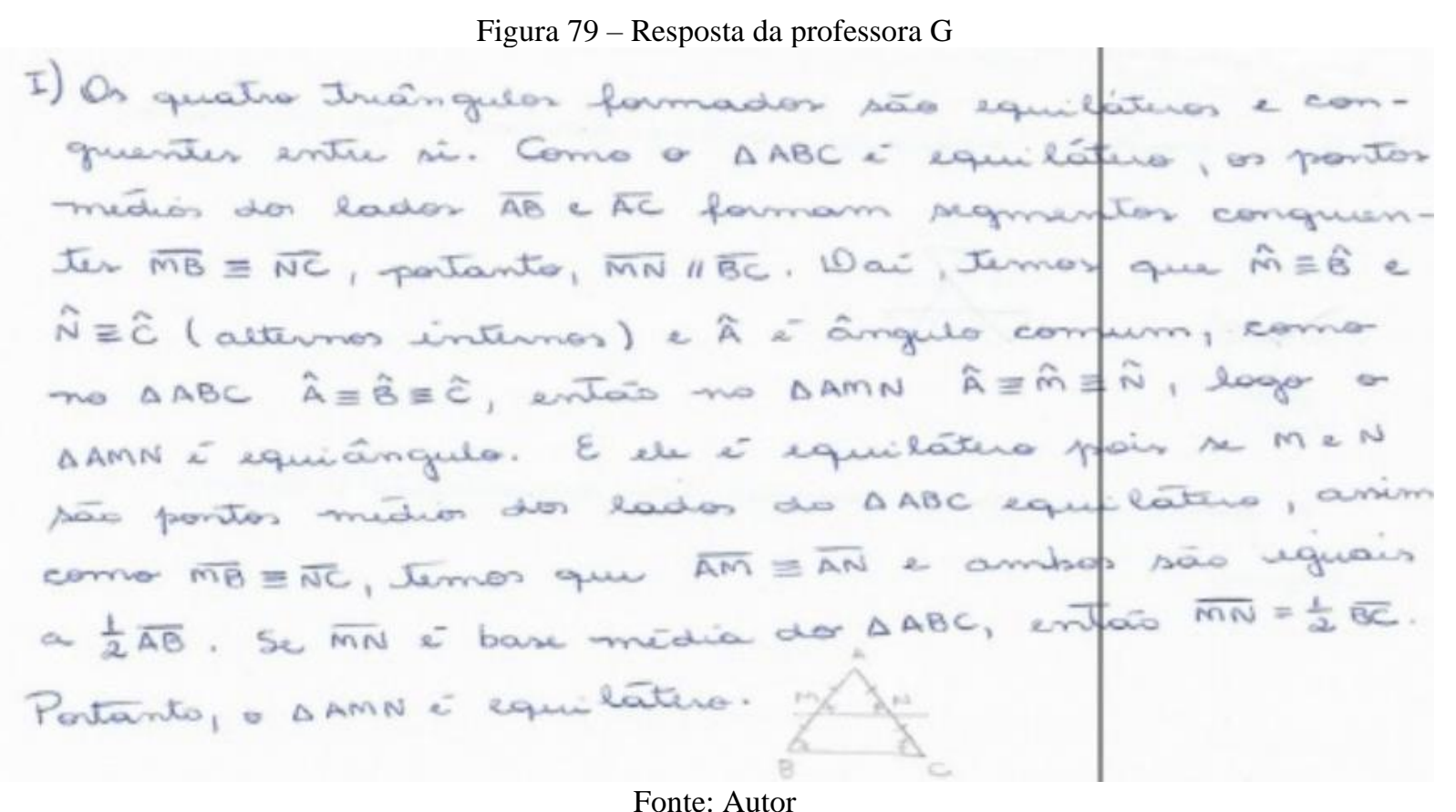

A professora $\mathrm{M}_{2}$ respondeu: "São equiláteros. O central é formado a partir do ponto médio, portanto tem a mesma medida que a metade do lado do triângulo original”. Mesmo utilizando uma linguagem adequada, a professora não justificou explicitamente a congruência, restringindo-se a indicar a relação entre o lado do triângulo central e o original.

Os demais professores não justificaram suas respostas, afirmando apenas que os 4 triângulos eram equiláteros por causa da base média construída. Nesse item, verificamos novamente, a identificação de propriedades pertinentes sem um detalhamento de suas consequências para justificar os resultados, por parte dos professores, em construir justificativas no nível de G2.

Como esperado, todos os professores compreenderam que a discussão do subitem II era sobre como a reprodução de triângulos equiláteros, por meio da reflexão com espelhos planos, pôde formar hexágonos regulares. Nesse item, as respostas obtidas podem ser identificadas ao 
nível do G2, sendo que foi feita uma análise sobre uma propriedade que foi observada anteriormente.

Muitas das respostas tinham caráter descritivo e não justificavam todas as suas afirmações. Frases do tipo "são formados seis triângulos congruentes" justificavam porque se formava um hexágono. Não apareceu, em meio às respostas dadas, a discussão sobre o ângulo interno do triângulo equilátero original ser reproduzido de forma a compor seis ângulos de $60^{\circ}$ em torno de um vértice, pelo efeito do caleidoscópio, por exemplo.

No item III, item a professora $\mathrm{G}$ respondeu justificando como formar um hexágono regular a partir da reprodução de triângulos equiláteros. Mesmo com o destaque em negrito “maneiras diferentes", ela não descreveu outra(s). O professor R discutiu a formação a partir de quadriláteros, afirmando que dois vértices desses quadriláteros eram os pontos médios do hexágono produzido.

As respostas obtidas nos itens III e IV mostraram que nosso objetivo foi parcialmente alcançado. Os professores discutiram uma forma de se obter o hexágono regular a partir da construção na base para o caleidoscópio, mas não discutiram se haveriam outras construções possíveis.

Gostaríamos que os professores participantes discutissem que não seria possível se obter a configuração $(3,6,3,6)$ por meio de uma construção diferente. Em uma atividade concreta, seria possível observar com o caleidoscópio sobre uma pavimentação do plano tal como a que é formada no item a, estendida por toda uma folha e perceber que qualquer outra posição do caleidoscópio não produziria a pavimentação conhecida.

Apesar de estar explicitado no enunciado do item $b$ (cf. figura 80) a necessidade de se fazer a justificativa das afirmações, a maioria dos professores não o fez, embora tenham respondido os itens seguintes buscando fazer uma argumentação adequada. Todos afirmaram corretamente, que a pavimentação formada era $(3,4,6)$. O desenho formado pode ser observado na figura 81 a seguir. 
Figura 80 - Atividade 4, tarefa b

b) Na segunda folha faça a seguinte construção (escreva os nomes dos pontos no exterior do triângulo): nomeie os vértices do triângulo de $A, B$ e $C$; a partir do ponto médio $D$ do lado $\overline{A B}$, trace a lápis os segmentos $\overline{D E}$ e $\overline{D F}$, tais que $\mathrm{E} \in$ $\overline{C B}$ e $\mathrm{F} \in \overline{C A} \operatorname{com} A \hat{D F}$ e $B \hat{D E}$ medindo $45^{\circ}$. Apague os segmentos $\overline{D E}$ e $\overline{D F}$, mantendo apenas os pontos $\mathrm{E}$ e $\mathrm{F}$. Faça a projeção ortogonal dos pontos $\mathrm{E}$ e $\mathrm{F}$ sobre o lado $\overline{A B}$ determinando, respectivamente, os pontos $G$ e $\mathrm{H}$. Trace $\overline{F E}, \overline{H F}$ e $\overline{G E}$ com uma canetinha de cor escura ou caneta preta. Agora pinte o interior do retângulo $\mathrm{EFHG}$ com uma cor, os triângulos $\mathrm{EGB}$ e FHA com uma segunda cor e 0 triângulo $E C F$ com uma terceira cor. Observe com o caleidoscópio sobre o triângulo, se foi formada uma pavimentação. Justifique.

V) As reflexões sucessivas do triângulo $E G B$ e do triângulo $F H A$ (ambos irregulares) produziram qual polígono? Justifique.

VI) As reflexões sucessivas do retângulo FHGE formam quadrados, então como você poderia comparar os segmentos $\overline{F E}, \overline{H F}$ e $\overline{G E}$ ? Justifique.

VII) É possível produzir um quadrado a partir das reflexões sucessivas de outra construção da base para o caleidoscópio?

Fonte: Autor

Figura 81 - Exemplo de uma construção de base para $(3,4,6)$

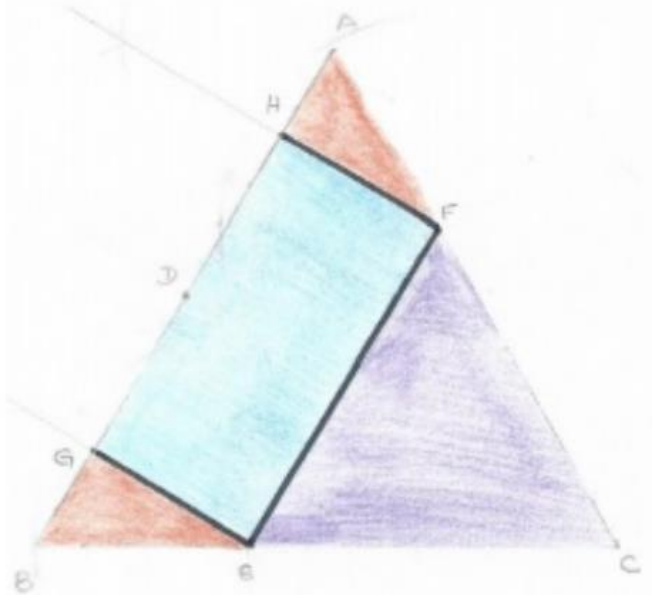

Fonte: Autor

No subitem $\mathrm{V}$, todos responderam que seria produzido um triângulo equilátero e a justificativa foi apresentada e argumentada. Dentre os argumentos, a professora $\mathrm{A}_{1}$ afirmou que “(o triângulo FHA) É refletido 6 vezes em torno de A”.

Em atividades dos encontros anteriores, havíamos discutido como determinar o número de imagens por meio de reflexões sucessivas em espelhos concorrentes de tal forma que os professores passaram a usar esse resultado de forma implícita em suas respostas. 
Essa mesma professora fez uma representação dessas reflexões sucessivas (cf. Figura 82). Nesse caso, foi feita uma argumentação que inicia em G2, ao se fazer afirmações sobre a reflexão em si, e partem para G1 ao usar uma representação gráfica em que a figura detém todos os elementos que são pertinentes à justificativa.

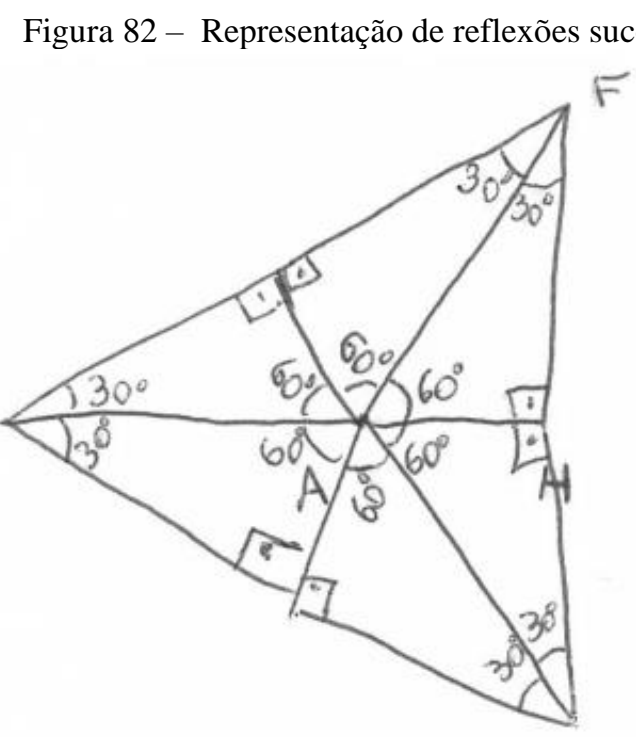

Fonte: Autor

Outros professores acrescentaram às suas respostas afirmações sobre a "duplicação" do ângulo HFA e do segmento FH.

A afirmação de que "As reflexões sucessivas do retângulo FHGE formam quadrados" foi dada como verdadeira no subitem VI, em vista de que a justificativa deveria ser apresentada e discutida anteriormente, no item b, mas como ela não foi feita, os professores se convenceram disso a partir do aspecto visual produzido no caleidoscópio.

Mesmo que o caleidoscópio seja um objeto concreto e manipulável, nesse caso não podemos entender que se trata de um paradigma de G0, pois o objeto de estudo são as pavimentações do plano, as quais são representadas por meio do caleidoscópio, caracterizando então, uma Geometria espaço-gráfica G1.

A discussão se deu sobre as propriedades da reflexão. Nesse caso, a conclusão é que os segmentos $\underline{H F}$ e $\underline{G E}$ medem a metade do segmento $\underline{F E}$. O objetivo era que os professores participantes pudessem perceber que também seria possível se concluir que seria obtido um quadrado, por meio das reflexões, se eles pudessem demonstrar primeiro, que vale essa propriedade dos segmentos. 
Foi discutido nos encontros que existem duas formas de se produzir hexágonos regulares a partir do caleidoscópio. Em uma delas era reproduzido o quadrilátero determinado pelo centro do hexágono um vértice e os pontos médios adjacentes (item III).

Uma resposta dada pelo professor R ao subitem VII foi: "Não, pois deveríamos construir um ângulo de $90^{\circ}$, o que não é possível realizar de outra maneira”; acreditamos que possivelmente ele considerou uma construção como a do hexágono regular, citada acima. Uma observação pertinente é que essa construção pode ser feita se usarmos um caleidoscópio retângulo (com um dos três ângulos internos sendo reto).

A maioria dos professores não respondeu essa questão e a professora $\mathrm{G}$ respondeu um argumento semelhante ao do professor $\mathrm{R}$, mas sugeriu o uso dos eixos de simetria do quadrado (respondeu "sim").

A tarefa c foi realizada em casa e apresentaremos aqui, o enunciado da tarefa $\mathrm{c}$ da atividade 4 , já corrigido:

a) $\mathrm{Na}$ terceira folha faça a seguinte construção: nomeie os vértices do triângulo de $\mathrm{A}, \mathrm{B}$ e C (escreva os nomes dos pontos no exterior do triângulo); encontre o ponto médio $\mathrm{D}$ do lado $\mathrm{AB}$ e os pontos médios E e F de AD e DB, respectivamente. Faça a projeção ortogonal dos pontos

E e F sobre os lados AC e BC, respectivamente, determinando $\mathrm{G}$ e $\mathrm{H}$, respectivamente. Trace HF e GE com uma canetinha de cor escura ou caneta preta. Pinte o interior dos triângulos FHB e EGA com uma cor e o pentágono CGEFH com uma segunda cor. Observe com o caleidoscópio sobre o triângulo, se foi formada uma pavimentação. Justifique.

VIII) Como você poderia alterar essa construção a fim de que os segmentos EG, ED, DF e FH fossem congruentes entre si?

A partir dessa alteração, responda:

IX) As imagens do pentágono CGEFH formaram qual polígono? Justifique.

$\mathrm{X}$ ) Por que essa construção produziu dodecágonos regulares cuja medida do lado é igual a medida do lado dos triângulos equiláteros? Justifique.

\subsubsection{Análise da Atividade 5}

Na seguinte etapa do oitavo encontro foi realizada, individualmente, a atividade 5, sobre pavimentações do plano, com discussões realizadas em duplas. Cada um teve que entregar suas 
resoluções, justificativas e construções em uma folha de sulfite. Na figura a seguir podemos ver os professores participantes em diferentes etapas da realização dessa atividade: as duas professoras a direita estavam elaborando a construção da base para o caleidoscópio, o professor a esquerda estava fazendo as observações empíricas com caleidoscópio e a outra professora estava escrevendo suas justificativas e argumentações.

Figura 83 - Etapas da Atividade 5

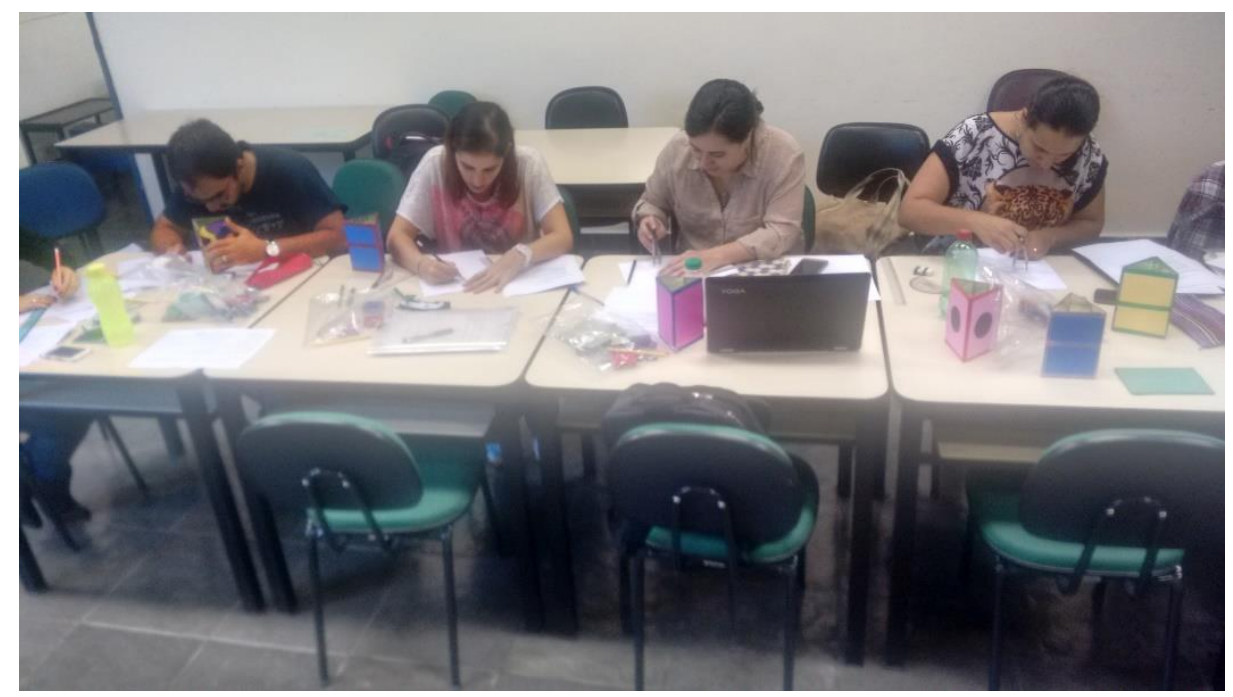

Fonte: Autor

Posteriormente, foram realizadas as correções dessas folhas e devolvidas no nono encontro. Professores que não estiveram presentes no nono encontro, para receber a folha corrigida, puderam buscar no CAEM em outro momento.

A utilização da definição de pavimentação do plano aparece nas resoluções da atividade anterior, e foi tomada como sabida e implícita na atividade 5 (cf. Figura 81), como esperado. A construção no interior do triângulo equilátero (a base) foi realizada de forma que os traçados representam, ao mesmo tempo, o lado de dois polígonos e a reflexão em espelhos planos reproduz o padrão da base por todo o plano. 
Figura 84 - Atividade 5 de Pavimentações

CAEM - IME - USP

\title{
Encontro 8 - Pavimentações com Polígonos Regulares
}

\begin{abstract}
Atividade 5
Escolha um dos caleidoscópios equiláteros e faça, em uma folha, um triângulo equilátero $A B C$ que seja congruente à base do caleidoscópio escolhido.

Faça a seguinte construção no triângulo obtido:

- encontre o ponto médio $D$ do segmento $A B$;

- determine os pontos $E$ e $F$ em $A C$ e $B C$, respectivamente, tais que $A D E \equiv B D F$ e ambos medem $45^{\circ}$;

- determine as bissetrizes $b_{1}$ e $b_{2}$ dos ângulos $A C D$ e $B C D$, respectivamente;

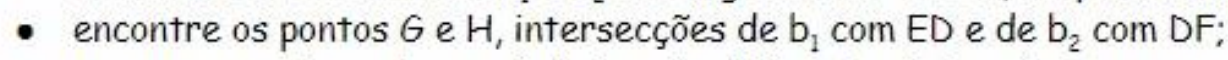

- apague seus traçados no interior do triângulo, deixando apenas os pontos $G$ e H marcados;

- faça a projeção ortogonal do ponto $G$ sobre o segmento $A B$, obtendo $I$, e sobre o segmento $A C$, obtendo $\mathrm{J}$;

- faça a projeção ortogonal do ponto $H$ sobre o segmento $A B$, obtendo $K$, e sobre o segmento $B C$, obtendo $L$;

- pinte o quadrilátero GHKI com uma cor, os quadriláteros HLBK e GJAI com uma segunda cor e o pentágono $\mathrm{CLHGJ}$ com uma terceira cor.
\end{abstract}

Observe com o caleidoscópio sobre o triângulo, se foi formada uma pavimentação. Justifique.

Fonte: Autor

Essa atividade consistiu em dois momentos: o primeiro deles foi a construção da base para o caleidoscópio (cf. Figura 85) e, em seguida, foi feita a observação por meio do caleidoscópio sobre essa base para a constatação experimental da produção de uma pavimentação do plano. O caleidoscópio, sendo um objeto formado por espelhos, é uma concretização do objeto teórico eixo de reflexão, portanto sua utilização caracteriza uma Geometria de paradigma G0, mas a base observada, bem como suas reproduções nos espelhos são de G1, por se tratar de uma representação gráfica de objetos ideais tais como quadriláteros. Já a argumentação utilizada para descrever e justificar essa formação se da no nível G2. 
Figura 85 - Construção da Professora $\mathrm{A}_{2}$

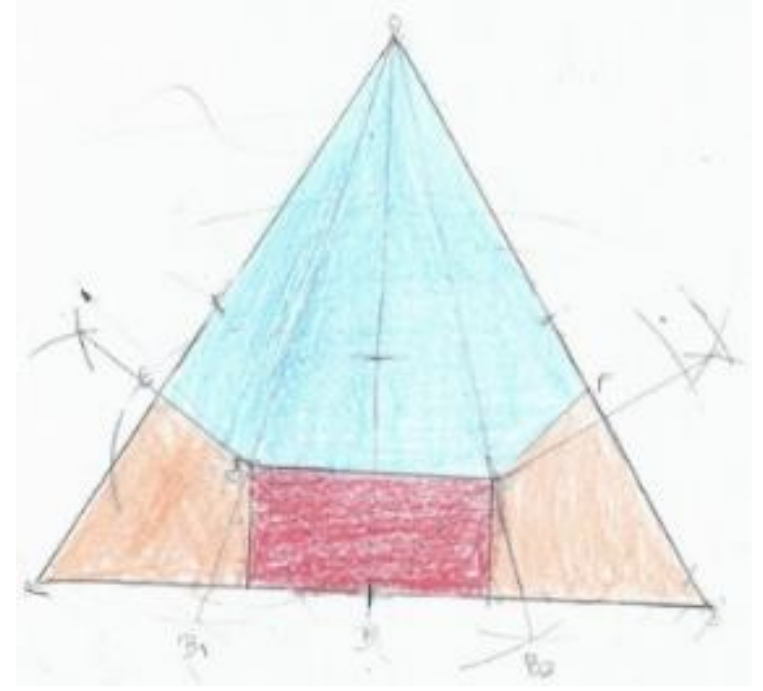

Fonte: Autor

Após constatarem experimentalmente usando o caleidoscópio, a formação de uma pavimentação (cf. figura a seguir), foi solicitado que justificassem o porquê, então esperávamos que eles discutissem sobre a formação dos polígonos que é, nesse caso, explicar a formação de quadrados, hexágonos e dodecágonos regulares por meio da construção feita no interior da base e utilizar a definição de pavimentação do plano, além de fazer a representação na simbologia adequada de $(12,6,4)$.

Figura 86 - Configuração $(4,6,12)$ no caleidoscópio

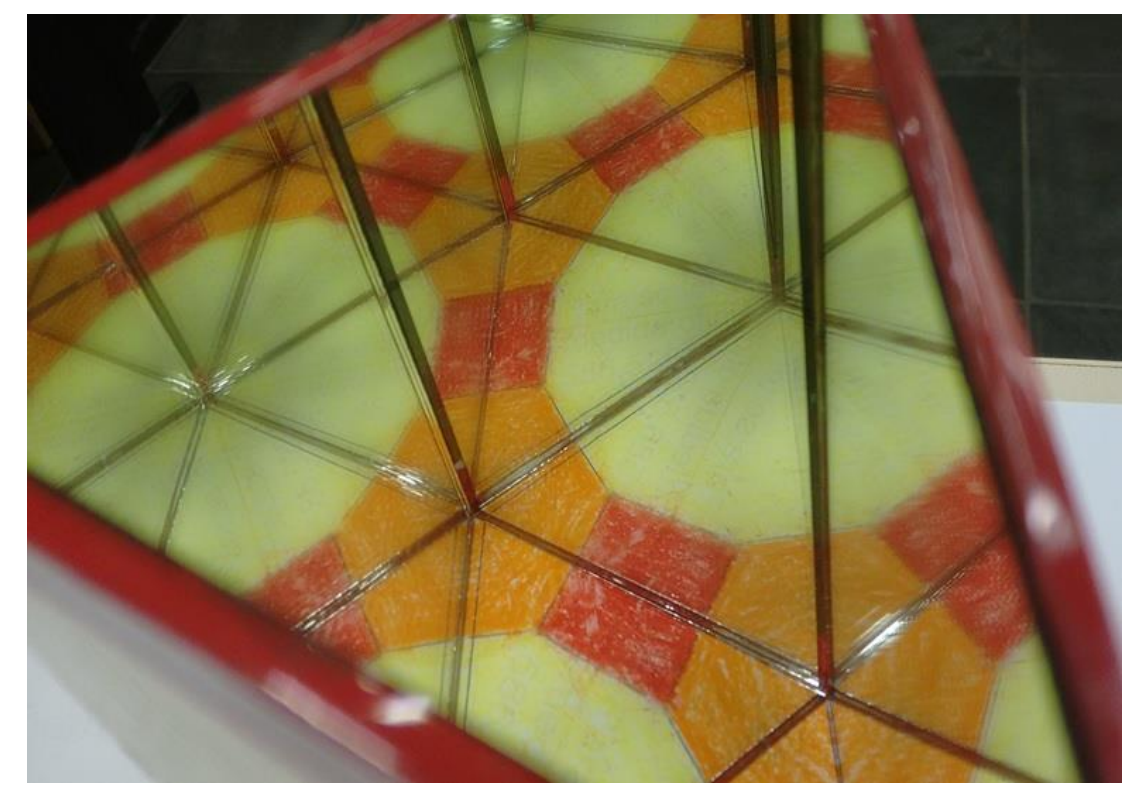

Fonte: Autor

Durante a realização da atividade, fizemos uma primeira leitura do enunciado e ressaltamos o que gostaríamos que eles destacassem nas justificativas. Após a entrega, fizemos uma avaliação das sete resoluções recebidas e o quadro 10 a seguir ilustra o desempenho de 
cada um em meio aos critérios estabelecidos. A cor verde indica que o critério foi alcançado, a cor amarela indica que foi parcialmente alcançado e a rosa indica que não foi alcançado.

Quadro 10 - Construção e Argumentação da Atividade 5

\begin{tabular}{|c|c|c|c|c|c|c|c|}
\hline \multicolumn{6}{|c|}{ QUADRO 1 - CONSTRUÇÃO E ARGUMENTAÇÃO DA ATIVIDADE 5 DE PAVIMENTAÇÕES DO PLANO } \\
\hline Professor & $\mathrm{R}$ & $\mathrm{M} 2$ & $\mathrm{~L}$ & $\mathrm{G}$ & $\mathrm{C} 2$ & $\mathrm{~A} 2$ & $\mathrm{~A} 1$ \\
\hline $\begin{array}{c}\text { Realizou toda a } \\
\text { construção }\end{array}$ & OK & OK & OK & OK & OK & OK & OK \\
\hline $\begin{array}{c}\text { Precisão } \\
\text { de Medidas }\end{array}$ & Adequado & Adequado & Impreciso & Impreciso & Impreciso & Adequado & Adequado \\
\hline $\begin{array}{c}\text { Justificativa do } \\
\text { Quadrado }\end{array}$ & Completa & Incompleta & $\begin{array}{c}\text { Não } \\
\text { justificou }\end{array}$ & Completa & Incompleta & $\begin{array}{c}\text { Não } \\
\text { justificou }\end{array}$ & Completa \\
\hline $\begin{array}{c}\text { Justificativa do } \\
\text { Hexágono }\end{array}$ & Completa & Incompleta & $\begin{array}{c}\text { Não } \\
\text { justificou }\end{array}$ & Incompleta & $\begin{array}{c}\text { Não } \\
\text { justificou }\end{array}$ & $\begin{array}{c}\text { Não } \\
\text { justificou }\end{array}$ & Completa \\
\hline $\begin{array}{c}\text { Justificativa do } \\
\text { Dodecágono }\end{array}$ & Completa & Incompleta & $\begin{array}{c}\text { Não } \\
\text { justificou }\end{array}$ & Incompleta & $\begin{array}{c}\text { Não } \\
\text { justificou }\end{array}$ & $\begin{array}{c}\text { Não } \\
\text { justificou }\end{array}$ & Completa \\
\hline $\begin{array}{c}\text { Uso de } \\
\text { Simbologia }\end{array}$ & Utilizou & Utilizou & Utilizou & Utilizou & Utilizou & $\begin{array}{c}\text { Não } \\
\text { utilizou }\end{array}$ & Utilizou \\
\hline
\end{tabular}

Fonte: Autor

Realizou toda a construção: se todas as etapas da construção foram seguidas e executadas corretamente;

Precisão de Medidas: se houve precisão no traçado, para não provocar ambiguidades ou interpretações equivocadas das imagens (como um polígono não aparentar regularidade);

Justificativa do Quadrado: explicou com justificativas, porque a construção produz um quadrado;

Justificativa do Hexágono: explicou com justificativas, porque a construção produz um hexágono regular;

Justificativa do Dodecágono: explicou com justificativas, porque a construção produz um dodecágono regular;

Uso de Simbologia: se utilizou a simbologia das configurações de pavimentações do plano no caso $(12,6,4)$, introduzida anteriormente.

A partir dos dados do quadro 10, podemos verificar que todos os professores tiveram um resultado satisfatório nos critérios relacionados com o paradigma $\mathrm{G} 1$, pois suas construções foram realizadas adequadamente, ainda que haja ressalvas quanto a imprecisões. E com exceção de uma professora, todos fizeram uso adequado da simbologia tanto para objetos como ponto, segmentos, congruências, etc. como para discriminar a configuração de pavimentação obtida, 
mostrando que nesta etapa do curso a maioria dos professores consegue interpretar suas construções como representações reais de objetos teóricos, ou seja, se colocam na perspectiva de G2 e também há evidências que diferenciam satisfatoriamente uma validação perceptiva de uma validação dedutiva.

A justificativa em si, argumentando por meio do raciocínio hipotético-dedutivo foi realizado adequadamente por dois professores, outros dois não conseguiram justificar nenhum dos três polígonos obtidos e os demais fizeram justificativas parciais. Verificamos assim, que também foi obtido um desenvolvimento da capacidade de fazer demonstrações de uma Geometria Axiomática G3.

Observando o desempenho dos professores de forma geral, percebemos que, embora tenha sido desafiador para eles realizar uma atividade sem a nossa intervenção e também ter que explicitar a justificativa de uma pavimentação, houve um desenvolvimento dos paradigmas das Geometrias axiomáticas e de um uso adequado e dirigido de materiais concretos. Em seu diário de bordo, o professor $\mathrm{R}$ escreveu que "Sobre as atividades 4 e 5, achei muito legal fazer algumas construções no triângulo que, aparentemente pareciam não formar uma pavimentação, mas depois de usar os espelhos, a pavimentação se concretizava."

Mostrando que as pavimentações observadas com o caleidoscópio podem ser compreendidas em um primeiro momento, nos níveis $\mathrm{G} 0$ e $\mathrm{G} 1$, pois a representação gráfica na base se torna um objeto concreto no que diz respeito à percepção visual.

Por meio do processo de construção da base, de manipulação do caleidoscópio, bem como a observação de seu interior, posicionado sobre a folha, descrição do tipo de pavimentação formada e justificativa de tal formação, utilizando propriedades e características já conhecidas, tivemos elementos para discutir a transição realizada pelos professores do paradigma G1 para G2. Ilustra-se na figura a seguir, as respostas dos professores $\mathrm{G}, \mathrm{R}$ e $\mathrm{M}_{2}$. 


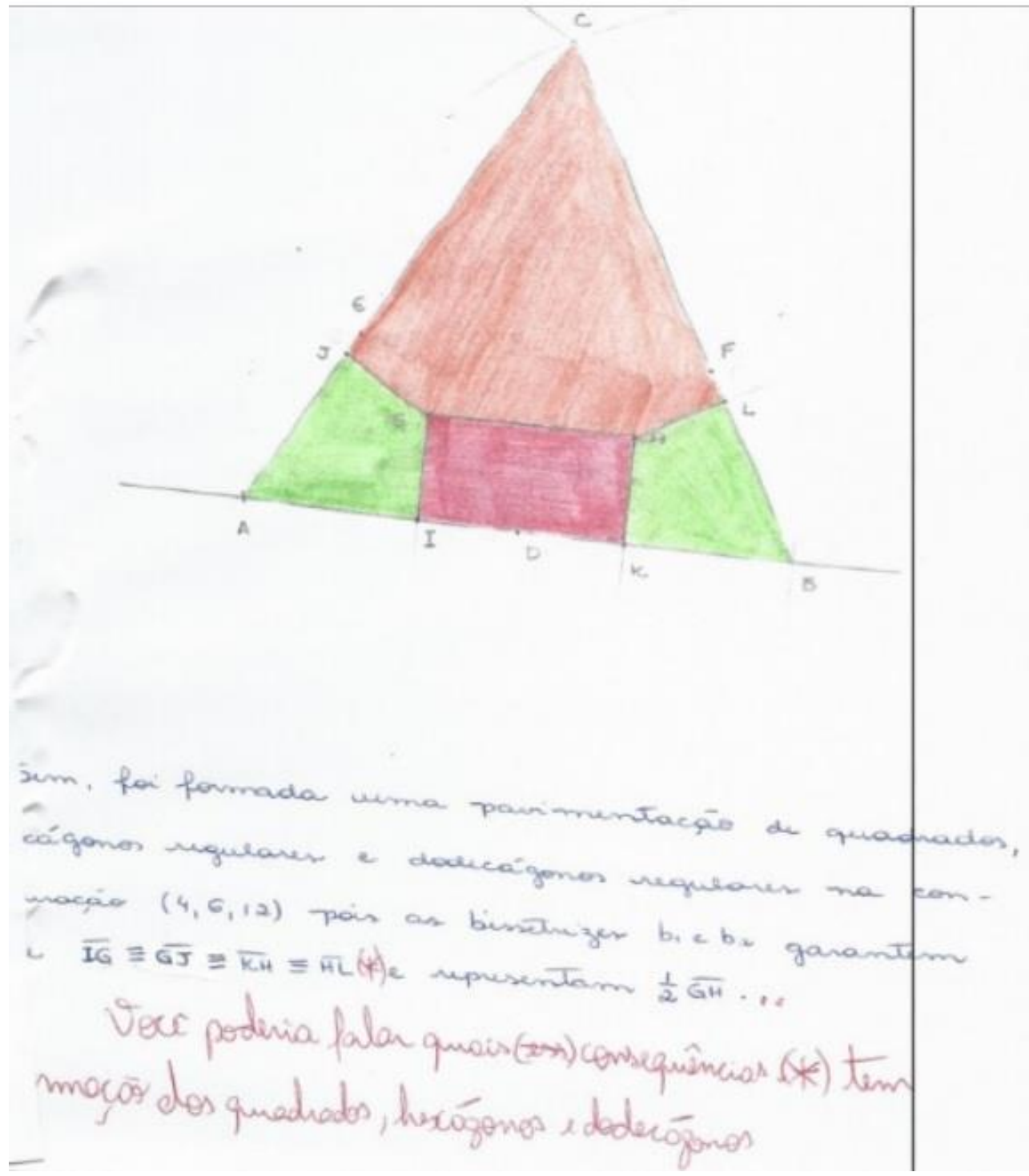

Fonte: Autor

Observando as respostas dessa professora podemos ver que, mesmo sem deixar explícito a formação de cada um dos três polígonos que compõem essa configuração, ela discutiu e comparou as medidas dos segmentos construídos, de tal maneira que consideramos que sua argumentação pode justificar a formação do quadrado. O uso de simbologia adequada para a configuração e comparação de segmentos de reta mostram que a professora buscou uma forma de justificar como a construção produziu a pavimentação observada, em sua discussão falou como os polígonos do interior da base produzem os polígonos da pavimentação. 
Figura 88 - Resolução do professor R

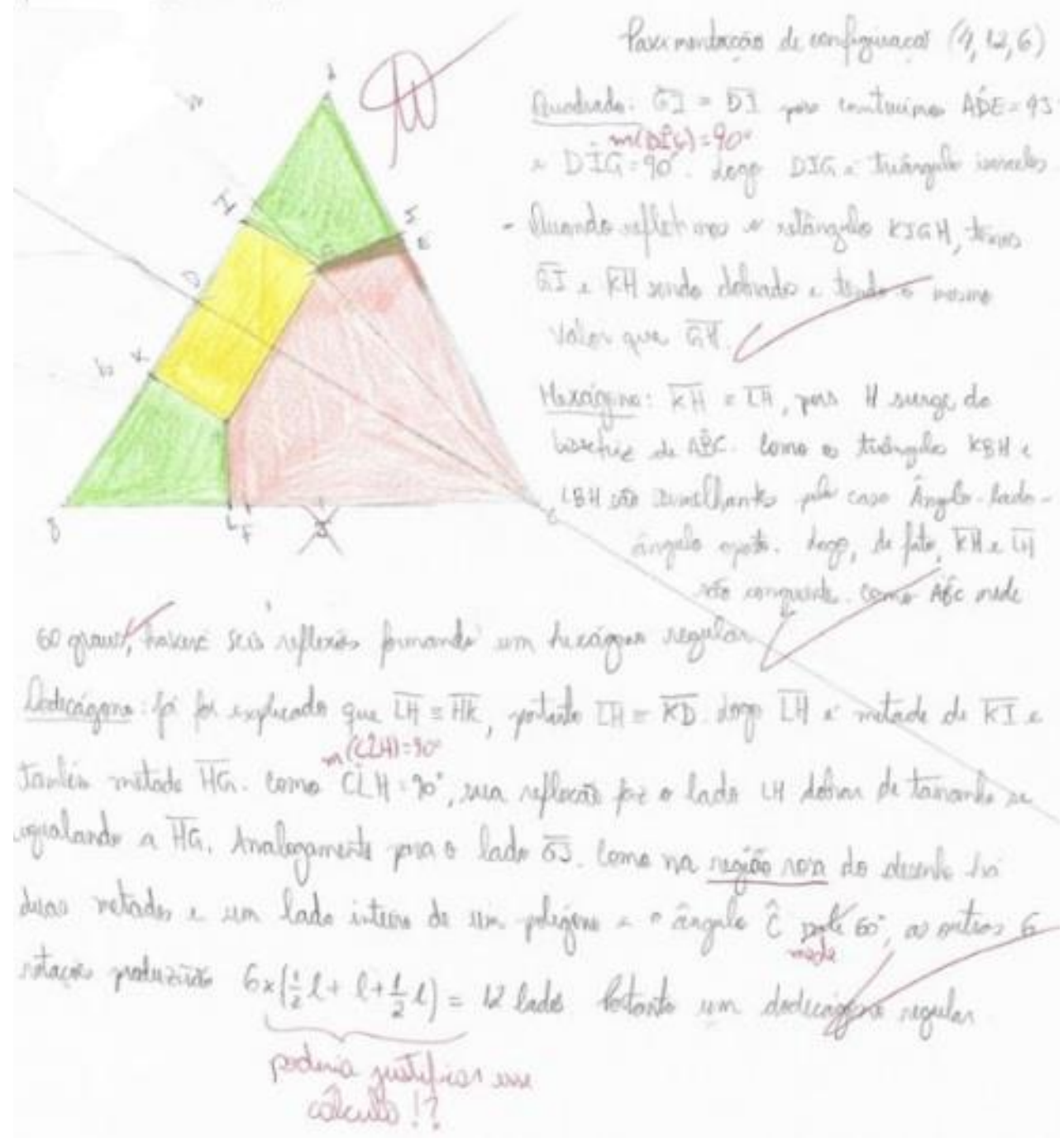

Fonte: Autor

Na resolução vista na figura 88 , o professor iniciou mostrando qual a configuração de pavimentação foi formada e, em seguida, apresentou de maneira explícita a formação dos quadrados, dos hexágonos e dos dodecágonos, com suas respectivas justificativas. Ele usou corretamente a simbologia para discutir congruência de segmentos e para compará-los, no entanto, em meio a sua argumentação aparecem alguns erros tais como trocar "congruentes" por "semelhantes" no caso do hexágono regular, ou igualar a representação do ângulo com sua medida em "DÎG $=90^{\circ}$ ". Na sua justificativa, usa termos que não são próprios da linguagem 
Matemática, como ao afirmar que "temos $\overline{G I}$ e $\overline{K H}$ sendo dobrados" ao argumentar a formação do quadrado, então podemos caracterizá-lo no nível G2 em toda sua resolução.

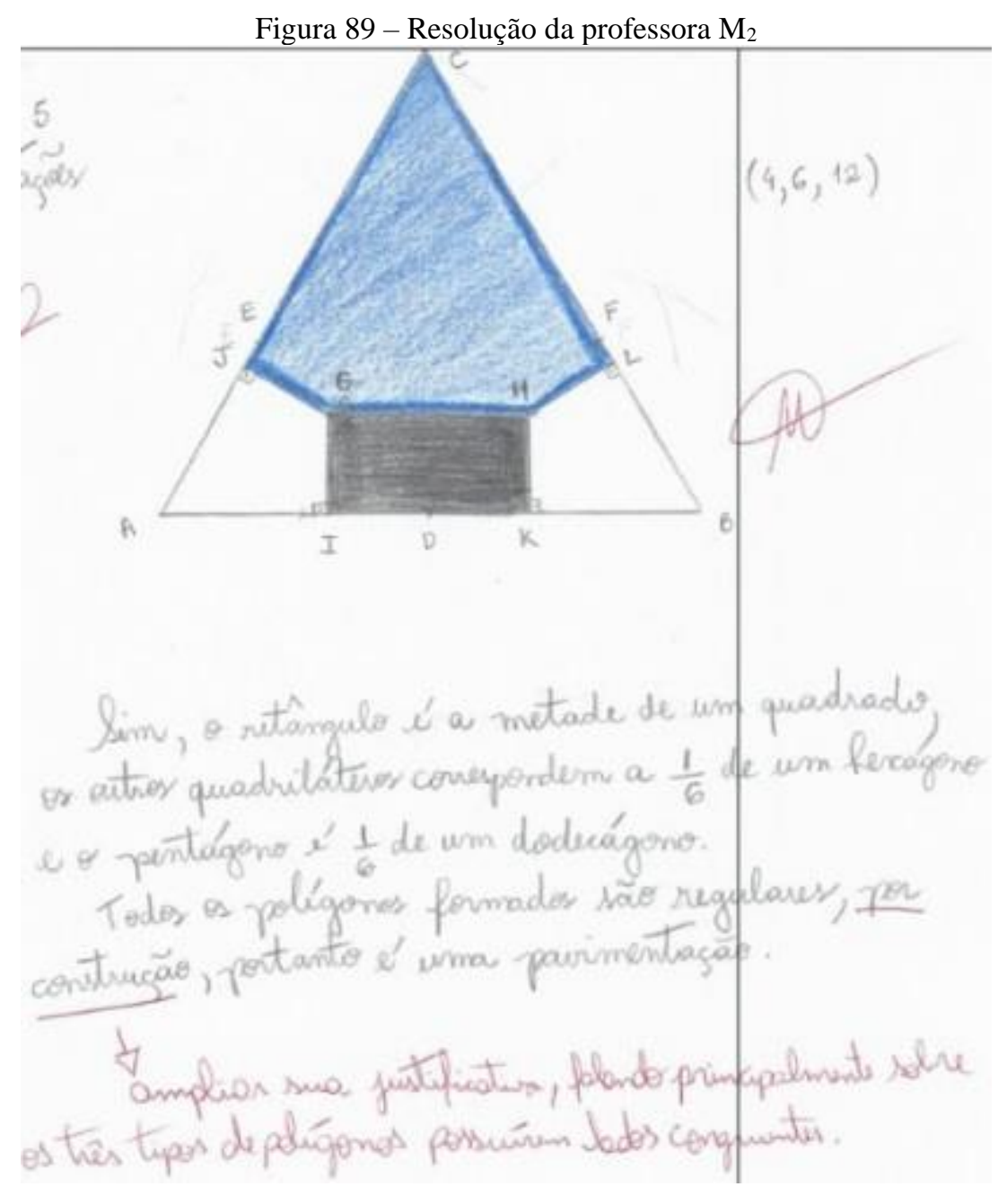

Fonte: Autor

Consideramos a resolução apresentada acima como incompleta, pois a professora fez afirmações sobre aspectos visuais somente, sem justificá-los. Esses aspectos aparecem quando se observa os quadriláteros brancos da Figura 89 com o uso de um caleidoscópio sobre essa base, efetivamente eles “correspondem a $\frac{1}{6}$ de um hexágono". Esse tipo de afirmação mostra que a professora fez a discussão com base apenas nas características destacadas pela representação construída e observada, ou seja, podemos caracterizar essa resolução no nível G1. Solicitamos oralmente a justificativa, mas ainda assim nem todos os professores a fizeram e apenas dois a fizeram de maneira completa.

Na última etapa do encontro ocorreram as apresentações dos professores R e L, pois os mesmos não poderiam comparecer no dia marcado para o nono encontro e ambos já haviam 
elaborado sua sequência didática. O professor R conseguiu experimentar com seus alunos essa sequência e o professor L não teve essa mesma oportunidade.

No nono encontro ocorreram as apresentações dos trabalhos finais das professoras G, $\mathrm{A}_{2}, \mathrm{C}_{2}, \mathrm{M}_{3}$ e $\mathrm{A}_{1}$, os demais não estiveram presentes no dia. Por meio dos registros obtidos, bem como as discussões presenciais apresentamos, no capítulo seguinte, uma análise detalhada dos trabalhos finais.

\section{ANÁLISE DOS TRABALHOS FINAIS}

O trabalho final do curso consistiu em os professores entregarem, além do plano de aula reformulado a partir das nossas orientações, o relatório descrevendo as intervenções feitas em sala de aula, o processo de aplicação e uma reflexão sobre os resultados, analisando se os objetivos foram alcançados.

\subsection{Planos de aula}

Desde o início do curso era de conhecimento dos participantes que, como componente de avaliação individual, deveriam elaborar e experimentar, em uma ou mais aulas, uma sequência didática com seus alunos utilizando atividades, desenvolvidas por eles mesmos, inspiradas nas atividades estudadas nos encontros presenciais. Para tanto, os professores elaboraram um plano de aula, em que descreveram o planejamento de uma ou mais aulas nas quais explorariam suas atividades.

No sexto encontro, apresentamos (utilizando slides e analisando um caso) e discutimos as cinco práticas para orquestração de discussões Matemáticas produtivas em sala de aula (STEIN \& SMITH, 2011) e solicitamos que os professores descrevessem em seus planos de aula a partir delas e nos enviassem via e-mail para que pudessem receber o devido feedback antes do encontro seguinte.

Estes desenvolveram seus planos de aula baseados em nossas instruções, dadas oralmente no sexto encontro, em direção a auxiliá-los a pensar uma forma de se desenvolver uma atividade, ou sequência didática, inspirada em suas experiências dos encontros do presente curso.

Para nós, a importância da elaboração e experimentação desse plano de aula está em analisar e avaliar em que medida os professores se apropriaram do conhecimento pedagógico 
do conteúdo desenvolvido nos encontros do curso e analisar possíveis impactos dessa apropriação para a prática dos professores e para o aprendizado de seus alunos. Dessa forma, pudemos analisar, com certa nitidez, a aplicabilidade dos contextos explorados, supondo que o público-alvo das atividades poderia ser composto por alunos da Educação Básica ou do Ensino Superior.

\subsection{Atividade Final}

\section{Desenvolvimento dos planos de aula}

De forma geral, os planos de aula foram apresentados em três momentos:

- Primeiro "rascunho" do plano de aula, sujeito à correção;

- Segunda versão do plano de aula, já corrigida;

- Versão integrada à atividade final, com ou sem modificações.

A primeira versão dos planos de aula desenvolvida pelos professores foi elaborada a partir das instruções que demos no sexto encontro, em aspectos gerais. Enquanto a versão seguinte foi elaborada seguindo um modelo que lhes indicamos que chamamos de elementos para $o$ plano de aula.

Essas instruções foram apresentadas juntamente às nossas primeiras sugestões de modificações, em direção a auxiliar os professores a pensarem uma forma de desenvolver atividades e sua sequência didática. Nos dispusemos a irmos às suas escolas para auxiliar na aplicação e também a emprestar os materiais utilizados no decorrer dos encontros (fornecidos pelo CAEM).

\subsection{Contexto das sequências didáticas}

\subsubsection{Tópicos para análise}

Elaboracão: Verificar se o professor se apropriou dos elementos do plano de aula baseados na abordagem das cinco práticas (sobretudo antecipar), tentando inseri-los em sua sequência didática, a partir das discussões coletivas e sugestões dos formadores. 
Aplicacão: Escolher uma das suas atividades para verificar a metodologia/abordagem adotada, percebendo se os objetivos de aprendizagem estavam explicitados, quais tipos de materiais foram utilizados e se houve incentivo à produção de justificativas, além de discutir de que forma foi proposta a transição de G1 para G2.

Análise das producões: Se possível, analisar de que forma a referida transição efetivamente ocorreu observando respostas, resoluções e construções produzidas pelos alunos dos professores participantes, evidenciando também, eventuais elementos constitutivos do conhecimento pedagógico do conteúdo desenvolvidos pelo professor.

\subsubsection{Professora $C_{2}$}

Quadro 11 -Contexto da Sequência Didática da professora C2

\begin{tabular}{|c|c|}
\hline Público-alvo & $\begin{array}{c}\text { Duas turmas de } 8^{\circ} \text { ano com } 25 \text { e } 28 \text { alunos divididos em grupos de } 5 \\
\text { ou } 4 .\end{array}$ \\
\hline Escola & Uma escola estadual de São Paulo. \\
\hline Tema & Polígonos e Pavimentações. \\
\hline $\begin{array}{l}\text { Competências e } \\
\text { Habilidades }\end{array}$ & $\begin{array}{l}\text { Indicou esse tópico mas apenas escreveu uma } \\
\text { descrição geral da pertinência do estudo. }\end{array}$ \\
\hline Recursos/Materiais & 250 peças de acrílico, 10 cartolinas e 10 papéis-cartão. \\
\hline \multicolumn{2}{|r|}{ Organização da Sequência (aulas de 50 minutos cada) } \\
\hline $1^{\text {a }}$ aula & $\begin{array}{c}\text { Pesquisa na internet e discussão sobre pavimentação, ladrilhamento, } \\
\text { polígonos, entre outros. }\end{array}$ \\
\hline $2^{\mathrm{a}}$ aula & Exploração livre dos polígonos em acrílico. \\
\hline $3^{\text {a }}$ aula & Descoberta de algumas pavimentações com polígonos regulares. \\
\hline \multicolumn{2}{|r|}{ Expectativas de Aprendizagem e de Intervenções } \\
\hline
\end{tabular}

Pedir para os alunos pesquisarem e confrontarem as respostas encontradas e buscar preparar peças de papel para representar polígonos. Não indicou as expectativas de aprendizagem.

Fonte: Autor

Assim como outros professores participantes, a professora $\mathrm{C}_{2}$ iniciou as suas atividades com a discussão do conceito de polígono e suas principais propriedades, seguida da discussão 
de como compor uma pavimentação. Foi a única, dentre os participantes, que destacou as distinções que existem entre pavimentação e ladrilhamento. O contexto de seu trabalho se deu em uma escola estadual de São Paulo, com estudantes do oitavo ano durante três aulas de 50 minutos cada.

\section{A elaboração}

Na elaboração de sua sequência didática, a professora $\mathrm{C}_{2}$ indicou os conhecimentos a serem desenvolvidos pelos alunos por meio de um tópico intitulado "competências e habilidades a serem adquiridas", no entanto, fez apenas uma descrição geral da pertinência do estudo, muito próxima do texto do currículo de Geometria de sua referência, com isso, os objetivos não foram explicitados.

Nos demais tópicos de seu plano, fez a previsão de material e de alternativa em função de sua disponibilidade, pensou na organização da turma, propondo trabalho em grupo e elaborou as questões norteadoras das discussões que pretendia realizar ao longo das atividades

Por outro lado, notamos que não enunciou expectativas de aprendizagem e/ou possíveis resoluções/respostas (corretas ou incorretas) dos alunos, conforme sugerido nas discussões com os participantes do curso.

Esse planejamento mostra a apropriação que essa professora fez de a prática antecipar, dando atenção ao registro dos principais questionamentos que seriam colocados em sua aula, como também algumas de suas intervenções. No entanto, não discutiu sobre quais seriam as dificuldades de seus alunos e como lidaria com determinados tipos de erros.

Acreditamos que esse tipo de reflexão não é realizado habitualmente pelo grupo de professores participantes, pois na maioria dos planos de aula por eles apresentados, ou esses elementos não foram descritos, em particular os possíveis obstáculos na realização das atividades propostas, ou a descrição foi bastante superficial.

\section{A(s) atividade(s)}

A sequência didática foi iniciada com a proposta de os alunos pesquisarem as definições de polígonos e pavimentações (na internet) e, depois, confrontarem e discutirem o que foi descoberto. Essa escolha da docente pode ter sido influenciada pela vivência nos momentos do curso em que foram discutidas e elaboradas algumas definições de objetos matemáticos - 
polígonos, estrelas poligonais, pavimentações, entre outras - na perspectiva de envolver os professores na reflexão de diferentes formulações para definir ou caracterizar esses objetos e entender suas consequências, analisando ainda casos de equivalência ou não das definições adotadas.

Em seguida, a professora $\mathrm{C}_{2}$ propôs um primeiro contato com as peças de acrílico por meio de experimentações em que os alunos puderam fazer exploração livre, formando diferentes composições com as peças. Após esse momento, a professora direcionou os alunos a tentarem responder algumas questões (cf. Quadro 12), apoiados na manipulação das peças, cujo objetivo parece ter sido o de apoiar a formulação de conjecturas pelos alunos. As questões propostas pela professora $\mathrm{C}_{2}$ são uma seleção, que consideramos ser muito pertinente, de algumas das questões apresentadas pelos formadores nas atividades de pavimentação.

Quadro 12- Questões propostas pela Professora $\mathrm{C}_{2}$

\begin{tabular}{|l}
\hline Na $3^{\circ}$ aula, faremos pavimentações e análise de cada pavimentação, respondendo algumas perguntas: \\
\hline a) É possível obter uma pavimentação em que apareçam pentágonos? E hexágono? E heptágono? Quais? Justifique. \\
\hline b) Podemos fazer uma pavimentação usando, simultaneamente, quadrados e triângulos equiláteros? De que forma (s)? \\
\hline c) Utilize os poligonos recebidos para dispor, ao redor de um vértice, uma configuração sem deixar lacunas e sem sobreposições, formada por: \\
\hline I) 3 polígonos regulares; \\
\hline II) 4 poligonos regulares; \\
\hline III) 5 poligonos regulares; \\
\hline I) 6 poligonos regulares; \\
\hline Justifique porque cada configuração obtida é possível. \\
\hline
\end{tabular}

Fonte: Autor

Notamos que a docente ressalta a necessidade de justificar as respostas, utilizando uma prática que foi recorrente nas atividades do curso. Entendemos ser esse aspecto muito importante para engajar os alunos em um fazer matemático se aproximando do nível G2, pois permite focar nas propriedades Matemáticas dos objetos para além dos aspectos percebidos no nível espaço-gráfico (G1). É o que passamos a analisar a partir dos resultados relatados pela docente.

\section{Análise dos resultados}

Segundo a professora $\mathrm{C}_{2}$, os alunos conseguiram descobrir algumas das pavimentações a partir da manipulação dos materiais concretos (ver figura 90) enquanto outras, a professora sentiu necessidade de um direcionamento mais preciso, com novos questionamentos e sugestões de análise de composições com peças específicas. 
Figura 90 - Configurações dos alunos da professora $\mathrm{C}_{2}$

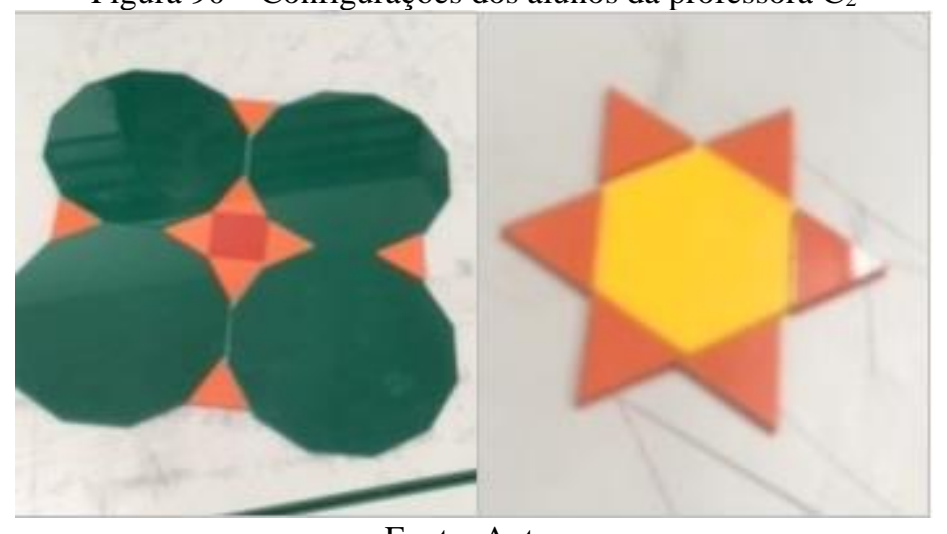

Fonte: Autor

A professora relatou que houve certa dificuldade por parte dos alunos em justificar suas respostas, pois eles não estavam familiarizados com alguns conceitos geométricos, tais como polígonos e ângulos. Segundo ela, as principais dificuldades decorreram do curto período para sua sequência e da necessidade de mais tempo para explorar o uso de outros materiais concretos e manipuláveis: "eles apenas conhecem régua, compasso e esquadro, e pouco utilizaram na aula

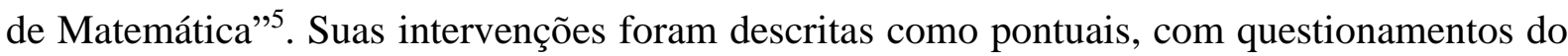
tipo “e se você tentar usar hexágonos dessa vez?”. E, em outros momentos, mais expositivas, descrevendo explicitamente uma configuração de pavimentação.

Em certa medida, podemos dizer que ela se apropriou das principais atividades do curso e que incentivou o uso de materiais concretos para visualização das composições e auxiliar na elaboração das respostas $(\mathrm{G} 0)$ e, posteriormente, produzir justificativas almejando uma passagem ao nível G2. Como ela mesma criticou a falta de familiaridade dos alunos com o uso de régua e compasso, podemos supor que esta foi a razão para não incluir a produção de representações figurais. Entretanto, acreditamos que justamente uma maior imersão em G1 teria colaborado com o processo de criação de justificativas por parte dos alunos.

\subsubsection{Professora $A_{2}$}

Quadro 13 - Contexto da Sequência Didática da professora A2

\begin{tabular}{|c|c|}
\hline Público-alvo & Uma turma de $8^{\circ}$ ano com 33 alunos. \\
\hline Escola & Uma escola estadual de São Paulo. \\
\hline
\end{tabular}

${ }^{5}$ As frases com aspas foram extraídas do relatório entregue pela professora $\mathrm{C}$ 


\begin{tabular}{|c|c|}
\hline Tema & Reflexão em reta, usando espelhos e caleidoscópios. \\
\hline Objetivos & $\begin{array}{l}\text { Descreveu brevemente como o raciocínio matemático } \\
\text { auxilia os alunos na resolução de problemas. }\end{array}$ \\
\hline $\begin{array}{l}\text { Competências e } \\
\text { Habilidades }\end{array}$ & $\begin{array}{l}\text { Resolver problemas geométricos a partir da experimentação e } \\
\text { indicou outros que não foram contemplados nas aulas. }\end{array}$ \\
\hline Recursos/Materiais & Espelhos planos, réguas e caleidoscópios. \\
\hline \multicolumn{2}{|r|}{ Organização da Sequência (aulas de 50 minutos cada) } \\
\hline $\mathbf{1}^{\mathrm{a}}$ aula & $\begin{array}{l}\text { Usou dois espelhos dispostos perpendicularmente sobre um papel } \\
\text { para observação de diferentes objetos. }\end{array}$ \\
\hline $2^{\mathrm{a}}$ aula & $\begin{array}{c}\text { Propôs a visualização dos objetos a partir de outros ângulos entre os } \\
\text { espelhos e apresentou o caleidoscópio caseiro }{ }^{6} \text {. }\end{array}$ \\
\hline \multicolumn{2}{|r|}{ Expectativas de Aprendizagem e de Intervenções } \\
\hline & Não realizou. \\
\hline
\end{tabular}

Fonte: Autor

A professora elaborou, inicialmente, um plano de aula com o objetivo de auxiliar alunos de uma turma de oitavo ano de uma escola estadual de São Paulo, na compreensão de propriedades da reflexão em reta por meio da resolução de problemas geométricos a partir da experimentação. Nessa primeira versão, o plano de aula não apresentava suas intervenções durante a aula e como seria o desenvolvimento da atividade, por isso, sugerimos um maior detalhamento segundo esses critérios, bem como uma descrição dos materiais a serem utilizados e quais enunciados guiariam os alunos pela atividade. A partir das sugestões, ela produziu uma nova versão de seu plano de aula que mostra uma certa apropriação das cinco práticas, ainda que não haja muita descrição de suas intervenções e do desenvolvimento (cf. Figura 91).

\footnotetext{
${ }^{6}$ Utilizamos esse termo para nos referir aos caleidoscópios produzidos com réguas, ao invés de espelhos, encobertas por um papel opaco em forma de prisma triangular.
} 
Figura 91 - Intervenções e Desenvolvimento da Atividade da professora $\mathrm{A}_{2}$

Estratégias e Recursos:

Atividades investigativas

Atividades experimentais

Leitura de textos

Resolução de questionários de interpretação

Discussões coletivas

Avaliação:

Consideração das ideias dos alunos para interpretar e observar no decorrer dos conteúdos

Propostas de situações-problemas do cotidiano para os alunos

Avaliação escrita

Participação em sala de aula.

Fonte: Autor

Sua proposta se destacou em relação as demais por ter incentivado os alunos a fazerem, antes da atividade, o registro do significado de reflexão apoiado pelo conteúdo do livro didático utilizado regularmente pela turma. Esse formato de discussão inicial pode fomentar a discussão sobre o tema, como etapa introdutória a seguinte, que depende da manipulação de materiais concretos, como os espelhos planos (ver a atividade 1 da Figura 93).

Figura 92 - Sequência didática da professora $\mathrm{A}_{2}$

Atividade 1: Apresentação de um roteiro da atividade, usando uma folha de sulfite, régua, dois espelhos e objeto colocados entre os espelhos ( bola de gude, chaveiro e pedrinhas coloridas). Em uma folha de sulfite, será realizado um desenho, dois segmento da reta paralela com $12 \mathrm{~cm}$. Colocando entre esse segmento de reta os objetos (bolinha de gude, chaveiro e pedrinhas coloridas).

Observações das imagens formada entre os espelhos e verificando a quantidades e posição da imagem com a reflexão em reta.

Atividade 2: Apresentação do roteiro da atividade, usando uma folha de sulfite, transferidor, régua e triângulos equiláteros formado por espelhos. Construção de ângulos e observação da construção de imagens usando o triângulo equilátero e apresentação de um caleidoscópio caseiro construído com régua.

Atividade 3: Construção da síntese sobre a aula 1 e aula 2.

Fonte: Autor

Em seu plano de aula, destacou a presença de discussões coletivas na efetivação da atividade, afirmou considerar às ideias dos alunos ao avaliá-los e indicou, na atividade 3, que 
os alunos fariam uma síntese do que foi estudado. Esses elementos em sua proposta de atividade mostram que, de certa forma, a professora se apropriou das cinco práticas.

O desenvolvimento das atividades não possuiu um texto de enunciado, de maneira que a professora dirigiu oralmente a aula e as tarefas dos alunos. Uma de suas atividades demandou a construção de um caleidoscópio caseiro, produzido utilizando, ao invés de espelhos planos, réguas transparentes envolvidas por um papel escuro (inspirado na construção sugerida em um vídeo do Manual do Mundo) e caracterizou-se pela observação de figuras e objetos no interior desse caleidoscópio.

Segundo a professora, sua coordenadora acompanhou a aula e percebeu um entusiasmo por parte dos alunos, solicitando fosse dada continuidade nas atividades nas demais aulas em que essa professora entrasse nessa ou em outra turma da escola.

\subsubsection{Professor $R$}

Quadro 14 - Contexto da Sequência Didática da professora R

\begin{tabular}{|c|c|}
\hline Público-alvo & Uma turma de $7^{\mathbf{o}}$ ano. \\
\hline Escola & Uma escola estadual de São Paulo. \\
\hline Tema & Polígonos e Pavimentação do Plano. \\
\hline Objetivos & Retomar o conceito de polígono e desenvolver \\
o conceito de pavimentação.
\end{tabular}


observação livre e dispô-los sobre as bases construídas.

\section{Expectativas de Aprendizagem e de Intervenções}

A descrição das aulas acima apresenta as ações de intervenção que o professor escreveu em seu plano, sendo essas de caráter expositivo. Indicou possíveis dificuldades dos alunos.

Fonte: Autor

O professor elaborou um plano de aula para ser explorado em três aulas que ocorreram em uma turma de sétimo ano do Ensino Fundamental de uma escola estadual de São Paulo. Esse professor foi o primeiro a fazer as correções sugeridas para seu plano de aula (cf. Figura 93) e desenvolver as atividades com seus alunos.

As correções sugeridas consistiram em: especificar tempo de duração e data, materiais utilizados, descrição maior das expectativas de aprendizagem e das possíveis dificuldades dos alunos e a especificação das suas principais intervenções.

Figura 93 - Plano de aula da atividade 2 do professor $\mathrm{R}$

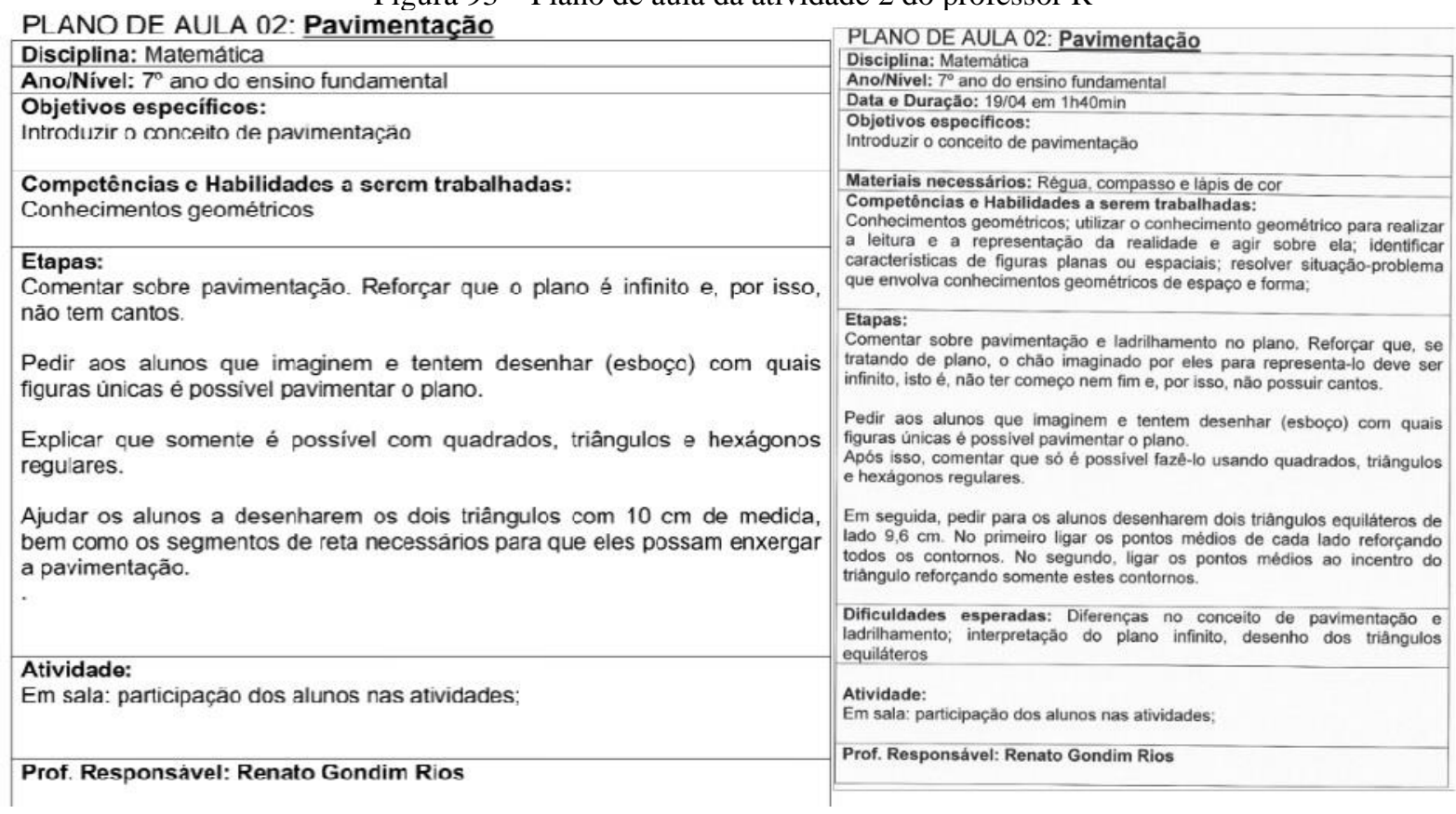

Fonte: Autor

Em sua primeira aula, discutiu com os alunos o significado de polígono e de polígono regular partindo da visualização de figuras que não são polígonos. Em outra aula, iniciou com uma discussão sobre o que os alunos já conheciam de pavimentação e ladrilhamento. Então 
pediu que os alunos pensassem e registrassem quais polígonos poderiam pavimentar o plano utilizando um único tipo.

A atividade mostrada no plano de aula da Figura 93 se caracteriza, na abordagem, pela criação de hipóteses a partir de representações figurais de possíveis pavimentações do plano com polígonos regulares, e, nas tarefas, pela construção de uma base para o caleidoscópio (da mesma forma que foi discutida nas atividades do curso). A criação de hipóteses e o destaque a elementos dos objetos de estudo não partiram inicialmente da manipulação de materiais concretos, porém o uso de espelhos e caleidoscópios aparece na terceira atividade.

Propôs a construção de dois tipos de bases que produzem diferentes tipos de pavimentações do plano e as explorou utilizando caleidoscópios. Em seguida, solicitou que os alunos escrevessem, de forma breve, suas considerações sobre a atividade (cf. Figura 94), mas não indicou a eles a necessidade de se buscar uma justificativa para as construções realizadas e para as pavimentações produzidas.

Figura 94 - Considerações dos alunos do Professor R

"Eu gostei muito da aula de hoje, principalmente a parte dos espelhos, mas năo entendi a parte do $9,6^{4}$

"Foi legal e eu gostei, mas foi um pouco chato"

"Năo gostei da parte que tem que ficar medindo os triângulos. Mas tirando isso gostei de tudo"

"Gostei muito, aprendi muita coisa e vi coisas que eu nunca vi e isso é interessante"

"Eu gostei da parte que a gente colocou o espelho nos desenhos, foi muito loko, foi mó briza. Eu nâo gostei da parte que tinhamos que ficar medindo os triângulos"

"Achei legal, interessante e criativo. Foi uma nova experiência porque nunca tinha visto isso"

"Eu achei legal e interessante que com o reflexo se cria imagens infinitas. Eu so fiquei confuso que as duas imagens săo ladrilhamento e pavimentaçăo"

"Gostamos porque a partir de diversos desenhos podemos formar outros que parecem ser ainda mais agradáveis, quando o triângulo è movido podemos notar diferentes mudanças. De ruim năo temos nenhum argumento. A experiência de lidar com o objeto como esse é muito viciante. Dorque os desenhos săo muito bonitos."

Fonte: Autor

A transição de representações figurais a fim de se produzir hipóteses para a manipulação de materiais concretos, transitando, portanto, de G1 para G0, poderia ser direcionada para uma compreensão de propriedades de G2, se o professor desse uma continuidade à sequência didática e se os alunos elaborassem conclusões sobre os resultados percebidos e buscassem justificar as hipóteses criadas, com ou sem o suporte da evidência material. 


\subsubsection{Professora $M_{3}$}

\section{Elaboraç̃o}

Quadro 15 - Contexto da Sequência Didática da professora M3

\begin{tabular}{|c|c|}
\hline Público-alvo & $\begin{array}{c}\text { 10 alunos de Licenciatura e de Bacharelado } \\
\text { em Matemática de diferentes semestres. }\end{array}$ \\
\hline Escola & A universidade particular em que leciona. \\
\hline Tema & Uma oficina sobre pavimentação do plano e reflexão em reta. \\
\hline Objetivos & $\begin{array}{r}\text { Indicou um objetivo global relacionado com propriedades da } \\
\text { reflexão em reta, de polígonos e pavimentações. } \\
\end{array}$ \\
& $\begin{array}{c}\text { Escreveu objetivos específicos de cada atividade } \\
\text { e elencou os principais conteúdos explorados }\end{array}$
\end{tabular}

\begin{tabular}{|c|c|}
\hline $\begin{array}{l}\text { Competências e } \\
\text { Habilidades }\end{array}$ & fez tópicos relacionados com as propriedades dos objetos de estudo. \\
\hline Recursos/Materiais & $\begin{array}{l}\text { Pares de espelhos articulados, polígonos em acrílico, caleidoscópios } \\
\text { e folhas com enunciados para direcionar o estudo. }\end{array}$ \\
\hline \multicolumn{2}{|r|}{ Organização da Sequência (oficina de 3 horas) } \\
\hline Atividade 1 & $\begin{array}{l}\text { Ângulos internos e centrais de polígonos } \\
\text { regulares explorados por meio da reflexão. }\end{array}$ \\
\hline Atividade 2 & $\begin{array}{l}\text { Pavimentação do plano com polígonos } \\
\text { regulares em peças de acrílico. }\end{array}$ \\
\hline Atividade 3 & $\begin{array}{l}\text { Verificar e justificar as pavimentações geradas } \\
\text { a partir do uso de caleidoscópios. }\end{array}$ \\
\hline
\end{tabular}

Indicou como desenvolveria cada atividade, destacando o que falaria para os alunos, como dirigiria a discussão e o que esperava que os alunos respondessem, corretamente ou não. 
A professora $\mathrm{M}_{3}$ desenvolveu sua sequência didática no contexto de uma oficina da $V I$ Semana da Matemática do Centro Universitário onde atuava como docente (cf. figura a seguir). Figura 95 - Oficina da professora $\mathrm{M}_{3}$

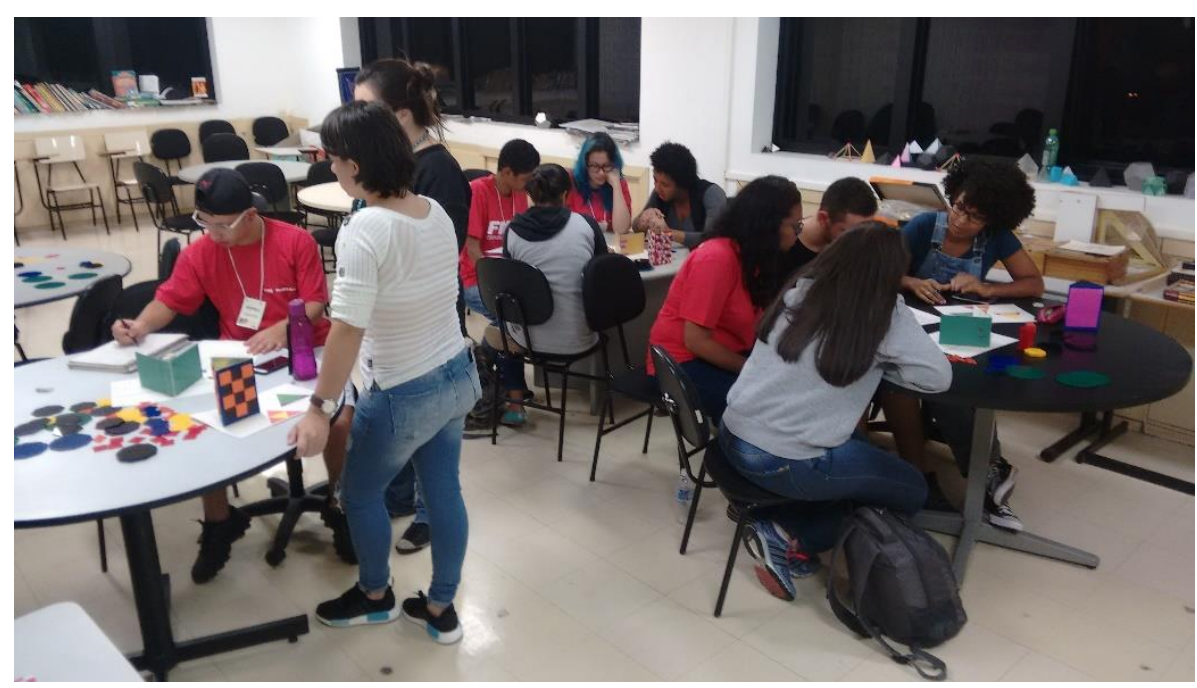

Fonte: Autor

Os participantes dessa oficina eram estudantes do curso de Licenciatura em Matemática da referida instituição. Estiveram presentes 10 estudantes, com o acompanhamento do formador. A proposta da oficina foi composta por três atividades, das quais duas podem ser observadas de forma resumida na figura 92. 
Figura 96 - Plano de aula da professora $\mathrm{M}_{3}$ com atividades 1 e 2

1.2 Plano de aula

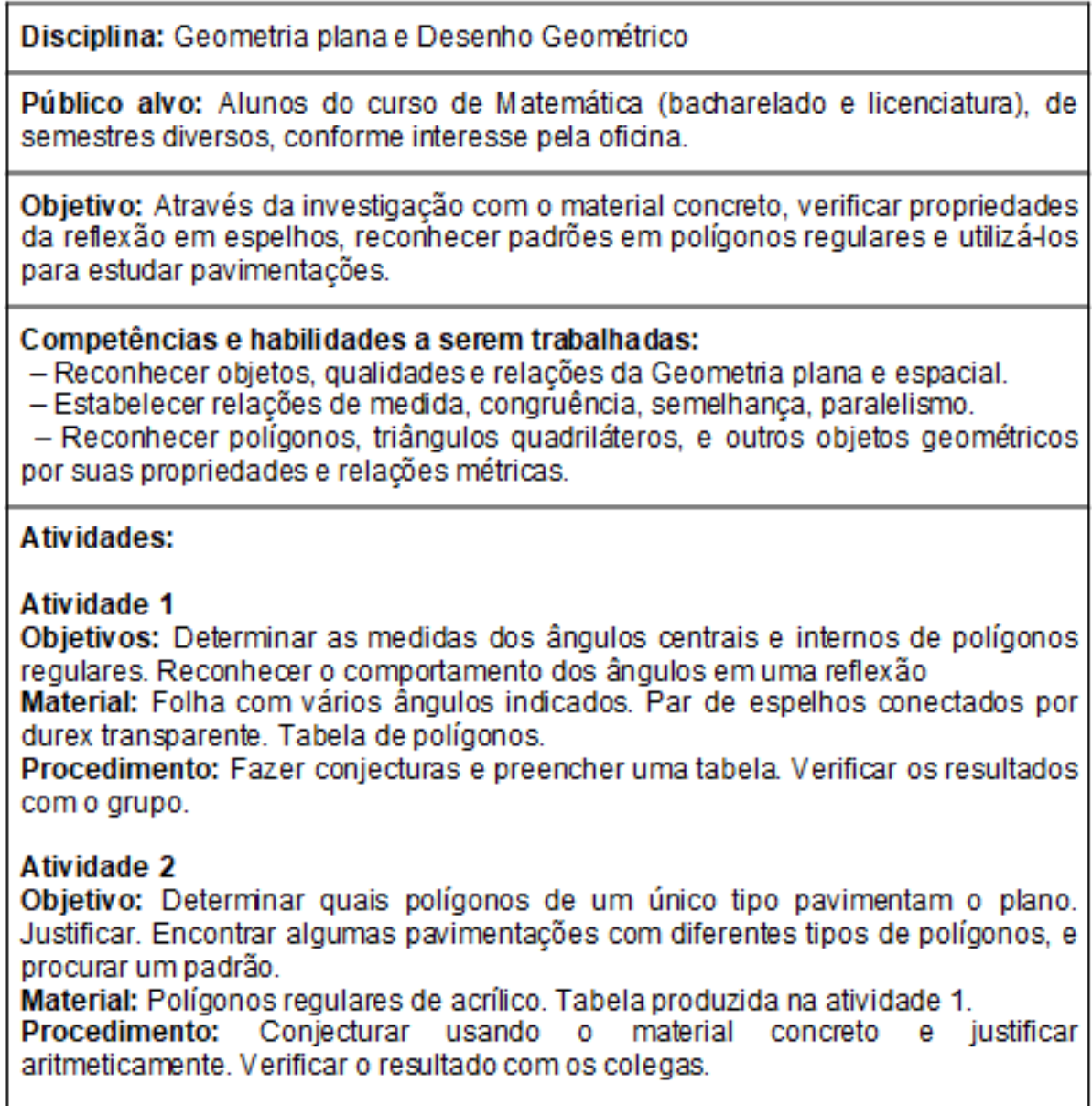

Fonte: Autor

Como se pode observar na Figura 96, seu plano de aula contempla os elementos do plano de aula, apresentados anteriormente, ao descrever procedimentos, objetivos e caracterizar os estudantes. Outros importantes aspectos desses elementos são apresentados posteriormente, em seu próprio texto, como, por exemplo, expectativas de aprendizagem e tempo de duração da oficina.

A elaboração da atividade, com seus respectivos materiais, seguida das modificações/adaptações do plano após devolutiva dos formadores que suscitaram a determinação das expectativas de aprendizagem, escolha de determinadas intervenções, formato e duração da oficina, compuseram a prática de antecipar, por parte da docente.

No tópico de expectativas de aprendizagem, a professora destacou possíveis respostas e, sobretudo, as respostas corretas esperadas. Dentre elas, descreveu que poderia obter respostas em língua materna, de forma numérica e/ou por meio de representações figurais. 
Suas intervenções foram previamente descritas pela forma de se usar os materiais, orientar as discussões durante e ao final de cada atividade (estabelecendo conexões com as respostas apresentadas pelos estudantes) e quais questionamentos pretendia fazer durante todo o processo.

Percebemos, no entanto, que a professora não destacou eventuais dificuldades e/ou erros dos estudantes em cada atividade em sua primeira versão do plano de aula e, com isso, não explicitou previamente estratégias ou intervenções para abordá-los. Embora esse aspecto tenha sido explorado na formação, não esteve presente na concepção de seu plano.

\section{$\underline{\text { Aplicação }}$}

As intervenções realizadas pela professora $\mathrm{M}_{3}$ se caracterizaram por questionamentos, indagações e exemplos. Além disso, suas ações se relacionam com a prática monitorar da seguinte forma: a turma foi dividida em grupos com quatro pessoas (cada um recebeu uma folha impressa com enunciados); os materiais (espelhos, folhas com enunciados e com os ângulos, espelhos planos e polígonos em acrílico) já estavam dispostos nas mesas redondas antes que os estudantes chegassem; a professora circulou pela sala fazendo questionamentos e selecionando algumas falas e respostas para serem expostas e discutidas com todos os presentes.

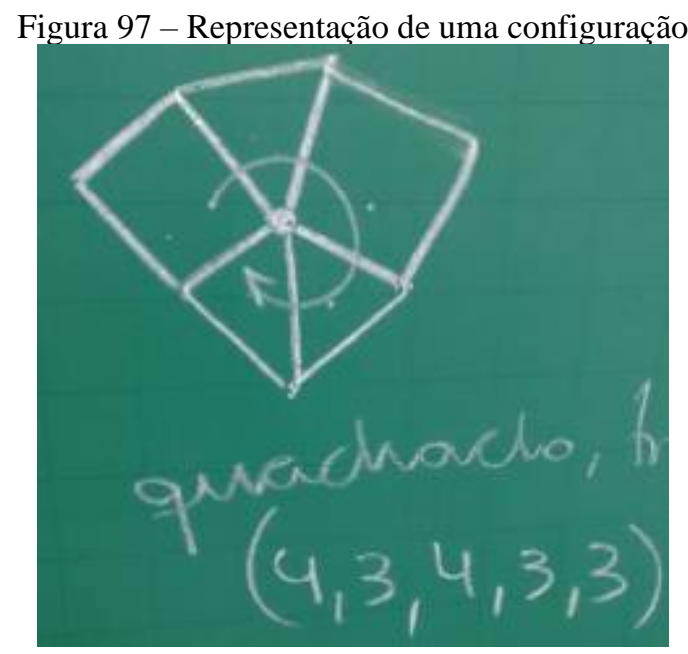

Fonte: Autor

A Figura 97 mostra como a professora, dentre suas intervenções, utilizou-se do desenho para ilustrar a configuração $(4,3,4,3,3)$. $\mathrm{O}$ destaque com uma seta indica não apenas o sentido em que se observa os polígonos, mas também indica qual o primeiro e o último. No caso, a seta 
começa em um quadrado, passa por um triângulo, um outro quadrado, um triângulo e termina em outro triângulo, correspondendo a representação da configuração citada.

Como material de apoio para a resolução da atividade 1, a professora produziu folhas com diversos ângulos de mesma bissetriz, destacados com diferentes cores, além de pares de espelhos planos conectados por uma fita adesiva (cf. Figura 98).

O plano de aula e o uso dos materiais com seus alunos mostra a valorização e apropriação de um trabalho experimental dada, por parte da docente, e observada nos encontros. Isso impactou também em suas ações no curso e em suas atividades, bem como em suas reflexões finais.

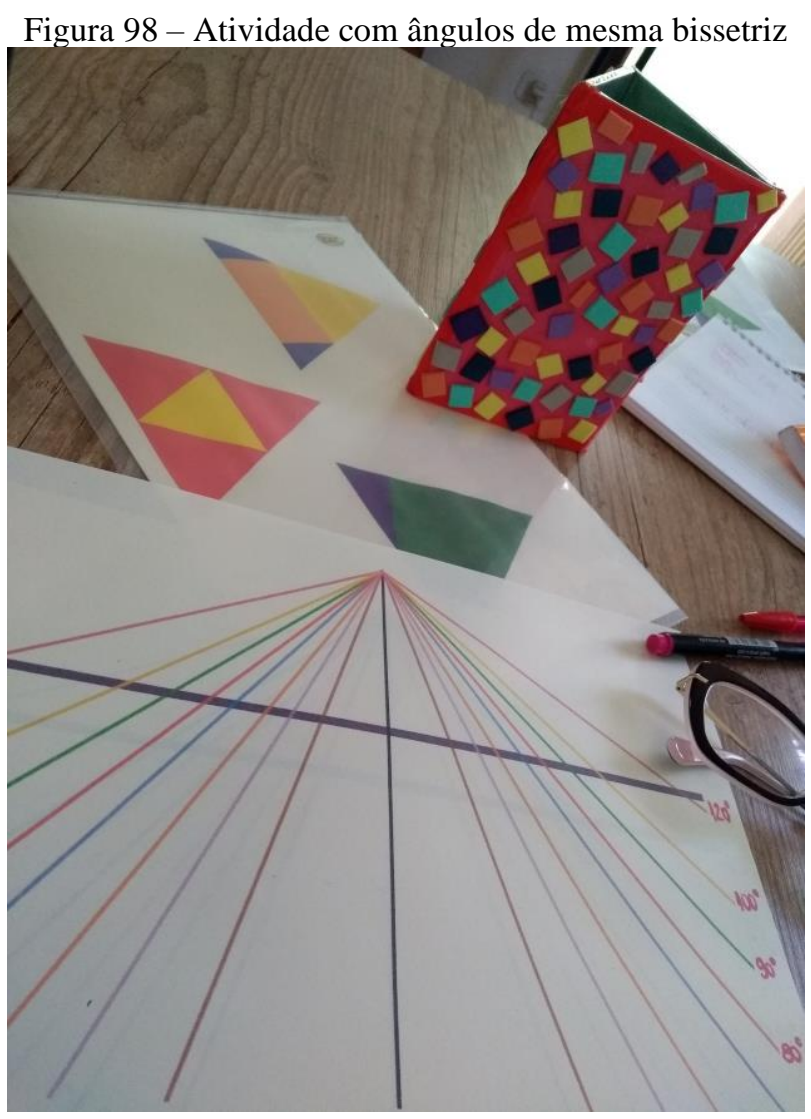

Fonte: Autor

Percebemos que, em suas reflexões sobre os resultados, a professora $\mathrm{M}_{3}$ discutiu a forma como o uso de materiais concretos pode auxiliar no processo de sistematização de ideais e conceitos e concluiu que uma discussão coletiva proveniente de ações colaborativas entre os alunos auxiliam o desenvolvimento do raciocínio geométrico:

“[...] A experiência desta oficina foi muito rica, e fechou bem toda a trajetória que vivi no curso; todo esse processo me levou a profundas 
reflexões sobre a minha prática. A mais importante delas é a importância de viver a experiência concreta antes de formalizar ideias, ou mesmo apresentar conceitos abstratos. Percebi que o rigor com que eu trato as discussões em minhas aulas pode ser um fator negativo, pois atrapalha o livre pensamento e a discussão colaborativa que deve ocorrer antes da generalização".

Em todo seu texto, a professora ressalta que esse rigor, possivelmente excessivo, pode inibir a criação livre de conjecturas e que a resistência de seus alunos na produção escrita pode partir desse fator. Destaca também, que planejou enviar um material de apoio sobre os principais conceitos envolvidos na oficina, mas que por não ter conseguido, acredita que mais dificuldades (conceituais) ocorreram.

\section{Análise das producões}

Cabe observar que como a maioria dos participantes da oficina eram licenciandos em Matemática, possivelmente futuros professores, a própria professora $\mathrm{M}_{3}$ mostrou, em seu tópico de objetivos, dedicar-se a apresentar a importância do uso de materiais concretos para o ensino de Matemática:

\footnotetext{
Uma vez que a oficina foi produzida principalmente para os alunos da Licenciatura em Matemática, também visou-se discutir o conhecimento pedagógico relacionado ao conteúdo: assim, visamos promover a reflexão acerca de como o uso do material concreto pode favorecer o aprendizado de conteúdos abstratos.
}

O desenvolvimento de um saber que seja próprio do nível G2 está ligado com a criação de conjecturas a partir do uso de materiais concretos e manipuláveis e do uso de representações figurais ou por meio de desenhos e construções geométricas, sobretudo com estudantes da Educação Básica. Dessa forma, em um curso para futuros professores, explorar a transição para G2 é essencial.

Na resolução da atividade 1, na etapa em que era necessário se calcular os ângulos centrais e internos de polígonos regulares, os alunos fizeram oralmente, logo no início, a criação de uma conjectura acertada, no entanto houve muita resistência para registrarem a ideia, pois para eles uma conjectura que não tem uma prova já sabida não pode ser colocada na folha de respostas, pois não estão acostumados a testar suas ideias e corrigi-las quando necessário.

Os alunos conseguiram resolver a atividade 2 a partir da discussão coletiva entre os grupos e com o restante da turma, que consistia em descobrir quais polígonos regulares poderiam pavimentar o plano utilizando as propriedades descobertas na atividade 1 . Nessa 
atividade os alunos já estavam mais adaptados a formulação de conjecturas a partir da manipulação de materiais concretos e conseguiram finalizar suas respostas com maior prontidão.

A atividade 3, que também estava no planejamento da professora $\mathrm{M}_{3}$, não foi estudada pois as atividades anteriores ocuparam todo o tempo disponível da oficina. No entanto ela se mostrou compreensiva a essa situação: "A principal conclusão dessa oficina foi de que aquilo que se movimenta na discussão é mais importante que a quantidade de atividades realizadas".

Em relação aos impactos do curso em sua prática docente mostrou que buscará dar maior importância na produção de conjecturas a partir da experimentação e maior valorização as discussões coletivas.

\subsubsection{Professora $A_{1}$}

Quadro 16 - Contexto da Sequência Didática da professora A1

\begin{tabular}{|c|c|}
\hline Público-alvo & Alunos de $6^{\circ}$ ano. \\
\hline Escola & Uma escola estadual de São Paulo. \\
\hline Tema & Pavimentação. \\
\hline Objetivos & $\begin{array}{c}\text { Buscou como objetivo geral, explorar os conceitos de pavimentação } \\
\text { e de polígono e indicou objetivos específicos relacionando esses } \\
\text { conceitos. }\end{array}$ \\
\hline Recursos/Materiais & $\begin{array}{c}\text { Folhas com enunciados, figuras e tabelas, celular e polígonos } \\
\text { móveis. }\end{array}$ \\
\hline \multicolumn{2}{|c|}{ Organização da Sequência ( 3 aulas de 100 minutos cada) } \\
\hline $\begin{array}{l}\text { Não especificou o } \\
\text { que foi trabalhado } \\
\text { em cada aula. }\end{array}$ & $\begin{array}{c}\text { Buscou construir coletivamente uma definição de "pavimentação" a } \\
\text { partir do que os alunos trouxeram. Explorou exemplos de } \\
\text { pavimentações. }\end{array}$ \\
\hline \multicolumn{2}{|r|}{ Expectativas de Aprendizagem e de Intervenções } \\
\hline $\begin{array}{r}\text { Descreveu as } \\
\text { aulas, mas n }\end{array}$ & $\begin{array}{l}\text { rincipais ações dela e dos alunos para o desenvolvimento das } \\
\text { indicou possíveis erros e dificuldades por parte dos alunos. }\end{array}$ \\
\hline
\end{tabular}


Em seu plano de aula, para que fosse desenvolvido em seis aulas, com seus alunos de $6^{\circ}$ ano, a professora detalhou quais seriam os materiais utilizados ao antecipar como os alunos chegariam a justificativas das suas respostas e quais seriam suas intervenções, de forma geral (cf. Figura 95).

\section{Estratégia/metodologias:}

Figura 99 - Estratégias do plano de aula da professora $\mathrm{A}_{2}$

- Através de uma breve pesquisa dos alunos, socializar as diversas definições de pavimentações encontradas e buscar construir uma coletivamente; As atividades a seguir serão realizadas por grupos de três ou quatro alunos:

- Através desta definição analisar diversos exemplos trazidos pelos alunos com o objetivo de identificar quais respeitam a definição de pavimentação construída;

- Analisar as composiçøes (peças) presentes nas pavimentaçס̋es identificadas, identificando semelhanças e diferenças na forma e buscando um critério para classifica-las - apresentar no final uma classificação por número de lados;

- Fornecer impressões com os seguintes polígonos regulares e outros não regulares (triângulo, quadrado, pentágono, hexágono) para os alunos recortarem e descobrirem outro critério possivel de classificar os poligonos - quanto ao ângulo;

- Propor a construção de pavimentações através de peças móveis na forma de poligonos regulares e analisar as construçōes que constituíram pavimentaçōes e as que não constituiram pavimentações, buscando uma explicação. Para apoiar as explicaçōes, fornecer impressర̃es de circunferência com o centro marcado com forma de mensurar a abertura de duas retas consecutivas de um polígono - se necessário oriente a somar os ângulos de diferentes polígonos ligados por um vértice nesta circunferência.

Fonte: Autor

Esses tópicos, chamados pela professora de estratégia, mostram que suas ações seriam voltadas a auxiliar os alunos a compreender conceitos e buscar propriedades das pavimentações a partir de uma exploração com materiais concretos. E em seguida, levá-los a justificarem suas ideias, dirigindo-os à discussão a respeito de medida de ângulo de polígonos regulares. Em suas atividades, os alunos foram levados, primeiramente, a pesquisar o significado e exemplos de pavimentação, discutir as definições encontradas e buscar figuras que ilustrassem a definição encontrada, inclusive por meia de representações figurais (impressas em papel ou construídas na lousa).

A professora solicitou que os alunos escrevessem na lousa (cf. Figura 100) uma reflexão obtida em grupo, a respeito de imagens pesquisadas, explorando as características que cada "unidade" (uma peça/polígono que compunha a pavimentação pesquisada) tinha, destacando os aspectos em comum e os diferentes entre cada tipo de unidade. 


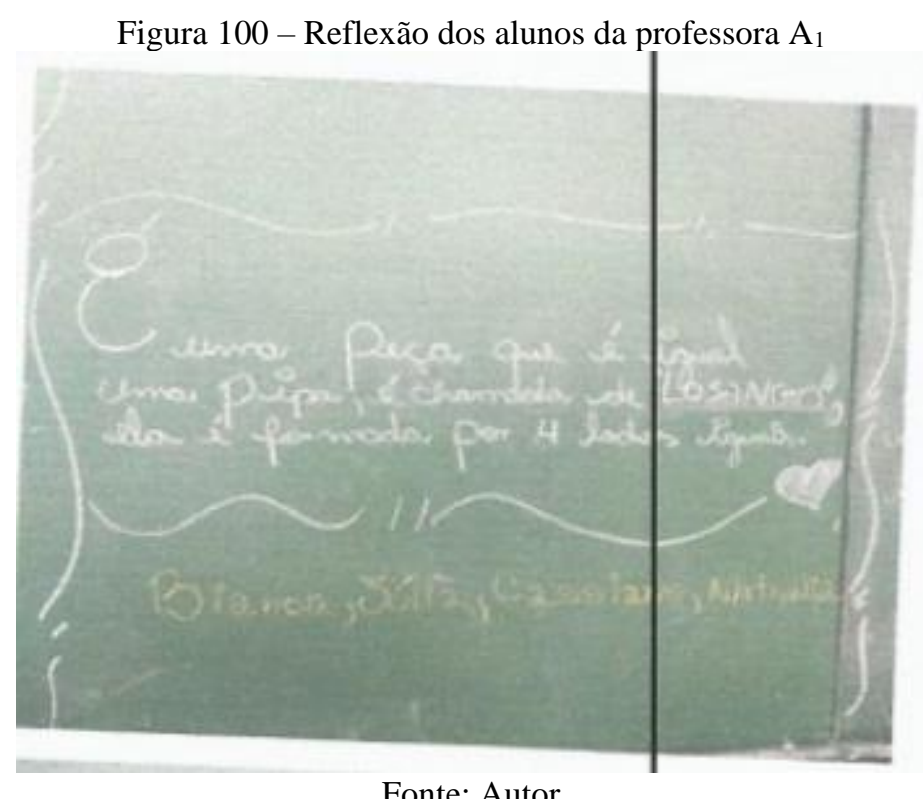

Em meio às discussões, a professora tomou um momento para destacar a definição etimológica de polígono, mostrar exemplos, seus elementos principais, como vértices, lados e ângulos e as propriedades de um polígono regular e irregular.

A experimentação dirigida foi caracterizada pelo estudo realizado em que os alunos tiveram a oportunidade de representar uma pavimentação do plano utilizando peças em formato de polígonos regulares e irregulares, feitas de papel sulfite, recortado, pelos próprios alunos, de um material entregue pela professora.

A exploração seguinte foi dada por meio do uso das peças de acrílico utilizadas no curso, representando os polígonos regulares. Nesse momento, os alunos puderam experimentar livremente, tentando construir uma configuração de pavimentação ao redor de alguns vértices. Segundo a professora, os alunos se colocaram em uma discussão a respeito do ângulo, questionando qual ângulo seria adequado para ser combinado com determinado polígono para preencher o plano ao redor de um vértice, no entanto essa discussão não teve um fechamento.

Ela concluiu que as atividades com as peças de acrílico e de papel levaram os alunos a perceberem a relação entre os tipos de pavimentações possíveis e os ângulos internos dos polígonos regulares utilizados, mostrando que ela poderia realizar uma maior exploração com os alunos em alguma proposta de continuação, permeando propriedades próprias do nível G2. Em suas palavras: "algumas construções resultam em pavimentações e os alunos perceberam que tais resultados dependiam do ângulo dos polígonos. [...] os alunos tentavam encaixar os polígonos a partir de seus ângulos, contudo faltou a discussão sobre as construções”.

Suas intervenções tiveram caráter de mediação, de tal forma que em meio as discussões, os alunos foram instigados com questionamentos e os incentivados a criar conjecturas e testá- 
las e, inclusive, mesmo que algumas respostas e resoluções não tenham sido alcançadas por todos, as discussões realizadas inseriram todos os alunos no estudo em questão.

\subsubsection{Professora $G$}

Quadro 17 - Contexto da Sequência Didática da professora G

\begin{tabular}{|c|c|}
\hline Público-alvo & Duas turmas de $8^{\circ}$ ano \\
\hline Escola & Uma escola municipal de São Paulo \\
\hline Tema & Pavimentação do plano com um único tipo de polígono \\
\hline Objetivos & $\begin{array}{c}\text { Indicou objetivos gerais, como explorar os conceitos de polígono, } \\
\text { plano e ângulo e específicos, como estudar ângulo interno de } \\
\text { polígono regular }\end{array}$ \\
\hline Recursos/Materiais & Folhas de sulfite, lápis e polígonos em acrílico \\
\hline \multicolumn{2}{|c|}{ Organização da Sequência (aulas de 45 minutos cada) } \\
\hline $1^{\text {a }}$ aula & $\begin{array}{l}\text { Definiu objetos como polígono e plano a partir de uma } \\
\text { discussão sobre as ideias prévias dos alunos e de exemplos }\end{array}$ \\
\hline $2^{\mathrm{a}}$ aula & $\begin{array}{l}\text { Em grupos, os alunos tentariam descobrir quais polígonos de um } \\
\text { único tipo podem pavimentar o plano e discutir sobre aqueles que } \\
\text { não podem }\end{array}$ \\
\hline \multicolumn{2}{|r|}{ Expectativas de Aprendizagem e de Intervenções } \\
\hline $\begin{array}{r}\text { Indicou tant } \\
\text { dificuld } \\
\text { determinadas } p\end{array}$ & $\begin{array}{l}\text { Is principais expectativas de aprendizagem como algumas } \\
\text { es relacionadas com o momento de justificar por que } \\
\text { imentações são possíveis, mas não destacou as Intervenções. }\end{array}$ \\
\hline
\end{tabular}

Fonte: Autor

Suas atividades ocorreram em duas turmas de oitavo ano, de 9 a 11 de maio, em uma escola municipal de São Paulo e tiveram foco no estudo das propriedades de polígonos e em como compor, quando possível, pavimentações com polígonos de três a sete lados.

As atividades foram desenvolvidas primeiramente por meio de uma discussão sobre o que significa polígono e se conheciam o termo "pavimentação" e, após a discussão, a professora apresentou a definição usual desses objetos. Para definir polígonos ela utilizou uma atividade muito semelhante à atividade 1, de pavimentações, estudada no curso, apresentando 
inicialmente figuras que são polígonos com diversos números de lados, dentre côncavos e convexos, e depois, as que não são polígonos, por várias razões: segmentos cruzados, linhas arredondadas, abertas e figuras com mais de uma região interna delimitada (ver figura a seguir).

\section{São polígonos:}

Figura 101 - Desenhos de polígonos e não-polígonos
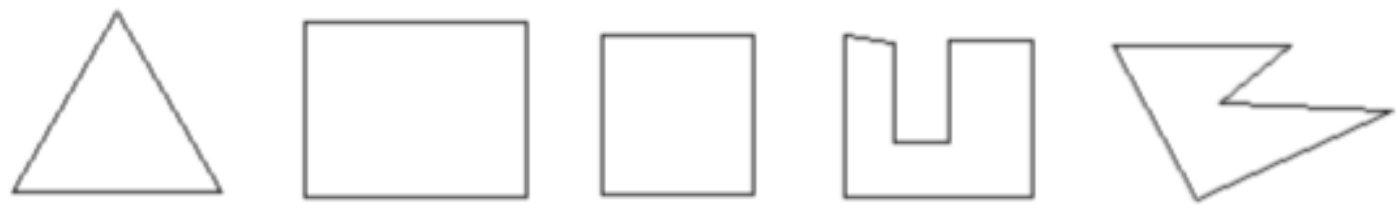

Não são polígonos:
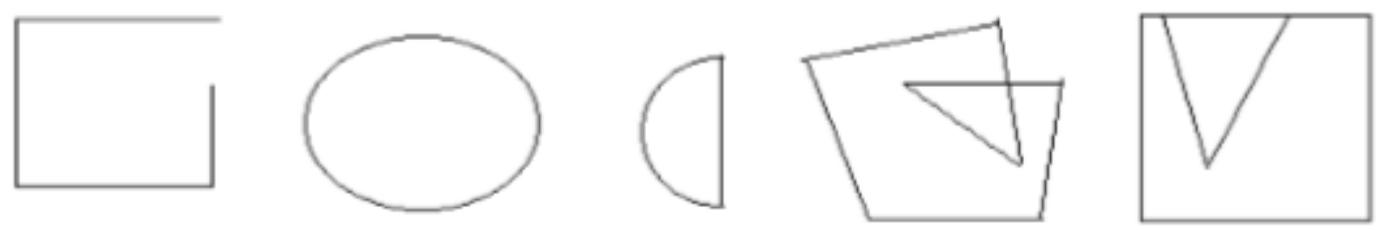

Fonte: Autor

A partir da comparação das figuras que são e as que não são polígonos, a professora instigou seus alunos a adotarem uma definição que correspondesse às respostas dadas e a escreveu na lousa: "polígono é uma figura fechada, formada apenas por segmentos de reta que não se cruzam e possui uma única região interna".

O segundo momento, pode ser identificado pelo uso das peças de acrílico para se descobrir experimentalmente configurações de pavimentação do plano com polígonos regulares, foram colocadas algumas questões norteadoras para a realização desse estudo. Os alunos deveriam responder quais polígonos regulares, de um único tipo, pavimentam o plano e depois justificar suas respostas, para aqueles que não pavimentam.

Em sua análise, a professora afirmou que alguns alunos não consideraram, a princípio, que as configurações obtidas no concreto representavam uma pavimentação do plano, pois o plano deveria ser preenchido com infinitos polígonos, mostrando uma possível dificuldade em perceber que o padrão obtido poderia ser estendido indefinidamente. O professor $R$ também fez essa leitura sobre a recepção dos alunos à atividade proposta e o professor L afirmou em suas expectativas, que imagina que essa dificuldade de abstração apareceria em seus alunos.

$\mathrm{Na}$ discussão dos polígonos de um único tipo que não pavimentam o plano, foi verificado que as respostas dos alunos indicavam que faltava uma parte a ser preenchida e que não havia um polígono para ser encaixado. Para a professora, esse fato significou que os seus 
alunos, mesmo já tendo explorado o conceito de ângulo, não souberam indicar que o ângulo interno do polígono regular que não pavimentou o plano tem uma medida que não divide 360, essa discussão foi induzida pela própria professora posteriormente.

\subsubsection{Professora $M_{2}$}

Dois dos professores participantes, a $\mathrm{M}_{2}$ e o L, não tiveram a oportunidade de aplicar alguma atividade em suas respectivas turmas por conta do cronograma de suas escolas. A professora $\mathrm{M}_{2}$, inclusive, lecionava em uma escola particular em que o currículo deveria ser seguido catedraticamente, não sendo possível utilizar uma aula para aplicar uma atividade que fosse diferente das atividades do material apostilado próprio de sua escola.

Dessa forma acordamos que esses professores seriam avaliados com outro tipo de trabalho final, no qual a sequência didática teria maior detalhamento e seria mais fiel aos elementos do plano de aula. Assim, os dois tiveram um pouco mais de liberdade para explorar uma possível sequência didática, sugerindo a quantidade de aulas que considerassem ideais e supondo todos os materiais necessários disponíveis.

Quadro 18 - Contexto da Sequência Didática da professora $\mathrm{M}_{2}$

\begin{tabular}{|c|c|}
\hline Público-alvo & Duas turmas de 6º ano, com 22 e 20 alunos \\
\hline Escola & Uma escola particular da cidade de São Paulo \\
\hline Tema & Polígonos e reflexão em reta \\
\hline Objetivos Específicos & $\begin{array}{c}\text { Elencou objetivos acerca do tema, como "identificar propriedades } \\
\text { básicas da reflexão" e "investigar as propriedades de polígonos } \\
\text { regulares" }\end{array}$ \\
\hline Recursos/Materiais & $\begin{array}{c}\text { Espelhos, folhas com enunciados impressos, régua, tesoura, entre } \\
\text { outros }\end{array}$ \\
\hline \multicolumn{2}{|c|}{ Organização da Sequência (aulas de 50 minutos cada) } \\
\hline $\mathbf{1}^{\mathbf{a}}$ aula & Explorar a reflexão \\
\hline $\mathbf{2}^{\mathbf{a}}$ aula & Explorar o triângulo e as partições de um polígono \\
\hline $\mathbf{3}^{\mathbf{a}}$ aula & Exlexão com retas concorrentes \\
\hline
\end{tabular}




\begin{tabular}{|c|c|}
\hline $\mathbf{4}^{\mathbf{a}}$ aula & Construir e analisar um triângulo equilátero \\
\hline $\mathbf{5}^{\mathbf{a}}$ aula & Construir e analisar um triângulo isósceles retângulo \\
\hline \multicolumn{2}{|c|}{ Expectativas de Aprendizagem e de Intervenções } \\
\hline \multicolumn{2}{|c|}{$\begin{array}{c}\text { Descreveu as expectativas do que gostaria que os alunos aprendessem, bem como as } \\
\text { resoluções ideais e possíveis erros ou dificuldades. No entanto não escreveu quais seriam } \\
\text { suas intervenções }\end{array}$} \\
\hline
\end{tabular}

Fonte: Autor

A professora $\mathrm{M}_{2}$ sugeriu uma sequência com cinco atividades para alunos de $6^{\circ}$ ano do Ensino Fundamental, com o foco em estudar conceitos relacionados com reflexão em reta e as principais propriedades de polígonos. Suas atividades tiveram os seguintes focos:

Atividade 1 - Explorar a reflexão

Atividade 2 - Explorar a reflexão com retas concorrentes

Atividade 3 - Explorar o triângulo e as partições de um polígono em triângulos

Atividade 4 - Construir um triângulo equilátero e analisá-lo com espelhos

Atividade 5 - Construir um triângulo isósceles retângulo e analisá-lo com espelhos

As atividades 1 e 2 consistiram em propor que os alunos utilizassem um e dois espelhos, respectivamente, e observassem a imagem formada de algum objeto. Em seguida deveriam responder algumas questões que indicavam a exploração de alguma propriedade da reflexão, tal como mostrado na figura 102. 
Figura 102 - Questões da Atividade 2 (professora $\mathrm{M}_{2}$ )

1) Os objetos e letras refletidas mudaram de posição?

2) Mudaram de tamanho (medidas)?

3) Quantas cópias podem ser observadas de cada um?

4) $\mathrm{O}$ que acontece com a quantidade de imagens formadas nos espelhos ao aumentar e diminuir o ângulo entre os espelhos?

$>$ Conjectura sobre o que acontece com o número de imagens refletidas ao mudar o ângulo entre os espelhos.

Fonte: Autor

Primeiramente essas atividades se caracterizaram pelo uso de materiais concretos de G0 e pela observação de objetos reais e suas imagens produzidas nos espelhos. Em seguida, a discussão seria dirigida a fim de se ressaltar propriedades como preservação de medidas e a relação entre o ângulo entre os espelhos e o número de imagens obtidas.

Nas atividades 3 e 4, seriam estudados os elementos dos triângulos e suas classificações a partir de figuras de triângulos entregues para os alunos, com o uso de instrumentos de medida como régua e transferidor. O item 5 da atividade 4 (cf. Figura 103) faz com que os alunos tenham que se referir a propriedades próprias de uma Geometria axiomática em que se define convexidade de polígonos. Aqui ela parte de representações de triângulos de G1 visando discutir as propriedades da figura, além de buscar a justificativa das respostas das questões colocadas, guiando a exploração para G2. Para resolver o item 7 e 8, é necessário utilizar o fato de que a reflexão preserva medida de segmento e de ângulo. 
Figura 103 - Atividade 4 (professora $\mathrm{M}_{2}$ )

- Recortar o triângulo e colar na folha da atividade 4.

- Nomear esse triângulo como DEF.

1) Anote as medidas dos lados do triângulo DEF.

2) Com o auxílio de um transferidor, determine as medidas dos ângulos internos desse triângulo.

3) Classifique o triângulo DEF quanto as medidas dos lados (equilátero, isósceles e escaleno)

4) Classifique o triângulo DEF quanto as medidas dos ângulos internos (acutângulo, retângulo ou obtusângulo).

5) Colocar os espelhos sobre os lados DE e DF. Observe. A figura geométrica formada é um polígono côncavo ou convexo?

6) Classifique esse polígono quanto ao número de lados.

7) Qual a medida dos ângulos internos desse polígono? Justifique.

8) Qual a medida dos lados desse polígono? Justifique.

Fonte: Autor

Em suas expectativas, a professora $\mathrm{M}_{2}$ descreveu que certa resistência ou dificuldade de seus alunos decorreria do fato de que eles utilizavam pouco instrumentos de medidas como régua, compasso e transferidor. Com exceção desse aspecto, ela acredita que os alunos conseguiriam desenvolver o conceito de reflexão em reta e suas propriedades, bem como as propriedades dos polígonos regulares.

\subsubsection{Professor $L$}

Quadro 19 - Contexto da Sequência Didática do professor L

\begin{tabular}{|c|c|}
\hline Público-alvo & Uma turma de $9^{\circ}$ ano. \\
\hline Escola & Não se aplica. \\
\hline Tema & Caracterização de polígonos regulares. \\
\hline Objetivos & $\begin{array}{r}\text { identificar as principais características de polígonos, destacando seus } \\
\text { ângulos internos; ladrilhamentos. }\end{array}$ \\
\hline Recursos/Materiais & Folha com enunciados impressos, transferidor e uma coleção de \\
& polígonos manipuláveis. \\
\hline
\end{tabular}




\begin{tabular}{|c|c|}
\hline \multicolumn{2}{|c|}{ Organização da Sequência (aulas de 50 minutos cada) } \\
\hline $\begin{array}{c}\text { 2 atividades com } \\
\text { duração de } 4 \text { aulas }\end{array}$ & Atividade 1: Investigar características em comum ou não de \\
polígonos. \\
Atividade 2: Análise dos ângulos internos de polígonos. \\
\hline \multicolumn{2}{|c|}{ Expectativas de Aprendizagem e de Intervenções } \\
Colocar os alunos para separarem os polígonos sob algum critério, sem intervir. Pensou em \\
apenas conduzir as discussões. Escreveu brevemente expectativas e possíveis dificuldades. \\
\hline
\end{tabular}

Fonte: Autor

Devido a um currículo extenso a ser seguido, o professor L. não teve a oportunidade de propor suas atividades as suas turmas, ainda que tenha elaborado um plano de aula e o tenha refeito após a nossa revisão.

Suas atividades tiveram como objetivo explorar as principais características de polígonos, mas suas intervenções não foram explicitadas. Acreditamos que esse professor não se apropriou satisfatoriamente da abordagem apresentada, das cinco práticas, pois fez uma descrição superficial dos resultados esperados e das ações dos alunos, além de não ter antecipado erros e dificuldades, focando apenas nas resoluções ideais (cf. Figura 104).

Figura 104 - Expectativas do Professor L

c) $\mathrm{O}$ que elas têm de diferentes?

Algumas formam pavimentação, outras ladrilhamento, etc.

Algumas tem lacunas, outras não.

Atividade 2

Investigando ângulos e lados dos polígonos.

1.Separe os polígonos da coleção de acordo com o número de ângulos retos. Quantos grupos vocês formaram? Esboce uma figura de cada grupo.

Dependerá da quantidade de integrantes da equipe e da quantidade de polígonos disponíveis.

Fonte: Autor

Na descrição do desenvolvimento das atividades, propôs o estudo de ladrilhamentos utilizando as peças de acrílico ou outro material que pudesse representar polígonos regulares e 
irregulares, a separação da turma em grupos de três ou quatro alunos com uma folha com enunciados para guiá-los em cada etapa.

O que nos chama a atenção é que o professor sugere na primeira atividade, que os alunos manipulem os polígonos de acrílico a fim de se produzir ladrilhamentos e pavimentações e, em seguida, na segunda atividade, solicita que os alunos busquem reproduzir a formação obtida em uma figura em uma folha em branco. Nesse momento, consideramos que o incentivo à produção figural a partir da observação de objetos concretos caracteriza a transição do nível G0 para G1, em que se faz necessário descobrir as principais características do objeto para poder representálo.

Em seu texto, o professor indica que esse processo auxiliaria seus alunos a destacarem adequadamente, utilizando instrumentos de medida, propriedades essenciais de uma pavimentação do plano, tais como tipos de polígonos e ângulos e comparação entre eles. Ao longo da atividade 2, o aluno é levado a representar diversos tipos de figuras de cada tipo de propriedade observada. No fechamento de seu trabalho, o professor mostra que as intervenções necessárias ao se estabelecer conexões, caracterizam-se por meio de uma discussão sobre a resolução das atividades visando justificar as ideias desenvolvidas: "O professor deve solicitar explicações e não somente respostas e procurar envolver a turma nas discussões”.

\section{AVALIAÇÃO E ANÁLISE DAS SEQUÊNCIAS DIDÁTICAS}

A fim de se sintetizar como avaliamos, por meio das análises das sequências didáticas elaboradas e experienciadas, a apropriação dos professores participantes dos tipos de atividades vivenciadas no curso, bem como suas respectivas abordagens, e os possíveis impactos em sua prática docente, apresentaremos mais adiante os quadros com a descrição da sequência didática de cada professor por meio de elementos avaliativos.

\subsection{Elementos de análise}

Os elementos, explicitados a seguir, auxiliaram-nos a fazer uma análise qualitativa sobre como se deu a apropriação, por parte dos professores participantes, em relação ao que foi solicitado como trabalho final: formulação (e reformulação) de seus planos de aula inspirados nas cinco práticas; elaboração de uma sequência didática com atividades realizadas no curso 
adaptadas para seus alunos, valorizando o uso de materiais concretos e manipuláveis no estudo da Geometria Plana; tentativa de fazer como que os alunos se apropriem de uma estrutura de pensamento própria de uma Geometria axiomática; apresentação dos resultados do desenvolvimento de suas sequências didáticas com suas turmas. Nos quadros, a cor indica o tipo de análise da seguinte forma: vermelho se refere às ações dos professores relacionadas com as cinco práticas para a orquestração de discussões Matemáticas produtivas (STEIN \& SMITH, 2011); branco são os critérios principais para a avaliação das sequências didáticas; verde ilustra o uso, inspirado em um laboratório de ensino de Matemática, de materiais concretos e manipuláveis; e amarelo para a estrutura das atividades que sugerem um desenvolvimento do pensamento geométrico em função dos níveis de uma Geometria axiomática.

1. Realizou modificações do plano de aula após feedback dos formadores.

2. Interveio com provocações pontuais.

3. Interveio com explicações expositivas.

4. Realizou momentos de síntese ou sistematização de conhecimentos geométricos a partir de discussões com os alunos.

5. Desenvolveu sua sequência didática com seus alunos.

6. Apresentou e discutiu os resultados da experimentação em um encontro presencial.

7. No relatório por escrito, apresentou uma discussão dos resultados das atividades.

8. Adaptou atividades desenvolvidas no curso, bem como as abordagens de ensino

9. Utilizou materiais concretos e manipuláveis.

10. Incentivou a construção de justificativas dos resultados matemáticos.

11. Os enunciados das atividades incluíram o uso de diferentes representações, em particular, figuras ou desenhos.

12. Solicitou a construção de diferentes figuras, por parte dos alunos. 


\begin{tabular}{|c|c|c|c|c|}
\hline \multicolumn{5}{|c|}{ Quadro 21 - Avaliação das Sequências Didáticas } \\
\hline AvaliaçãolProfessores & R & $\mathbf{M}_{\mathbf{2}}$ & $\mathbf{L}$ & $\mathbf{G}$ \\
\hline Elemento 1 & Satisfatório & Satisfatório & Parcialmente & Satisfatório \\
\hline Elemento 2 & pouco & não se aplica & não se aplica & muito \\
\hline Elemento 3 & muito & não se aplica & não se aplica & pouco \\
\hline Elemento 4 & Parcialmente & não se aplica & não se aplica & Satisfatório \\
\hline Elemento 5 & OK & não se aplica & não se aplica & OK \\
\hline Elemento 6 & OK & não se aplica & não se aplica & OK \\
\hline Elemento 7 & OK & não se aplica & não se aplica & OK \\
\hline Elemento 8 & OK & OK & OK & OK \\
\hline Elemento 9 & OK & propôs o uso & propôs o uso & OK \\
\hline Elemento 10 & NÃO & OK & OK & OK \\
\hline Elemento 11 & OK & apenas objetos & apenas objetos & OK \\
\hline Elemento 12 & OK & OK & OK & NÃO \\
\hline
\end{tabular}

Fonte: Autor

\begin{tabular}{|c|c|c|c|c|}
\hline \multicolumn{5}{|c|}{ Quadro 22 - Avaliação das Sequências Didáticas } \\
\hline Avaliação\Professores & C2 & A2 & $\mathbf{A}_{1}$ & M \\
\hline Elemento 1 & Parcialmente & Parcialmente & Satisfatório & Satisfatório \\
\hline Elemento 2 & muito & Muito & Muito & muito \\
\hline Elemento 3 & pouco & Pouco & Pouco & pouco \\
\hline Elemento 4 & Parcialmente & Insatisfatório & Satisfatório & Satisfatório \\
\hline Elemento 5 & OK & OK & OK & OK \\
\hline Elemento 6 & OK & OK & OK & OK \\
\hline Elemento 7 & OK & OK & OK & OK \\
\hline Elemento 8 & OK & OK & OK & OK \\
\hline Elemento 9 & OK & OK & OK & OK \\
\hline Elemento 10 & OK & NÃO & OK & OK \\
\hline Elemento 11 & NÃO & OK & OK & OK \\
\hline Elemento 12 & NÃO & OK & OK & OK \\
\hline
\end{tabular}

Fonte: Autor

O elemento 1 pode ser relacionado com a prática antecipar, exibindo as possíveis intervenções dos professores, possíveis respostas corretas e incorretas dos alunos. Podemos observar que a maioria dos professores apresentou um plano de aula em concordância com esta prática e concluímos que aqueles que não conseguiram mostraram certa dificuldade em prever 
ações e dúvidas dos alunos e pensamos que esse fato pode estar relacionado com a falta de hábito de se trabalhar com sequências didáticas com detalhamento do planejamento das aulas.

O elemento 2 e o elemento 3, de certa forma, se contrapõe enquanto ações pedagógicas e se relacionam com a prática monitorar, pois diz respeito à forma como o professor observa as interações dos estudantes e como lida com elas. Satisfatoriamente os relatos mostraram que os professores que puderam desenvolver suas sequências didáticas em sala de aula, com exceção do professor R, interviram muito mais com questionamentos pontuais e provocações do que com explicações expositivas. A forma como as discussões coletivas se deram nos primeiros contatos com as atividades não foram destacadas com muita precisão pelos professores, embora tenha ficado evidente que ocorreram algumas pausas para que os alunos pudessem expor dúvidas e discuti-las com a turma.

Já com relação ao elemento 4 , que pode ser relacionado com a prática estabelecer conexões, podemos ver que alguns professores não realizaram momentos de sistematização de conceitos adquiridos com uma discussão. $\mathrm{O}$ professor $\mathrm{R}$, por exemplo, expôs as ideias e definições para os alunos sem que partissem deles e a professora $\mathrm{C}_{2}$, ao perceber que seus alunos estavam tendo complicações para prosseguir em determinada etapa da atividade, expôs aos seus alunos uma possibilidade de pavimentação do plano com polígonos regulares de um único tipo. Esse fato nos leva a conjecturar que também pode ser habitual e, até mesmo, cultural essa prática nas suas respectivas escolas, ou seja, haveria alguma resistência para que mudassem para ações em que a conclusão Matemática parte dos alunos em meio a uma discussão.

Os elementos 5, 6 e 7 dizem respeito aos principais critérios para a aprovação do trabalho final dos professores. Para além do caráter avaliativo, um professor conseguiu testar uma breve sequência didática inspirada nas atividades do nosso curso significa uma possibilidade de testar certas modificações em sua própria prática docente embasadas pelas principais ações propostas pela nossa fundamentação teórica e metodológica.

Dado que uma das principais características do curso foi o uso de materiais concretos e manipuláveis, ocorreu, por consequência, que todos os professores propuseram atividades em que o estudo da Geometria plano é realizado com o auxílio de diferentes tipos de materiais que possibilitam a criação de conjecturas a partir da evidência material. Dessa forma os elementos 8 e 9 estiveram presentes de forma significativa em todas as sequências didáticas propostas pelos professores. Algo que sugere uma aproximação das práticas docentes deles com a forma como se estudou Geometria no curso pode ser destacada no uso da pavimentação e das reflexões em retas (utilizando espelhos planos) para se estudar propriedades de outros conceitos, na 
elaboração de definições a partir de discussões coletivas com os alunos, no uso de materiais concretos para a construção de representações gráficas e para auxiliar no processo de abstração, etc.

Basicamente, o elemento 10 foi avaliado a partir das solicitações escritas nos enunciados das atividades. Se o professor apenas solicita que o aluno escreva uma resposta correta para uma pergunta, mas não sugere que faça a justificativa das ideias, dificilmente ocorrerá uma discussão rica em que se exercite o pensamento geométrico de nível G3. Dois entre os professores não fizeram essa solicitação aos alunos e foram aqueles que transpareceram maior resistência às abordagens de ensino adotadas no curso.

Os últimos dois elementos, 11 e 12, desempenham o papel de avaliar se o professor efetivamente desenvolveu atividades em que são analisadas ou elaboradas representações (gráficas ou figurais) de objetos geométricos em nível G1 ou G2. A representação esperada possui a função de destacar, pôr em evidência e ilustrar características e propriedades particulares de determinado objeto, bem como facilitar a construção de conjecturas e a busca pelas respectivas justificativas. Apenas a professora $C_{2}$ não solicitou e nem apresentou representações do objeto de estudo (pavimentações do plano com polígonos regulares, no caso) o que nos faz refletir sobre o fato de ela ter tido a necessidade de expor resultados de uma das atividades pois os alunos não conseguiram descobrir determinado tipo de pavimentação. Acreditamos que ao oferecer ao aluno a oportunidade de explorar ou elaborar uma representação figural permite que ele perceba propriedades que "façam o desenho estar correto" e, então, concluí-las em suas justificativas.

\subsection{Padrões: definições de conceitos matemáticos}

Os professores $\mathrm{R}, \mathrm{C}_{2}$ e $\mathrm{A}_{1}$ solicitaram uma pesquisa sobre as definições de polígono e pavimentação, enquanto a professora $G$ utilizou somente os conhecimentos prévios de seus alunos sobre esses conceitos para guiar uma discussão que fomentasse a conclusão desejada.

A professora $\mathrm{M}_{3}$ preparou um material com as definições sobre os conceitos de polígonos, pavimentação, retas paralelas, ângulos, entre outros, mas não teve tempo hábil de enviar para seus alunos antes do dia de sua oficina. A professora $\mathrm{A}_{2}$, que desenvolveu atividades com foco na reflexão em reta, solicitou que os alunos realizassem, logo no início, uma consulta em seus livros didáticos de Matemática para discutirem a definição de reflexão adotada nesse material. 
Contudo, todos esses professores mostraram a importância de se partir de ideias iniciais trazidas por seus alunos com, ou sem, uma busca prévia em materiais didáticos ou em páginas da internet. Isso mostra que as apresentações das definições tiveram pouco aspecto expositivo e foram obtidas por meio de discussões em conjunto com os estudantes.

A professora $\mathrm{M}_{2}$ escreveu em meio a seus resultados, que os seus alunos poderiam consultar a apostila de Matemática durante a realização das atividades, mas não especificou para qual finalidade, no entanto, suas ações nos levaram a acreditar que uma possível utilização seria para se buscar o conceito de reflexão em reta. Em sua primeira atividade, propõe que o aluno faça uma exploração com um espelho plano e, em seguida, pede para o aluno definir, com suas próprias palavras, o que é reflexão.

Como a professora $\mathrm{M}_{2}$ propõe uma discussão sobre as conclusões ao final de cada atividade, acreditamos que o conceito de reflexão, assim como para a professora $\mathrm{A}_{2}$, seria concebido com a colaboração dos alunos e de suas ideias.

O professor L, que é um dos dois professores que não conseguiram desenvolver suas atividades com seus alunos, não descreveu em seu plano de aula, como seria o desenvolvimento das atividades no que diz respeito aos principais conceitos e definições explorados.

Como o tratamento adotado no curso, no que diz respeito a se apresentar definições, caracterizou-se pela construção colaborativa de ideias que surgiram entre os professores durante discussões, análises de problemas e de figuras, acreditamos que os professores se sentiram motivados a adotar uma construção de conceitos e definições com essa mesma perspectiva. As ações dos professores podem mostrar também certa aprovação ou apreço pelo ensino de conceitos e tópicos de Geometria por meio de discussões com todos os estudantes.

\subsection{Padrões: comparação entre as atividades propostas}

De forma geral, todos os professores buscaram realizar atividades inspiradas nas atividades desenvolvidas no curso, mostrando, em diferentes proporções, atenção ao tipo de enunciados propostos e também cuidado com a forma de se comunicar com os alunos, como dividir as turmas, a escolha de materiais, bem como a maneira de usá-los e como guiar o desenvolvimento de todo o processo partindo de um planejamento inicial, com objetivos definidos.

Após a elaboração da primeira versão dos planos de aula, alguns professores haviam desenvolvido atividades com foco apenas no estudo de polígonos e surgiu a discussão sobre qual enfoque poderiam ter. Nesse momento, sugerimos que poderiam ser considerados os 
principais tópicos estudados no curso, que foram, de forma resumida, polígonos e pavimentação do plano e, mais especificamente, se teve enfoque no conceito de reflexão em reta, nas justificativas das pavimentações do plano que podem ser obtidas com polígonos regulares e como usar o caleidoscópio para a observação e para a produção de pavimentações do plano.

A composição de figuras, formando as imagens dentro do caleidoscópio, por exemplo, é um conceito que poderia ser explorado para se justificar algumas pavimentações do plano, mas que não esteve presente nas sequências didáticas desenvolvidas, pois esse conceito só seria explorado em maiores detalhes no sétimo e oitavo encontro, que ocorrem após a primeira versão dos planos de aula. A professora $\mathrm{M}_{3}$ chegou a solicitar, em sua terceira atividade, que os estudantes justificassem porque o caleidoscópio formava determinadas pavimentações do plano, mas não conseguiu trabalhar essa atividade em sua oficina.

Dentre todos os principais conceitos explorados antes do sétimo encontro, o único que praticamente não esteve presente nas sequências didáticas dos professores foi o de estrela poligonal, mas podemos concluir que essa ausência não teve impacto negativo nas aulas com seus alunos e tão pouco significa que não houve apropriação desse conceito, por parte dos professores.

Uma possível inferência que pode ser feita aqui é que explorar a Geometria das estrelas poligonais como foi feito no curso, tem mais potencial de oferecer um aprofundamento aos professores no tipo de atividade em que as justificativas e definições partem de discussões, no uso de materiais concretos para criação de conjecturas e no estudo próprio da Geometria do caleidoscópio e das pavimentações do plano do que dar inspiração para a produção de atividades para a Educação Básica.

Os enfoques dados por cada professor podem ser observados a seguir, de maneira resumida.

M2: estudo da reflexão com espelhos planos e tipos de triângulos;

A2: estudo da reflexão com espelhos planos;

C2: estudo das pavimentações do plano com peças de acrílico;

A1: estudo de pavimentações do plano e polígonos regulares; 
G: estudo de pavimentações do plano e polígonos regulares;

M3: estudo de polígonos regulares, configurações de pavimentações do plano e caleidoscópios para a produção de pavimentações;

R: estudo de polígonos, pavimentações do plano e caleidoscópios para observação;

L: estudo de tipos de polígono e seus elementos, tais como ângulo e lado.

Dentre as atividades propostas, foram abordados problemas visando valorizar as propriedades da reflexão em reta em uma pavimentação ou explorar e descobrir as propriedades dos polígonos regulares por meio de pavimentações. Nas sequências didáticas em que as situações solicitadas aos alunos eram de descobrir as propriedades e as justificar evidencia-se um nível de pensamento de G2 em que os polígonos e composições dependem de construções geométricas.

\subsection{Padrões: desenvolvimento das atividades}

Cada professor buscou, em alguma medida, desenvolver suas atividades a partir de uma organização da sala e das aulas que favorecessem as discussões em grupos, a criação de conjecturas a partir da análise de figuras ou da manipulação de materiais concretos e a elaboração de uma conclusão sobre os principais resultados matemáticos obtidos pelas turmas. Muitos dos professores utilizaram espelhos planos para o estudo das propriedades da reflexão, como a invariância de medida de segmento, de ângulo e de distâncias e buscaram relacionar tais propriedades no estudo de ângulos internos e centrais de polígonos regulares.

$\mathrm{O}$ estudo de ângulos internos e centrais de polígonos regulares foi associado com o estudo das possíveis configurações que podem pavimentar o plano. Nesse estudo, boa parte dos professores utilizou os polígonos de acrílico para que os alunos pudessem perceber quais configurações seriam possíveis e trouxeram para a discussão o cálculo do ângulo interno para justificar essas configurações. O conceito de ângulo central foi explorado somente pela professora $\mathrm{M}_{3}$ para o cálculo do ângulo interno de polígonos regulares, enquanto outros professores, como a $\mathrm{G}$, mostraram como se obter a medida do ângulo interno a partir do número de lados, ou seja, a partir de uma fórmula ou apresentaram uma tabela com os valores discriminados. 
No que diz respeito as intervenções, de acordo com os respectivos relatos, todos os professores, com exceção do $\mathrm{R}$, buscaram auxiliar o desenvolvimento dos alunos com as atividades fazendo majoritariamente questionamentos pontuais que guiassem a discussão em grupos em detrimento de uma explicação expositiva dos resultados e definições. Conforme seus alunos resolviam as atividades os professores buscavam fazer uma discussão com toda a turma para se obter uma conclusão, um resultado matemático tal como descobrir quais pavimentações são possíveis com polígonos regulares de um único tipo e perceber que os polígonos regulares que podem pavimentar o plano possuem ângulos internos cuja medida divide 360 .

\section{ANÁLISE GLOBAL}

Foram destacados anteriormente os principais indícios de que os professores participantes se mostraram confiantes com relação às práticas de ensino de Geometria que foram desenvolvidas durante o curso e também ao modelo descrito por Stein e Smith (2011) para desenvolverem suas próprias atividades.

Pelo que foi discutido na análise dos padrões e na comparação de atividades propostas, acreditamos que os futuros professores e futuros leitores desse trabalho poderão encontrar em nossas sequências didáticas, possibilidades de se adotar ou adaptar atividades para seu próprio contexto de sala de aula. Alguns dos professores, como a professora $\mathrm{A}_{2}$ que afirmou que dará continuidade às atividades que desenvolveu com suas turmas, mostraram interesse em utilizar as atividades do curso em futuras aulas.

Uma questão que se coloca aqui é a respeito da possível continuidade de determinadas práticas dos professores, pois gostaríamos de ter conhecimento sobre como os professores buscarão desenvolver futuramente suas aulas, sobretudo as de Geometria, utilizando um planejamento de sequência didática bem como o vivenciado, adotando o uso de materiais concretos e manipuláveis e incentivando as discussões coletivas para a sistematização de conceitos.

\subsection{Análise do questionário de feedback}

Após o último encontro do curso, enviamos aos professores, via e-mail, um arquivo com um questionário de avaliação do curso, contendo questões sobre o que os professores pensam em relação à carga horária do curso, se tiveram dificuldades conceituais, nos enunciados ou no 
uso de materiais etc. As questões nos ajudam também a evidenciar em que medida o curso colaborou com a formação deles em suas próprias palavras, sobretudo no que diz respeito aos impactos das atividades do curso em suas práticas, com o planejamento de sequências didáticas que demandam o uso de materiais concretos no ensino de Geometria, entre outras possíveis colaborações.

A seguir, faremos uma discussão das respostas obtidas pelos professores $\mathrm{M}_{3}, \mathrm{M}_{2}, \mathrm{~L}, \mathrm{~A}$, $\mathrm{C}_{2}, \mathrm{G}$ e R, destacando os padrões em suas falas e fazendo uma análise global.

O questionário, apresentado na figura a seguir, era composto de nove questões, algumas com subitens e todas demandando respostas dissertativas.

Figura 101 - Questionário de Feedback

I. Você diria que o tempo de curso foi adequado para a realização de todas as atividades? Comente Se respondeu não, você acredita que oferecer esse mesmo curso, mas com uma carga horária maior seria melhor? Por que?

II. Durante o curso você teve dificuldades:

a) com o uso de materiais? Qual(is)?

b) em conceitos e definições? Qual(is)

c) na realização de atividades práticas? Qual(is)?

d) em expor suas ideias? Comente.

III. Para você, as atividades possuíam enunciados e objetivos claros? Comente.

IV. Você considera que o curso contribuiu para sua formação, em particular para consolidar conceitos e práticas do ensino de Geometria? Comente.

V. Você se sente confiante para trabalhar com Geometria em sala de aula? E com o conteúdo de transformações geométricas e demais tópicos abordados no curso? Comente.

VI. Se um aluno seu te perguntasse: "por que eu preciso aprender Geometria?" o que você lhe diria? De alguma forma, o curso contribuiu para a elaboração de sua resposta?

VII. No que diz respeito a planejamento de aulas $\varepsilon$ aplicação de atividades dirigidas, a abordagem apresentada no curso agregou à sua formação enquanto professor?

VIII. Escreva suas críticas (positivas e/ou negativas) a respeito da sua vivência durante o curso. IX. Escreva suas sugestões para aprimoramento do curso.

Fonte: Autor

Ilustramos em dois quadros, a seguir, um resumo das respostas dadas pelos professores por meio de palavras-chave. 
Quadro 23 - Respostas ao Questionário de feedback (professores $\mathrm{C}_{2}$, L e R)

\begin{tabular}{|c|c|c|c|}
\hline $\begin{array}{l}\text { Professorl } \\
\text { Questões }\end{array}$ & $\mathbf{C}_{2}$ & $\mathbf{L}$ & $\mathbf{R}$ \\
\hline 1 - Sim ou Não & Não & Não & Não \\
\hline I - Comentários & $\begin{array}{c}\text { Trabalho com } \\
\text { conteúdo e } \\
\text { com ideais de aulas } \\
\text { práticas }\end{array}$ & $\begin{array}{l}\text { Pois não segue uma } \\
\text { abordagem tradicional }\end{array}$ & $\begin{array}{l}\text { Foi necessário um } \\
\text { encontro extra }\end{array}$ \\
\hline II a & Não & Não & Não \\
\hline II b & $\begin{array}{l}\text { Sim, mosaico e } \\
\text { ladrilhamento }\end{array}$ & Sim & Não \\
\hline II c & Não & Não & Em algumas \\
\hline II d & Não & Sim, novos conceitos & Não \\
\hline III - Sim ou Não & Não & Depende & Sim \\
\hline III - Comentários & $\begin{array}{l}\text { Precisou discutir } \\
\text { coletivamente }\end{array}$ & $\begin{array}{l}\text { Depende de quanto o } \\
\text { conceito lhe era } \\
\text { familiar }\end{array}$ & $\begin{array}{l}\text { Não entendeu um } \\
\text { enunciado }\end{array}$ \\
\hline IV - Sim ou Não & Sim & Sim & Sim \\
\hline IV - Comentários & $\begin{array}{l}\text { Possibilidades de } \\
\text { trabalho }\end{array}$ & Agregou conhecimento & $\begin{array}{l}\text { Abordagem } \\
\text { interessante }\end{array}$ \\
\hline V - Sim ou Não & Sim & Sim & Sim \\
\hline V - Comentários & $\begin{array}{l}\text { Uso de outros } \\
\text { materiais }\end{array}$ & $\begin{array}{c}\text { Precisa } \\
\text { estudar mais }\end{array}$ & $\begin{array}{l}\text { Pavimentação e } \\
\text { Caleidoscópios }\end{array}$ \\
\hline VI - Comentários & $\begin{array}{l}\text { Desenvolver o } \\
\text { raciocínio } \\
\text { lógico-dedutivo }\end{array}$ & $\begin{array}{l}\text { Desperta a criatividade } \\
\text { e noção espacial }\end{array}$ & $\begin{array}{c}\text { Sem especificar um } \\
\text { uso prático }\end{array}$ \\
\hline VII - Sim ou Não & Sim & Sim & Sim \\
\hline VII - Comentários & $\begin{array}{c}\text { Formas de abordar } \\
\text { os temas }\end{array}$ & Não comentou & Muito \\
\hline VIII - Comentários & $\begin{array}{l}\text { Formas de abordar } \\
\text { os temas }\end{array}$ & Teve dificuldades & $\begin{array}{l}\text { Pouco tempo em } \\
\text { atividades } \\
\text { empobrecem } \\
\text { a discussão }\end{array}$ \\
\hline IX - Comentários & $\begin{array}{l}\text { O curso deveria ter } \\
\text { mais tempo de } \\
\text { duração }\end{array}$ & $\begin{array}{c}\text { Selecionar quem tem } \\
\text { conhecimento de } \\
\text { Geometria }\end{array}$ & $\begin{array}{l}\text { Melhor } \\
\text { aproveitamento } \\
\text { do tempo }\end{array}$ \\
\hline
\end{tabular}


Quadro 24 - Respostas ao Questionário de feedback (professoras $\mathrm{M}_{2}, \mathrm{~A}_{2}$ e $\mathrm{M}_{3}$ )

\begin{tabular}{|c|c|c|c|}
\hline $\begin{array}{l}\text { Professorl } \\
\text { Questões }\end{array}$ & $\mathbf{M}_{2}$ & $\mathbf{A}_{2}$ & M3 \\
\hline I - Sim ou Não & Não & Sim & Parcialmente \\
\hline I - Comentários & $\begin{array}{l}\text { Abordagem } \\
\text { diferente } \\
\text { nas atividades }\end{array}$ & Foi Adequado & $\begin{array}{l}\text { Pré-requisitos e } \\
\text { Discussões }\end{array}$ \\
\hline II a & Não & Não & Não \\
\hline II b & Não & Não respondeu & Não \\
\hline II c & Não & Sim & Não \\
\hline II d & Sim & Não respondeu & Não, bom ambiente \\
\hline III - Sim ou Não & Sim & Sim & Parcialmente \\
\hline III - Comentários & Sem problemas & $\begin{array}{l}\text { Não entendeu } \\
\text { todos os } \\
\text { enunciados }\end{array}$ & $\begin{array}{c}\text { Enunciados } \\
\text { confusos } \\
\text { Pediu intervenção }\end{array}$ \\
\hline IV - Sim ou Não & Sim & Sim & Sim \\
\hline IV - Comentários & $\begin{array}{c}\text { Aulas mais práticas } \\
\text { Pavimentação }\end{array}$ & $\begin{array}{l}\text { Uso de espelhos } \\
\text { em sala de aula }\end{array}$ & $\begin{array}{l}\text { Reflexão sobre } \\
\text { sua prática }\end{array}$ \\
\hline V - Sim ou Não & Sim & Sim & Sim \\
\hline V - Comentários & $\begin{array}{c}\text { Busca } \\
\text { possibilidades } \\
\text { de ensino }\end{array}$ & $\begin{array}{l}\text { Colocar em } \\
\text { prática } \\
\text { atividades do } \\
\text { curso }\end{array}$ & $\begin{array}{l}\text { Metodologias } \\
\text { de ensino }\end{array}$ \\
\hline VI - Comentários & $\begin{array}{l}\text { Motricidade, } \\
\text { abstração, } \\
\text { memória e } \\
\text { cognição }\end{array}$ & $\begin{array}{c}\text { Está presente em } \\
\text { tudo, } \\
\text { natureza e } \\
\text { cotidiano }\end{array}$ & $\begin{array}{l}\text { É divertida, linda. } \\
\text { Resolver problemas }\end{array}$ \\
\hline VII - Sim ou Não & Sim & Sim & Sim \\
\hline VII - Comentários & $\begin{array}{l}\text { Sequência } \\
\text { pedagógica }\end{array}$ & Uso de espelhos & Organizar o registro \\
\hline $\begin{array}{c}\text { VIII - } \\
\text { Comentários }\end{array}$ & $\begin{array}{c}\text { Descobertas de } \\
\text { práticas, teóricas e } \\
\text { pedagógicas; } \\
\text { faltou tempo }\end{array}$ & $\begin{array}{l}\text { Preparar aulas, } \\
\text { discussão com } \\
\text { alunos, } \\
\text { novas práticas }\end{array}$ & $\begin{array}{c}\text { Proveitoso. } \\
\text { Atividades } \\
\text { bem planejadas e } \\
\text { (re)organizadas }\end{array}$ \\
\hline IX - Comentários & $\begin{array}{l}\text { Continuação } \\
\text { do curso } \\
\text { Explorar mais } \\
\text { o tema } \\
\end{array}$ & Não respondeu & $\begin{array}{l}\text { Menos atividades, } \\
\text { reflexões mais } \\
\text { profundas }\end{array}$ \\
\hline
\end{tabular}

Fonte: Autor 
A maioria dos professores respondeu, na questão I, que o tempo do curso não foi adequado para a realização das atividades e alguns deles também retomaram essa discussão nas últimas duas questões. Em suas respostas, apareceram as seguintes justificativas: como muitos não haviam tido um estudo sobre a Geometria das transformações durante sua graduação, as discussões sobre os tópicos aparentemente simples, acabavam se desdobrando em reflexões profundas sobre a própria Geometria e sobre o ensino dos conceitos abordados; havia uma quantidade vasta de conteúdos e de atividades desenvolvidas no decorrer do curso e também novas ideias sobre práticas de ensino.

Acreditamos que, inicialmente, os professores se apropriariam rapidamente dos conceitos abordados nas primeiras atividades sobre reflexão em reta, no entanto, algumas atividades que seriam aparentemente desenvolvidas rapidamente, acabaram tomando mais tempo do que o previsto. Esse pode ser um dos fatos que fizeram com que fosse necessário, inclusive, um encontro extra após o oitavo encontro.

Entre as poucas dificuldades que foram destacadas na questão II, a distinção entre os termos mosaico, ladrilhamento e pavimentação nos chamou mais a atenção. As respectivas definições foram apresentadas por nós e discutidas coletivamente no início das atividades de pavimentações. Se tivéssemos mais tempo disponível para se introduzir esses conceitos, poderíamos ter construído esses significados de forma colaborativa fazendo com que esses termos pudessem ser melhores compreendidos e diferenciados.

Foi destacado pelo professor L, em meio às questões II-d e III, que houve dificuldade com os enunciados pois muitos conceitos, definições e termos utilizados nas atividades eram desconhecidos ou recém apresentados para ele. Além desse caso, não houve comentários significativos na questão III, como podemos ver no quadro anterior.

$\mathrm{Na}$ questão IV, todos os professores afirmaram que houve uma contribuição em sua formação e os comentários se direcionaram para dar destaque às práticas de ensino de Geometria, como nas respostas das professoras $M_{3}, G$ e $C_{2}$. Já a professora $A_{2}$ foi mais específica e disse que aprendeu como usar espelhos em aulas de Geometria e nos levou a crer, inclusive pela sua própria fala nos encontros presenciais, que pretende usá-los, bem como os “caleidoscópios caseiros”, em mais aulas, mesmo após o término do curso.

Em geral, os professores afirmaram que, na questão V, se sentiram confiantes para trabalharem com a Geometria em sala de aula. Com relação aos tópicos de transformações geométricas, o professor R especificou em sua resposta que não se sente confiante e a professora $\mathrm{G}$ disse que o curso contribuiu para esse ganho de confiança os demais não fizeram comentários 
sobre esses tópicos. Já a professora $\mathrm{C}_{2}$, falou um pouco sobre como o curso a deixou mais confiante, pois conheceu formas de usar determinados tipos de materiais para se desenvolver conteúdos de Geometria e a professora $\mathrm{M}_{3}$ disse que o curso a influenciou para buscar aprender mais sobre metodologias de ensino de Matemática.

Em especial, na questão VII, esperávamos reconhecer nas respostas, evidências de apropriação das cinco práticas por parte dos professores, mas algumas das respostas mostraram, de certa forma, ideias gerais. A professora $\mathrm{C}_{2}$ falou sobre o uso de materiais como uma forma melhor de abordar os temas com os seus alunos e a professora $\mathrm{A}_{2}$. falou sobre o uso de espelhos na sala de aula. Ambas se detiveram a responder com foco na aplicação de atividades e não falaram sobre o planejamento de aulas.

Por outro lado, a professora $\mathrm{M}_{2}$ disse que o curso lhe agregou, sobretudo, na forma como as atividades foram apresentadas, divididas em partes, o que chamou de "sequência pedagógica". Acreditamos que a professora $\mathrm{M}_{3}$, ao falar que a "organização do registro das atividades" teve impacto na sua prática, mostra que as etapas de construção de conceitos em forma de uma sequência didática com discussões e reflexões sobre o registro colaboraram para sua formação.

As críticas expostas no item VIII mostraram impressões positivas e negativas, inclusive com padrões entre os pensamentos dos professores a respeito do curso. No entanto, apesar de serem itens distintos, afirmações que responderiam o item VIII, foram colocadas no item IX e vice-versa, de tal forma que apresentaremos aqui uma discussão relacionando esses dois itens.

O professor R expôs que sentiu a grande importância das discussões, mas que achou que elas demandavam um tempo maior do que o tempo que tiveram (o problema do tempo escasso apareceu em boa parte de suas respostas). No mesmo sentido, a professora $\mathrm{M}_{3}$ sugeriu que fosse reduzida a quantidade de atividades realizadas para que sobrasse mais tempo para as discussões, já que, segundo ela, as atividades mais simples já geraram reflexões profundas entre o grupo de professores.

Essa reflexão posta pelos professores nos mostra que deveria ser dado um maior cuidado para as discussões que ocorrem durante a resolução das atividades, sobretudo durante a prática de monitorar, bem como maior tempo disponível.

Como pretendemos continuar atuando na formação inicial e continuada de professores de Matemática, sobretudo no que diz respeito à Geometria Plana, pretendemos refletir sobre o feedback obtido para repensarmos nossa abordagem a fim de melhorar o envolvimento e aprendizado dos participantes. Em meio as discussões entre nós e o grupo de professores, dois 
tipos de sugestões se destacaram, um relacionado com o tempo disponibilizado no curso e um destacando a importância de uma fase seguinte do curso.

Primeiramente ficou evidente que os professores sentiram que houve pouco tempo no curso no que diz respeito a carga horário total, pois haveriam mais discussões e temas a serem explorados, dentre os quais, os professores já se sentiam instigados a investigar, como, por exemplo, as chamadas "falhas" nas imagens produzidas nas atividades 2 e 3.2.; e em relação ao tempo fornecido para a realização de cada tarefa e cada atividade, pois as discussões, inclusive durante as atividades iniciais, eram muito produtivas e, geralmente, tinham vários desdobramentos.

E a fim de ilustrar como os professores começaram a sentir o desejo de que o curso se estendesse, podemos destacar que, a partir do sexto encontro, alguns deles começavam a mostrar interesse em continuar os estudos das isometrias e suas propriedades, os quais haviam sido explorados no encontro anterior a este. O professor L, por exemplo, afirmou que nunca havia estudado anteriormente as isometrias enquanto transformações do plano e o professor $\mathrm{R}$ disse que se identificou muito com o estudo teórico das isometrias. Essas afirmações podem mostrar um pouco da motivação que eles tiveram para desejar dar continuidade a esses estudos.

A professora $\mathrm{M}_{2}$ falou que as abordagens exploradas no curso eram novidade para ela e que, até então, não havia visto muitas formas de se desenvolver os vários tópicos da Geometria plana na Educação Básica, como reflexão em reta e polígonos. O que para ela são denominadas “abordagens”, para Shulman (1987) seria o conhecimento pedagógico do conteúdo, um saber que mesmo sendo muito importante para a formação de um professor, muitas vezes é mais presente em cursos de formação continuada do que em cursos de licenciatura. Em seu questionário de feedback, ela evidenciou que gostaria de uma continuação do curso para se trabalhar mais as transformações geométricas.

Uma observação que pode ser ressaltada aqui é que na realização dos trabalhos finais, nos quais os professores experimentaram atividades com seus próprios alunos, alguns dos professores se queixaram de que tópicos relacionados aos tipos de pavimentações do plano foram apresentados só após a elucidação do trabalho final, ou seja, a partir do sexto encontro, fazendo com que eles tivessem certa dificuldade em fazer uma proposta de atividade com tópicos que eles estavam começando a se aprofundar ainda.

Portanto, pensando na possibilidade de continuação do curso e no uso adequado do tempo, acreditamos que seria interessante uma proposta de oferecer um curso com as mesmas atividades, mas com mais tempo para resolução, em outras palavras, aumentar a carga horária 
do curso. Ainda estamos em processo de elaboração de uma nova proposta de curso, no entanto, temos a expectativa de que se trataria de um curso de carga horária próxima de 40 horas; haveria mais tempo para as discussões, sobretudo relacionadas com as atividades inicias que ressaltavam as propriedades básicas da reflexão em reta, explorar mais pavimentações do plano, elucidar com mais antecedência as sequências didáticas produzidas e experimentadas pelos professores e por fim, diluir em mais encontros a discussão teórica sobre isometrias e composição de isometrias.

Uma discussão um pouco mais aprofundada será feita para os padrões de respostas observados na questão VI, no tópico a seguir.

\subsection{A importância da Geometria segundo os professores participantes}

Embora no curso tenham sido apresentadas formas de se abordar tópicos de Geometria Plana na Educação Básica e na licenciatura e não tenhamos dado foco em tentar responder a questão “por que ensinar Geometria?", essa pergunta esteve presente no questionário final para que pudéssemos avaliar em que medida os professores buscam ou buscarão inserir os tópicos abordados no curso, em suas aulas regulares, bem como de que forma eles avaliam a importância desse estudo.

Em relação a questão VI "Se um aluno seu te perguntasse: 'por que eu preciso aprender Geometria?' o que você lhe diria? De alguma forma, o curso contribuiu para a elaboração de sua resposta?", pudemos reconhecer um determinado padrão nas respostas apresentadas, que costumamos ouvir de outros professores de Matemática cotidianamente; foram apontadas justificativas das quais a maioria se centrou em afirmar que a Geometria está presente em tudo, no dia a dia e que pode ser percebida na natureza.

Acreditamos que os tópicos apresentados no curso relacionados com pavimentação do plano podem ser relacionados com o estudo de padrões da natureza e da arquitetura, mas essa é uma associação que não necessariamente precisaria ser feita. $\mathrm{O}$ estudo das pavimentações permeou durante o curso, o estudo das transformações geométricas, sobretudo a reflexão em reta.

Esses estudos podem colaborar com o desenvolvimento da percepção espacial e capacidade de abstração. Bressan, Bogisic e Grego (2006) discutem sete justificativas do ensino de Geometria na Educação Básica e destacam dentre elas: a habilidade de visualizar objetos no espaço, perceber suas propriedades e elaborar representações no plano. 
O desenvolvimento dessa habilidade pode ser descrito pelos níveis do pensamento geométrico de Parzysz (2006) ao se explorar a Geometria concreta, representar os objetos em uma Geometria espaço-gráfica e buscar compreender propriedades e resultados de uma Geometria proto-axiomática, ou demonstrá-los em uma Geometria axiomática.

Em nosso curso, tal desenvolvimento se deu por meio de atividades que partiram da manipulação de materiais concretos como os espelhos planos, seguido pelo reconhecimento das propriedades da reflexão em reta e suas justificativas obtidas com discussões coletivas.

Uma pesquisa de Lovis \& Franco (2015), realizada com 27 professores do estado do Paraná, visou identificar e analisar concepções $^{7}$ a respeito da importância de se ensinar Geometria na Educação Básica. Foi constatado, a partir de entrevistas e questionários, que as concepções estão relacionadas com a sua aplicabilidade, em situações do cotidiano, para se compreender o mundo e como ferramenta para resolução de problemas.

Comumente os professores relacionam a importância do estudo da Geometria com o estudo de medidas de área e de volume, por exemplo, fazendo uma associação com situações em que é necessário o cálculo dessas medidas, como na agricultura. Na referida pesquisa, os professores destacaram a aplicabilidade relacionando a Geometria com determinadas profissões.

Uma das justificativas apresentadas por Bressan, Bogisic e Grego (2006), que está ligada com o aspecto utilitário da Geometria apresentado pelos professores, é resolver problemas que demandam o cálculo de medidas, leitura de mapas e construção de objetos. Em geral, as respostas obtidas por Lovis \& Franco (2015) dos 27 professores participantes mostraram um destaque nesse aspecto.

Ao fazer uma relação estrita da Geometria com a resolução de problemas relacionados com situações do cotidiano e a determinadas profissões, pode-se fazer com que as demais facetas da Geometria não sejam exploradas pelos alunos e que determinados tópicos, como aqueles relacionados com o estudo de alguns teoremas ou casos de semelhanças, possam acabar sendo negligenciados ou pouco explorados.

O papel que a Geometria pode exercer no desenvolvimento do pensamento matemático, como um conjunto de modelos que se organizam de forma lógica e colaboram para o desenvolvimento do pensamento científico como um todo pode acabar não sendo vivenciado, mesmo que esse aspecto também possa auxiliar na resolução de problemas.

\footnotetext{
${ }^{7} \mathrm{O}$ termo concepções refere-se, para os autores, a preferências, opiniões e ideias apresentadas pelos professores a respeito da importância da Geometria na Educação Básica.
} 
Podemos perceber nas palavras dos professores ao responderem à questão seis do questionário de feedback, que existe um padrão de pensamento relacionado com a justificativa utilitária criticada por Lovis \& Franco (2015).

Respostas relacionando a Geometria com seu uso no cotidiano, na natureza e no dia a dia, foram apresentadas por quase todo o grupo de professores, em diferentes medidas. Alguns trechos das respostas relacionados com essa discussão estão expostos a seguir:

a) "Para aprender questões do dia-a-dia, independentemente da área a que se vá dedicar como futuro profissional, [...] Geometria dos objetos, das casas, das artes, arquiteturas novas e arrojadas" (professora $\mathrm{C}_{2}$ ).

b) “A Geometria está em todo lugar como na natureza, por exemplo, por isso temos que aprender Geometria" (professor L).

c) "A Geometria, além de estar presente no cotidiano em tudo que nos cerca, também possui o desenvolvimento [...] em diversas áreas" (professora $\mathrm{M}_{2}$ ).

d) "A Geometria está presente em todos os lugares e no seu cotidiano, na natureza e explicaria onde usar a Geometria" (professora $\mathrm{A}_{2}$ ).

e) "Precisa aprender as habilidades relacionadas à Geometria para se localizar no mundo, para reconhecer objetos, relações, resolver problemas” (professora $\mathrm{M}_{3}$ ).

Somente o professor $\mathrm{R}$ disse que não costuma dizer isso a seus alunos: "Como tudo na Matemática, eu não especifico o uso dela na prática”.

Mais precisamente, Lovis e Franco (2015) concluem que muitos dos professores não tiveram ou tiveram poucas disciplinas com enfoque no estudo da Geometria Euclidiana e, portanto, pouco lhes é familiar metodologias de ensino. Crescenti (2005) faz uma relação entre a percepção limitada de alguns professores de Matemática da cidade de São Carlos (SP) e uma formação inicial insuficiente e sugere que a busca por uma formação continuada, por meio de cursos, pesquisas, reflexões e discussões com outros professores de Matemática, atrelada a melhores condições de trabalho, podem fazer com que essa percepção seja ampliada.

Apesar de que o aspecto utilitário da Geometria tenha sido recorrente nas respostas, ele não foi o único. Os professores sinalizaram outras justificativas da importância do ensino 
Geometria na Educação Básica, tais como o desenvolvimento do raciocínio lógico-dedutivo, desenvolvimento da capacidade de abstração e que a Geometria é "linda e divertida".

Como não foi realizado um questionário inicial com essa mesma questão, não temos evidências suficientes para afirmar em que medida o curso colaborou com essas respostas e com suas motivações para o ensino de Geometria. No entanto, o desenvolvimento das sequências didáticas no final do curso evidenciou uma maior valorização às discussões em sala de aula sobre os tópicos de Geometria Plana, bem como uma busca, por parte dos professores, a uma construção colaborativa de conceitos e definições em um trabalho direcionado a uma Geometria axiomática (PARZYSZ, 2006). Isso mostra que houve uma contribuição significativa para a prática docente dos participantes e para a percepção da Geometria como uma ciência organizada logicamente por meio de conjecturas, deduções, generalizações, etc.

\section{CONSIDERAÇÕES FINAIS}

Desde o início do curso, nos encontros iniciais, pudemos perceber que o grupo de professores se engajou logo ao uso dos materiais concretos nas tarefas exploratórias e em discussões coletivas. A partir das produções, dos relatos e dos trabalhos finais dos professores percebemos também que eles buscaram adaptar, em diferentes medidas, suas práticas em sala de aula em um processo de investigação Matemática. Além disso, as análises dos encontros presenciais e das sequências didáticas mostraram que, em diferentes medidas, os professores se apropriaram de forma significativa dos conceitos explorados e das formas de se planejar e produzir uma sequência didática com foco no desenvolvimento do pensamento geométrico.

E apesar de terem se adaptado logo a esse tipo de dinâmica, nos momentos de registros escritos as produções foram difíceis para praticamente todos do grupo. O que pudemos verificar é que essa resistência ou dificuldade em transpor ideias e estratégias pensadas e testadas manual ou oralmente para um registro escrito foi se transformando e os professores foram se habituando a buscar uma justificativa cada vez mais matematicamente "elegante".

Nota-se que, o estudo da Geometria via taquimetria pode colaborar muito com esse processo, para Parzysz (2006) a tomada de consciência sobre quais ferramentas do raciocínio matemático podem ser usadas na resolução de problemas de Geometria relacionados com o domínio material e concreto é fundamental para o desenvolvimento de um pensamento de nível axiomático. Então ainda que nem todos os professores participantes tenham conseguido dominar uma argumentação de nível G2 ou G3, o fato de eles terem transitado, por meio das atividades investigativas, entre esses níveis faz com que tenham conseguido desenvolver suas 
estratégias de resolver problemas e justificar suas soluções, bem como desenvolver um olhar crítico para o ensino de Geometria na Educação Básica.

Os momentos em que a articulação G1 - G2 ocorreu de forma mais explícita, em todo o curso, foram nas atividades de pavimentação do plano, o que mostra que, efetivamente, os professores não permanecem de forma estática em um nível ou outro e ainda assim desenvolvem seu pensamento geométrico. Nessas atividades os professores elaboraram uma construção com régua e compasso, perceberam experimentalmente qual pavimentação o caleidoscópio mostrava e, em seguida argumentavam a formação da configuração de pavimentação produzida, bem como ilustrado na subseção 5.8.2.

Acreditamos que a formação continuada de professores de Matemática é determinante e necessária para uma melhora na qualidade de ensino, mas compreendemos também que existem limitações entre as nossas colaborações com a formação dos professores participantes, pois o impacto sofrido em suas práticas foi diferente para cada um e não o alcançamos em todos os aspectos que esperávamos. No entanto, notamos que houveram grandes ganhos com relação à apropriação dos próprios conceitos geométricos envolvidos nas discussões dos encontros.

A partir da análise global realizada no capítulo 7, chegamos à conclusão de que é possível que algumas das dificuldades dos professores podem estar relacionadas com aspectos que vão além do contexto do curso oferecido, como, por exemplo, terem visto (ou não) conceitos da Geometria das transformações anteriormente, bem como alguns conceitos mais gerais da Geometria euclidiana relacionados com polígonos, ângulos e lugares geométricos.

Acreditamos inicialmente que, os professores que não tivessem conhecimento desses conceitos poderiam se apropriar por meio das próprias atividades de investigação matemática, o que aconteceu em diferentes medidas para cada professor. Mas percebemos que essa abordagem não era muito comum para eles e que muitas vezes sua bagagem de conceitos geométricos esteve muito ligada a processos que envolvem um professor lhes explicando de forma expositiva um conteúdo, com axiomas, definições, propriedades e demonstrações de teoremas, ou seja, uma abordagem que talvez demande pouca autonomia dos sujeitos que, segundo Ponte (2003), se desenvolve a partir da investigação matemática, seja com tarefas exploratórias, seja com tarefas investigativas.

Além disso, houve alguma resistência entre alguns professores, como o professor L e o professor R, a esse tipo de abordagem com tarefas exploratórias, pois estava já muito habituados a esse tipo de ensino tradicional centrado na exposição das falas de um professor. Talvez lhes falte uma sensibilização para o fato de que o desenvolvimento do pensamento matemático 
demanda mais fluidez e, naturalmente, ocorre a presença de erros e acertos nas tentativas dos estudantes e criação de conjecturas precedendo suas validações ou refutações, tais características fazem parte da investigação matemática que, segundo Ponte (2003) é fortemente justificada pois em:

estudos realizados [em Portugal], existem numerosos exemplos que atestam o grande entusiasmo e envolvimento dos alunos na realização de investigações matemáticas. Este envolvimento constitui uma base fundamental para a aprendizagem e esta tem sido bem documentada no que respeita às diversas fases da realização de investigações matemáticas, a diversos objectivos transversais (em especial, a capacidade de comunicação oral e escrita, o desenvolvimento da autonomia e a capacidade de trabalhar em grupo), bem como no que se refere à mudança das concepções dos alunos (PONTE, 2003, p.68).

Momentos presenciados ou ilustrados pelos professores mostram um pouco em que medida as atividades de investigação Matemática colaboraram com sua formação em conceitos geométricos e de que forma ocorreram algumas tentativas de levar para suas práticas tanto os conceitos como a abordagem utilizada no curso. Ao analisarmos a apresentação da professora $\mathrm{A}_{1}$, por exemplo, vimos que ela colocou seus alunos pra investigarem o termo "polígono" de forma mais independente antes que ela discutisse sua definição, assim como o conceito de pavimentação do plano. A professora $\mathrm{G}$ produziu uma definição de polígono a partir das falas e ideias dos seus alunos ao confrontarem (assim como em nossa atividade 1 de polígonos) figuras que são ditas polígonos com as que não são, ao invés de apenas expor uma definição prévia, por exemplo.

Em uma tentativa, a professora $\mathrm{C}_{2}$ se aproximou da concretização da caracterização de uma atividade investigativa com seus alunos, quando pediu que eles manipulassem os polígonos de acrílico para descobrirem quais pavimentações do plano com polígonos de mais de um tipo seriam possíveis e acabou falando a resposta e representando na lousa. Isso ocorreu devido à demora e dificuldade dos alunos ou mesmo devido a uma falta de hábito de se estudar com esse tipo de abordagem. A professora poderia ter incentivado mais a discussão, destacado as ideias dos seus alunos, confrontando suas respostas e seguindo, por exemplo, o modelo das cinco práticas de Stein e Smith (2011).

Ou seja, a valorização do desenvolvimento do pensamento matemático e da autonomia dos estudantes em meio a uma investigação matemática deve ser exercitada em vários momentos da carreira de um professor - durante suas aulas e em cursos de formação continuada - e na vida escolar dos estudantes da Educação Básica - podendo ser explorada em vários momentos de sua formação, tanto no Ensino Fundamental como no Ensino Médio. 
Também fazemos uma reflexão do que nos cabe com relação a importância de possíveis melhorias no contexto do curso oferecido, sabemos que precisaríamos rever o momento de solicitar os planos de aula, pois acreditamos que seria importante que os professores participantes experimentassem as atividades de pavimentação do plano, mas essas só teriam sido apresentadas após iniciarem a elaboração dos seus planos de aula. Para esse problema, pensamos que poderíamos, por exemplo, reduzir a quantidade de pavimentações do plano experimentadas (talvez removendo a atividade 5), assim poderíamos falar em um momento mais tardio sobre os planos de aula, teríamos mais tempo no oitavo encontro para as discussões acerca de quais atividades eles escolheriam e deixaríamos o nono encontro (que foi considerado como extra) apenas para as apresentações. E, nesse caso, talvez se fizesse necessário a realização de um décimo encontro, ou seja, seria necessário revermos a carga horário do curso, inclusive.

Acreditamos também que seria fundamental uma reelaboração do curso com maior enfoque aos processos formativos. Gostaríamos de propor duas experimentações de sequências didáticas, ao invés de apenas uma, e garantir nossa participação presencial nessas experimentações com os professores em suas próprias salas de aula, além de ter maior tempo para discussão presencial com o grupo de professores a respeito da sequência didática de cada um dos professores participantes.

Um questionamento que nos deparamos na finalização dessa dissertação é a respeito das falas do professor L, que afirmava que para a participação do curso deveria ser feita uma seleção prévia dos professores. Isso nos fez pensar em, talvez, ter mais cuidado com os diferentes conhecimentos e bagagens acadêmicas e profissionais de cada professor, ou seja, poderíamos ter maior foco para falar sobre o que é uma reflexão em reta e quais as consequências de se utilizar uma representação com espelhos planos, ter momentos para se explorar com mais tempo as construções geométricas que foram utilizadas como ferramentas nas resoluções das atividades propostas e, novamente, poderíamos pensar em ser um pouco menos ambiciosos, no sentido de quantidade de conteúdo, dando mais foco para a qualidade das discussões coletivas.

Até o presente momento não elaboramos uma reformulação do curso e nem uma proposta de continuação, no entanto, acreditamos que haveria a possibilidade de se estender o que foi a etapa final do curso, no estudo das pavimentações do plano nas atividade 3 , 4 e 5, ou seja, poderíamos ter usado mais tempo com cada uma dessas atividades e analisado seu desdobramento. Em vista disso, pensamos que uma proposta de continuação poderia surgir apenas após uma nova experimentação desse curso, com maior carga horária e mais tempo 
destinado para as discussões e para o estudo das pavimentações do plano e, para tanto, talvez pudéssemos reduzir o número de tarefas em várias das atividades desenvolvidas (como buscamos explorar todo o potencial de cada objeto de estudo, as atividades podem ter ficado com um número excessivo de tarefas).

No que diz respeito ao uso dos materiais do curso atrelados à investigação Matemática, em especial os espelhos, caleidoscópios e os polígonos em acrílico, constatamos que o grupo buscou adaptações para suas próprias salas de aula, para trabalharem com seus próprios alunos.

Em determinados momentos o professor $\mathrm{R}$ afirmou que sentia falta de um momento com uma explicação de nossa parte expondo, por exemplo, definições e resultados matemáticos de antemão e no relatório do seu trabalho final ele mostrou que não incentivou o processo de investigação matemática com seus alunos, nas atividades que elaborou, embora seja possível vermos em seu plano de aula que ele pediu para os alunos tentarem descobrir (ou investigar) quais pavimentações do plano com polígonos regulares seriam possíveis. Por outro lado outros professores mostraram maior apropriação tanto da abordagem como dos próprios materiais: depois de desenvolver uma experiência com os caleidoscópios emprestados por nós, a professora $\mathrm{A}_{2}$ construiu com os alunos caleidoscópios que pudessem utilizar em aulas futuras, feitos com réguas; depois de desenvolver uma experiência com as peças de acrílico, a professora $\mathrm{C}_{2}$ construiu com seus alunos polígonos regulares cortados em EVA.

De toda forma, Oliveira e Leivas (2017) colaboram com a justificativa desse tipo de trabalho pois

\footnotetext{
os materiais manipuláveis podem ser utilizados como contribuição para o desenvolvimento da capacidade de visualização. [...] A utilização de modelos concretos permite que a figura geométrica possa ser observada em várias posições e angulações, tornando o registro da imagem mental mais dinâmico e, com isso, o aluno poderá explorar melhor as propriedades do objeto, fazer conjecturas e tirar conclusões sobre o mesmo. (2017, p. 111)
}

Variáveis como a angulação dos espelhos em relação a mesa na atividade 1 de reflexões em retas, ou a observação em diferentes posições e ângulos entre espelhos concorrentes nas atividades 2 e 3 de composições de reflexões em retas concorrentes podem ser discutidas e analisadas a partir da experimentação e, dessa forma, o uso do espelhos potencializa a percepção das propriedades das reflexões em retas.

De maneira mais específica, podemos afirmar que o curso em si, em vários momentos, contribuiu na forma de se abordar uma definição de conceitos geométricos em sala de aula a partir de discussões coletivas e levantamento de conhecimentos prévios em um processo 
colaborativo. Pudemos notar evidências dessa contribuição em vários dos relatos das sequências didáticas desenvolvidas pelos professores participantes (como mostrado, por exemplo, pelas professoras $\mathrm{Ge}_{2}$ ).

Ainda a respeito da abordagem utilizada, a professora $\mathrm{M}_{2}$ parece ter se apropriado da importância de um trabalho de investigação matemática proposto por meio de uma sequência didática, como relatou em seu questionário de feedback. Outros professores também mostraram essa apropriação, em diferentes medidas, em suas experiências com suas próprias sequências didáticas como, por exemplo, quando a professora $A_{1}$ nos conta que fez as atividades em várias etapas, incluindo pesquisa, discussão, representações na lousa e sistematização de conceitos.

Para além da formação relativa ao conhecimento pedagógico do conteúdo (SHULMAN, 1987), percebemos que foi desenvolvido também o conhecimento do conteúdo nos professores participantes a respeito dos conceitos relacionados com a Geometria escolar, tais como: lugar geométrico, reflexão em reta, ângulos e polígonos, divisibilidade relacionada a decomposições e congruência. Acrescentamos ainda, que o trabalho realizado no início do quinto encontro pode ter colaborado também com os conceitos a respeito da Geometria das transformações, como: reflexão, rotação, translação e composição de reflexões.

Ao analisarmos o significado desse processo, pensamos que ao se falar de formação de professores existem diferentes formas de se instigar a autonomia dos alunos e a forma que é discutida na formação inicial e continuada é fundamental para determinar a prática docente. De certa forma, uma aula com uma ou mais tarefas exploratórias e investigativas demanda um bom planejamento e uma boa orquestração das discussões para a sistematização de conceitos Matemáticos e, por consequência, ela desenvolve não apenas o pensamento matemático do aluno, como também sua autonomia, argumentação e, talvez, até um senso colaborativo.

No entanto, quando falta um planejamento que possa conduzir todo esse processo, o incentivo a autonomia em situações em que o professor da definições, resultados e fórmulas para a resolução de exercícios e coloca o aluno para resolver uma lista de exercícios seguindo um modelo pode ser um ato de violência contra o desenvolvimento do pensamento matemático e, por consequência, pode fazer com que o estudante não ganhe gosto pela Matemática.

Pensamos que, inclusive, nossa própria prática foi afetada, pois esse processo significou para nós uma profunda reflexão sobre as nossas ações enquanto professores e alguns aspectos foram desenvolvidos em nossa ação docente, tais como: valorizar as ideias, estratégias e tentativas de argumentação dos alunos, pensar um planejamento de nossas aulas sempre levando em consideração os conhecimentos prévios dos estudantes e pensar de forma ampla no 
desenvolvimento de aulas em que um modelo de laboratório de ensino de Matemática esteja presente.

Em relação aos desdobramentos dessa pesquisa, pensamos em meios de ampliar o acesso desse trabalho aos professores de Matemática que buscam o desenvolvimento por meio da formação continuada. Algumas possibilidades podem ser destacadas com relação a:

- o conjunto de atividades produzidas - disponibilizá-las em alguma plataforma virtual de educação Matemática, desenvolvê-las em outros cursos de formação continuada e/ou produzir um material como um livro ou um tipo de guia para um professor de Matemática que queira desenvolvê-las com seus alunos;

- a abordagem do curso - desenvolver, posteriormente, oficinas com enfoque na articulação G1 - G2 e na valorização do laboratório de educação Matemática inserido em uma sequência didática de Geometria com tarefas exploratórias;

- leitura interativa desse trabalho - elaborar um modelo em algum software de Geometria dinâmica que simule as manipulações de espelhos e de caleidoscópios, visando facilitar a compreensão de cada atividade durante a leitura dessa dissertação ou mesmo a exploração da sequência didática em sala de aula.

Esses e os outros desdobramentos discutidos, sobretudo, com relação a reformulação ou continuação do curso oferecido, nos instigam profundamente a refletir sobre a continuidade dessa pesquisa ampliando nossas produções acadêmicas, inclusive em um programa de doutorado. 


\section{REFERÊNCIAS BIBLIOGRÁFICAS}

ABRANTES, P. (1999). Investigações em Geometria na sala de Aula. In ABRANTES P. et al Investigações Matemáticas na Aula e no Currículo. p. 153-167. Lisboa: Projecto MPT e APM. 1999.

ABRANTES, Paulo. Avaliação e educação Matemática. Rio de Janeiro: MEM/USUGEPEM, 1995. 88 p. Série Reflexões em Educação Matemática, v. 1.

ALVES, S.; GALVÃO, M. E. L. Um Estudo geométrico das transformações elementares. São Paulo, IME-USP, 1996.

BARBOSA, R. M. Descobrindo padrões em mosaicos. São Paulo: Atual Editora, 2005.

BARBOSA, R. M., ROCHA, L. M.; Curso Ginasial Moderno: Matemática, volume 1. São Paulo: IBEP, 1970.

BIANCHINI, E. Matemática: ensino fundamental II, sexto ano. Editora Moderna. São Paulo, 2011.

BIGODE, A. J. L. Projeto Velear: Matemática. São Paulo: Scipione, 2012.

BONJORnO, J. R.; BONJORNO, R. A.; OLIVARES, A. Matemática: fazendo a diferença 60 ano. São Paulo: FTD, 2006.

BRASIL, Ministério da Educação. Secretaria de Educação Média e Tecnológica. PCN Ensino Médio: ciências da natureza, Matemática e suas tecnologias. Brasília, DF, 2000.

BRASIL. Ministério da Educação. Base Nacional Comum Curricular. Brasília: MEC, 2017.

BRASIL. Secretaria de Educação Fundamental. Parâmetros curriculares nacionais: terceiro e quarto ciclos do ensino fundamental, introdução aos parâmetros curriculares nacionais. Brasília, DF, 1998.

BRESSAN, A. M; BOGISIC, B.; GREGO, K. Razones para enseñar geometría en la educación básica. Mirar, construir, decir y pensar... Novedades Educativas. Buenos Aires. 2006. 
BROUSSEAU, G. Fondements et Méthodes de la Didactique des Mathématiques. Recherches em Didactique des Mathématiques, Grenoble, v. 7, n. 2, p. 33-116, 1986.

CHEVALLARD, Y. La transposición didáctica: del saber sabio al saber enseñado. Buenos Aires: Aique, 1991.

CRESCENTI, E. P. Os Professores de Matemática e a Geometria: opiniões sobre a área e seu ensino. Dissertação: mestrado em Educação Matemática. Universidade Federal de São Carlos. São Paulo, 2005. 252 p.

DANTE, L. R. Projeto Teláris: Matemática, sexto ano. São Paulo: Ática, 2012.

DENYS, B.; GRENIER, D. Symétrie orthogonale: des élèves français et japonais face à une même tache de construction. Petit x, nº 12, França. 1986.

DOUADY, R. Des apports de la didactique des mathématiques à l'enseignement. Repères IREM 6, 132-158, 1992.

FOSS, A. M.; WICHNOSKI, P.; BASSOI, T. S. Tarefas exploratórias e investigativas: uma análise dos trabalhos publicados no XI e XII Encontro Nacional de Educação Matemática. BoEM, Joinville, v. 6, n. 12, p. 145-162, dez 2018

GAY, M. R. G. Projeto Araribá: Matemática, sexto ano. São Paulo: Ed. Moderna, 2014.

HADJI, C. Avaliação desmistificada. Porto Alegre: Editora Artmed, 2001.

HENRY, M. L'introduction des probabilités au lycée: un processus de modélisation comparable à celui de la géométrie, in Repères-IREM n 36, pp. 15-34, 1999.

HOUDEMENT, C.. \& KUZNIAK, A. (2003) :. Quand deux droites sont « à peu près » parallèles ou le versant géométriques du « presque » égal. Revue «petit $X$ » n 61 . Grenoble.

IMENES, L. M.; LELLIS M. Componente Curricular: Matemática, sexto ano. São Paulo: Moderna, 2009.

IRACEMA, M.; ONAGA, D. S. Matemática: ideia e desafios, sexto ano. São Paulo: Saraiva, 2012.

KINGSTON. M. Mosaics by Reflections. The Mathematics Teacher, p. 280 - 286, 1957. 
LAKATOS, I. A lógica do descobrimento matemático: Provas e Refutações. Rio de Janeiro: Zahar. 1978.

LORENZATO, S. (Org.). O Laboratório de ensino de Matemática na formação de professores. Campinas: Autores associados, 2006, v.1.

LORENZATO, S. Por que não ensinar Geometria? Educação Matemática em Revista, SBEM/São Paulo, 1995, p. 3-13.

LOVIS, K. A.;, FRANCO, V.S. As concepções de um grupo de professores de Matemática sobre a importância da Geometria na Educação Básicaeducação básica. RPEM, Campo Mourão, Pr, v.4, n.7, p.72-88, jul.-dez. 2015.

MABUCHI, S. T. Transformações geométricas: a trajetória de um conteúdo ainda não incorporado às práticas escolares nem à formação de professores. 2000. 259 f. Dissertação (Mestrado em Educação) - Pontifícia Universidade Católica de São Paulo, São Paulo, 2000.

MARCHIVIE, F. A propos du Statu Didactique des Transformations dans L'enseignement des Mathématiques. In: Suivi Scientifique, França. 1986.

MARTINS, R. A. Ensino-aprendizagem de Geometria: uma proposta fazendo uso de caleidoscópios, sólidos geométricos e softwares educacionais. 2003. 246 f. Dissertação (mestrado) - Universidade Estadual Paulista, Instituto de Geociências e Ciências Exatas, 2003. Disponível em: 〈http://hdl.handle.net/11449/91156>. Rio Claro (SP). Acesso em 26 fev. 2020.

MATOS, J. M.; SILVA, M. C. L. da, O Movimento da Matemática Moderna e Diferentes Propostas Curriculares para o Ensino de Geometria no Brasil e em Portugal. Boletim de Educação Matemática. vol. 24, nº . 38, abril, 2011; p.171-196. Universidade Estadual Paulista Júlio de Mesquita Filho, Rio Claro. Disponível em: <https://www.redalyc.org/articulo.oa?id=291222086008>. Acesso em 26 fev. 2020.

MURARI, C.;, PEREZ, G. A. Geometria na ótica do caleidoscópio. Revista de Educação Matemática, SBEM-SP, Ano 6, n5, dezembro de 1999, p.43-50.

TRENTIN OLIVEIRA, M. T.; PINTO LEIVAS, J. C. P. Visualização e Representação Geométrica com suporte na Teoria de Van Hiele Ciência e Natura, vol. 39, núm. 1, jan.abr., 2017, pp. 108-117 Universidade Federal de Santa Maria Santa Maria, Brasil 
OLIVEIRA, Z. V.; KIKUCHI, L. M.. O laboratório de Matemática como espaço de formação de professores. Cadernos de Pesquisa. vol.48 no.169 São Paulo July/Sept. 2018

PARZYSZ, B. La géométrie dans l'enseignement secondaire et en formation de professeurs des écoles : de quoi s'agit-il?. "Quaderni di Ricerca in Didattica”, n.17, 2006. G.R.I.M. Department of Mathematics, University of Palermo, Itáliaaly.

PONTE, J. P.; BROCADO, J.; OLIVEIRA, H. Investigações Matemáticas na sala de aula. Belo Horizonte: Autêntica Editora, 2003.

PONTE, J. P.; ROCHA, A.. Aprender Matemática investigando. Zetetiké, 14(26), 25 p., 2006.

RIBEIRO, J. S. Projeto Radix, sexto ano. São Paulo: Scipione, 2009.

RIBEIRO, M. A. S. Transformações geométricas planas: um estudo experimental e dinâmico. 2016. 235 f. Dissertação (Mestrado Profissional em Ensino de Matemática) Instituto de Matemática e Estatística da Universidade de São Paulo, São Paulo, 2016.

ROCHA, C. A. et al. Uma discussão sobre o ensino de área e perímetro no ensino fundamental. Laboratório de ensino de Matemática. (LEMAT-DMAT-UFPE). UFPE. 2016. Disponível

em: <http://www.ufrgs.br/espmat/disciplinas/geotri2014/modulo2/rocha_et_al_area\%20e\%20peri metro_minicurso.pdf.>. Acesso em 13 ago. 2017.

RODRIGUES, F. C. Laboratório de educação Matemática: descobrindo as potencialidades do seu uso em um curso de formação de professores. Dissertação de Mestrado, Pontifícia Universidade Católica de Minas Gerais. Belo Horizonte, 2012. 195f.

SALLUM. E. M. Ladrilhamentos. 2015. Disponível em: <http://www.ime.usp.br/ matemateca>. Acesso em: 7 de nov. de 20142018.

SANTOS, V. H. M. Pavimentação do Plano com Espelhos e Caleidoscópios. 12 de dezembro de 2014. 36 p. Monografia (Licenciatura em Matemática) - Instituto de Matemática e Estatística, Universidade de São Paulo (IME-USP), 2014.

SÃO PAULO (Estado), Secretaria de Educação. MACHADO, N. J. (Org.) Currículo do Estado de São Paulo: Matemática e suas tecnologias. 2011. 72 p. 
SÃO PAULO (Estado), Secretaria Municipal de Educação. Direitos de Aprendizagem dos Ciclos Interdisciplinar e Autoral: Matemática. São Paulo: SINESP, 2016, 112 p.

SÃO PAULO (Munícipio). Secretaria Municipal da Educação. Currículo da cidade, ensino fundamental: componente curricular Matemática. São Paulo, 2017. 128p.

SÃO PAULO, Secretaria de Educação, 1975. Guias Curriculares para o Ensino de Matemática: $1^{\circ}$ grau. São Paulo: SE/Cenp.

SÃO PAULO, Secretaria de Educação, 1994. Experiências Matemáticas. São Paulo: SE/Cenp.

SHULMAN, L. Knowledge and teaching: Foundations of the new reform. Harvard Educational Review no 1, vol. 57, fev.1987, p. 1-22.

SILVA, A. B.; SILVA, L. B. Educação e Desenvolvimento na Perspectiva do Direito à Educação: O Currículo de Geometria e a Formação do Professor de Matemática. In: Encontro de Pesquisa Educacional em Pernambuco, Garanhuns (PE), 2014. Anais... Pernambuco: Fundação Joaquim Nabuco, 2014. 16 p.

SILVEIRA, E.; MARQUES, C. Matemática: compreensão e prática, sexto ano. São Paulo: Moderna, 2013.

SOUZA, J. R.; PATARO, R. M. Vontade de Saber: Matemática, sexto ano. São Paulo: FTD, 2015.

STEIN, M. K.;, SMITH, M. S. National Council of Teachers of Mathematics: Five Practices for Orchestrating Productive Mathematics Discussions. Virgínia (EUA): Corwin, 2011.

TAHAN, M. Didática da Matemática. vol. 2. São Paulo: Saraiva, 1962.

VAN HIELE, P. M. (2002): Similarities and differences between the theory of learning and teaching of Skemp and the Van Hiele levels of thinking. Intelligence, learning and understanding in mathematics. A tribute to Richard Skemp. D. Tall \& M. Thomas, eds. PostPressed, Flaxton, Australia. 2002. 


\section{LEITURAS COMPLEMENTARES}

ABREU, A. O Menino e o Mundo. Direção: Alê Abreu, Produção: Filme de Papel, 2013. Disponível em: <https://www.youtube.com/watch?v=_N5KGcBDe_M>. Acesso em 20 out. 2017.

AZEVEDO, H. W. Transformações geométricas na formação inicial e continuada de professores de Matemática: atividades investigativas envolvendo reflexões por retas e GeoGebra. 2016. 125 f. Dissertação (Mestrado em Educação Matemática) - Instituto de Matemática e Estatística da Universidade de São Paulo (IME-USP). São Paulo/SP, 2016.

BALL, D. L.; THAMES, M. H.; PHELPS, G. Content Knowledge for Teaching: What makes it special? Journal of Teacher Education, no 5, vol. 59, Michigan, nov./dez. 2008, p. 389407.

BODGAN, R.; BIKLEN, S. Investigação Qualitativa em Matemática. Porto/Portugal: Porto Editora, 1994.

BORGES, C. Saberes docentes: diferentes tipologias e classificações de um campo de pesquisa. Educ. Soc., 2001, vol.22, no.74, p.59-76. ISSN 0101-7330.

BORTOlOSSI, H. J. Pavimentação com Polígonos Regulares. Universidade Federal Fluminense (UFF), 2009. Disponível em: <http://www.uff.br/cdme/ppr/ppr-html/pprbr.html\#mt>. Acesso em 01 fev. 2018.

BRASIL, Ministério da Educação. Guia de livros didáticos PNLD: Matemática, 2017. Brasília: Ministério da Educação, 2017. Disponível em: 〈http://www.fnde.gov.br/pnld-2017/>. Acesso em 12 fev. 2018.

BRASIL, Ministério da Educação. Secretaria de Educação. PCN+ Ensino Médio: Orientações Educacionais complementares aos Parâmetros Curriculares Nacionais Ciências da Natureza, Matemática e suas Tecnologias. Brasília, DF, 2002.

BREWSTER, D. The kaleidoscope: its history, theory and construction with application to the fine and useful arts. Londres: ed.2.1858. Disponível em: <\&lt; https://archive.org/stream/kaleidoscopeits00unkngoog\#page/n8/mode/2up>. Acesso em 31 jan. 2018. 
CENTURIÓN, M.; JAKUBOVIK, J. Nos dias de hoje: Matemática na medida certa, sexto ano. São Paulo: Leya, 2015.

CONGRESSO INTERNACIONAL DE ENSINO DA MATEMÁTICA, 7., 2017. Ulbra Canoas, Rio Grande do Sul. Anais... Mapa conceitual como instrumento de aprendizagem significativa no ensino Geometria plana: os polígonos. Comunicação Científica, Campus Canoas da Universidade Luterana do Brasil, 2017.

CORREA, N.. Estudo das pavimentações do plano utilizando um objeto de aprendizagem. Defesa em 1 de março de 2013. 189 folhas. Dissertação. Universidade Federal de Santa Catarina, Florianópolis, 2013.

ENCONTRO PAULISTA DE EDUCAÇÃO MATEMÁTICA (EPEM), Conexões entre prática docente e a pesquisa em educação Matemática, 13, 2017. Anais... São Paulo: Universidade da Cidade de São Paulo (UNICID), 2017. Disponível em: <http://sbempaulista.org.br/xiii-epem- 2/>. Acesso em 01 fev. 2018.

EVES, H.. Introdução à História da Matemática. Tradução: Hygino H. Domingues. Campinas, SP: Editora da Unicamp, 2004.

GIOVANI, J. R.; CASTRUCCI, B. A conquista da Matemática, sexto ano. São Paulo: FTD, 2012.

GUTIERREZ, R.; PASTOR, J. A. El grupo de las isometrias del plano. Madri: Editorial Sintesis SA, 1996.

MARTINEZ, B. Pintando las estrellas. El Rincón de Senda: un sitio donde compartir ideas con los demás. 28 de outubro de 2012. Disponível em: <http://elrincondesenda.blogspot.com.br/2012/10/dibujando-estrellas.html>. Acesso em 13 ago. 2017.

MILlMAN, R. S.; PARKER, G. D. Geometry: A metric Approach with Models. São Francisco: Springer. 1991.

MOREIRA, P. C.; DAVID, M. M. M. S. Matemática escolar, Matemática científica, saber docente e formação de professores. ZETETIKÉ - Cempem - FE - Unicamp - v.11 - n. 19, jan./jun. 2003. 
MORENO, J. G. DidactMatic Primaria. Investigación y desarrollo de contenidos educativos digitales multimedia para la enseñanza-aprendizaje de las Matematicas. Disponível em: <http://www.didactmaticprimaria.com>. Acesso em: 13 ago. 2017.

OLIVEIRA, S. A. de; PASSOS, C. L. B. Resolução de problemas na formação continuada e em aulas de Matemática nos anos iniciais: saberes e aprendizagens docentes, Educ. Matem. Pesq., São Paulo, v.15, Número Especial, pp.873-893, 2013.

PONTE, J. P. O desenvolvimento profissional do professor de Matemática. Educação e Matemática, 31. p. 9-12 e p. 20. Lisboa, 1994.

SANTOS, V. H. M.; JAHN, A. P. Pavimentações do plano com espelhos e caleidoscópios. In: Encontro Paulista de Educação Matemática, 13, 2017. São Paulo (SP). Anais... Universidade da Cidade de São Paulo (UNICID), 2017. p. 446 - 452.

SHULMAN, L. Those who understand: Knowledge growth in teaching. Educational Researcher $\mathrm{n}^{\circ}$ 2, vol. 15, Washington, fev. 1986, p. 4-14.

THENÓRIO, I. Manual do Mundo: Como fazer um caleidoscópio em casa. Direção, música e apresentação: Iberê Thenório. Produção: Cristiane Poveda. 2013. Disponível em: <https://www.youtube.com/watch?v=F5YpClQpNXQ>. Acesso em: 20 out. 2017. 


\section{APÊNDICES}

Apêndice 1 - Texto das mesas

CAEM - IME - USP

\section{A MATEMÁTICA DOS CALEIDOSCÓPIOS}

\section{O Filme O Menino e o Mundo}

O foco dessa produção brasileira é a visão de um menino que mora com os pais em uma pequena cidade do campo. Devido à falta de trabalho, o pai parte para a cidade grande. Os dias que se seguem são tensos e de memórias confusas para o garoto. Até que então, ele faz as malas, pega o trem e vai descobrir o novo mundo em que seu pai mora.

Apesar de encontrar uma sociedade que sofre com a exploração de trabalhadores, a criança é capaz de observar a música que há por trás da rotina de trabalho e a beleza das cores de grandes comércios que, por sua vez, é observada e redescoberta com um brinquedo especial dado pelo seu pai.

Por meio desse brinquedo - um CALEIDOSCÓPIO - o pequeno garoto viaja na pluralidade das cores e de padrões geométricos sem mesmo perceber os lugares por onde está andando. Essa sensação, de ser levado para outros lugares, onde os objetos são simplesmente cores e formas, é exatamente o que torna o caleidoscópio um objeto atrativo para explorar tópicos de Matemática escolar, em particular, de Geometria.

Aqui você poderá assistir um trecho e se encantar com a estética de traços surreais deste filme brasileiro "O menino e o mundo", assim como pode brincar, observar, se divertir e descobrir como os caleidoscópios de brinquedo são feitos.

Se você quiser construir o seu próprio caleidoscópio, o vídeo de Iberê Thenório, “Como fazer um caleidoscópio em casa", mostra como fazer, de forma simples, usando réguas transparentes no lugar de espelhos planos. 
CAEM - IME - USP

\section{A MATEMÁTICA DOS CALEIDOSCÓPIOS}

\section{Exploração de Caleidoscópios}

Caleidoscópios mais elementares podem e devem ser usados com figuras, desenhos e imagens no papel.

\section{Convidamos você a explorar esse tipo de caleidoscópio e viajar por entre cores e formas!}

Inicialmente, escolha um caleidoscópio e observe imagens livremente, por exemplo, o teto da sala, a lousa, objetos sobre a mesa, ou ainda, posicionando o caleidoscópio na borda da mesa com uma "ponta" para fora. A observação pode ser feita movimentando suavemente o caleidoscópio para frente, para trás, para a direita ou esquerda, girando um pouco e girando ao mesmo tempo em que ele é movimentado.

Agora, veja o que acontece posicionando o caleidoscópio sobre figuras disponibilizadas sobre a mesa. Escolha diferentes figuras e diferentes caleidoscópios.

Os desenhos da mesa são produções de alunos de escolas públicas, feitos em aulas de Geometria dos professores Vitor (EMEF JULIO MESQUITA), Rogério (CAEM-IME-USP) e Ernani (EA-FEUSP). 
CAEM - IME - USP

\section{A MATEMÁTICA DOS CALEIDOSCÓPIOS}

\section{Pavimentações do Plano}

Para você, o que lembra a palavra "Pavimentação"?

As Pavimentações também podem ser relacionadas com o que chamamos de Ladrilhamentos ou, ainda, com Mosaicos.

Você já viu obras de arte, desenhos animados, painéis ou arte de rua em que são usados esses tipos de configuração?

Agora você pode criar as suas pavimentações! Use as peças em acrílico - que representam polígonos regulares - para tentar fazer um padrão geométrico que possa ser estendido pelo tablado.

Para isso, basta dispor os polígonos lado a lado, sem sobreposição e sem deixar lacunas, repetindo as configurações obtidas.

Veja de quantas maneiras e com quais polígonos você pode pavimentar e tente justificar tais possibilidades. 
CAEM - IME -USP

\section{A MATEMÁTICA DOS CALEIDOSCÓPIOS}

\section{Pavimentações com Caleidoscópios}

Para você, o que lembra a palavra "Pavimentação"?

As Pavimentações também podem ser relacionadas com o que chamamos de Ladrilhamentos ou, ainda, com Mosaicos.

Você já viu obras de arte, desenhos animados, painéis ou arte de rua em que são usados esses tipos de configuração?

Veja como é possível obter algumas pavimentações do plano usando caleidoscópios equiláteros.

Como primeira experiência, observe o desenho de uma pavimentação do plano e, em seguida, tente descobrir qual posição do caleidoscópio repete a mesma configuração do desenho. Com isso, você está observando como cada pavimentação foi gerada.

Agora, você vai obter algumas pavimentações. Para isso, disponha o caleidoscópio sobre as folhas que possuem triângulos equiláteros construídos com certos elementos e tente identificar tanto as características da pavimentação obtida quanto do triângulo inicial.

\section{E aí, percebeu o que esse tipo de caleidoscópio propicia?}


CAEM - IME - USP

\section{A MATEMÁTICA DOS CALEIDOSCÓPIOS}

\section{Exploração livre com Caleidoscópios}

Caleidoscópios mais elementares podem e devem ser usados com figuras, desenhos e imagens no papel.

\section{Convidamos você a explorar esse tipo de caleidoscópio \\ e viajar por entre cores e formas de sua preferência!}

Escolha um caleidoscópio e observe o que acontece posicionando-o e movimentando-o sobre desenhos disponibilizadas sobre a mesa. Aproveite as cores, formas e incríveis figuras e pavimentações que podem ser obtidas.

Agora é com você! Faça seu próprio desenho e explore configurações, pavimentações e novas figuras que podem ser formadas.

Revele seu poder criativo e artístico 
Apêndice 2 - Folha 1 e tabela

Imagem da folha 1

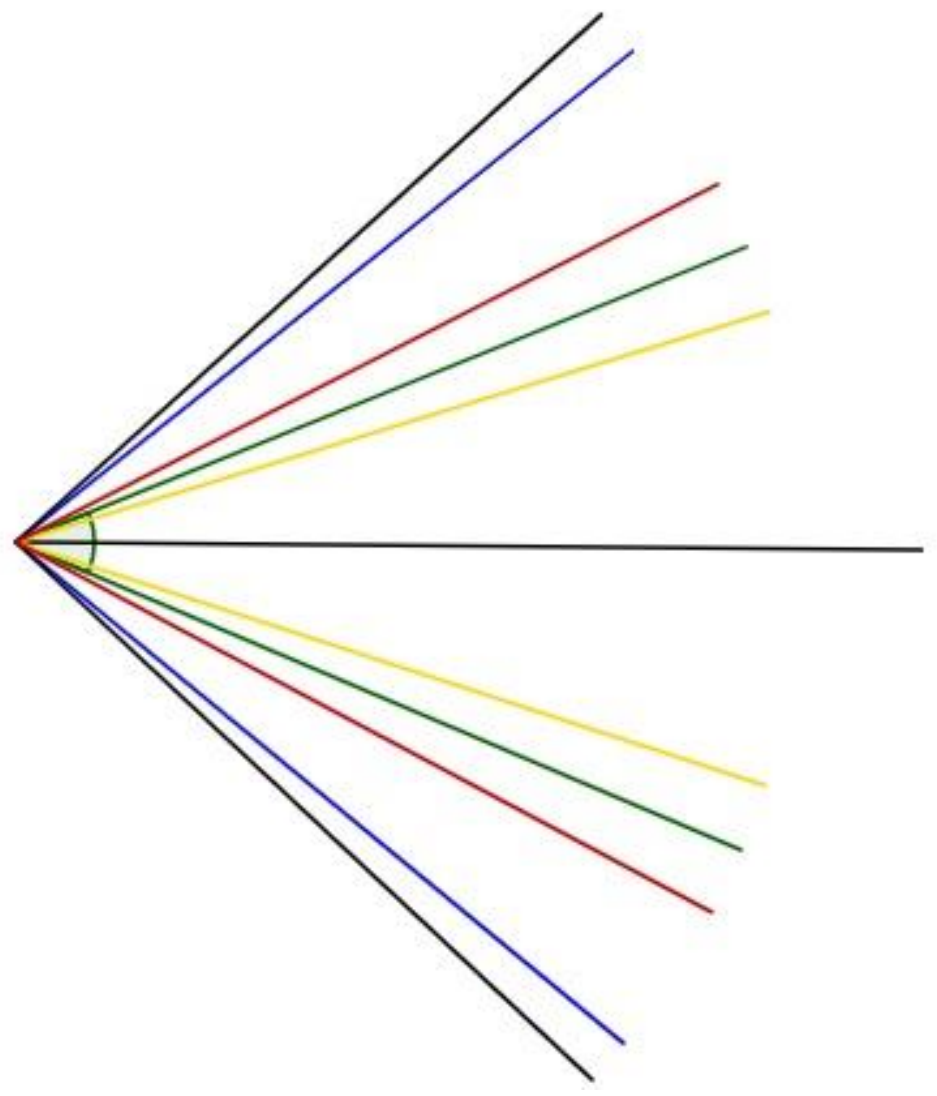


Apêndice - Tabela da atividade 2

\begin{tabular}{|l|l|l|l|}
\hline Nome do Polígono & $\begin{array}{c}\text { Medida do Ângulo } \\
\text { entre os espelhos }\end{array}$ & Número de Lados & Regular (S ou N) \\
\hline & & & \\
\hline & & & \\
\hline & & & \\
\hline & & & \\
\hline & & & \\
\hline & & & \\
\hline
\end{tabular}

Considerações - Ângulos Grandes

Considerações - Ângulos Pequenos 
Apêndice 3 - Questionário de feedback sobre as atividades de composição de reflexões em retas $(1,2$ e 3.1$)$

NOME:

1) Em quais atividades teve mais facilidade ou mais dificuldade? Por que?

2) Quais são os conceitos/tópicos matemáticos que podem ser explorados com essas atividades?

3) Avalie as atividades propostas e indique se mudaria ou acrescentaria algo. O que acha que pode ser melhorado ou complementado? Considera que tais atividades têm potencial didático, isto é, para uso em sala de aula? Justifique. 
Apêndice 4 - Elementos para o plano de aula

\section{Elementos para o plano de aula}

\section{Objetivos Globais e Currículo}

Definir o que você pretende que seus alunos aprendam, qual conteúdo será trabalhado e como o desenvolvimento do pensamento matemático será instigado.

\section{Planejamento das tarefas da atividade}

\section{Descrição e Enunciados}

Descrever o que você fará, quais suas intervenções e organização da aula que irão guiar o seu trabalho. Além disso, explicitar os enunciados que os alunos terão em mãos (quando houver).

\section{Expectativas de aprendizagem}

Descrever tudo que se espera no que diz respeito às respostas e interações dos alunos com a atividade proposta. Fazer uma reflexão sobre quais as principais dificuldades esperadas e o que será mais fácil para a maioria dos alunos. Além disso, explicitar quais são as ações previstas em ambas as situações.

\section{Possibilidades de resoluções (comuns e incomuns)}

Escrever quais são as possíveis respostas para as questões e problemas colocados. Destacar quais você imagina que serão mais recorrentes e quais são as mais incomuns, tanto as corretas como as incorretas.

\section{Objetivos de aprendizagem específicos}


Determinar quais noções, conceitos, técnicas, habilidades e competências relacionadas com o objetivo global compõem seus objetivos de aprendizagem.

\section{Tempo de Duração}

Quantas aulas serão usadas, quantos minutos tem cada aula e a atividade será aplicada em quantas turmas?

\section{Propostas de Continuação}

Imagine que, após a aplicação da sua atividade, você poderia aplicar uma próxima atividade, em uma sequência didática que usaria mais aulas. Escreva qual é sua proposta de continuação, o passo seguinte, as próximas tarefas. 